\title{
Towards personalized antiplatelet therapy
}

Citation for published version (APA):

Bouman, H. J. (2012). Towards personalized antiplatelet therapy. [Doctoral Thesis, Maastricht University]. Maastricht University Press. https://doi.org/10.26481/dis.20120322hb

Document status and date:

Published: 01/01/2012

DOI:

10.26481/dis.20120322hb

Document Version:

Publisher's PDF, also known as Version of record

\section{Please check the document version of this publication:}

- A submitted manuscript is the version of the article upon submission and before peer-review. There can be important differences between the submitted version and the official published version of record.

People interested in the research are advised to contact the author for the final version of the publication, or visit the DOI to the publisher's website.

- The final author version and the galley proof are versions of the publication after peer review.

- The final published version features the final layout of the paper including the volume, issue and page numbers.

Link to publication

\footnotetext{
General rights rights.

- You may freely distribute the URL identifying the publication in the public portal. please follow below link for the End User Agreement:

www.umlib.nl/taverne-license

Take down policy

If you believe that this document breaches copyright please contact us at:

repository@maastrichtuniversity.nl

providing details and we will investigate your claim.
}

Copyright and moral rights for the publications made accessible in the public portal are retained by the authors and/or other copyright owners and it is a condition of accessing publications that users recognise and abide by the legal requirements associated with these

- Users may download and print one copy of any publication from the public portal for the purpose of private study or research.

- You may not further distribute the material or use it for any profit-making activity or commercial gain

If the publication is distributed under the terms of Article $25 \mathrm{fa}$ of the Dutch Copyright Act, indicated by the "Taverne" license above, 
Towards personalized antiplatelet therapy

Heleen J. Bouman 
Het verschijnen van dit proefschrift werd mede mogelijk gemaakt door financiële steun van de afdeling Klinische Chemie, de Maatschap Cardiologie en de Raad van Bestuur van het St. Antonius Ziekenhuis te Nieuwegein, Cardiovascular Research Institute Maastricht te Maastricht en Stichting KNMP-Fondsen te Den Haag. Veel dank.

Financial support for the publication of this thesis by Accumetrics, Eli Lilly and Kordia is gratefully acknowledged.

\section{Towards personalized antiplatelet therapy}

(c) Heleen J. Bouman, Utrecht, 2012. The copyright of the articles that have been published has been transferred to the respective journals.

ISBN: 978-90-9026233-8

Cover: Robert Lombarts

Lay-out: Wendy Schoneveld, www.wenziD.nl

Printed by: Datawyse, Universitaire Pers Maastricht 


\section{Towards personalized antiplatelet therapy}

\section{PROEFSCHRIFT}

ter verkrijging van de graad van doctor aan de Universiteit Maastricht, op gezag van de Rector Magnificus, Prof. mr. G.P.M.F. Mols, volgens het besluit van het College van Decanen, in het openbaar te verdedigen op donderdag 22 maart 2012 om 14:00 uur

door

Helena Josina Bouman

Geboren op 3 juli 1985 te Waalwijk 


\section{Promotor}

Prof. dr. H. ten Cate

\section{Copromotores}

Dr. C.M. Hackeng (St. Antonius Ziekenhuis, Nieuwegein)

Dr. J.W. van Werkum

\section{Beoordelingscommissie}

Prof. dr. M.P. van Dieijen-Visser (voorzitter)

Prof. dr. A. de Boer (Universiteit Utrecht)

Prof. dr. H.J.G.M. Crijns

Prof. dr. T.M. Hackeng

Prof. dr. F. Zijlstra (Erasmus Universiteit Rotterdam)

Financial support by the Dutch Heart Foundation for the publication of this thesis is gratefully acknowledged. 
Voor mijn ouders en Robert 


\section{CONTENTS}

PART I

\section{Chapter 1}

A case-control study on platelet reactivity in coronary stent thrombosis

\section{Chapter 2}

Cangrelor increases the magnitude of platelet inhibition and reduces interindividual

variability in clopidogrel-pretreated subjects

\section{Chapter 3}

The importance of anticoagulant agents in measuring platelet aggregation in patients

treated with clopidogrel and aspirin

\section{Chapter 4}

Comparison between hirudin and citrate in monitoring the inhibitory effects of $\mathrm{P}_{2} \mathrm{Y}_{12}$ receptor antagonists with different platelet function tests

\section{PART II}

\section{Chapter 5}

The Cone-and-Plate(let) analyzer is not suitable to monitor clopidogrel therapy: a comparison with the flowcytometric VASP assay and optical aggregometry

\section{Chapter 6}

Which platelet function test is suitable to monitor clopidogrel responsiveness?

A pharmacokinetic analysis on the active metabolite of clopidogrel

\section{Chapter 7}

Comparison of platelet function tests in predicting clinical outcome in patients undergoing coronary stent implantation 
PART III

\section{Chapter 8}

The influence of variation in the $\mathrm{P}_{2} \mathrm{Y}_{12}$ receptor gene on in vitro platelet inhibition with

\section{Chapter 9}

Common variation in the platelet receptor $P_{2} R Y_{12}$ gene is associated with residual on-clopidogrel platelet reactivity in patients undergoing elective percutaneous coronary interventions

\section{Chapter 10}

The relevance of $\mathrm{P}_{2} \mathrm{Y}_{12}$-receptor gene variation for the outcome of clopidogrel-treated patients undergoing elective coronary stent implantation: a clinical follow-up

\section{PART IV}

\section{Chapter 11}

Variability in on-clopidogrel platelet reactivity explained by $\mathrm{CYP}_{2} \mathrm{C}_{1}{ }_{1} * 2$ genotype is modest in patients undergoing coronary stenting

\section{Chapter 12}

Cytochrome P-450 Polymorphisms and Response to Clopidogrel

\section{Chapter 13}

Paraoxonase-1 is a major determinant of clopidogrel efficacy

General discussion 


\section{ABBREVIATIONS}

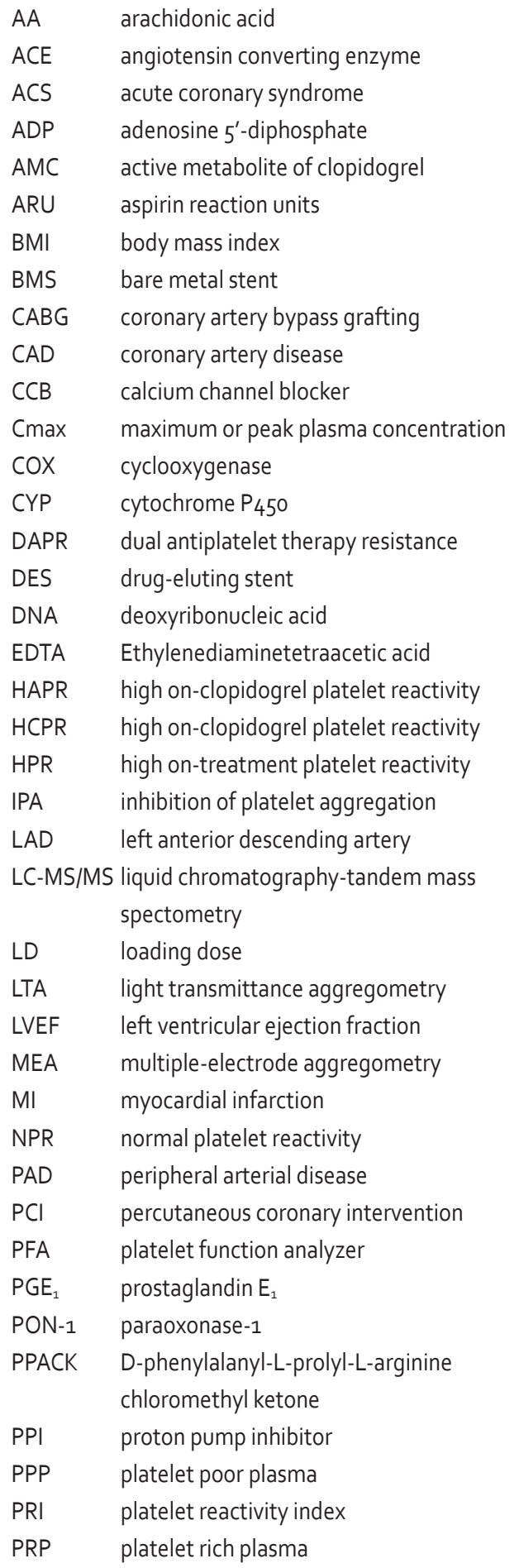

PRU $\quad \mathrm{P}_{2} \mathrm{Y}_{12}$ reaction units

RNA ribonucleic acid

SC surface coverage

SNP single nucleotide polymorphism

ST stent thrombosis

STEMI ST-segment elevation myocardial infarction

TIMI thrombolysis in myocardial infarction

TRAP thrombin receptor-activating peptide

$\mathrm{TXA}_{2}$ thromboxane $\mathrm{A}_{2}$

VASP vasodilator associated phosphoprotein

WBA whole blood aggregometry 
Introduction and outline of the thesis 
Introduction

\section{THE ERA OF PERSONALIZED MEDICINE}

The notice that not all patients respond equally to a standard one size fits all dosing regimen of any given drug therapy is generally appreciated. It has led to the development of personalized medicine: the use of new methods of analysis to better manage an individual patient's disease or predisposition to disease ${ }^{1}$. This concerns both the aims to achieve an increased efficacy in hyporesponsive patients as well as to dampen the burden of side-effects in susceptible patients or hyperresponders. Recent advances in the fields of genomics (genome-wide association studies and whole exome or targeted region sequencing) ${ }^{2}$, transcriptomics (mRNA expression profiling) ${ }^{3}$, proteomics (protein structure, function and expression profiling) ${ }^{4,5}$ and metabolomics (profiling of metabolites) ${ }^{6}$ enable comprehensive searches for potential determinants of a variable drug response. The increasing development of bedside diagnostic tests allows the subsequent implementation of near patient testing in clinical practice ${ }^{7}$. In the last decade, numerous diseases and therapies across different fields of medicine have been subject to attempts to stratify risk and personalize treatment based on individual genetic and phenotypic characteristics, including antiplatelet therapy.

The antiplatelet drug clopidogrel exhibits a high degree of interindividual variation in response resulting in hyporesponsiveness accompanied by an increase in atherothrombotic events at one end of the spectrum and hyperresponsiveness with consequent bleeding at the other end of the spectrum ${ }^{8-10}$. Alternative, more potent antiplatelet agents have recently become available and are suggested to replace clopidogrel therapy to overcome thrombotic events due to hyporesponsiveness to clopidogrel ${ }^{11}$ ${ }^{12}$. However, the majority of patients respond adequately to clopidogrel and thus not every patient may benefit from stronger antiplatelet therapy but will have the risk to experience side-effects due to over-treatment. This phenomenon has been described in 1981 by Geoffrey Rose as the prevention paradox: 'A preventive measure which brings much benefit to the population offers little to each participating individual ${ }^{13}$. On the contrary of this population-based approach there is the high-risk strategy, which aims to trace and focus on susceptible individuals with characteristics suggesting high-risk of disease to apply preventive measures. Advantages of this strategy include that treatment interventions are appropriate to the individual, increasing the motivation to comply to the intervention for both the patient as well as the treating physician, and more favorable cost-benefit and benefit-risk ratios $^{14}$. Finding determinants of the variable response to clopidogrel might help to identify subjects that do benefit from stronger antiplatelet therapy, and is therefore an essential step on the road towards individualized antiplatelet therapy.

\section{ANTIPLATELET THERAPY ARMAMENTARIUM}

The first antiplatelet agent successfully used in the secondary prevention of coronary thrombosis was the irreversible COX-inhibitor acetylsalicylic acid (aspirin) ${ }^{15}$. At present, patients undergoing percutaneous coronary intervention $(\mathrm{PCl})$ are treated with aspirin life-long and a thienopyridine for a duration of at least 1 month to 1 year, depending on the clinical presentation and type of stent implanted ${ }^{16,17}$. Dual antiplatelet therapy decreases the occurrence of thrombotic complications following $\mathrm{PCl}$, including myocardial infarction, stent thrombosis and death ${ }^{18,19}$. 


\section{Thienopyridines}

Thienopyridines are a group of structurally related pro-drugs that irreversibly antagonize the platelet ADP-receptor $\mathrm{P}_{2} \mathrm{Y}_{12}{ }^{20}$. At the time the first thienopyridines were marketed, neither the exact mechanism of action nor the structure of the targeted receptor had been elucidated ${ }^{21,22}$.

Ticlopidine (Ticlid ${ }^{\circledR}$, Sanofi-Aventis) was the first thienopyridine available ${ }^{23}$. The side-effect agranulocytosis (occurring in $\pm 1 \%$ ) and a slow onset of action taking 5-6 days, were major drawbacks of the use of ticlopidine and created the urge for novel $P_{2} Y_{12}$-receptor antagonists ${ }^{24}$. In 1998 the thienopyridine clopidogrel (Plavix ${ }^{\circledR}$, Sanofi-Aventis) was registered in Europe ${ }^{25}$. For more than a decade, clopidogrel and aspirin were the antiplatelet agents of choice following $\mathrm{PCl}$. Clopidogrel is an effective antiplatelet agent, but some limitations leave room for improvement. Despite the use of a loading dose (LD) of clopidogrel - reaching maximal effect within 24 hours (300 mg LD) or even 4-6 hours (6oo mg LD) - the delay in the onset of clopidogrel action remains an issue in the management of ACS. Furthermore, the response to clopidogrel varies widely among individuals, resulting in a higher event-rate in patients who can be classified as poor responders ${ }^{26,27}$. Both the slow onset of action as well as the wide variation in response are caused by the complex and inefficient formation of the active metabolite of clopidogrel $(A M C)^{28}$. Moreover, the irreversible nature of receptor-binding causes inhibition of the platelet for the duration of the rest of its lifespan. This may result in bleeding problems especially when elective or emergent surgery is required in patients on dual antiplatelet therapy, while discontinuation poses a risk for stent thrombosis ${ }^{20}$.

A series of novel $P_{2} Y_{12}$-antagonists were developed with the aim of an improved therapeutic profile. Prasugrel was registered in 2009 as Effient (USA) or Efient (Europe; Eli-Lilly) ${ }^{29}$. Structurally, the active metabolites of prasugrel and clopidogrel are almost identical, but generation of the active metabolite of prasugrel is much more efficient. While a major part of approximately $85 \%$ of the absorbed pro-drug clopidogrel is inactivated by carboxylesterases, prasugrel uses carboxylesterases for the first step of its transformation to the active metabolite. The resulting higher plasma levels of the active metabolite of prasugrel with a faster onset of action of approximately 2 hours after a $60 \mathrm{mg}$ LD and less variation in active metabolite levels, create a pharmacokinetic benefit of prasugrel over clopidogre ${ }^{30,31}$. Clinically this property was translated into a further reduction of thrombotic events following $\mathrm{PCl}$ compared to clopidogrel, as expected against the price of a higher rate of bleeding ${ }^{12}$. However, when taking both thrombotic and bleeding events into account, prasugrel had a net clinical benefit over clopidogrel ${ }^{12,32}$.

\section{Reversible $\mathrm{P}_{2} \mathrm{Y}_{12}$-inhibitors}

Cangrelor and ticagrelor are reversibly acting, $\mathrm{P}_{2} \mathrm{Y}_{12}$-antagonising ATP-analogues (cyclopentyltriazolopyrimidines) that do not require metabolic activation for their antiplatelet effect and exhibit a more potent antiplatelet profile than clopidogrel33. Cangrelor (not registered, The Medicines Company) is administered intravenously and has a very short time to onset as well as a rapid offset of action, creating an 'on-off-feature' enabling temporary suppression of platelet activation on top of oral platelet inhibition during and after $\mathrm{PCl}^{34}$. A major problem is that cangrelor prevents binding of the active metabolite of clopidogrel to the $\mathrm{P}_{2} \mathrm{Y}_{12}$-receptor, creating the need for a drug-free interval before administration of clopidogrel in the early time-frame after $\mathrm{PCl}$ in which patients are vulnerable to early thrombotic complications including acute stent thrombosis ${ }^{35,36}$. Although promising, the two phase III clinical trials CHAMPION-PCI and CHAMPION-PLATFORM were prematurely terminated by the sponsor due to a lack of clinical efficacy compared to, or on top of, clopidogrel, respectively ${ }^{37-39}$. 
Introduction

Currently, cangrelor is investigated as bridging antiplatelet agent in thienopyridine-treated patients undergoing coronary artery bypass grafting (CABG) to minimize the period without antiplatelet therapy around surgery (the BRIDGE-study) $4^{\circ}$.

The orally administered ticagrelor (Brilinta [USA] or Brilique [Europe], AstraZeneca) reaches optimal antiplatelet action within 2 hours, with 2- to 3 -fold higher levels of platelet inhibition as compared to clopidogre ${ }^{41,42}$. Also the offset-time is shorter than for clopidogrel, although a period of several days is still needed for clearance of the antiplatelet effect ${ }^{43}$. Clinically, this resulted in a reduction of myocardial infarction, stent thrombosis and death ${ }^{11}$. This benefit was troubled by an increase in non-CABG major bleeding. Of note, besides bleeding ticagrelor has several side-effects distinct from thienopyridine therapy, including bradycardia (especially in the initial week of treatment), dyspnoea and an increase in plasma creatinine and urea, of which the clinical consequences are unclear as of yet ${ }^{11}$.

Elinogrel (PRT060128, not registered, Novartis) is a novel $\mathrm{P}_{2} \mathrm{Y}_{12}$-antagonist currently between phaseII and III clinical studies. Results of preliminary studies are promising, showing that elinogrel reaches a higher magnitude of platelet inhibition than clopidogrel reaching its optimum at 20 minutes, the first time-point measured, and that platelet function returns to pre-drug values within 24 hours 44,45 . The INNOVATE-PCI study randomized patients undergoing elective $\mathrm{PCI}$ to treatment with either clopidogrel $75 \mathrm{mg}$, elinogrel $100 \mathrm{mg}$ or elinogrel $150 \mathrm{mg}$ daily for a duration of 120 days. It was demonstrated that the incidence of thrombotic events and bleeding did not exceed that of clopidogrel, as expected in a phase II study underpowered to detect clinically significant differences between elinogrel and clopidogre ${ }^{46}$. Salient is the fact that elinogrel is available as preparations for both oral as well as intravenous administration ${ }^{47}$. Importantly, this enables fast and continuous suppression of platelet reactivity without the problems of a therapeutic gap as encountered with the combination of cangrelor and a thienopyridine ${ }^{35}$.

\section{CLOPIDOGREL}

Clopidogrel is orally administered as a prodrug, requiring a two-step transformation to its active metabolite for its antiplatelet effect. After absorption in the gastro-intestinal tract, approximately $85 \%$ of the parent compound is immediately degraded by carboxylesterases into its inactive carboxylmetabolite. The remaining $15 \%$ first undergoes oxidation by different enzymes of the hepatic cytochrome P450 (CYP) enzyme system to 2-oxo-clopidogrel. Then opening of the $\gamma$-thiobutyrolactone ring represents the final step to formation of the active thiol metabolite 48,49 . There is an ongoing debate on which enzymes are precisely responsible for the transformation of clopidogrel into its active metabolite. Different dosing regimens are applied for optimal inhibition of platelet aggregation. In the acute setting, loading doses of either $300 \mathrm{mg}$ or $600 \mathrm{mg}$ can be used, which reach their maximal antiplatelet effect 24 and 4-6 hours after administration, respectively ${ }^{50,51}$. With daily doses of $75 \mathrm{mg}$ in the chronic setting, optimal antiplatelet effects are established after approximately 5 days $5^{2}$. Due to the irreversible binding of clopidogrel to the $\mathrm{P}_{2} \mathrm{Y}_{12}$-receptor, it takes 1 week until baseline platelet reactivity is restored after clopidogrel discontinuation ${ }^{53}$.

The clinical efficacy of clopidogrel has been established in several large randomized clinical trials. Clopidogrel was compared to aspirin in patients with recent $\mathrm{Ml}$, ischemic stroke and symptomatic PAD in the CAPRIE-study ${ }^{18}$. In the total group clopidogrel achieved a relative risk reduction (RRR) in ischemic 
stroke, MI or vascular death of $8.7 \%(p=0.043)$ compared to aspirin at a mean follow-up duration of 1.91 years. Subanalyses showed that this benefit was mainly caused by an effect in patients with PAD and that clopidogrel and aspirin were equally effective in the subgroup of patients with recent MI. When clopidogrel was administered on top of aspirin in the CURE-study, a $20 \%$ relative risk reduction for ischemic events after non-ST elevated myocardial infarction (non-STEMI; RR [95\% confidence interval, $\mathrm{Cl}] 0.80[0.72-0.90]$, $\mathrm{p}<0.001$ ) was observed, which was even higher when considering only patients who underwent $\mathrm{PCl}(\mathrm{RR}[95 \% \mathrm{Cl}]$ for $\mathrm{CV}$ death or $\mathrm{Ml}$ at 30 days $0.69[0.54-0.87], p=0.002) 54$. Importantly, the PCl-CURE study showed that this benefit was consistent during long-term follow-up of on average 8 months ${ }^{19}$. Later it was shown that also patients with STEMI benefit more from dual antiplatelet therapy with aspirin and clopidogrel as compared to platelet inhibition with aspirin alone in the CLARITY-study (OR[95\% CI] for CV death, recurrent $\mathrm{MI}$ or recurrent ischemia with urgent revascularization at 30 days post- $\mathrm{PCl} 0.80[0.65-0.97], p=0.03)^{55}$.

\section{MEASURING THE RESPONSE TO CLOPIDOGREL}

The need for large trials with thousands of patients to study the clinical effects of antiplatelet therapy encourages the search for biomarkers to evaluate clopidogrel response on a smaller scale. Clopidogrel response is traditionally measured using platelet function tests. Also the active metabolite of clopidogrel can be quantified, but the unstable character of the active metabolite of clopidogrel requires a laborintensive protocol that is not apposite for use in clinical practice ${ }^{56,57}$. The currently available platelet function tests can be categorized according to the principle of technique as based on agonist-induced aggregation such as the historical gold-standard light transmittance aggregometry (LTA $)^{58}$, VerifyNow ${ }^{\circledR}$ (Accumetrics Inc, San Diego CA, USA)59 ${ }^{5}$ PlateletWorks assay (Helena Laboratories, Beaumont TX, USA ${ }^{60}$ and whole blood impedance aggregometry performed with the Multiplate ${ }^{\circledR}$ Analyzer [Dynabyte, Munich, Germany) or Chronolog device (Chronolog, Havertown PN, USA) ${ }^{61,62}$; shear-stress-based including the platelet function analyzer (PFA)-100 ${ }^{\circledR}$ (Siemens Healthcare Diagnostics Products $\mathrm{GmbH}$, Marburg, Germany) $)^{63}$ and the cone-and-platelet analyzer (Impact-R ${ }^{\mathrm{TM}}$, Diamed, Cressier, Switzerland ${ }^{64}$; or flowcytometric tests including the vasodilator-stimulated phosphoprotein (VASP) assay (PLTVASP/ $\mathrm{P}_{2} \mathrm{Y}_{12}$, Biocytex, Marseille, France) ${ }^{65}$.

\section{HIGH ON-TREATMENT PLATELET REACTIVITY}

A large heterogeneity in clopidogrel response exists among patients, following a Gaussian curve rather than a more favorable and easy to interpret bimodal distribution separating responders from nonresponders ${ }^{26}$. The lower response to clopidogrel in part of the treated individuals has been designated different terms, including clopidogrel resistance, poor or non-responsiveness to clopidogrel and high on-treatment platelet reactivity ${ }^{66}$. The term resistance implies that the drug clopidogrel would not be able to reach its pharmacological target, impairing responsiveness to clopidogrel. Responsiveness to clopidogrel is defined as the degree of ADP-induced platelet aggregation before (baseline or intrinsic platelet reactivity) minus the degree after (on-treatment platelet reactivity) the administration of clopidogrel. The major drawback of the term responsiveness is that the required baseline measurement will not be available for most patients in clinical practice. Furthermore, baseline platelet aggregation 
Introduction

is also subject to substantial interindividual variation. Therefore clopidogrel-resistance or a low level of responsiveness can be accompanied by either a high or low level of on-treatment platelet reactivity, depending on the degree of baseline platelet reactivity ${ }^{67,68}$. In 2010 a consensus document was published stating that the appropriate measure for clopidogrel response is the absolute degree of platelet reactivity during treatment with clopidogrel termed on-treatment platelet reactivity to $A D P_{\text {, }}$ since this measure represents the net result of baseline ADP-induced platelet reactivity and responsiveness to clopidogrel ${ }^{69}$.

\section{OUTLINE OF THE THESIS}

The present thesis concerns achievements in the personalization of clopidogrel therapy. The presence and consequences of the large heterogeneity in on-treatment platelet reactivity among patients are described. Furthermore, methods to measure on-treatment platelet reactivity are evaluated and potential determinants of the laboratory and clinical efficacy of clopidogrel are investigated.

Part I of this thesis describes the presence of high on-treatment platelet reactivity to both aspirin and clopidogrel in patients with early stent thrombosis (Chapter 1), the capability of a novel, more potent $\mathrm{P}_{2} \mathrm{Y}_{12}$-inhibitor to decrease the degree of variation in clopidogrel response (Chapter 2), and the relevance of blood withdrawal conditions for the measurement of on-treatment platelet reactivity (Chapter 3 and 4 ).

Part II starts with an evaluation of the shear-stress based cone and platelet analyzer compared to the historical gold-standard platelet function test LTA and the VASP-assay (Chapter 5), followed by identification of the most appropriate platelet function test to measure the response to clopidogrel with respect to correlation with plasma levels of the active metabolite of clopidogrel (Chapter 6) and clinical outcome (Chapter 7 ).

The contribution of $\mathrm{P}_{2} \mathrm{Y}_{12}$-receptor genetics to the extent of heterogeneity in on-treatment platelet reactivity is described in Part III for the in vitro response to cangrelor in healthy volunteers (Chapter 8) and on-treatment platelet reactivity (Chapter 9) as well as clinical outcome (Chapter 10) in clopidogreltreated patients undergoing elective coronary stent implantation.

Part IV concerns the impact of pharmacokinetic determinants of on-treatment platelet reactivity in clopidogrel-treated patients. First the relative contribution of the ${ }^{2} 2$ genetic polymorphism of the $\mathrm{CYP}_{2} \mathrm{C}_{19}$-enzyme was determined in clopidogrel-treated patients undergoing elective $\mathrm{PCl}$ (Chapter 11). Then, the role of $\mathrm{CYP}_{2} \mathrm{C}_{19}$ in the transformation of the intermediate clopidogrel metabolite 2-oxoclopidogrel into the active thiol metabolite of clopidogrel was established using human microsome preparations expressing $\mathrm{CYP}_{2} \mathrm{C}_{19}$ (Chapter 12). Finally, a comprehensive in vitro metabolomics study determining the exact pathway of clopidogrel metabolism, with confirmation of the role of paraoxonase- 1 in a cohort of stent thrombosis patients and patients undergoing coronary stent implantation was performed (Chapter 13). 
Introduction

\section{REFERENCES}

1. Personalized Medicine Coalition. About the Personalized Medicine Coalition. Available at: http://www.personalizedmedicinecoalition.org/about. Accessed June 1st 2011, 2011.

2. Cirulli ET, Singh A, Shianna KV et al. Screening the human exome: a comparison of whole genome and whole transcriptome sequencing. Genome Biol. 2010;11(5):R57.

3. Wang Z, Gerstein M, Snyder M. RNA-Seq: a revolutionary tool for transcriptomics. Nat Rev Genet. 2009;10(1):57-63.

4. Patterson SD, Aebersold RH. Proteomics: the first decade and beyond. Nat Genet. 2003;33 Suppl:311-323.

5. Van Eyk JE. Overview: the maturing of proteomics in cardiovascular research. Circ Res. 2011;108(4):490-498.

6. Hollywood K, Brison DR, Goodacre R. Metabolomics: current technologies and future trends. Proteomics. 2006;6(17):4716-4723.

7. Tudos AJ, Besselink GJ, Schasfoort RB. Trends in miniaturized total analysis systems for point-of-care testing in clinical chemistry. Lab Chip. 2001;1(2):83-95.

8. Gurbel PA, Bliden KP, Hiatt BL, O'Connor CM. Clopidogrel for coronary stenting: response variability, drug resistance, and the effect of pretreatment platelet reactivity. Circulation. 2003;107(23):2908-2913.

9. Jaremo P, LindahITL, Fransson SG, Richter A. Individual variations of platelet inhibition after loading doses of clopidogrel. J Intern Med. 2002;252(3):233-238.

10. Sibbing $D$, Steinhubl SR, Schulz S et al. Platelet aggregation and its association with stent thrombosis and bleeding in clopidogrel-treated patients: initial evidence of a therapeutic window. J Am Coll Cardiol. 2010;56(4):317-318.

11. Wallentin L, Becker RC, Budaj A et al. Ticagrelor versus clopidogrel in patients with acute coronary syndromes. N Engl J Med. 2009;361(11):1045-1057.

12. Wiviott SD, Braunwald $\mathrm{E}, \mathrm{McC}$ abe $\mathrm{CH}$ et al. Prasugrel versus clopidogrel in patients with acute coronary syndromes. N Engl J Med. 2007;357(20):2001-2015.

13. Rose G. Strategy of prevention: lessons from cardiovascular disease. Br Med J (Clin Res Ed). 1981;282(6279):1847-1851.

14. Rose G. Sick individuals and sick populations. Int J Epidemiol. 2001;30(3):427-432; discussion 433-424.

15. Randomised trial of intravenous streptokinase, oral aspirin, both, or neither among 17,187 cases of suspected acute myocardial infarction: ISIS-2. ISIS-2 (Second International Study of Infarct Survival) Collaborative Group. Lancet. 1988;2(8607):349-360.

16. Wijns W, Kolh $\mathrm{P}$, Danchin N et al. Guidelines on myocardial revascularization: The Task Force on Myocardial Revascularization of the European Society of Cardiology (ESC) and the European Association for CardioThoracic Surgery (EACTS). Eur Heart J. 2010;31(20):2501-2555

17. Kushner FG, Hand M, Smith SC, Jr. et al. 2009 Focused Updates: ACC/AHA Guidelines for the Management of Patients With ST-Elevation Myocardial Infarction (updating the 2004 Guideline and 2007 Focused Update) and ACC/AHA/SCAI Guidelines on Percutaneous Coronary Intervention (updating the 2005 Guideline and 2007 Focused Update): a report of the American College of Cardiology Foundation/American Heart Association Task Force on Practice Guidelines. Circulation. 2009;120(22):2271-2306.

18. CAPRIE Steering Committee. A randomised, blinded, trial of clopidogrel versus aspirin in patients at risk of ischaemic events (CAPRIE). Lancet. 1996;348(9038):1329-1339.

19. Mehta SR, Yusuf S, Peters RJ et al. Effects of pretreatment with clopidogrel and aspirin followed by long-term therapy in patients undergoing percutaneous coronary intervention: the PCI-CURE study. Lancet. 2001;358(9281):527-533.

20. Cattaneo M. New P2Y(12) inhibitors. Circulation. 2010;121(1):171-179. 
Introduction

21. Kunapuli SP. Functional characterization of platelet ADP receptors. Platelets. 1998;9(6):343-351.

22. Hollopeter $G$, Jantzen $H M$, Vincent $D$ et al. Identification of the platelet ADP receptor targeted by antithrombotic drugs. Nature. 2001;409(6817):202-207.

23. Thebault JJ, Blatrix CE, Blanchard JF, Panak EA. Effects of ticlopidine, a new platelet aggregation inhibitor in man. Clin Pharmacol Ther. 1975;18(4):485-490.

24. Bhatt DL, Bertrand ME, Berger PB et al. Meta-analysis of randomized and registry comparisons of ticlopidine with clopidogrel after stenting. J Am Coll Cardiol. 2002;39(1):9-14.

25. European Medicines Agency. European public assessment report for Plavix. 1998.

26. Serebruany VL, Steinhubl SR, Berger PB et al. Variability in platelet responsiveness to clopidogrel among 544 individuals. J Am Coll Cardiol. 2005;45(2):246-251.

27. Breet NJ, van Werkum JW, Bouman $\mathrm{HJ}$ et al. Comparison of platelet function tests in predicting clinical outcome in patients undergoing coronary stent implantation. JAMA.303(8):754-762.

28. Shuldiner AR, O'Connell JR, Bliden KP, Gandhi A, Ryan K, Horenstein RB, Damcott CM, Pakyz R, Tantry US, Gibson Q, Pollin TI, Post W, Parsa A, Mitchell BD, Faraday N, Herzog W, Gurbel PA. Association of cytochrome $\mathrm{P}_{450}$ 2 $_{19}$ genotype with the antiplatelet effect and clinical efficacy of clopidogrel therapy. JAMA. 2009;302(8):849-857.

29. European Medicines Agency. European public assessment report for Efient. 2009.

30. Brandt JT, Payne CD, Wiviott SD, Weerakkody G, Farid NA, Small DS, Jakubowski JA, Naganuma H, Winters KJ. A comparison of prasugrel and clopidogrel loading doses on platelet function: magnitude of platelet inhibition is related to active metabolite formation. Am Heart J. 2007;153(1):66 e69-16.

31. Sugidachi A, Ogawa T, Kurihara A et al. The greater in vivo antiplatelet effects of prasugrel as compared to clopidogrel reflect more efficient generation of its active metabolite with similar antiplatelet activity to that of clopidogrel's active metabolite. JThromb Haemost. 2007;5(7):1545-1551.

32. Wiviott SD, Braunwald E, Angiolillo DJ et al. Greater clinical benefit of more intensive oral antiplatelet therapy with prasugrel in patients with diabetes mellitus in the trial to assess improvement in therapeutic outcomes by optimizing platelet inhibition with prasugrel-Thrombolysis in Myocardial Infarction 38. Circulation. 2008;118(16):1626-1636.

33. Storey RF. Pharmacology and clinical trials of reversibly-binding $\mathrm{P}_{2} \mathrm{Y}_{12}$ inhibitors. Thromb Haemost.105 Suppl 1:S75-81.

34. Ferreiro JL, Ueno M, Angiolillo DJ. Cangrelor: a review on its mechanism of action and clinical development. Expert Rev Cardiovasc Ther. 2009;7(10):1195-1201.

35. Dovlatova NL, Jakubowski JA, Sugidachi A, Heptinstall S. The reversible $P_{2} Y$ antagonist cangrelor influences the ability of the active metabolites of clopidogrel and prasugrel to produce irreversible inhibition of platelet function. J Thromb Haemost. 2008;6(7):1153-1159.

36. SteinhubI SR, Oh JJ, Oestreich JH et al. Transitioning patients from cangrelor to clopidogrel: pharmacodynamic evidence of a competitive effect. Thromb Res. 2008;121(4):527-534.

37. Bhatt DL, Lincoff AM, Gibson CM et al. Intravenous platelet blockade with cangrelor during PCI. N Engl J Med. 2009;361(24):2330-2341.

38. Harrington RA, Stone GW, McNulty S et al. Platelet inhibition with cangrelor in patients undergoing $\mathrm{PCl}$. $\mathrm{N}$ Engl J Med. 2009;361(24):2318-2329.

39. Kastrati A, Ndrepepa G. Cangrelor - a champion lost in translation? N Engl J Med. 2009;361(24):2382-2384.

40. Ueno M, Ferreiro JL, Angiolillo DJ. Update on the clinical development of cangrelor. Expert Rev Cardiovasc Ther.8(8):1069-1077.

41. European Medicines Agency. European public assessment report for Brilique. 2010. 
42. Husted $\mathrm{S}$, Emanuelsson $\mathrm{H}$, Heptinstall $\mathrm{S}$ et al. Pharmacodynamics, pharmacokinetics, and safety of the oral reversible $\mathrm{P}_{2} \mathrm{Y}_{12}$ antagonist $A Z \mathrm{Z}_{6140}$ with aspirin in patients with atherosclerosis: a double-blind comparison to clopidogrel with aspirin. Eur Heart J. 2006;27(9):1038-1047.

43. Gurbel PA, Bliden KP, Butler K et al. Randomized double-blind assessment of the ONSET and OFFSET of the antiplatelet effects of ticagrelor versus clopidogrel in patients with stable coronary artery disease: the ONSET/ OFFSET study. Circulation. 2009;120(25):2577-2585

44. Berger JS, Roe MT, Gibson CM et al. Safety and feasibility of adjunctive antiplatelet therapy with intravenous elinogrel, a direct-acting and reversible $\mathrm{P}_{2} \mathrm{Y}_{12} \mathrm{ADP}$-receptor antagonist, before primary percutaneous intervention in patients with ST-elevation myocardial infarction: the Early Rapid ReversAl of platelet thromboSis with intravenous Elinogrel before $\mathrm{PCl}$ to optimize reperfusion in acute Myocardial Infarction (ERASE MI) pilot trial. Am Heart J. 2009;158(6):998-1004 e1001.

45. Gurbel PA, Bliden KP, Antonino MJ et al. The effect of elinogrel on high platelet reactivity during dual antiplatelet therapy and the relation to $\mathrm{CYP}_{2} \mathrm{C}_{1}{ }^{*}{ }_{2}$ genotype: first experience in patients. J Thromb Haemost.8(1):43-53.

46. Rao SV, for the INNOVATE PCI investigators. A randomized, double-blind, active controlled trial to evaluate intravenous and oral PRT060128 (elinogrel), a selective and reversible $\mathrm{P}_{2} \mathrm{Y}_{12}$ receptor inhibitor vs clopidogrel as a novel antiplatelet therapy in patients undergoing nonurgent percutaneous coronary interventions. European Society of Cardiology 2010 Congress. Stockholm, Sweden.

47. Ueno M, Rao SV, Angiolillo DJ. Elinogrel: pharmacological principles, preclinical and early phase clinical testing. Future Cardiol.6(4):445-453.

48. Clarke TA, Waskell LA. The metabolism of clopidogrel is catalyzed by human cytochrome $\mathrm{P}_{450} 3 \mathrm{~A}$ and is inhibited by atorvastatin. Drug Metab Dispos. 2003;31(1):53-59.

49. Pereillo JM, Maftouh M, Andrieu A et al. Structure and stereochemistry of the active metabolite of clopidogrel. Drug Metab Dispos. 2002;30(11):1288-1295

50. Angiolillo DJ, Fernandez-Ortiz A, Bernardo E et al. High clopidogrel loading dose during coronary stenting: effects on drug response and interindividual variability. Eur Heart J. 2004;25(21):1903-1910.

51. Muller I, Seyfarth M, Rudiger S et al. Effect of a high loading dose of clopidogrel on platelet function in patients undergoing coronary stent placement. Heart. 2001;85(1):92-93.

52. Gurbel PA, Cummings CC, Bell CR et al. Onset and extent of platelet inhibition by clopidogrel loading in patients undergoing elective coronary stenting: the Plavix Reduction Of New Thrombus Occurrence (PRONTO) trial. Am Heart J. 2003;145(2):239-247.

53. Weber AA, Braun M, Hohlfeld $T$ et al. Recovery of platelet function after discontinuation of clopidogrel treatment in healthy volunteers. Br J Clin Pharmacol. 2001;52(3):333-336.

54. Yusuf S, Zhao F, Mehta SR et al. Effects of clopidogrel in addition to aspirin in patients with acute coronary syndromes without ST-segment elevation. N Engl J Med. 2001;345(7):494-502.

55. Sabatine MS, Cannon CP, Gibson CM et al. Addition of clopidogrel to aspirin and fibrinolytic therapy for myocardial infarction with ST-segment elevation. N Engl J Med. 2005;352(12):1179-1189.

56. Takahashi M, Pang $\mathrm{H}$, Kawabata $\mathrm{K}$ et al. Quantitative determination of clopidogrel active metabolite in human plasma by LC-MS/MS. J Pharm Biomed Anal. 2008;48(4):1219-1224.

57. Taubert D, Kastrati A, Harlfinger $S$ et al. Pharmacokinetics of clopidogrel after administration of a high loading dose. Thromb Haemost. 2004;92(2):311-316.

58. Born GV. Aggregation of blood platelets by adenosine diphosphate and its reversal. Nature. 1962;194:927929.

59. Malinin A, Pokov A, Spergling M et al. Monitoring platelet inhibition after clopidogrel with the VerifyNow$\mathrm{P}_{2} \mathrm{Y}_{12}(\mathrm{R})$ rapid analyzer: the VERIfy Thrombosis risk ASsessment (VERITAS) study. Thromb Res. 2007;119(3):277284. 
Introduction

6o. van Werkum JW, Hackeng CM, Smit JJ et al. Monitoring antiplatelet therapy with point-of-care platelet function assays: a review of the evidence. Future Cardiol. 2008;4(1):33-55.

61. Mueller T, Dieplinger B, Poelz W et al. Utility of whole blood impedance aggregometry for the assessment of clopidogrel action using the novel Multiplate analyzer--comparison with two flow cytometric methods. Thromb Res. 2007;121(2):249-258.

62. Michelson AD. Methods for the measurement of platelet function. Am J Cardiol. 2009;103(3 Suppl):20A-26A.

63. Kundu SK, Heilmann EJ, Sio R et al. Description of an in vitro platelet function analyzer--PFA-100. Semin Thromb Hemost. 1995;21 Suppl 2:106-112.

64. Varon D, Dardik R, Shenkman B et al. A new method for quantitative analysis of whole blood platelet interaction with extracellular matrix under flow conditions. Thromb Res. 1997;85(4):283-294.

65. Geiger J, Teichmann L, Grossmann R et al. Monitoring of clopidogrel action: comparison of methods. Clin Chem. 2005;51(6):957-965.

66. Angiolillo DJ, Fernandez-Ortiz A, Bernardo E et al. Variability in individual responsiveness to clopidogrel: clinical implications, management, and future perspectives. J Am Coll Cardiol. 2007;49(14):1505-1516.

67. Samara WM, Bliden KP, Tantry US, Gurbel PA. The difference between clopidogrel responsiveness and posttreatment platelet reactivity. Thromb Res. 2005;115(1-2):89-94.

68. Tantry US, Bliden KP, Gurbel PA. What is the best measure of thrombotic risks--pretreatment platelet aggregation, clopidogrel responsiveness, or posttreatment platelet aggregation? Catheter Cardiovasc Interv. 2005;66(4):597-598.

69. Bonello L, Tantry US, Marcucci R et al. Consensus and future directions on the definition of high on-treatment platelet reactivity to adenosine diphosphate. J Am Coll Cardiol. 2010;56(12):919-933. 


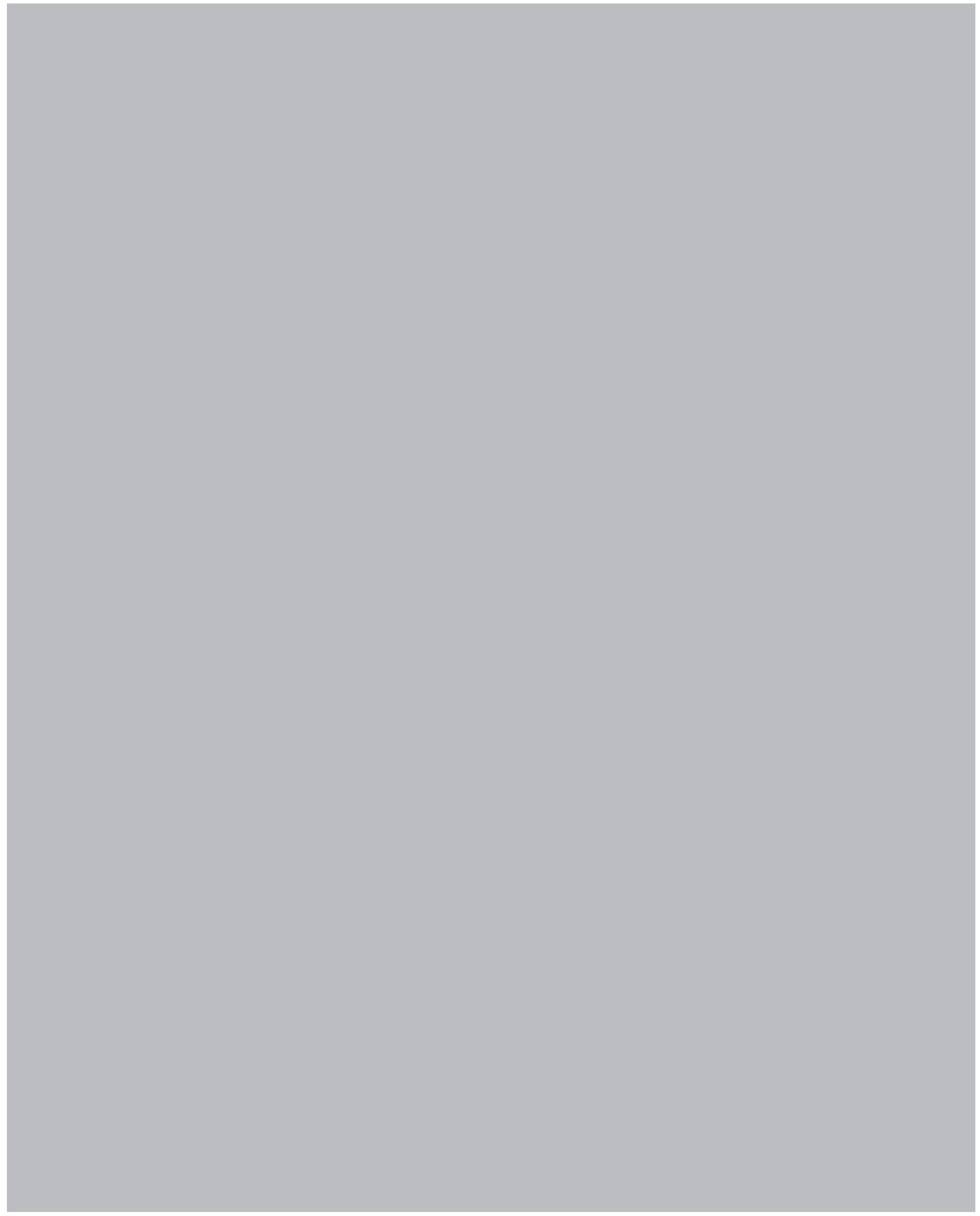




\section{Part I}

Interindividual variability in the response to antiplatelet therapy 


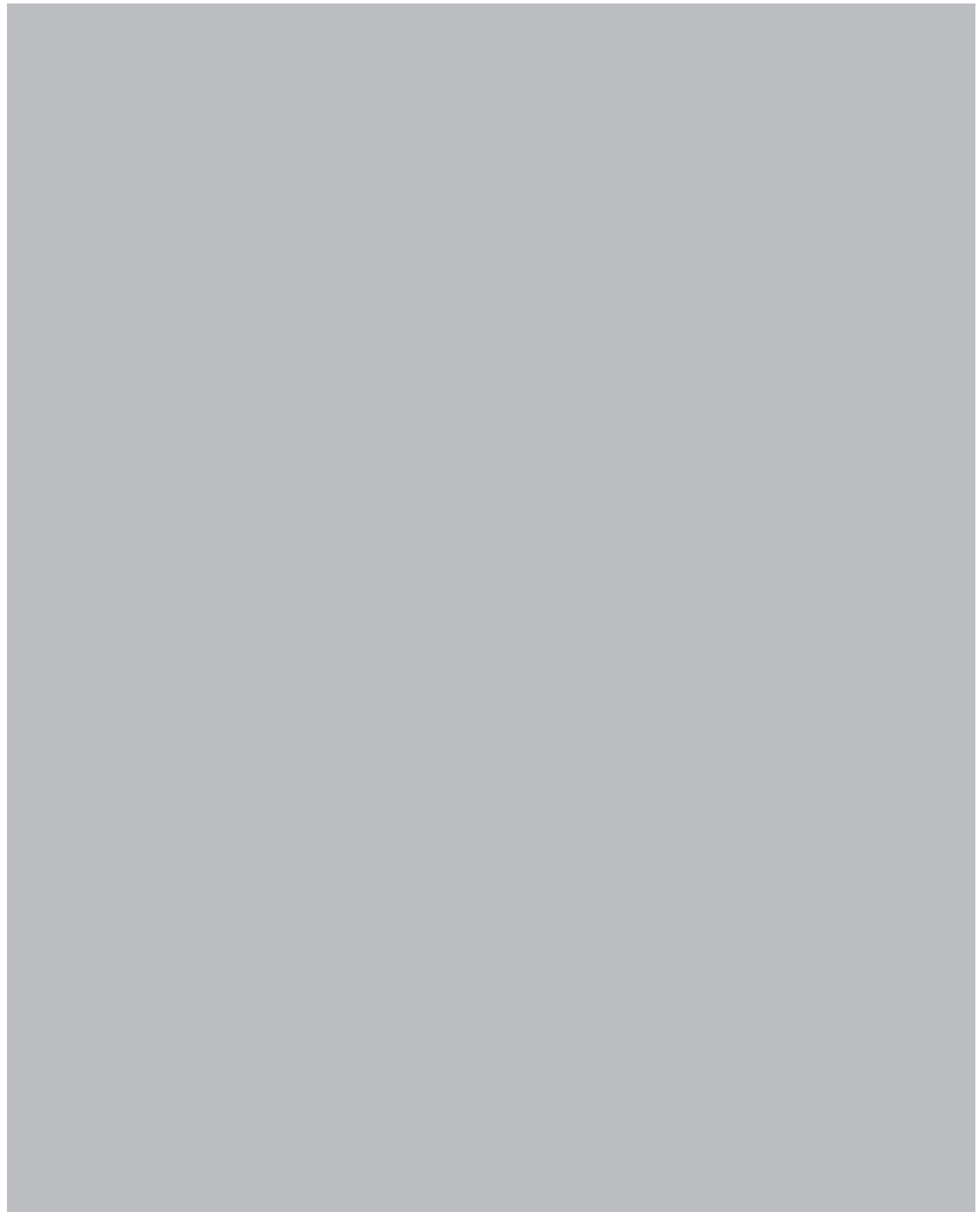




\section{Chapter 1}

\section{A case-control study on platelet reactivity \\ in coronary stent thrombosis}

JThromb Haemost. 2011 Mar;8(3):482-8

Heleen J Bouman Jochem W van Werkum

Nicoline J Breet

Hugo ten Cate

Christian M Hackeng

Jurriën M ten Berg

St Antonius center for Platelet Function Research, St Antonius Hospital, Nieuwegein, the Netherlands Department of Cardiology, St Antonius Hospital, Nieuwegein, the Netherlands Department of Internal Medicine, Cardiovascular Research Institute Maastricht,

Maastricht University Medical Center, Maastricht, the Netherlands Department of Clinical Chemistry, St Antonius Hospital, Nieuwegein, the Netherlands 


\section{ABSTRACT}

\section{Background}

The pathophysiology of ST has evolved from the identification of single causative factors to a complex multifactorial model.

\section{Objectives}

The aim of the present study was to investigate whether patients with a history of stent thrombosis (ST) exhibit a heightened platelet reactivity to clopidogrel and aspirin.

\section{Patients/Methods}

Pre- and on-treatment platelet reactivity status to clopidogrel and aspirin, as well as dual antiplatelet therapy resistance was determined in 84 patients with a history of definite ST (cases; 41 early ST, 43 late ST) and in 103 control patients with a previously implanted coronary stent but no ST after the index procedure. Platelet function was evaluated with optical aggregometry, the VerifyNow $\mathrm{P}_{2} \mathrm{Y}_{12}$ and Aspirin assays, PFA-100 Innovance $\mathrm{P}_{2} \mathrm{Y}$ cartridge, flowcytometric VASP-assay and urine 11-dehydro thromboxane $B_{2}$ measurement before and after the administration of a 6oomg loading dose of clopidogrel and 10omg aspirin. The study was registered at ClinicalTrials.gov, number NCT01012544.

\section{Results}

Patients with a history of early ST clearly demonstrated a higher on-clopidogrel platelet reactivity as compared to controls. Both early and late ST exhibited a heightened on-aspirin platelet reactivity status, and dual antiplatelet therapy resistance was more frequent.

\section{Conclusions}

Patients with a history of early ST exhibit a poor response to clopidogrel. Furthermore, both early as well as late ST are strongly and independently associated with a heightened on-aspirin platelet reactivity and dual antiplatelet therapy resistance is more frequent. 


\section{INTRODUCTION}

Stent thrombosis (ST) remains the dark site of coronary stenting since it is associated with a considerable morbidity and mortality as well as a high recurrence rate. ${ }^{1}$ The pathophysiology of ST has evolved from the identification of single causative factors to a complex multifactorial model. ${ }^{2}$ Predictors can be categorized as clinical, procedural, or lesion related. Recently, the involvement of novel determinants has been recognized, including an impaired responsiveness to antiplatelet therapy and a heightened platelet reactivity status despite antiplatelet therapy. ${ }^{3}$ Inhibition of circulating platelets with the combined treatment of aspirin and a thienopyridine is currently standard care in preventing ST in patients undergoing coronary stent implantation. ${ }^{4}$ However, the wide interindividual variability in the established response to the thienopyridine clopidogrel results in a poor responsiveness in a substantial number of patients. ${ }^{5}$ Similarly, aspirin exhibits a certain degree of variability in the residual platelet function among aspirin-treated individuals. ${ }^{6}$ Patients exhibiting a high on-treatment platelet reactivity status, either for clopidogrel, aspirin or both, have an increased risk of adverse clinical outcome after coronary stent implantation. . $^{37-12}$

As ST is a relatively rare complication occurring in 1-5\% undergoing coronary stent implantation, prospective studies mostly uncover only few cases of ST during follow-up, and even case-control studies investigating the relation between high on-treatment platelet reactivity and the occurrence of ST have drawn their conclusions on data from relatively small patient cohorts. ${ }^{13-21}$ In addition, it is known that platelet reactivity is increased during the early phase after an acute thrombotic event. ${ }^{22-25}$ Available studies on the relation between on-treatment platelet reactivity and ST have measured platelet reactivity at the time of the event or shortly thereafter. Hence, the measured high platelet reactivity may have been due to acute phase reaction after ST rather than being a causal factor in the onset of ST.

The aim of the present study was to explore differences in intrinsic and on-clopidogrel and on-aspirin platelet reactivity in a relatively large group of patients with a history of early and late ST, as compared to patients who previously underwent coronary stent implantation but did not incur ST.

\section{METHODS}

\section{Study design and Patient population}

This study was designed as a single-center case-control study. Cases were patients with a history of an angiographically confirmed ST ('definite' according to the Academic Research Consortium (ARC) criteria $\left.{ }^{26}\right)$. Controls were patients with a previously implanted coronary stent, but no ST during at least 12 months after the index-procedure for clopidogrel-naïve patients (i.e. patients not using clopidogrel at the time of inclusion) and at least 3 months for patients on clopidogrel maintenance therapy with $75 \mathrm{mg}$ clopidogrel daily at the time of inclusion (i.e. clopidogrel-maintenance group). Control patients were selected from the institutional administrative database that registers all patients undergoing $\mathrm{PCl}$. Because it was deemed unethical to discontinue the clopidogrel therapy in the clopidogrel maintenance group, these cases remained on dual antiplatelet therapy during the study. All patients were on aspirin at the time of inclusion. Compliance to antiplatelet therapy during $\geq 14$ days prior to inclusion was assessed by interview and verified by pharmacy refill data. Exclusion criteria for both cases and controls were a known allergy to aspirin or clopidogrel, an acute coronary syndrome (ACS) 
Part I | chapter 1

in the past 3 months, recent bleeding diathesis, bleeding disorder, known platelet dysfunction, or an abnormal platelet count (<150x10\%/L). The local institutional Ethics Committee approved the protocol. Written informed consent was obtained from all patients before enrollment. The study was registered at ClinicalTrials.gov, number NCT01012544.

\section{Study Procedure}

All eligible cases and controls visited the outpatient clinic for platelet function evaluation, physical examination and a standardized interview. First, blood was drawn for pre-loading platelet function evaluation, and to check for pseudo aspirin resistance due to non-compliance. Then, all subjects received a witnessed $600 \mathrm{mg}$ loading dose of clopidogrel and $100 \mathrm{mg}$ aspirin. At 6 hours post-loading, blood was drawn for measurement of on-clopidogrel and on-aspirin platelet reactivity.

\section{Blood and urine sample collection}

After an overnight fast and a rest of $\geq 30$ minutes, blood was collected from the antecubital vein into Vacuette ${ }^{\circledR}$ tubes (Greiner Bio-one, Frickenhausen, Germany) containing 3.2\% sodium citrate for all platelet function tests, except $3.8 \%$ sodium citrate for the PFA-100 ${ }^{\circledR}$ system. The first $5 \mathrm{~mL}$ of freeflowing blood was discarded to avoid spontaneous platelet activation. Platelet function testing was performed within 2 hours after blood withdrawal. All study participants were asked to provide a first morning urine specimen at the day of inclusion, which were subsequently stored at $-80^{\circ} \mathrm{C}$ until analysis.

\section{Laboratory measurements}

\section{Light Transmittance Aggregometry}

Light transmittance aggregometry (LTA) was quantified in non-adjusted platelet-rich-plasma (PRP) on an APACT 4004 aggregometer (LABiTec, Arensburg, Germany) and platelet-poor-plasma (PPP) served as the reference for $100 \%$ aggregation. The maximal $\%$ aggregation was determined after stimulation with either $20 \mu \mathrm{mol} / \mathrm{L}$ adenosine diphosphate (ADP) to measure $\mathrm{P}_{2} \mathrm{Y}_{12}$-receptor dependent platelet aggregation, or $0.5 \mathrm{mg} / \mathrm{mL}$ arachidonic acid (AA) for on-aspirin platelet reactivity.

The VerifyNow ${ }^{\circledR}$ Aspirin and $P_{2} Y_{12}$ assays

The VerifyNow ${ }^{\circledR}$ System (Accumetrics, San Diego, USA) is a whole blood assay designed to measure agonist-induced platelet aggregation. The Aspirin assay determines the response to aspirin, using AA in a final concentration of $1 \mathrm{mmol} / \mathrm{L}$ as the agonist. Results are reported as aspirin reaction units (ARU). The response to thienopyridines can be measured using the $\mathrm{P}_{2} \mathrm{Y}_{12}$ assay that contains $20 \mu \mathrm{mol} / \mathrm{L}$ ADP to induce $P_{2} Y_{12}$-dependent platelet aggregation, and 22nmol/L prostaglandin $E_{1}\left(P G E_{1}\right)$. Results of the $P_{2} Y_{12}$ assay are reported as $P_{2} Y_{12}$ reaction units (PRU). ${ }^{27}$

\section{Innovance ${ }^{\circledR} P F A P_{2} Y$}

The novel PFA-100 ${ }^{\circledR}$ analyzer (Dade Behring Marburg GmbH - A Siemens Company, Marburg, Germany) test cartridge Innovance ${ }^{\circledR}$ PFA $\mathrm{P}_{2} \mathrm{Y}$ was used, which measures platelet adhesion and aggregation in citrated whole blood under high shear conditions. The membrane of the Innovance ${ }^{\circledR}$ PFA $P_{2} Y$ cartridge is coated with $20 \mu \mathrm{g} \mathrm{ADP}, 5 \mathrm{ng} \mathrm{PGE}_{1}$ and $125 \mu \mathrm{g}$ calcium (as calcium chloride). The time needed to form a platelet plug occluding the aperture cut in this cartridge is determined and reported as closure time (CT, seconds). ${ }^{28}$ 
The flowcytometric vasodilator stimulated phosphoprotein (VASP) assay

Flowcytometric analysis of VASP phosphorylation was performed using a commercially available kit from Biocytex (Marseille, France). Samples were analyzed on a 500 MPL flowcytometer (Beckman Coulter, Marseille, France). The magnitude of platelet activation was expressed as the platelet reactivity index (PRI).

\section{Urinary Thromboxane B2 measurements}

The formation of the platelet-activating TxA from arachidonic acid by cyclooxygenase-1 (COX-1) is inhibited by aspirin. Urinary excretion of the stable $\mathrm{TxA}_{2}$ metabolite 11-dehydro thromboxane $\mathrm{B}_{2}$ (11dhTxB2, pg/mL) was measured using the commercially available kit AspirinWorks ${ }^{\circledR}$ (Corgenix, Westminster, CO, USA). After correction for urine creatinine concentration $(\mathrm{mg} / \mathrm{dL})$ results are presented as $\mathrm{pg} 11 \mathrm{dhT} \mathrm{TB}_{2}$ per $\mathrm{mg}$ creatinine.

\section{Definitions}

Platelet reactivity was measured before (pre-loading) and after clopidogrel loading (on-treatment, either on-clopidogrel or on-aspirin platelet reactivity). The occurrence of high on-treatment platelet reactivity was derived from on-treatment platelet reactivity values using a previously defined clinical cut-off as follows: high on-clopidogrel platelet reactivity (HCPR) was $20 \mu \mathrm{mol} / \mathrm{L}$ ADP-induced LTA $>64,5 \%$ or PRU>2367, high on-aspirin platelet reactivity (HAPR) was AA-induced LTA $>20 \%$ or ARU $>454^{29}$, and dual antiplatelet therapy resistance (DAPR) was the combined presence of HCPR and HAPR.

\section{Statistical analysis}

Continuous variables are presented as mean \pm SD or median [25-75 percentile] in case data deviated from normal distribution, and categorical data as frequencies (\%). Differences in continuous variables were compared by independent t-test or Mann-Whitney $U$ test, as appropriate. Dichotomous variables were compared by $\chi^{2}$-test or Fisher exact test. Analysis of variance (ANOVA) followed by least significant difference (LSD) post hoc testing or Kruskal-Wallis ANOVA, as appropriate, was used to compare platelet function test results between controls and cases with early and late ST. Since urinary ${ }_{11} \mathrm{dhT} \mathrm{TB}_{2}$ concentrations were skewed, geometric means $\pm \mathrm{SD}$ were calculated after log transformation of the data to compare results between cases and controls. Multivariate analysis using analysis of covariance (ANCOVA), was used to compare platelet function test results after adjustment for the following factors known to influence platelet function or the occurrence of ST: age, gender, body mass index (BMI, $\left.\mathrm{kg} / \mathrm{m}^{2}\right)$, current smoking, diabetes mellitus (DM), left ventricular ejection fraction (LVEF) $<45 \%$, use of proton pump inhibitors (PPI) or calcium channel blockers $(\mathrm{CCB})^{30}$, type of stent implanted during the index-procedure (bare-metal stent (BMS), drug-eluting stent (DES) or both), stenting of the left anterior descending artery (LAD) and indication of the index-PCI (ACS or stable angina pectoris $[S A P])^{2}$. Clopidogrel-related analyses were stratified according to clopidogrel treatment at the time of inclusion, i.e. clopidogrel naïve group and clopidogrel maintenance group. Analyses of on-aspirin platelet reactivity as well as analyses on the frequency of high on-aspirin (HAPR) and high onclopidogrel (HCPR) platelet reactivity and dual antiplatelet therapy resistance (DAPR) were performed on the total group. All statistical analyses were performed with SPSS (version 15.0; SPSS Inc., Chicago, IL, USA), and a two-sided $p$-value $<0.05$ was considered significant. 
Part I | chapter 1

\section{RESULTS}

\section{Patient characteristics}

A total of 84 patients with a history of ST were included. Of these, 39 patients ( 25 with early ST [within 30 days post- $\mathrm{PCI}$ ] and 14 with late $\mathrm{ST}$ [more than 30 days post-PCI]) were clopidogrel-naive at the time of inclusion, whereas 45 patients ( 16 with early and 29 with late ST) were on clopidogrel maintenance therapy with $75 \mathrm{mg}$ clopidogrel per day. These cases were compared with 74 clopidogrel-naïve controls and 29 controls on clopidogrel maintenance therapy. Further characteristics of the study cohort are illustrated in Table 1.

\section{Clopidogrel}

I. CLOPIDOGREL NAÏVE GROUP

Pre-loading platelet reactivity

Pre-loading platelet reactivity was similar between cases and controls for all platelet function tests (Figure 1A).

\section{On-clopidogrel platelet reactivity}

After the administration of a 6oomg loading dose of clopidogrel, patients with a history of early ST exhibited a higher on-clopidogrel platelet reactivity than controls when platelet reactivity was measured with the VerifyNow $\mathrm{P}_{2} \mathrm{Y}_{12}$ assay $(250 \pm 88 \mathrm{vs}$. $181 \pm 83 \mathrm{PRU}, p=0.002), 20 \mu \mathrm{mol} / \mathrm{L}$ ADP-induced LTA ( $58 \pm 16 \%$ vs. $46 \pm 17 \%, p=0.005$ ), and the PFA-100 Innovance $P_{2} Y$ cartridge ( 300 [80-300] vs. 300 [300-300] sec., $p=0.011$; Figure 1B). These associations remained significant after adjustment for potential confounders for LTA $(p=0.035)$ and the VerifyNow $\mathrm{P}_{2} \mathrm{Y}_{12}$ assay $(p=0.008)$. There was no difference in the results of the flowcytometric VASP-assay between cases and controls (Figure 1B). Furthermore, late ST was not associated with heightened on-clopidogrel platelet reactivity.

\section{CLOPIDOGREL MAINTENANCE GROUP}

Pre-loading platelet reactivity

The Innovance $\mathrm{P}_{2} \mathrm{Y}$ cartridge revealed a higher pre-loading platelet reactivity in patients with early ST as compared to controls (300 [73-300] vs. 300 [300-300] sec. respectively, $p=0.046 ;$ eFigure 1). No significant differences were observed between controls and patients with early or late ST when preloading platelet reactivity was measured with other platelet function tests.

On-clopidogrel platelet reactivity

In patients on clopidogrel maintenance therapy, the administration of a $600 \mathrm{mg}$ clopidogrel loading dose further reduced the magnitude of on-clopidogrel platelet reactivity. A higher on-clopidogrel value of PRU was demonstrated in patients with early ST as compared to controls (PRU $156 \pm 107$ Vs. 91 \pm 79 for controls, $p=0.026$; eFigure $1 B$ ), while patients with late ST had a higher on-clopidogrel platelet reactivity when measured with the Innovance $P_{2} Y$ cartridge (300 [300-300] vs. 300 [300-300] sec. respectively, $p=0.043 ;$ efigure 1 ). When possible confounders were included in multivariate analysis, these associations were no longer significant. No difference between cases and controls was observed when platelet reactivity was quantified with LTA or the VASP-assay (eFigure 1B). 
A
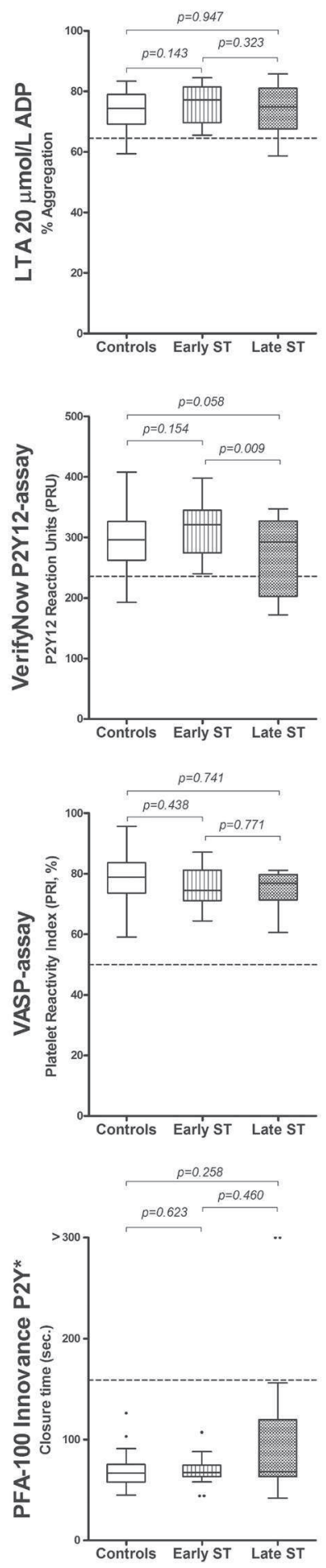

B
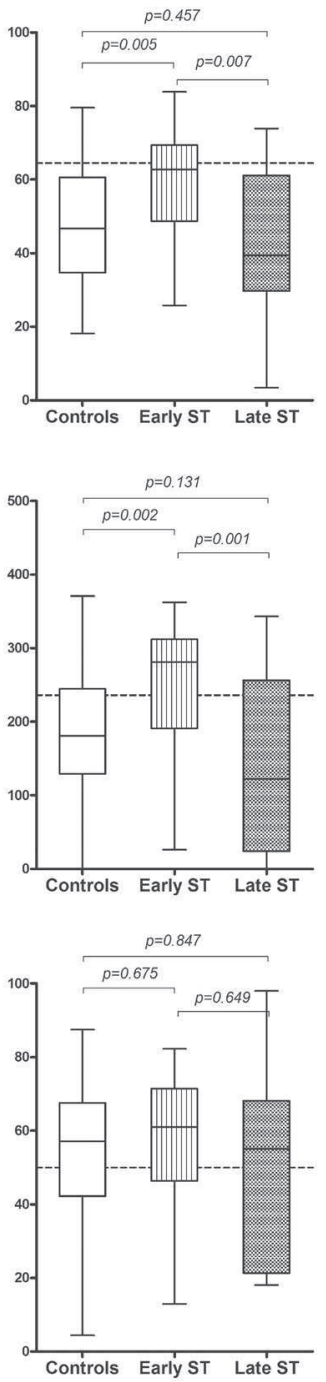

$p=0.480$

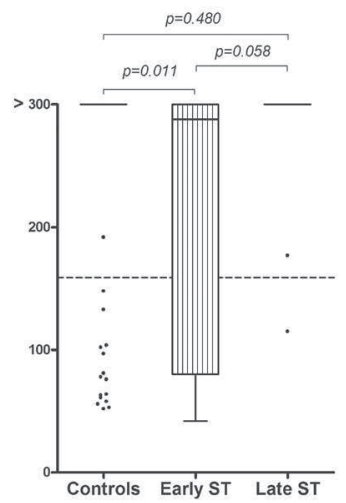

Figure 1 | Pre-and on-clopidogrel platelet reactivity.

Platelet reactivity was measured using $20 \mu \mathrm{mol} / \mathrm{L}$ ADP-induced LTA, the VerifyNow P2Y12-assay, the VASP-assay and the PFA-100 Innovance $P_{2} Y$ in the clopidogrelnaive group, and compared between controls $(n=74)$, early ST $(n=25)$, and late ST subjects ( $n=14)$. Panel A: pre-loading platelet reactivity, panel B: on-treatment platelet reactivity. Boxes cover the 25-75 percentiles with horizontal lines indicating medians, and the maximum length of each whisker is 1.5 times the interquartile range. Outliers are depicted as single data points. Horizontal dotted lines indicate cut-offs for high on-clopidogrel platelet reactivity, i.e. $64.5 \%$ $20 \mu \mathrm{mol} / \mathrm{L}$ ADP-induced LTA, 236 $P R U, 50 \% P R I$, and 159 seconds CT for the tests used, respectively. 7,34 
Part I | chapter 1

Table 1 | Patient characteristics

\begin{tabular}{|c|c|c|c|c|c|c|c|c|c|}
\hline \multirow[b]{2}{*}{ Characteristic } & \multicolumn{4}{|c|}{$\begin{array}{l}\text { Clopidogrel naive group } \\
\qquad n=113\end{array}$} & \multicolumn{3}{|c|}{$\begin{array}{l}\text { Clopidogrel maintenance group } \\
\qquad \mathrm{n}=74\end{array}$} & \multicolumn{2}{|c|}{$\begin{array}{c}\text { Total group } \\
\mathrm{n}=187\end{array}$} \\
\hline & 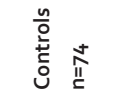 & 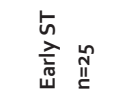 & 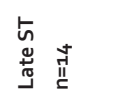 & $\frac{{ }^{*}}{0}$ & 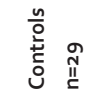 & 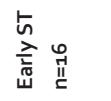 & 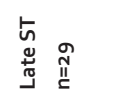 & 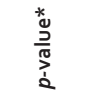 & 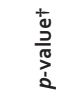 \\
\hline Male gender & $59(80 \%)$ & $23(92 \%)$ & $12(86 \%)$ & 0.353 & $21(72 \%)$ & $15(94 \%)$ & $23(79 \%)$ & 0.233 & 0.108 \\
\hline Age (years) & $60 \pm 9 \cdot 3$ & $63 \pm 11.9$ & $61 \pm 10.6$ & 0.389 & $57 \pm 11.5$ & $61 \pm 11.1$ & $59 \pm 8.8$ & 0.545 & 0.245 \\
\hline BMI $\left(\mathrm{kg} / \mathrm{m}^{2}\right)$ & $28.0 \pm 4.2$ & $27 \cdot 3 \pm 4.0$ & $25 \cdot 9 \pm 4 \cdot 4$ & 0.264 & $27.1 \pm 4.8$ & $26.3 \pm 3.4$ & $27 \cdot 3 \pm 4 \cdot 2$ & 0.736 & 0.405 \\
\hline Renal insufficiency $\ddagger$ & $2(3 \%)$ & $1(4 \%)$ & $1(7 \%)$ & 0.705 & $1(3 \%)$ & $\mathrm{o}(0 \%)$ & $2(7 \%)$ & 0.521 & 0.441 \\
\hline LVEF $\leq 45 \%$ & $8(11 \%)$ & $10(40 \%)$ & $5(36 \%)$ & 0.002 & $3(10 \%)$ & $4(25 \%)$ & $3(10 \%)$ & 0.316 & 0.004 \\
\hline Current smoking & $13(18 \%)$ & $5(20 \%)$ & $7(50 \%)$ & 0.026 & $11(38 \%)$ & $2(13 \%)$ & $11(38 \%)$ & 0.157 & 0.022 \\
\hline Family history of CAD & $43(58 \%)$ & $14(56 \%)$ & $9(64 \%)$ & 0.877 & $\mathrm{o}(0 \%)$ & o(०\%) & $1(3.4 \%)$ & 0.566 & 0.311 \\
\hline Diabetes Mellitus & $12(16 \%)$ & $1(4 \%)$ & $2(14 \%)$ & 0.296 & $4(14 \%)$ & $3(19 \%)$ & $7(24 \%)$ & 0.603 & 0.368 \\
\hline Hypercholesterolemia & $48(65 \%)$ & $17(68 \%)$ & $8(57 \%)$ & 0.791 & $20(69 \%)$ & $11(69 \%)$ & $24(83 \%)$ & 0.411 & 0.609 \\
\hline Hypertension & $41(55 \%)$ & $9(36 \%)$ & $7(50 \%)$ & 0.245 & $13(45 \%)$ & $10(63 \%)$ & $21(72 \%)$ & 0.097 & 0.201 \\
\hline \multicolumn{10}{|l|}{ Medication\$ } \\
\hline Statin & $6 o(81 \%)$ & $23(92 \%)$ & $13(93 \%)$ & 0.283 & $27(93 \%)$ & $14(88 \%)$ & $26(90 \%)$ & 0.810 & 0.473 \\
\hline Coumarin & $\mathrm{o}(0 \%)$ & $2(8 \%)$ & $\mathrm{o}(0 \%)$ & 0.028 & $1(3 \%)$ & $2(13 \%)$ & $2(7 \%)$ & 0.511 & 0.041 \\
\hline Beta-blocker & $47(64 \%)$ & $16(64 \%)$ & $14(100 \%)$ & 0.024 & $21(72 \%)$ & $13(81 \%)$ & $27(93 \%)$ & 0.116 & 0.001 \\
\hline CCB & $26(35 \%)$ & $8(32 \%)$ & $1(7 \%)$ & 0.115 & $8(28 \%)$ & $2(13 \%)$ & $8(28 \%)$ & 0.461 & 0.275 \\
\hline PPI & $22(30 \%)$ & $17(68 \%)$ & $6(43 \%)$ & 0.003 & $6(21 \%)$ & $8(50 \%)$ & $11(38 \%)$ & 0.115 & 0.001 \\
\hline \multicolumn{10}{|l|}{ Clinical chemistry } \\
\hline Platelet count ( $\left.10^{9} / \mathrm{L}\right)$ & $239 \pm 63$ & $240 \pm 53$ & $266 \pm 89$ & 0.370 & $262 \pm 80$ & $225 \pm 42$ & $256 \pm 76$ & 0.231 & 0.237 \\
\hline Mean platelet volume $(\mathrm{fL})$ & $8.6 \pm 0.9$ & $8.4 \pm 1.1$ & $8.4 \pm 0.9$ & 0.746 & $8.3 \pm 0.7$ & $8.4 \pm 1.0$ & $8.5 \pm 1.0$ & 0.834 & 0.845 \\
\hline $\begin{array}{l}\text { White blood cell count } \\
\left(10^{9} / \mathrm{L}\right)\end{array}$ & $6.6 \pm 1.7$ & $7.4 \pm 2.1$ & $8.1 \pm 2.1$ & 0.011 & $7.3 \pm 2.1$ & $6.2 \pm 2.6$ & $7.6 \pm 2.2$ & 0.106 & 0.031 \\
\hline \multicolumn{10}{|l|}{ Index-PCI } \\
\hline LAD stenting & $28(38 \%)$ & $16(64 \%)$ & $7(50 \%)$ & 0.079 & $15(52 \%)$ & $12(75 \%)$ & $13(45 \%)$ & 0.136 & 0.015 \\
\hline Stent type & $31(42 \%)$ & $16(64 \%)$ & $7(50 \%)$ & 0.279 & $12(41 \%)$ & $8(50 \%)$ & $10(34 \%)$ & 0.355 & 0.053 \\
\hline$D E S$ & $36(49 \%)$ & $8(32 \%)$ & $7(50 \%)$ & - & $15(52 \%)$ & $8(50 \%)$ & $19(66 \%)$ & - & - \\
\hline Mixed & $7(9 \%)$ & $1(4 \%)$ & o(०\%) & - & $2(7 \%)$ & o(०\%) & o(०\%) & - & - \\
\hline GPIIb/llla-blocker & $7(9 \%)$ & 4(16\%) & $5(36 \%)$ & 0.034 & $3(10 \%)$ & $5(31 \%)$ & $9(29 \%)$ & 0.119 & 0.003 \\
\hline \multicolumn{10}{|l|}{ Time frames ? } \\
\hline Index-PCI - inclusion & $\begin{array}{c}706 \\
{[592-898]}\end{array}$ & $\begin{array}{c}734 \\
{[550-1053]}\end{array}$ & $\begin{array}{c}846 \\
{[773-1256]}\end{array}$ & 0.195 & $\begin{array}{c}236 \\
{[165-341]}\end{array}$ & $\begin{array}{c}468 \\
{[262-743]}\end{array}$ & $\begin{array}{c}1164 \\
{[588-1343]}\end{array}$ & $<0.001$ & $<0.001$ \\
\hline Index-PCI-ST & - & $\begin{array}{c}2 \\
{[0-7]}\end{array}$ & $\begin{array}{c}335 \\
{[124-483]}\end{array}$ & $<0.001$ & - & $\begin{array}{c}2 \\
{[0-6]}\end{array}$ & $\begin{array}{c}461 \\
{\left[25^{8-919]}\right.}\end{array}$ & $<0.001$ & $<0.001$ \\
\hline ST - inclusion & - & $\begin{array}{c}733 \\
{[550-1044]}\end{array}$ & $\begin{array}{c}590 \\
{[427-1082]}\end{array}$ & 0.132 & - & $\begin{array}{c}466 \\
{[261-736]}\end{array}$ & $\begin{array}{c}371 \\
{[217-663]}\end{array}$ & $0.53^{8}$ & 0.040 \\
\hline
\end{tabular}

Continuous data are presented as means $\pm S D$ and statistical analysis of continuous data was performed using univariate ANOVA. Categorical variables as counts (\%), with differences between subgroups tested with $\chi^{2}$.

*p-value for comparison between controls, early ST and late ST within the clopidogrel naive and clopidogrel maintenance groups, and twithin the total group. $¥ G l o m e r u l a r$ filtration rate $(G F R)<6 \mathrm{oml} / \mathrm{min}$. \$Medication at the time of inclusion. IMedian days [interquartile range], statistical analysis with Kruskal-Wallis analysis of variance. ACE indicates angiotensin converting enzyme; $A R B$, angiotensin II receptor blocker; BMI, body mass index; BMS, bare metal stent; DES, drug eluting stent; GPIIb/IIIa, glycoprotein IIb/IIIa; LAD, left anterior descending artery; LVEF, left ventricular ejection fraction; $P C l$, percutaneous coronary intervention. 


\section{Aspirin}

Patients with a history of ST exhibited higher on-aspirin platelet reactivity levels as compared to

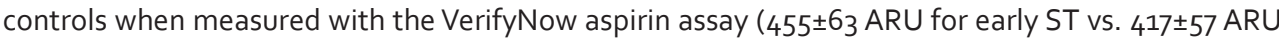
for controls, $p=0.001$ [multivariate $p=0.002$ ]) and AA-induced optical aggregometry $(22 \pm 12 \%$ for early ST and $20 \pm 12 \%$ for late ST vs. $14 \pm 7 \%$ for controls, $p<0.001$ for both [multivariate $p<0.001$ and $p=0.001$, respectively]; Figure 2). Furthermore, urinary levels of $11 \mathrm{dhTxB}_{2}$ were higher in both early ST (1180 \pm 250 $\mathrm{pg} / \mathrm{mg}$ creatinine) and late ST (1362 $\pm 247 \mathrm{pg} / \mathrm{mg}$ creatinine) as compared to controls (891 $\pm 41 \mathrm{pg} / \mathrm{mg}$ creatinine; $p=0.047$ [multivariate $p=\mathrm{ns}$ ] and $p=0.001$ [multivariate $p=0.007$ ], respectively).
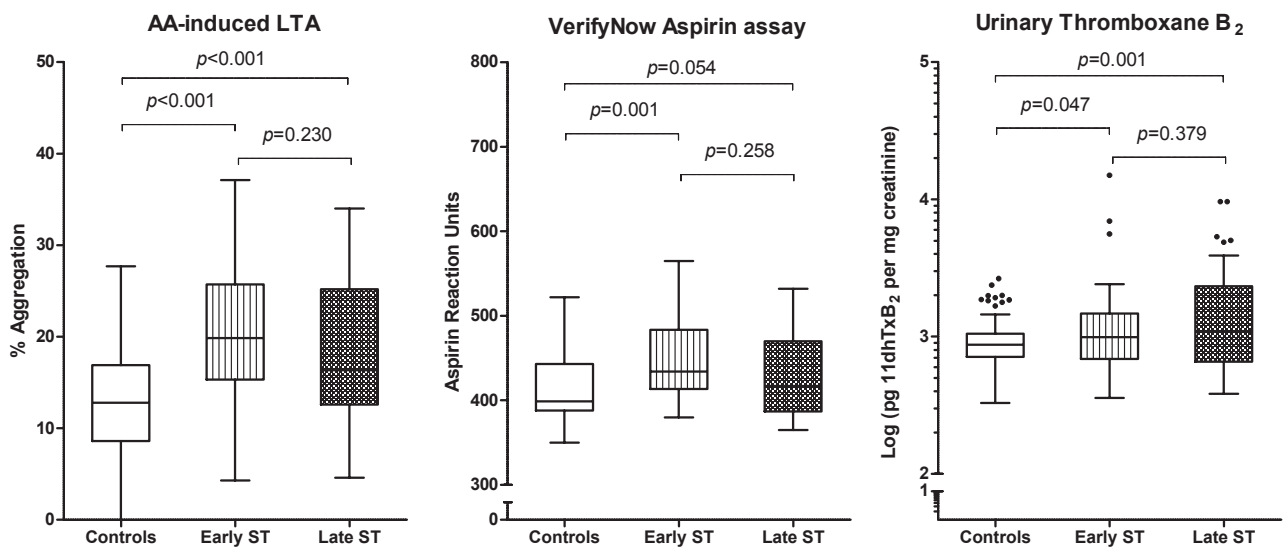

Figure 2 | On-aspirin platelet reactivity. Results were compared between controls ( $n=103)$ and patients with early ST $(n=41)$ and late ST $(n=43)$. Boxes cover the 25-75 percentiles with horizontal lines indicating medians, and the maximum length of each whisker is 1.5 times the interquartile range. Outliers are depicted as single data points. Since results of the urinary $11 d h T \times B_{2}$ measurements were skewed, data are presented on a log-scale and p-values represent statistical significance of differences in geometric means.

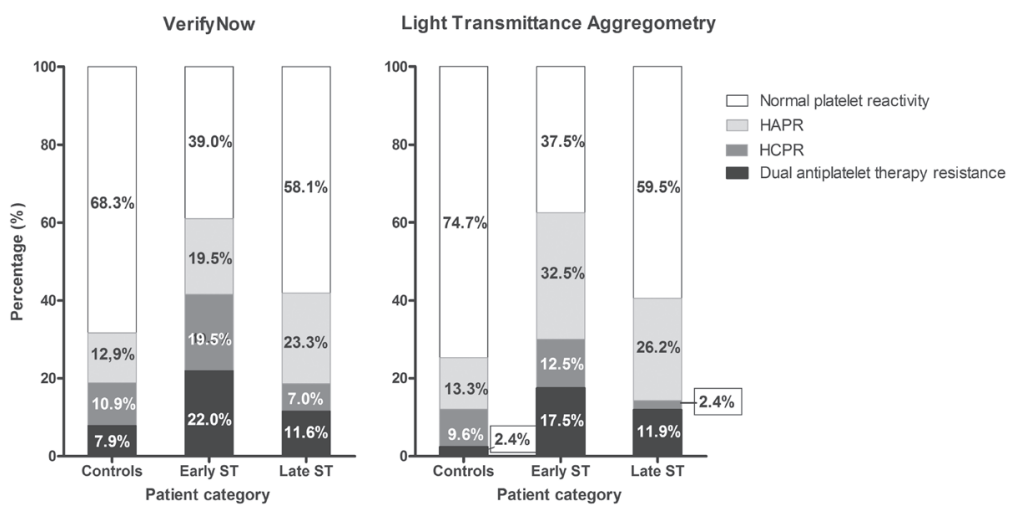

Figure 3 | Pattern of normal platelet reactivity, HAPR, HCPR and DAPR. Platelet reactivity was measured using 20 $\mu \mathrm{mol} / L A D P$ - and $A A$-induced $L T A$, and the VerifyNow $P_{2} Y_{12}-$ and Aspirin assays. A platelet reactivity value higher than previous determined cut-offs was considered as HCPR (>64.5\% LTA or $>236$ PRU) or HAPR (>20.0\% AA-induced LTA or $>454$ ARU) or DAPR (both HCPR and HAPR). [7, 29] Results were compared between controls $(n=103)$ and patients with early ST $(n=41)$ and late $S T(n=43)$. 
Part I | chapter 1

\section{Dual antiplatelet therapy resistance}

DAPR was more prevalent in both patients with early and late ST as compared to controls when assessed by LTA ( $p=0.003$ and $p=0.029$, respectively) and in early ST when measured with the VerifyNow ( $p=0.020$ compared to controls, Figure 3 ). Figure 3 shows the distribution of HAPR, HCPR and DAPR stratified by the three patient categories, demonstrating that over $60 \%$ of the patients with early ST and $40 \%$ of late ST have a high on-treatment platelet reactivity status to either aspirin, clopidogrel or both, compared to $25-30 \%$ of the controls. Furthermore, HCPR occurs more frequent in patients with early ST, while late ST has a higher prevalence of HAPR and DAPR, but less isolated HCPR.

\section{DISCUSSION}

Throughout recent years, the concept of a high on-treatment platelet reactivity status has been recognized in medical literature as a novel risk-factor for coronary ST and to the best of our knowledge the present study is the largest and most comprehensive evaluation of the relationship between platelet reactivity status and coronary ST. ${ }^{13-21}$

The principle findings of the present study include: $i$ ) patients with an early ST show an impaired responsiveness to clopidogrel as compared to controls resulting in a high on-clopidogrel platelet reactivity in up to $42 \%$ of the cases compared to up to $19 \%$ in controls; ii) Almost two-third of the patients with early ST exhibit high on-treatment platelet reactivity, to either clopidogrel, aspirin or both; iii) patients with a late ST respond well to a $600 \mathrm{mg}$ loading dose of clopidogrel; iv) both patients with a history of early and late ST exhibit a heightened on-aspirin platelet reactivity; and v) DAPR is more common in both early and late ST as compared to control subjects.

Previous studies have shown that ST was associated with a heightened on-clopidogrel platelet reactivity. However, platelet function was evaluated early after occurrence of ST ${ }^{13-19,21}$. Given that myocardial itself is characterized by a transient elevation of platelet reactivity that lasts for at least 30 days, it is unclear whether the established relationship between platelet reactivity and ST was biased by the timing of measurement ${ }^{22-25}$. Therefore, we evaluated platelet reactivity in patients with a history of ST, who were in a stable phase of disease at the time of inclusion. The results of the present study show that patients with ST exhibit a permanently heightened on-treatment platelet reactivity phenotype, implicating a role for genetic factors and/or ongoing disease states.

Patients with late ST had a higher prevalence of HAPR as compared to controls, whereas HCPR was only present as part of DAPR. This finding indicates that an isolated poor response to clopidogrel is less important in the pathophysiology of late ST, which is supported by results from the Trial to Assess Improvement in Therapeutic Outcomes by Optimizing Platelet Inhibition with Prasugrel - Thrombolysis in Myocardial Infarction (TRITON-TIMI) 38 study. ${ }^{31}$ In this trial it became evident that the prevention of ST by increasing the level of $\mathrm{P}_{2} \mathrm{Y}_{12}$-inhibition using prasugrel as compared to clopidogrel, was most prominent for early ST.

The Innovance P2Y PFA-100 cartridge became recently available. It was designed to specifically measure the magnitude of $\mathrm{P}_{2} \mathrm{Y}_{12}$-receptor inhibition, unlike the Col/ADP-cartridge that appeared to be insufficiently sensitive to the effects of clopidogrel. ${ }^{28,32}$ In the present study, the Innovance $P_{2} Y$ test was able to discriminate between patients with and without a history of early or late $\mathrm{ST}$, in line with the VerifyNow $\mathrm{P}_{2} \mathrm{Y}_{12}$ assay and ADP-induced LTA, though this association did not last when clinical variables were included in multivariate analysis. 
The flowcytometric VASP-assay has been commonly referred to as 'the biochemical gold standard' for the determination of clopidogrel responsiveness. In the present study, the VASP-assay was not able to detect a difference in response to clopidogrel between patients with and without a history of ST. These findings are in line with a recent study of Pinto Slottow and colleagues ${ }^{19}$, and may be explained by the finding that the VASP-assay was relatively insensitive to lower levels of $\mathrm{P}_{2} \mathrm{Y}_{12}$ inhibition, possibly resulting in the incapability to differentiate in the lower regions of the widely ranged response to clopidogrel. ${ }^{33}$

Some aspects of the present study may have hampered the quality of the results and merit attention. Inherent to the study design, an important subgroup of patients was excluded, i.e. patients who did not survive the ST or follow-up period. Considering the lethal nature of stent thrombosis, this leaves the evaluation with a substantial risk of survival bias. The obtained results were however in agreement with prospective studies that measured platelet function at the time of the index-procedure, suggesting that the effect of selection bias is small. Furthermore, urinary levels of $11 \mathrm{dhTXB_{2 }}$ were measured as an indication of aspirin response, instead of serum thromboxane $B_{2}$ levels, which is commonly regarded as the 'golden biochemical standard' for detecting aspirin response. Finally, although the total number of patients included in the present study was the largest until present, marked differences between subgroups (e.g. early and late ST, clopidogrel naïve and clopidogrel maintenance groups) that were not foreseen a priori, required post-hoc subdivision of the total group into smaller subgroups. As a result, multiple comparisons were performed, increasing the likelihood of chance findings.

In conclusion, patients with a history of early ST exhibit a heightened on-clopidogrel platelet reactivity. Furthermore, both early as well as late ST are strongly and independently associated with a heightened on-aspirin platelet reactivity and DAPR is more frequent.

\section{Acknowledgements}

The authors thank Drs. Sonja Postma and Drs. Olivier Witte for their support. 
Part I | chapter 1
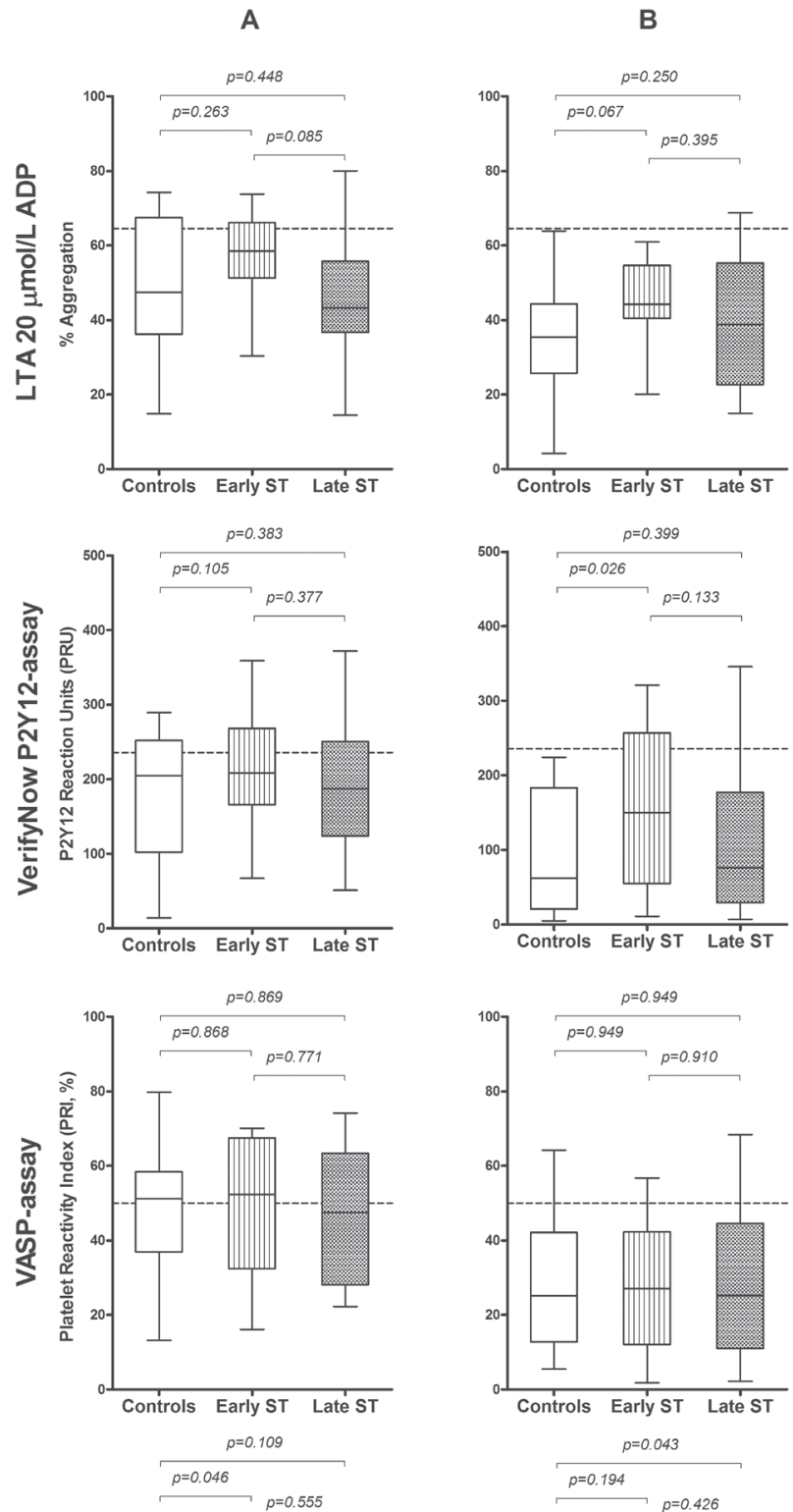

eFigure 1 | Pre-and on-clopidogrel platelet reactivity in the clopidogrel-maintenance group. Platelet reactivity was measured using 20 $\mu \mathrm{mol} / \mathrm{L}$ ADP-induced LTA, the VerifyNow $P_{2} Y_{12}$-assay, the VASPassay and the PFA-10o Innovance $P_{2} Y$ in the clopidogrel-maintenance group, and compared between controls $(n=29)$, early ST $(n=16)$, and late ST subjects $(n=29)$. Panel $A$ : pre-loading platelet reactivity, panel B: on-treatment platelet reactivity. Boxes cover the 25-75 percentiles with horizontal lines indicating medians, and the maximum length of each whisker is 1.5 times the interquartile range. Outliers are depicted as single data points. Horizontal dotted lines indicate cut-offs for high on-clopidogrel platelet reactivity, i.e. $64.5 \% 20$ $\mu \mathrm{mol} / \mathrm{L}$ ADP-induced LTA, 236 PRU, $50 \% P R I$, and 159 seconds CT for the tests used, respectively 7,34 


\section{REFERENCES}

1 van Werkum JW, Heestermans AA, de Korte FI et al. Long-term clinical outcome after a first angiographically confirmed coronary stent thrombosis: an analysis of 431 cases. Circulation. 2009; 119: 828-34.

2 van Werkum JW, Heestermans AA, Zomer AC et al. Predictors of coronary stent thrombosis: the Dutch Stent Thrombosis Registry. J Am Coll Cardiol. 2009; 53: 1399-409.

3 Combescure C, Fontana P, Mallouk N et al. Clinical implications of clopidogrel non-response in cardiovascular patients: a systematic review and meta-analysis. J Thromb Haemost. 2010; 8: 923-33.

4 King SB, 3rd, Smith SC, Jr., Hirshfeld JW, Jr. et al. 2007 focused update of the ACC/AHA/SCAI 2005 guideline update for percutaneous coronary intervention: a report of the American College of Cardiology/American Heart Association Task Force on Practice guidelines. J Am Coll Cardiol. 2008; 51: 172-209.

5 Gurbel PA, Bliden KP, Hiatt BL, O’Connor CM. Clopidogrel for coronary stenting: response variability, drug resistance, and the effect of pretreatment platelet reactivity. Circulation. 2003; 107: 2908-13.

6 Patrono C. Aspirin resistance: definition, mechanisms and clinical read-outs. J Thromb Haemost. 2003; 1: 1710-3.

7 Breet NJ, van Werkum JW, Bouman HJ et al. Comparison of platelet function tests in predicting clinical outcome in patients undergoing coronary stent implantation. JAMA. 2010; 303: 754-62.

8 Eikelboom JW, Hirsh J, Weitz Jl et al. Aspirin-resistant thromboxane biosynthesis and the risk of myocardial infarction, stroke, or cardiovascular death in patients at high risk for cardiovascular events. Circulation. 2002; 105: $1650-5$

9 Frelinger $\mathrm{AL}$, 3rd, LiY, Linden MD et al. Association of cyclooxygenase-1-dependent and -independent platelet function assays with adverse clinical outcomes in aspirin-treated patients presenting for cardiac catheterization. Circulation. 2009; 120: 2586-96.

10 Gori AM, Marcucci R, Migliorini A et al. Incidence and clinical impact of dual nonresponsiveness to aspirin and clopidogrel in patients with drug-eluting stents. J Am Coll Cardiol. 2008; 52: 734-9.

11 Gum PA, Kottke-Marchant K, Welsh PA et al. A prospective, blinded determination of the natural history of aspirin resistance among stable patients with cardiovascular disease. J Am Coll Cardiol. 2003; 41: 961-5.

12 Lev El, Patel RT, Maresh KJ et al. Aspirin and clopidogrel drug response in patients undergoing percutaneous coronary intervention: the role of dual drug resistance. J Am Coll Cardiol. 2006; 47: 27-33.

13 Ajzenberg N, Aubry P, Huisse MG et al. Enhanced shear-induced platelet aggregation in patients who experience subacute stent thrombosis: a case-control study. J Am Coll Cardiol. 2005; 45: 1753-6.

14 Geisler T, Zurn C, Simonenko R et al. Early but not late stent thrombosis is influenced by residual platelet aggregation in patients undergoing coronary interventions. Eur Heart J. 2010; 31: 59-66.

15 Gurbel PA, Bliden KP, Samara W et al. Clopidogrel effect on platelet reactivity in patients with stent thrombosis: results of the CREST Study. J Am Coll Cardiol. 2005; 46: 1827-32.

16 Huczek Z, Filipiak KJ, Kochman J et al. Baseline platelet size is increased in patients with acute coronary syndromes developing early stent thrombosis and predicts future residual platelet reactivity. A case-control study. Thromb Res. 2010; 125: 406-12.

17 Lev El, Alviar CL, Arikan ME et al. Platelet reactivity in patients with subacute stent thrombosis compared with non-stent-related acute myocardial infarction. Am Heart J. 2007; 153: 41.e1-6.

18 Morel O, Faure A, Ohlmann P et al. Impaired platelet responsiveness to clopidogrel identified by flow cytometric vasodilator-stimulated phosphoprotein (VASP) phosphorylation in patients with subacute stent thrombosis. Thromb Haemost. 2007; 98: 896-9.

19 Pinto Slottow TL, Bonello L, Gavini R et al. Prevalence of aspirin and clopidogrel resistance among patients with and without drug-eluting stent thrombosis. Am J Cardiol. 2009; 104: 525-30.

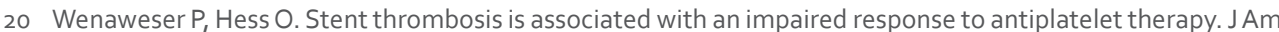
Coll Cardiol. 2005; 46: $\mathrm{CS}_{5}-6$. 


\section{Part I | chapter 1}

21 Barragan P, Bouvier JL, Roquebert PO et al. Resistance to thienopyridines: clinical detection of coronary stent thrombosis by monitoring of vasodilator-stimulated phosphoprotein phosphorylation. Catheter Cardiovasc Interv. 2003; 59: 295-302

22 Ault KA, Cannon CP, Mitchell J et al. Platelet activation in patients after an acute coronary syndrome: results from the TIMI-12 trial. Thrombolysis in Myocardial Infarction. J Am Coll Cardiol. 1999; 33: 634-9.

23 Gurbel PA, Bliden KP, Zaman KA et al. Clopidogrel loading with eptifibatide to arrest the reactivity of platelets: results of the Clopidogrel Loading With Eptifibatide to Arrest the Reactivity of Platelets (CLEAR PLATELETS) study. Circulation. 2005; 111: 1153-9.

24 Kubik MM, Richardson SG. A serial study of platelet reactivity throughout the first six months after myocardial infarction: its modification by sulphinpyrazone. Postgrad Med J. 1987; 63: 351-6.

25 Shimomura $\mathrm{H}$, Ogawa $\mathrm{H}$, Arai $\mathrm{H}$ et al. Serial changes in plasma levels of soluble P-selectin in patients with acute myocardial infarction. Am J Cardiol. 1998; 81: 397-400.

26 Cutlip DE, Windecker S, Mehran R et al. Clinical end points in coronary stent trials: a case for standardized definitions. Circulation. 2007; 115: 2344-51.

27 van Werkum JW, Harmsze AM, Elsenberg E et al. The use of the VerifyNow system to monitor antiplatelet therapy: a review of the current evidence. Platelets. 2008; 19: 479-88.

28 Linnemann B, Schwonberg J, Rechner AR et al. Assessment of clopidogrel non-response by the PFA-100 system using the new test cartridge INNOVANCE PFA P2Y. Ann Hematol. 2010; 89: 597-605.

29 Breet NJ, Van Werkum JW, Bouman HJ et al. High on-aspirin platelet reactivity as measured with aggregation based, COX-1 inhibition sensitive platelet function tests is associated with the occurrence of atherothrombotic events. JThromb Haemost. 2010; 8: 2140-8.

30 Siller-Matula JM, Lang I, Christ G, Jilma B. Calcium-channel blockers reduce the antiplatelet effect of clopidogrel. J Am Coll Cardiol. 2008; 52: 1557-63.

31 Wiviott SD, Braunwald E, McCabe $\mathrm{CH}$ et al. Intensive oral antiplatelet therapy for reduction of ischaemic events including stent thrombosis in patients with acute coronary syndromes treated with percutaneous coronary intervention and stenting in the TRITON-TIMI 38 trial: a subanalysis of a randomised trial. Lancet. 2008; 371: $1353-63$.

32 Harrison P, Frelinger AL, 3rd, Furman MI, Michelson AD. Measuring antiplatelet drug effects in the laboratory. Thromb Res. 2007; 120: 323-36.

33 Judge HM, Buckland RJ, Sugidachi A et al. Relationship between degree of $\mathrm{P}_{2} \mathrm{Y}_{12}$ receptor blockade and inhibition of $\mathrm{P}_{2} \mathrm{Y}_{12}$-mediated platelet function. Thromb Haemost. 2010; 103: 1210-7.

34 Bonello L, Paganelli F, Arpin-Bornet M et al. Vasodilator-stimulated phosphoprotein phosphorylation analysis prior to percutaneous coronary intervention for exclusion of postprocedural major adverse cardiovascular events. JThromb Haemost. 2007; 5: 1630-6 


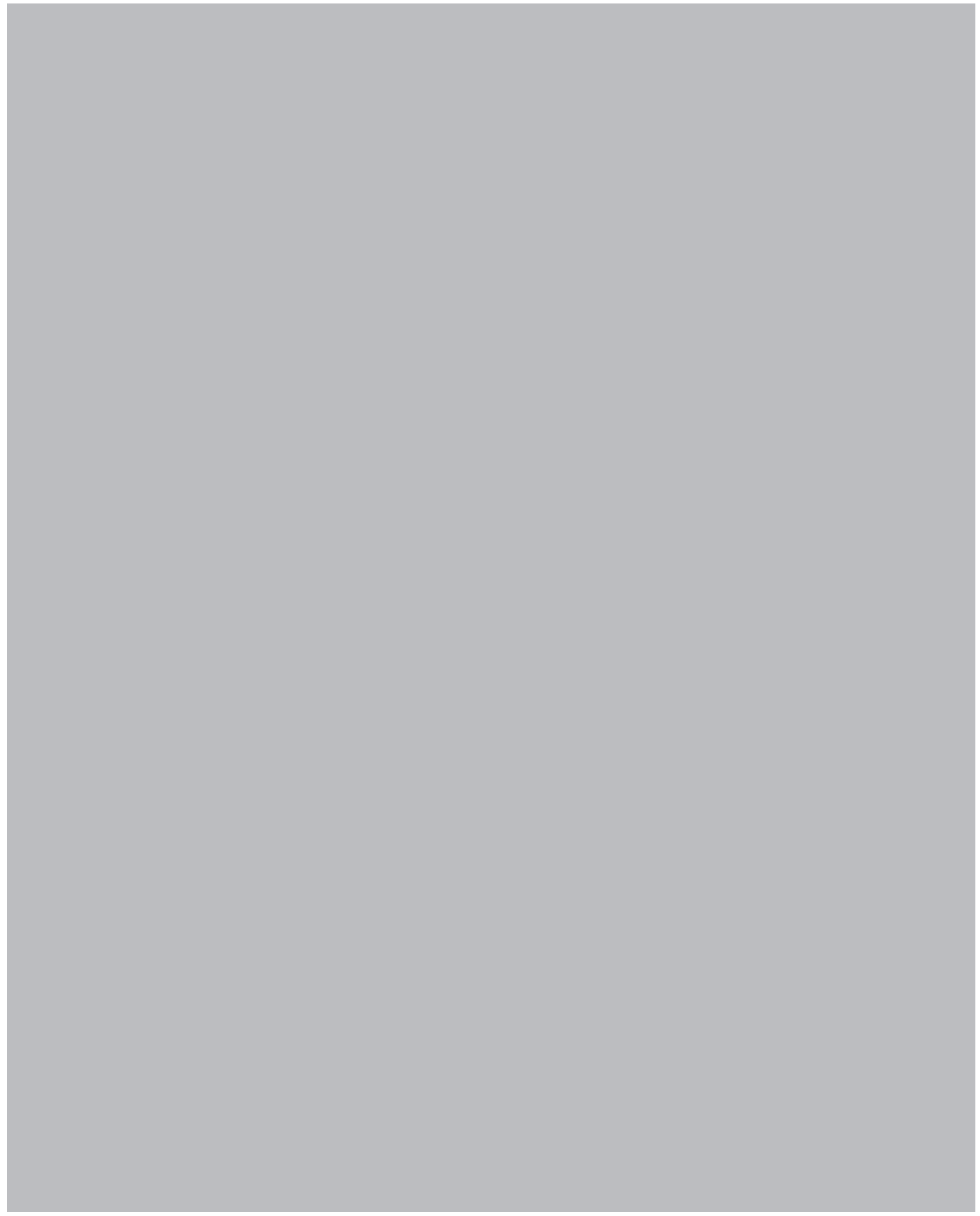




\section{Chapter 2}

\section{Cangrelor increases the magnitude of platelet inhibition and reduces interindividual variability in clopidogrel-pretreated subjects}

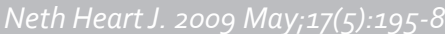

Heleen J Bouman Jochem $W$ van Werkum

Christian M Hackeng Nick Clappers Jurriën $\mathrm{M}$ ten Berg

Department of Cardiology, St. Antonius Hospital, Nieuwegein, the Netherlands Department of Clinical Chemistry, St. Antonius Hospital, Nieuwegein, the Netherlands Department of Cardiology, UMC St Radboud Nijmegen, the Netherlands 


\section{ABSTRACT}

\section{Background}

Inadequate platelet inhibition despite aspirin and clopidogrel therapy during and after a percutaneous coronary intervention is associated with an impaired clinical outcome. Cangrelor, a direct and reversible $\mathrm{P}_{2} \mathrm{Y}_{12}$ inhibitor that is currently in development, has the potential to achieve higher levels of inhibition of ADP-induced platelet aggregation than clopidogrel. The aim of the present study was to compare the magnitude of platelet inhibition in clopidogrel-pretreated patients before and after the in vitro addition of a subtherapeutic dose of cangrelor.

\section{Methods}

Blood samples were drawn from patients pretreated with clopidogrel and aspirin who were undergoing elective percutaneous coronary intervention ( $n=39$ ). Platelet function analysis with 'classical' light transmittance aggregometry (both peak and late aggregation [at 6 min]) was performed before and after the in vitro addition of cangrelor ( $0.25 \mu \mathrm{mol} / \mathrm{L})$ to platelet-rich plasma (PRP). After an incubation period of five minutes, platelet aggregation was induced by 5 and $20 \mu \mathrm{mol} / \mathrm{L}$ ADP.

\section{Results}

The in vitro addition of $0.25 \mu \mathrm{mol} / \mathrm{L}$ cangrelor to the PRP from clopidogrel-treated subjects resulted in an additional reduction in ADP-induced platelet aggregation. For ADP concentrations of 5 and 20 $\mu \mathrm{mol} / \mathrm{L}$, peak aggregation showed a decrease of 75 and $85 \%$, respectively $(\mathrm{p}<0.001$ for both), while late aggregation was almost completely diminished $(p=0.003$ and $p<0.001$, respectively). Furthermore, the interindividual variation in inhibition of ADP-induced platelet aggregation by clopidogrel was greatly reduced after the addition of cangrelor.

\section{Conclusion}

We demonstrate that the in vitro addition of even a subtherapeutic dose of cangrelor to the PRP of clopidogrel-pretreated patients results in an additional reduction of ADP-induced platelet aggregation. Moreover, cangrelor was able to diminish the interindividual variation observed in clopidogrel-inhibited platelet aggregation. 


\section{INTRODUCTION}

Clopidogrel is an orally administered prodrug that requires metabolic conversion to an active metabolite to inhibit platelet aggregation via the $\mathrm{P}_{2} \mathrm{Y}_{12}$ receptor. ${ }^{1}$ However, numerous studies have revealed that the efficacy of this metabolisation varies widely from subject to subject, resulting in a poor platelet inhibition in 5 to $44 \%$ of treated patients. ${ }^{2,3}$

Recent studies have demonstrated an association between the magnitude of post-clopidogrel treatment platelet aggregation and the occurrence of atherothrombotic events in patients undergoing percutaneous coronary intervention $(\mathrm{PCl}) \cdot 4^{4-6}$ On the background of these findings, it is important to note that the results of the recently published TRial to Assess Improvement in Therapeutic Outcomes by Optimizing Platelet InhibitioN with Prasugrel (TRITON study) clearly demonstrated that the proposed proof of principle 'a higher $\mathrm{P}_{2} \mathrm{Y}_{12}$ inhibition is associated with a reduction in atherothrombotic events', appears to be true. ${ }^{7}$ Specifically, intensified $\mathrm{P}_{2} \mathrm{Y}_{12}$ inhibition during and in the early days after $\mathrm{PCl}$ reduces myocardial infarction, as long as care is taken in certain patient groups who are a priori at high risk of bleeding.7 Cangrelor (formerly known as AR-C69931MX, The Medicines Company, Parsippany NJ USA) is an direct and reversible antagonist of the $\mathrm{P}_{2} \mathrm{Y}_{12}$ receptor that does not require conversion to an active metabolite for its antiplatelet action. ${ }^{8}$ Small phase Il dose-finding studies using two different concentrations of cangrelor $(2 \mu \mathrm{g} / \mathrm{kg} / \mathrm{min}$ and $4 \mu \mathrm{g} / \mathrm{kg} / \mathrm{min}$ ) in patients with an acute coronary syndrome have revealed a high magnitude of inhibition of platelet aggregation (IPA) after initiation of the cangrelor infusion. ${ }^{9,10}$ However, platelet function was measured with impedance aggregometry, a method that has not been very well studied with respect to $\mathrm{P}_{2} \mathrm{Y}_{12}$ inhibition. ${ }^{11}$ Therefore, we aimed to study the effect of cangrelor on platelet aggregation in patients pretreated with aspirin and clopidogrel using the 'gold standard' light transmittance aggregometry (LTA).

\section{METHODS}

Patients on aspirin and clopidogrel therapy scheduled for an elective PCI were enrolled. All subjects gave written informed consent. Risk factors and comorbidities were carefully obtained using a standard medical questionnaire. Physical examination of patients was performed by research physicians. Smoking was defined as any cigarette smoking in the last month. Hypertension was defined as a systolic blood pressure $>140 \mathrm{mmHg}$ or diastolic blood pressure $>90 \mathrm{mmHg}$. Diabetes mellitus was defined according to the World Health Organisation criteria. Hypercholesterolaemia was defined as a fasting LDL-cholesterol concentration $3.4 \mathrm{mmol} / \mathrm{L}$ or the need for statin therapy. Blood samples were drawn from the arterial sheath before heparinisation, into citrated (3.2\%) tubes (Sarstedt, Nümbrecht, Germany). The samples were then centrifuged at $120 \mathrm{~g}$ for ten minutes to recover platelet-rich plasma (PRP) and further centrifuged at $850 \mathrm{~g}$ for 15 minutes to recover platelet-poor plasma (PPP). PRP was adjusted to achieve a final platelet count between 250 and $300 \times 10^{9} / \mathrm{L}$ using the volunteer's PPP. Twohundred-and-fifty $\mu \mathrm{L}$ adjusted PRP was pipetted into four cuvettes, of which two were spiked with 25 $\mu \mathrm{L} 0.9 \% \mathrm{NaCl}$ and two were spiked with $25 \mu \mathrm{L}$ cangrelor in a final concentration of $0.25 \mu \mathrm{mol} / \mathrm{L}$ (this concentration represents the $2 \mu \mathrm{g} / \mathrm{kg} / \mathrm{min}$ infusion) and incubated for five minutes. Both peak and late aggregation (at 6 minutes) were quantified after stimulation with adenosine diphosphate (ADP; final concentrations 5 and $20 \mu \mathrm{mol} / \mathrm{L}$ ). ${ }^{12}$ Platelet aggregation was measured on an APACT 4004 aggregometer (LABiTec, Arensburg, Germany) and PPP served as the reference for 100\% aggregation. 
Part I | chapter 2

\section{Statistical analysis}

Discrete variables are reported as counts (percentages) and continuous variables as mean $\pm S D$. A paired Student's t-test was used to compare aggregation values before and after the addition of cangrelor. The F-test was used to compare standard deviations. Statistical analyses were performed using SPSS 11.5 and a p value of $<0.05$ was considered statistically significant.

\section{RESULTS}

A total of 39 patients on aspirin and clopidogrel therapy were enrolled. Patient characteristics are depicted in Table 1.Stimulation of PRP, obtained from patients pretreated with aspirin and clopidogrel, with 5 and $20 \mu \mathrm{mol} / \mathrm{L}$ ADP resulted in a peak aggregation of $25 \pm 13 \%$ and $42 \pm 18$, respectively. Late aggregation values were $13 \pm 13 \%$ and $26 \pm 24 \%$ after stimulation with 5 and $20 \mu \mathrm{mol} / \mathrm{L}$ ADP, respectively. Furthermore, despite adequate dosing of clopidogrel, a wide interindividual variability in the magnitude of platelet aggregation was observed between patients (Figure 1).

The in vitro addition of $0.25 \mu \mathrm{mol} / \mathrm{L}$ cangrelor resulted in a great reduction of ADP-induced platelet aggregation. For ADP concentrations of 5 and $20 \mu \mathrm{mol} / \mathrm{L}$, peak aggregation showed a decrease of 75 and $85 \%$, respectively $(p<0.001$ for both concentrations of ADP), while late aggregation was almost completely diminished, despite stimulation with ADP. Also, the interindividual variation in both 5 and $20 \mu \mathrm{mol} / \mathrm{L}$ ADP-induced platelet aggregation was greatly reduced after the addition of cangrelor (F-test probability value comparing standard deviations $\mathrm{p}<0.001$ ).

\begin{tabular}{lc} 
Table 1 | Patient characteristics \\
\hline Men & $33(85)$ \\
Age (years) & $62 \pm 9$ \\
BMI $\left(\mathrm{kg} / \mathrm{m}^{2}\right)$ & $27 \pm 4$ \\
Hypertension & $6(15)$ \\
Hypercholesterolaemia & $5(13)$ \\
Current smoker & $5(13)$ \\
Previous MI & $19(49)$ \\
Previous revascularisation & $19(49)$ \\
Medication & \\
$\quad$ Clopidogrel & $39(100)$ \\
Aspirin & $39(100)$ \\
Statin & $33(85)$ \\
B-blocker & $33(85)$ \\
ACE inhibitor & $12(31)$ \\
Platelet count (x 10 $/$ /)in EDTA & $307 \pm 85$ \\
Mean platelet volume (fL) & $6.8 \pm 0.6$ \\
\hline Values are presented as numbers (\%) or mean $\pm S D$. \\
BMI=body mass index, MI=myocardial infarction.
\end{tabular}

\section{DISCUSSION}

The purpose of this study was to evaluate the inhibitory effects of cangrelor with 'classical' LTA in patients pretreated with aspirin and clopidogrel. Although we used a lower concentration of cangrelor then currently studied in the ongoing CHAMPION studies (this is $4 \mu \mathrm{g} / \mathrm{kg} / \mathrm{min}$ infusion $\sim$ final concentration $0.5 \mu \mathrm{mol} / \mathrm{L}$ ), the addition of this subtherapeutic concentration of cangrelor yielded a large decrease of peak aggregation and an almost completely diminished late aggregation. Moreover, cangrelor was able to diminish the wide interindividual variation in platelet inhibition that was observed with clopidogrel therapy. 

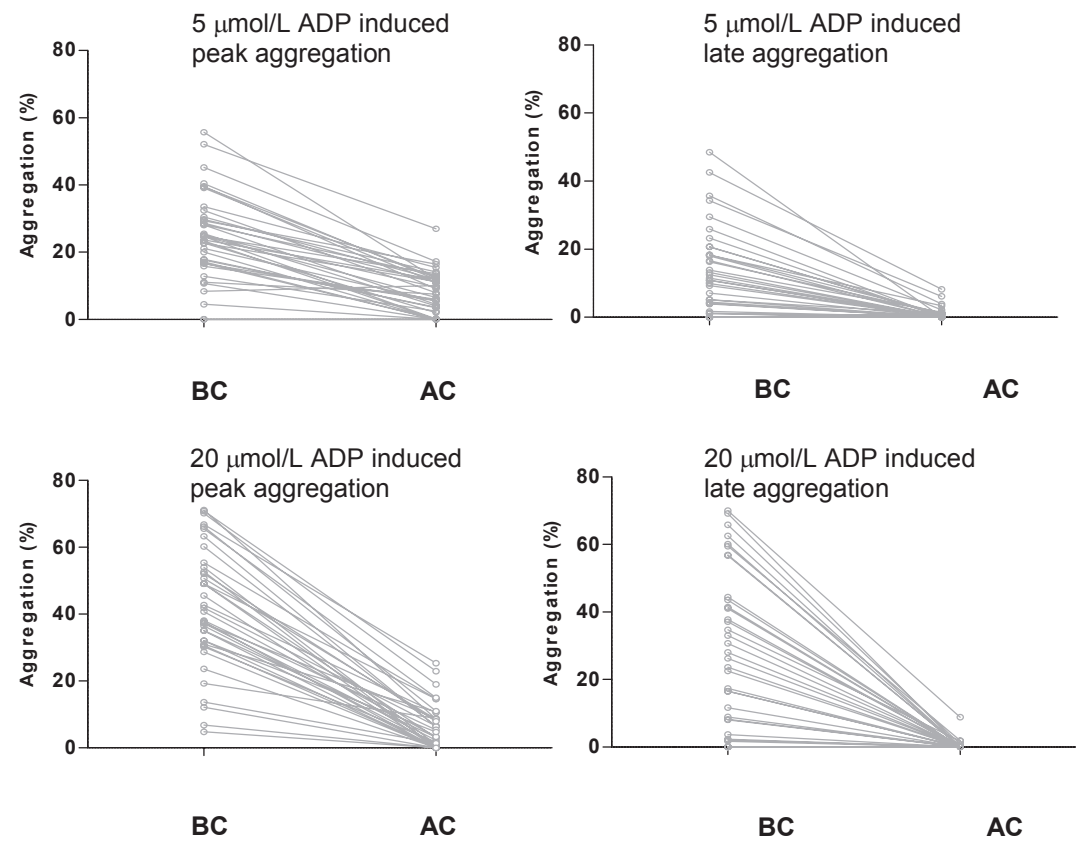

Figure 1 Peak and late ADP- induced platelet aggregation (5 and $20 \mu \mathrm{mol} / \mathrm{L}$ ) before $(B C)$ and after $(A C)$ the in vitro addition of $0.25 \mu \mathrm{mol} / \mathrm{L}$ cangrelor.

Recent studies have clearly demonstrated that a subset of patients who receive dual antiplatelet therapy with aspirin and clopidogrel do not reach adequate levels of platelet inhibition at the time of $\mathrm{PCl}^{3}$ And, more importantly, these patients are at a higher risk for the (re)occurrence of atherothrombotic events. ${ }^{4,6}$ Evidence that higher $\mathrm{P}_{2} \mathrm{Y}_{12}$ inhibition results in an improved clinical outcome is provided by the recently published TRITON study, which showed that the more potent platelet inhibition achieved by prasugrel results in an approximately $20 \%$ reduction of atherothrombotic events as compared to clopidogrel.7

Although prasugrel has a more rapid onset of action compared with clopidogrel, cangrelor has the additional advantage over clopidogrel and prasugrel of being a reversible and direct-acting $\mathrm{P}_{2} \mathrm{Y}_{12}$ antagonist, reaching optimal platelet inhibition in only minutes after the start of the infusion. In combination with a short half-life of several minutes, this results in a rapid 'on-off' feature that enables cangrelor to temporarily suppress platelet activation on top of an oral platelet inhibitor during and after $\mathrm{PCl}$. These features might improve clinical outcome concerning atherothrombotic events and avoid an increase in bleeding complications accompanying chronic intensified platelet inhibitor therapy. Two large-scale phase III, randomised clinical trials (CHAMPION-PCI and CHAMPION-PLATFORM) comparing clopidogrel with cangrelor and cangrelor on top of clopidogrel respectively, are currently assessing whether the superiority of cangrelor over clopidogrel in platelet inhibition will be translated into an improved clinical efficacy.

In conclusion, the in vitro addition of even a subtherapeutic concentration of cangrelor to the PRP of aspirin and clopidogrel pre-treated patients strongly reduces the magnitude of ADP-induced platelet aggregation. Moreover, cangrelor was able to diminish the interindividual variation observed in clopidogrel-inhibited platelet aggregation. 
Part I | chapter 2

\section{REFERENCES}

1 Savi P, Pereillo JM, Uzabiaga MF et al. Identification and biological activity of the active metabolite of clopidogrel. Thromb Haemost 2000;84:891-6.

2 Jaremo P, LindahITL, Fransson SG, Richter A. Individual variations of platelet inhibition after loading doses of clopidogrel. J Intern Med 2002;252:233-8.

3 Serebruany VL, Steinhubl SR, Berger PB et al. Variability in platelet responsiveness to clopidogrel among 544 individuals. J Am Coll Cardiol 2005;45:246-51.

4 Geisler T, Langer $\mathrm{H}$, Wydymus $\mathrm{M}$ et al. Low response to clopidogrel is associated with cardiovascular outcome after coronary stent implantation. Eur Heart J 2006;27:2420-5.

5 Cuisset T, Frere C, Quilici J et al. Benefit of a 60o-mg loading dose of clopidogrel on platelet reactivity and clinical outcomes in patients with non-ST-segment elevation acute coronary syndrome undergoing coronary stenting. J Am Coll Cardiol 2006;48:1339-45.

6 Buonamici P, Marcucci R, Migliorini A et al. Impact of platelet reactivity after clopidogrel administration on drug-eluting stent thrombosis. J Am Coll Cardiol 2007;49:2312-7.

7 Wiviott SD, Braunwald E, McCabe $\mathrm{CH}$ et al. Prasugrel versus clopidogrel in patients with acute coronary syndromes. N Engl J Med 2007;357:2001-15.

8 Fugate $\mathrm{SE}_{,}$Cudd LA. Cangrelor for treatment of coronary thrombosis. Ann Pharmacother 2006;40:925-30.

9 Storey RF, Newby LJ, Heptinstall S. Effects of $\mathrm{P}_{2} \mathrm{Y}(1)$ and $\mathrm{P}_{2} \mathrm{Y}(12)$ receptor antagonists on platelet aggregation induced by different agonists in human whole blood. Platelets 2001;12:443-7.

10 Storey RF, Oldroyd KG, Wilcox RG. Open multicentre study of the P2T receptor antagonist AR-C69931MX assessing safety, tolerability and activity in patients with acute coronary syndromes. Thromb Haemost 2001;85:401-7.

11 van Werkum JW, Hackeng CM, de Korte Fl et al. Point-of-care platelet function testing in patients undergoing PCl: between a rock and a hard place. Neth Heart J 2007;15:299-305

12 van Werkum JW, Kleibeuker M, Mieremet $\mathrm{N}$ et al. Evaluation of the platelet response to clopidogrel with light transmittance aggregometry: peak aggregation or late aggregation? J Thromb Haemost 2007:5:884-6. 


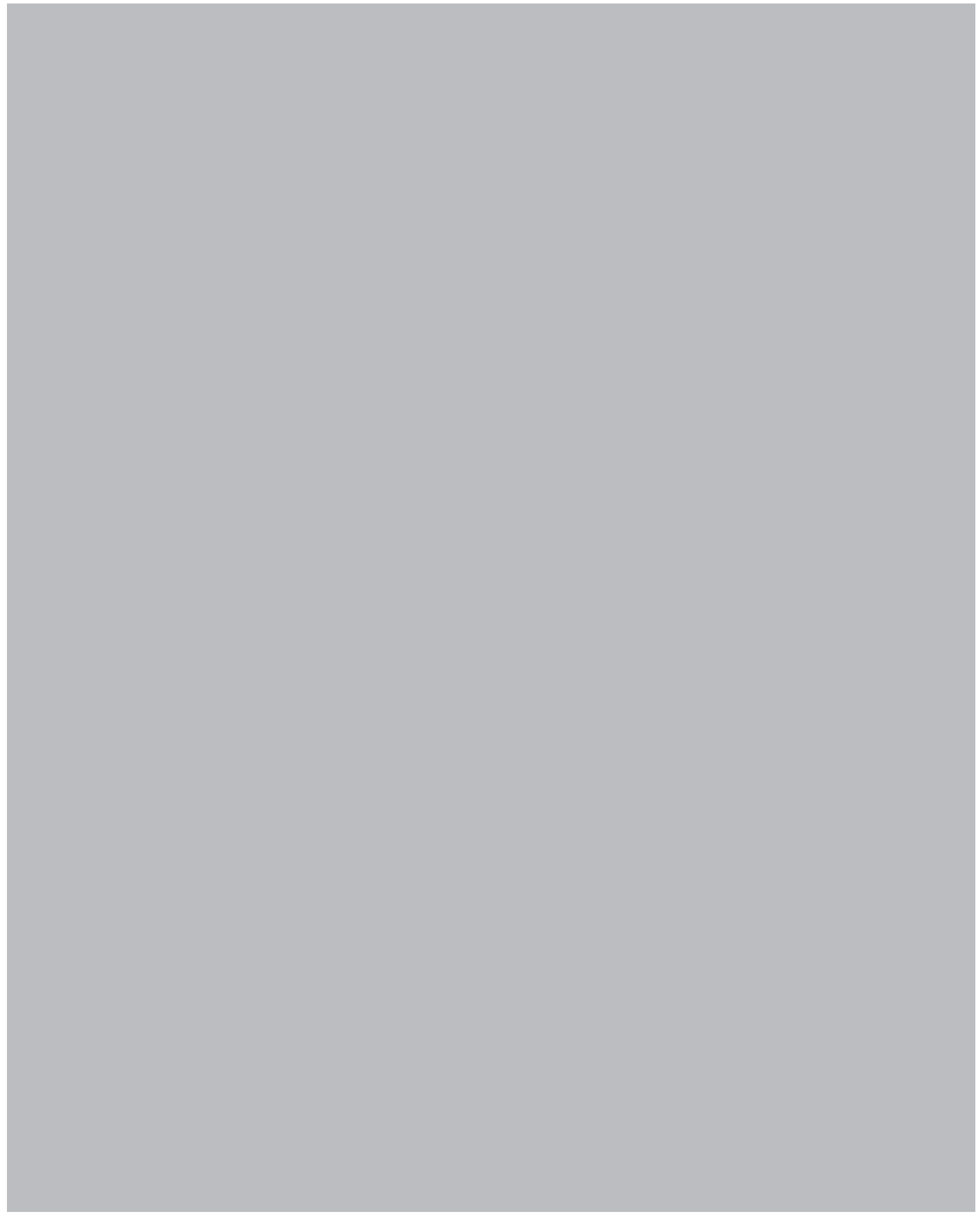




\section{Chapter 3}

The importance of anticoagulant agents in measuring platelet aggregation in patients treated with clopidogrel and aspirin

JThromb Haemost. 2008 Jun; 6(6):1040-2

Heleen J Bouman Jochem $W$ van Werkum

Christian M Hackeng Freek WA Verheugt Jurriën $\mathrm{M}$ ten Berg

Department of Cardiology, St. Antonius Hospital, Nieuwegein, the Netherlands Department of Clinical Chemistry, St. Antonius Hospital, Nieuwegein, the Netherlands Department of Cardiology, UMC St Radboud Nijmegen, the Netherlands 
Part I | chapter 3

Recent studies have demonstrated an association between the magnitude of post-treatment platelet reactivity and the occurrence of atherothrombotic events in patients undergoing percutaneous coronary intervention $(\mathrm{PCl}) .^{1 ; 2}$ Sodium citrate is the most commonly used anticoagulant when determining residual platelet reactivity in vitro because it is widely available at low costs. However, sodium citrate chelates extracellular calcium, creating an artificial milieu that does not represent the in vivo situation. An alternative in vitro anticoagulant is D-phenylalanyl-L-propyl-L-arginine chloromethyl ketone (PPACK), which acts by inhibiting thrombin, thereby maintaining physiologic extracellular calcium levels. ${ }^{3}$

In the last few years, two studies have been published comparing the magnitude of residual platelet reactivity in both citrate and PPACK anticoagulated blood. 4.5 Remarkably, although the same methods in a comparable patient population were used, the outcomes of these two studies are conflicting. Patel et al. demonstrated that residual platelet reactivity in clopidogrel pre-treated patients is significantly higher in citrated blood as compared to PPACK-anticoagulated blood(5), whereas Labarthe et al. have reported the opposite.(4)

The primary aim of the present study is to solve this conflict by investigating the effect of anticoagulation with citrate vs. PPACK on residual platelet aggregation in a large population on dual antiplatelet therapy with clopidogrel and aspirin.

Consecutive patients undergoing elective $\mathrm{PCl}$ were enrolled in the present study. Exclusion criteria included: glycoprotein Ilb/llla-therapy in the last 7 days and a platelet count of less than $150.10^{9} / \mathrm{L}$. The local Institutional Review Board approved the protocol and written informed consent was obtained from all patients. Blood samples were drawn from the arterial sheath before heparinization into tubes containing either $3.2 \%$ sodium citrate (Sarstedt, Nümbrecht, Germany) or 50 $\mathrm{mmol} / \mathrm{L}$ PPACK (Calbiochem, La Jolla, California). Post-treatment platelet reactivity was measured in non adjusted platelet-rich-plasma (PRP) by light transmission aggregrometry (APACT 4004 - LABiTec, Arensburg, Germany) as the percentage change in light transmission after stimulation with different concentrations of the agonists $\operatorname{ADP}(5,10$ and $20 \mu \mathrm{mol} / \mathrm{L})$ and arachidonic acid $(A A)(500 \mu \mathrm{g} / \mathrm{mL})$. Peak and late aggregation (at $360 \mathrm{~s}$ ) results were checked for normality by a Kolmogorov-Smirnov test and statistical significance in peak and late platelet reactivity was determined by the student's paired t-test or the Wilcoxon test (in case the data were not normally distributed). Linear regression between posttreatment platelet reactivity parameters in PPACK and citrate anticoagulated blood was determined by Spearman's correlation analysis.

Two-hundred-and-fifty patients were enrolled. Of these patients, $224(89,6 \%)$ were on dual antiplatelet therapy with clopidogrel and aspirin, and 26 patients (10.4\%) were on a combination of clopidogrel and a coumadin. The mean ( \pm SD) age of the studied population was 63.7 ( \pm 10.3$)$ years. The prevalence of traditional cardiovascular risk-factors was high and included male gender in $76.4 \%$, hypertension in $76.4 \%$, dyslipidemia in $82.4 \%$, current smoking in $9.6 \%$ and diabetes in $19.6 \%$. Concomitant medication consisted of statins in $81.2 \%$, $\beta$-blockers in $75.6 \%$ and ACE-inhibitors in $33.6 \%$.

Post-treatment platelet reactivity was significantly higher in citrated blood as compared to PPACK anticoagulated blood ( $p<0.0001$ for all concentrations of ADP and AA [figure 1]). This accounts for both peak aggregation and late aggregation, although the difference is much more pronounced in late aggregation. Both peak and late aggregation correlated well between PPACK and citrate 

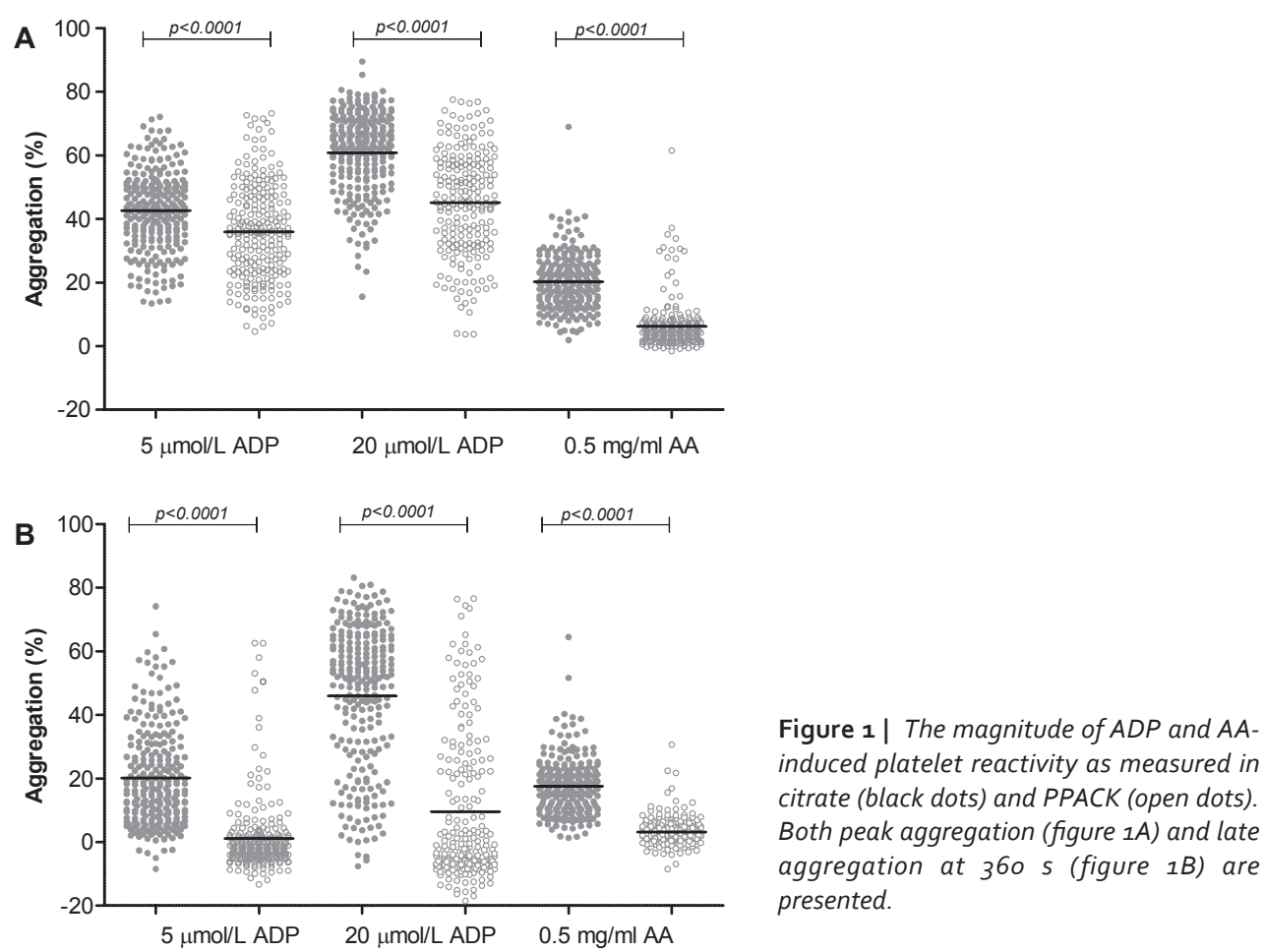

anticoagulated blood for 5 and $20 \mu \mathrm{M}$ ADP-induced aggregation, with $r=0.81$ and 0.74 for peak aggregation, and $r=0.57$ and 0.74 for late aggregation respectively $(p<0.001$ for all).

As expected and in line with recent literature, peak and late aggregation correlated well in citrate anticoagulated blood (the correlation between peak and late aggregation was 0.69 and 0.94 for 5 and $20 \mu \mathrm{M}$ ADP ( $p<0.0001$ for both), respectively ${ }^{8}$. In whole blood with PPACK as anticoagulant, however, the correlation between peak aggregation and late aggregation was less apparent (the correlation between peak and late aggregation was 0.58 and 0.78 for 5 and $20 \mu \mathrm{M}$ ADP ( $p<0.0001$ for both), respectively).

The overall findings of the present study are in accordance with the reported results of Labarthe and colleagues, who also demonstrated that late post-treatment platelet reactivity is significantly reduced when measured in PPACK anticoagulated blood as compared to citrated blood. ${ }^{4}$ Although their findings also show a trend towards lower peak residual platelet reactivity in PPACK, no significant differences between PPACK and citrate could be observed. Probably, statistical significance could not be reached because their study was hampered by a small sample size. Remarkably, Patel and colleagues reveal opposite findings, as they report a higher residual platelet reactivity in PPACK anticoagulated blood as compared to citrated blood. ${ }^{5}$ Importantly, there were no differences in the studied population, methodology or protocol. A limitation of the study by Patel and coworkers is the fact that they do not report measures of late aggregation at all, which is considered to be a better reflection of the clopidogrel response in vivo. ${ }^{4,6} \mathrm{It}$ is important to note that in PPACK anticoagulated blood, and to a much lesser extent in citrated blood, the majority of late aggregation values are below $0 \%$ aggregation. 
Part I | chapter 3

Also, it appears that these negative aggregation values further decrease after stimulation with higher concentrations of ADP. An explanation for this phenomenon remains pure speculative, but it is possible that the aggregates which are formed upon ADP stimulation dissociate into platelets with a more rounded form with pseudopods (similar to the shape change signal directly after the addition of ADP).

In conclusion, the main purpose of this correspondence was to resolve the ongoing discussion concerning recent published results regarding the use of either citrate or PPACK as an anticoagulant in assessing residual platelet reactivity. Although our findings are not directly of clinical relevance, with the increased interest in monitoring of antiplatelet therapy it is of utmost importance to use an anticoagulant which provides the best representation of the in vivo situation. In line with the observations of Labarthe and coworkers, we confirm in a large cohort of patients that the magnitude of post-treatment platelet reactivity (both peak and late aggregation) is lower when PPACK is used as anticoagulant as compared to citrate. The important question: "which of the two anticoagulants is a better representation of the in vivo situation and correlates superiorly with clinical outcome" warrants further study in a larger cohort of patients. 


\section{REFERENCES}

1 Geisler T, Langer H, Wydymus $\mathrm{M}$ et al. Low response to clopidogrel is associated with cardiovascular outcome after coronary stent implantation. Eur Heart J 2006; 27: 2420-25.

2 Buonamici P, Marcucci R, Migliorini A et al. Impact of platelet reactivity after clopidogrel administration on drug-eluting stent thrombosis. J Am Coll Cardiol 2007; 49: 2312-17.

3 Lyon ME, Drobot DW, Harding SR, Lyon AW. Evaluation of the thrombin inhibitor D-phenylalanyl-L-prolyl-Larginine chloromethylketone (PPACK) with the factor Xa inhibitor 1,5-dansyl-L-glutamyl-L-glycyl-L-arginine chloromethylketone (GGACK) as anticoagulants for critical care clinical chemistry specimens. Clin Chim Acta 1999; 280: 91-99.

4 Labarthe B, Theroux P, Angioi M, Ghitescu M. Matching the evaluation of the clinical efficacy of clopidogrel to platelet function tests relevant to the biological properties of the drug. J Am Coll Cardiol 2005; 46: 638-45

5 Patel P, Gonzales R, Dokainish H, Lakkis N. Impact of adenosine diphosphate and calcium chelation on platelet aggregation testing in patients receiving clopidogrel therapy. J Am Coll Cardiol 2006; 47: 464-65.

6 van Werkum JW, Kleibeuker M, Mieremet N et al. Evaluation of the platelet response to clopidogrel with light transmittance aggregometry: peak aggregation or late aggregation? J Thromb Haemost 2007; 5: 884-86. 


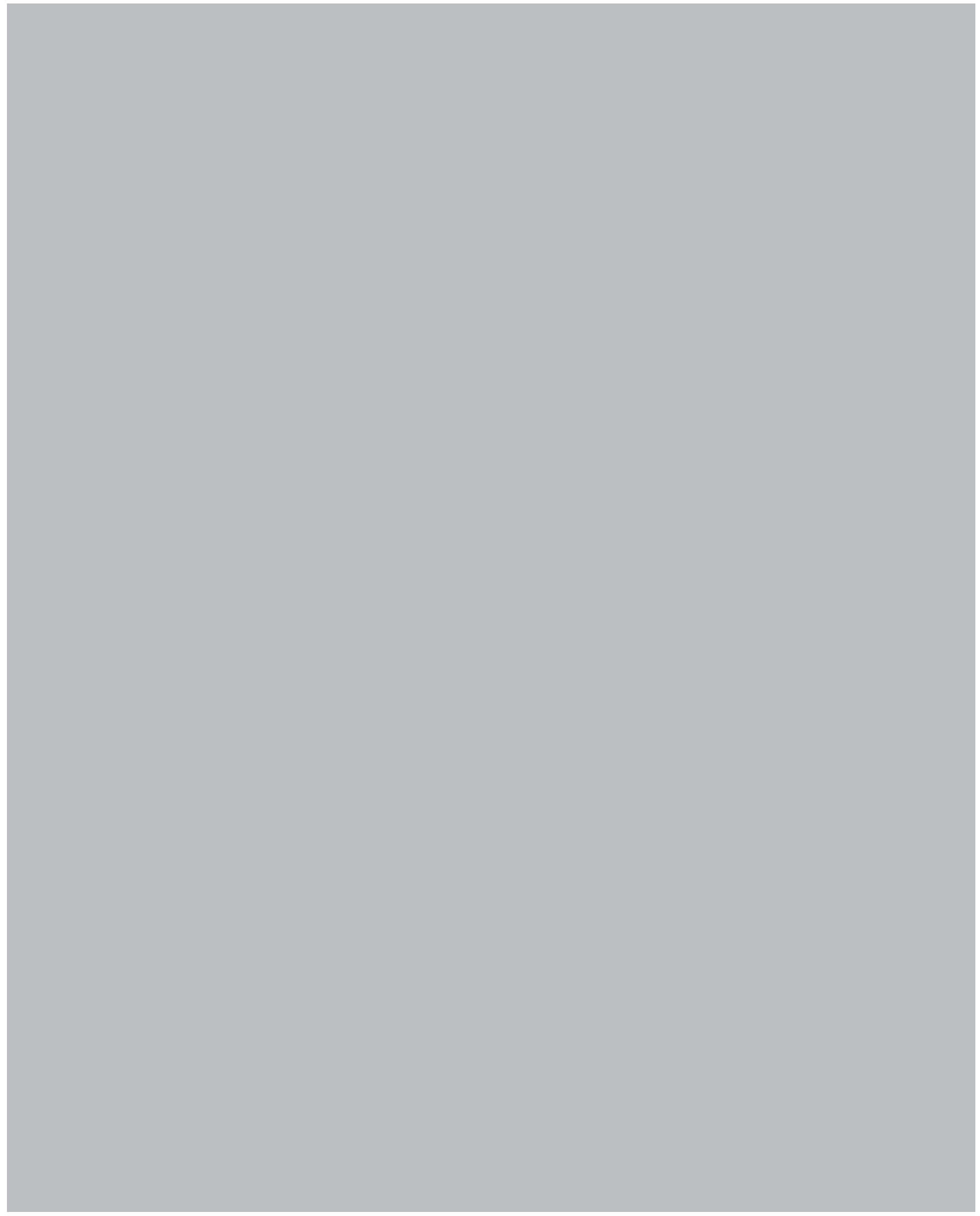




\section{Chapter 4}

Comparison between hirudin and citrate in monitoring the inhibitory effects of $\mathrm{P}_{2} \mathrm{Y}_{12}$ receptor antagonists with different platelet function tests

J Thromb Haemost. 2009 Novi7(11):1929-32

Carina A Pittens* Heleen J Bouman* Jochem $W$ van Werkum Jurriën $\mathrm{M}$ ten Berg Christian M Hackeng

*Both authors contributed equally

Department of Cardiology, St. Antonius Hospital, Nieuwegein, the Netherlands Department of Clinical Chemistry, St. Antonius Hospital, Nieuwegein, the Netherlands 
Part I | chapter 4

Dual treatment with aspirin and clopidogrel is currently the therapy of choice in the prevention of recurrent cardiovascular events following coronary stent implantation. However, not all patients benefit equally from this antiplatelet regimen, since inadequate suppression of platelet aggregation by clopidogrel and/or aspirin - also referred to as "high on-treatment platelet reactivity" or "antiplatelet therapy resistance" - is associated with worsened clinical outcome. The prevalence of this phenomenon varies widely and is highly dependent on the type of platelet function test and the type of anticoagulant that is being used ${ }^{1 ; 2}$.

"Classical" light transmission aggregometry (LTA) using adenosine diphosphate (ADP) as agonist is considered to be the gold standard platelet function test for determining the effectiveness of clopidogrel. Its use in daily practice is however not viable due to important limitations ${ }^{3}$. To overcome these limitations, various whole-blood platelet function assays designed to evaluate the efficacy of $\mathrm{P}_{2} \mathrm{Y}_{12}$ receptor antagonism have been introduced to the commercial market.

Trisodium citrate dihydrate is the preferred anticoagulant agent for platelet function testing as it has been in use for more than 40 years. However, measurements in citrate do not resemble physiological conditions, since citrate inhibits coagulation by chelating calcium. This could result in an under- or overestimation of the true inhibitory effects of $\mathrm{P}_{2} \mathrm{Y}_{12}$ receptor antagonists in vivo. Other anticoagulants, such as hirudin and D-phenylalanyl-L-prolyl-L-arginine chloromethyl ketone [PPACK] prevent coagulation of blood by direct inhibition of thrombin, thereby maintaining physiological calcium levels $s^{4}$. This approach might therefore mimick the in vivo situation of platelet function more precisely as compared to anticoagulation with citrate. Previous studies on this issue demonstrate a general higher magnitude of ADP induced platelet aggregation in blood anticoagulated with citrate as compared to PPACK or hirudin when measured with classical LTA ${ }^{5-7}$.

The manufacturers of MEA strongly recommend the use of hirudin instead of citrate as anticoagulant agent. Two recent publications report a reduced area-under the MEA curve, which indicates a lower magnitude of platelet aggregation, when platelet function was measured in citrated blood as compared to hirudin anticoagulated blood ${ }^{8 ; 9}$. This finding is opposite to the results obtained with classical LTA when measured in citrate versus PPACK (or hirudin) ${ }^{5 i 7}$. For the whole blood assays determining the efficacy of $\mathrm{P}_{2} \mathrm{Y}_{12}$ receptor antagonists, no information regarding the effects of anticoagulants other than citrate on the test performance is currently available.

The aim of the present study was to compare the effects of the anticoagulants citrate and hirudin on the test performance of four different platelet function assays that are currently in use for the monitoring of platelet inhibition with $\mathrm{P}_{2} \mathrm{Y}_{12}$ receptor antagonists.

Seventeen healthy volunteers, 9 male and 8 female, without coronary artery disease were enrolled after written informed consent was obtained. The mean age was $28.9 \pm 7.2$ and $35.9 \pm 13.3$ for males and females, respectively. Subjects were ineligible if they had used any medication in the past 7 days known to influence platelet function. Other exclusion criteria were a known platelet dysfunction or bleeding disorder, a platelet count $<150 \times 10^{\%} / \mathrm{L}$ and age $<18$ years. To avoid platelet activation, blood was drawn without a tourniquet from the antecubital vein into tubes containing either $3.2 \%$ trisodium citrate or lepirudin ( $25 \mu \mathrm{g} / \mathrm{ml}$, Refludan, hirudin blood collection tubes, Dynabyte), after discarding the first $5 \mathrm{ml}$ of blood. Aliquots of both the citrate and the hirudin anticoagulated blood samples were spiked with increasing concentrations of the direct $\mathrm{P}_{2} \mathrm{Y}_{12}$ receptor antagonist cangrelor (The Medicines Company, Parsippany, NJ, USA; in final subtherapeutic concentrations of $0.015 \mu \mathrm{mol} / \mathrm{L}$ and $0.15 \mu \mathrm{mol} / \mathrm{L}$ ) or $0.9 \%$ saline (for baseline measurements) and incubated for exactly 5 minutes. 
Platelet function testing was performed with LTA (using $20 \mu \mathrm{mol} / \mathrm{L}$ ADP induced peak and late aggregation ${ }^{10}$, the PFA-100 ${ }^{\circledR}$ Collagen/ADP (CADP) cartridge and the novel PFA-100 cartridge INNOVANCE PFA P $2 Y$ (Siemens Healthcare Diagnostics Products $\mathrm{GmbH}$, Germany), the VerifyNow $\mathrm{P}_{2} \mathrm{Y}_{12}$ assay $\left(\mathrm{VN}_{i}\right.$ Accumetrics, San Diego, USA), the the Multiplate ${ }^{\circledR}$ analyzer -also referred to as Multiple-Electrode Aggregometry- (MEA; Dynabite, Germany) ADP-test (20 $\mu \mathrm{mol} / \mathrm{L}$ ADP) and highsensitivity ADP test (ADP HS test, $20 \mu \mathrm{mol} / \mathrm{LADP}+9,4 \mathrm{nmol} / \mathrm{L}$ prostaglandin E1). Detailed descriptions of these tests have been published elsewhere ${ }^{1 ; 3}$. All tests were performed at 1 hour after blood sampling and according to the manufacturers' recommendations. The membrane of the INNOVANCE PFA $P_{2} Y$ is coated with $A D P$, prostaglandin $\mathrm{E}_{1}$ and calcium chloride.

Differences between citrate and hirudin anticoagulated blood samples were determined using the paired student's t-test and Pearson correlation. For PFA-10o results the nonparametric Mann-Whitney $\mathrm{U}$ test and Spearman correlation were used. PFA-100 results reported as $>300$ seconds were displayed as 300 seconds in the analyses.

As shown in Figure 1, absolute aggregation values obtained with LTA and VN revealed a significant higher magnitude of platelet aggregation when measured in citrate as compared to hirudin. In hirudin and citrate anticoagulated blood samples respectively, peak platelet aggregation was $64 \pm 19 \%$ and $84 \pm 6 \%$ for baseline $(p<0.01)$, and $38 \pm 13 \%$ vs $60 \pm 21 \%$ after in vitro addition of $0.015 \mu \mathrm{mol} / \mathrm{L}$ cangrelor $(p=0.01)$ and $6.4 \pm 2.7 \%$ vs $18 \pm 8.8 \%$ after $0.15 \mu \mathrm{mol} / \mathrm{L}$ cangrelor $(p<0.001)$. Similar results were observed for late platelet aggregation values.

$P_{2} Y_{12}$ reaction units ( $P R U$ ), obtained with the $V N P_{2} Y_{12}$ assay, were $194 \pm 52$ vs $257 \pm 51$ for baseline measurements ( $p<0.01$, for hirudin and citrate, respectively), $132 \pm 55$ Vs $184 \pm 85$ after in vitro addition of $0.015 \mu \mathrm{mol} / \mathrm{L}$ cangrelor $(p=0.01$ ) and $17 \pm 25 \mathrm{Vs} 19 \pm 17$ after $0.15 \mu \mathrm{mol} / \mathrm{L}$ cangrelor $(p=n s)$. In both tests, the absolute difference in the magnitude of ADP-induced aggregation between hirudin and citrate declined with increasing concentrations of cangrelor.

Thrombin-receptor activating peptide (TRAP)-induced platelet aggregation (represented by the VerifyNow "BASE"-value) was also highly affected by the anticoagulant agent used (Figure 1C). Remarkably, the absolute magnitude of TRAP-induced platelet aggregation in either hirudin or citrate was not affected by cangrelor.

For the CADP cartridge, baseline closure times were $101 \pm 19 \mathrm{sec}$. in hirudin vs $97 \pm 13 \mathrm{sec}$. in citrate ( $p=\mathrm{ns}$ ). A notable prolongation of the $C T$ to $188 \pm 76 \mathrm{sec}$. and $155 \pm 62 \mathrm{sec}$. was observed after incubation with $0.15 \mu \mathrm{mol} / \mathrm{L}$ cangrelor (hirudin and citrate respectively, $p=n s$ ). Similar results were obtained with INNOVANCE PFA P $2 Y$, with a CT of $72 \pm 15 \mathrm{sec}$. and $69 \pm 9 \mathrm{sec}$ at baseline $(p=n s)$ and $272 \pm 57 \mathrm{sec}$. and $290 \pm 32 \mathrm{sec}$. after $0.15 \mu \mathrm{mol} / \mathrm{L}$ cangrelor $(p=n s)$ for hirudin and citrate, respectively. However, the magnitude of $C T$ prolongation after in vitro cangrelor addition was much higher with INNOVANCE PFA $P_{2} Y$ as compared to the CADP.

In contrast to the results of the other platelet function assays, results obtained with MEA demonstrated an inverse trend towards a higher magnitude of platelet aggregation when measured in hirudin anticoagulated blood as compared to citrate. The baseline AUC of the MEA ADP test was $49.5 \pm 23.6$ and 40.6 \pm 15.7 for hirudin and citrate respectively.

The AUC decreased after in vitro addition of increasing concentrations of cangrelor, but a trend towards a higher AUC in hirudin was still present (Figure $\mathbf{1 G}$ ). The results obtained with the MEA ADP HS test showed similar trends (Figure $\mathbf{1} \mathrm{H}$ ). 
LTA 20 ADP (peak aggregation)

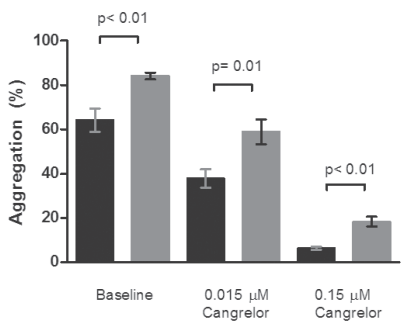

VerifyNow TRAP induced

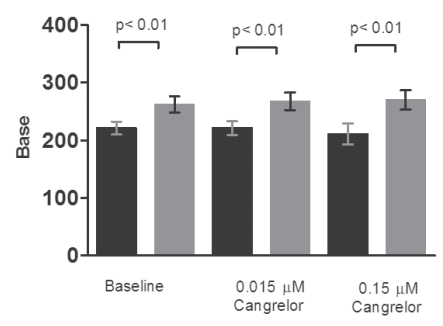

PFA-100 COL/ADP

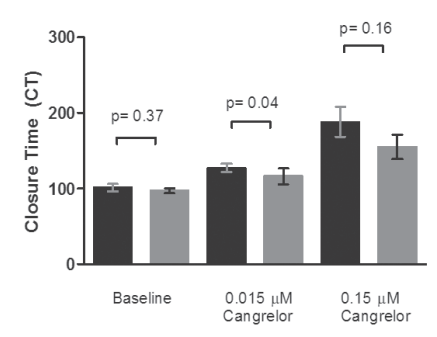

MultiPlate ADP

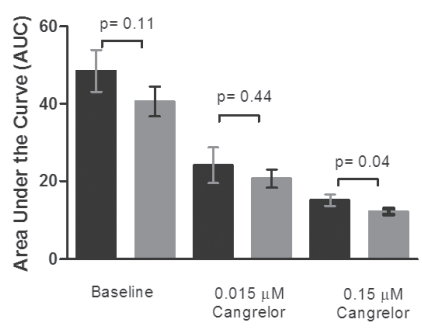

LTA 20 ADP (late aggregation)

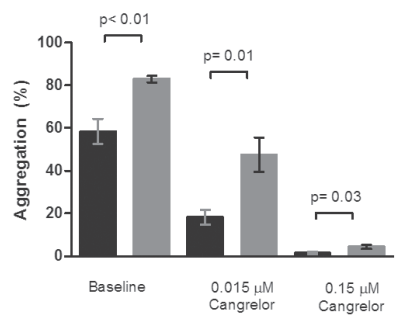

VerifyNow P2Y12 reaction Units

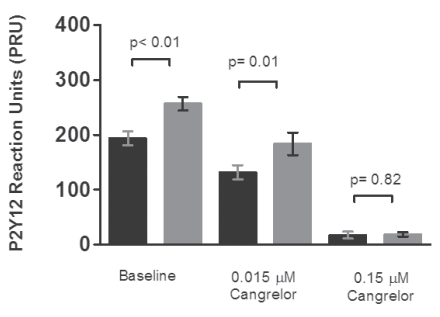

PFA-100 INNOVANCE P2Y

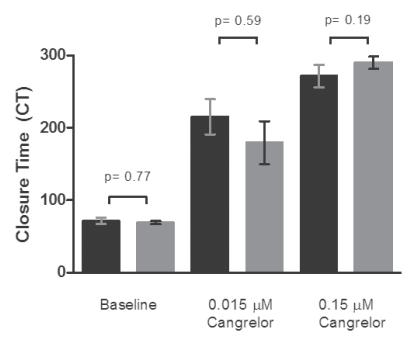

MultiPlate ADP+PGE 1

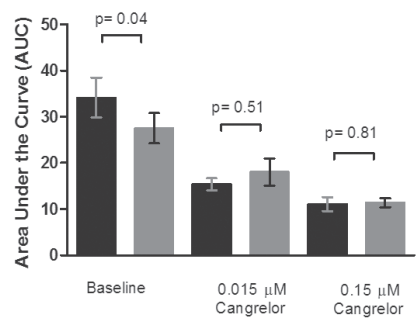

Figure 1 Inhibition of platelet function by cangrelor as measured with the various platelet function tests. The effects of in vitro addition with cangrelor (in final concentrations of $0.015 \mathrm{~mol} / \mathrm{L}$ and $0.15 \mathrm{~mol} / \mathrm{L}$ ) when measured in either citrate or hirudin are shown. 
Importantly, a strong intra-individual correlation was observed between hirudin and citrate anticoagulated blood samples ( $r=0.84$ for LTA peak aggregation, $r=0.79$ for LTA late aggregation, $r=0.88$ for $V N, r=0.72$ for the MEA ADP test and $r=0.63$ for MEA ADP HS test, with $P<0.0001$ for all). Results of the PFA-100 collagen/ADP and INNOVANCE PFA $P_{2} Y$ were respectively $r=0.57$ and $r=0.61$ with $\mathrm{p}<0.0001$ for both.

The present study was designed to study the impact of different anticoagulants on the test performance of multiple platelet function assays. Clearly, our results extent the current knowledge that the nature of the used anticoagulant influences platelet aggregation when measured with various platelet function methods. Results obtained with both LTA as well as the VN assay demonstrated a higher magnitude of platelet reactivity when measured in citrate as compared to hirudin. These results are in agreement with previous findings of Labarthe and colleagues and a previous finding from our group ${ }^{5 i 7}$.

In contrast, results obtained with the PFA-100 CADP cartridge and PFA-100 INNOVANCE PFA P2Y cartridge were not significantly influenced by the anticoagulant used. Interestingly, the results obtained with MEA are opposite to the other platelet aggregation tests since a higher AUC was measured in hirudin as compared to citrate. Whether this effect might be due to the higher conductivity of the hirudinized blood samples as compared to the citrated blood samples or indeed due to an increased platelet functionality remains to be clarified ${ }^{8 ; 9}$.

Another interesting finding includes the fact that the novel PFA-100 INNOVANCE PFA P $2 Y$ cartridge has an increased sensitivity to $P_{2} Y_{12}$ receptor inhibition when compared to the CADP cartridge since INNOVANCE PFA $\mathrm{P}_{2} \mathrm{Y}$ revealed a more pronounced prolongation of the $\mathrm{CT}$ in particular after in vitro addition of relatively low concentrations of cangrelor. More studies are underway to define the sensitivity of the PFA-10o INNOVANCE PFA $P_{2} Y$ cartridge for the effects of different $P_{2} Y_{12}$ inhibitors (e.g. clopidogrel, prasugrel and ticagrelor).

Three limitations of the present study need to be acknowledged. First, the study did not explore relationships between platelet function test findings and clinical outcomes as platelet function was evaluated using healthy control samples, spiked with a $\mathrm{P}_{2} \mathrm{Y}_{12}$ inhibitor ex vivo. Second, platelet function analysis was performed in the absence of ASA. Therefore, it remains to be determined whether the same findings are observed in aspirin treated subjects. Third, although the present study contains a sufficient number of subjects to study the effects of different anticoagulants on the magnitude of platelet reactivity, it does not allow an answer to the question which of these tests -if any- is the most predictive one for the (re)occurrence of atherothrombotic events

In conclusion, the present study confirms that the results of platelet function assays are highly dependent on the type of ex vivo anticoagulation. Solely aggregation based methods such as "classical" LTA and the VerifyNow system revealed a higher magnitude of platelet aggregation when measured in citrate as compared to hirudin. In contrast, the Multiplate demonstrated a higher magnitude of aggregation when using hirudin as anticoagulant when compared to citrate as anticoagulant. 
Part I | chapter 4

\section{REFERENCES}

1 Lordkipanidze M, Pharand C, Nguyen TA et al. Assessment of VerifyNow $\mathrm{P}_{2} \mathrm{Y}_{12}$ assay accuracy in evaluating clopidogrel-induced platelet inhibition. Ther Drug Monit 2008; 30: 372-78.

2 van Werkum JW, Heestermans AACM, Deneer VHM et al. Clopidogrel resistance: Fact and Fiction. Future Cardiology 2006; 2: 215-28.

3 van Werkum JW, Hackeng CM, Smit JJ et al. Monitoring antiplatelet therapy with point-of-care platelet function assays: a review of the evidence. Future Cardiology 2008; 8: 33-55.

4 Lyon ME, Drobot DW, Harding SR, Lyon AW. Evaluation of the thrombin inhibitor D-phenylalanyl-L-prolyl-Larginine chloromethylketone (PPACK) with the factor Xa inhibitor 1,5-dansyl-L-glutamyl-L-glycyl-L-arginine chloromethylketone (GGACK) as anticoagulants for critical care clinical chemistry specimens. Clin Chim Acta 1999; 280: 91-99.

5 Bouman $\mathrm{HJ}$, van Werkum JW, Hackeng CM et al. The importance of anticoagulant agents in measuring platelet aggregation in patients treated with clopidogrel and aspirin. JThromb Haemost 2008; 6: 1040-42.

6 Frelinger AL, III, Jakubowski JA, LiY et al. The active metabolite of prasugrel inhibits ADP-stimulated thromboinflammatory markers of platelet activation: Influence of other blood cells, calcium, and aspirin. Thromb Haemost 2007; 98: 192-200.

7 Labarthe $B$, Theroux $\mathrm{P}$, Angioi M, Ghitescu M. Matching the evaluation of the clinical efficacy of clopidogrel to platelet function tests relevant to the biological properties of the drug. J Am Coll Cardiol 2005; 46: 638-45.

8 Toth $\mathrm{O}$, Calatzis A, Penz S et al. Multiple electrode aggregometry: a new device to measure platelet aggregation in whole blood. Thromb Haemost 2006; 96: 781-88.

9 Johnson A, Dovlatova N, Heptinstall S. Multiple electrode aggregometry and P2Y(12) antagonists. Thromb Haemost 2008; 99: 1127-29.

10 van Werkum JW, Kleibeuker M, Mieremet N et al. Evaluation of the platelet response to clopidogrel with light transmittance aggregometry: peak aggregation or late aggregation? J Thromb Haemost 2007; 5: 884-86. 


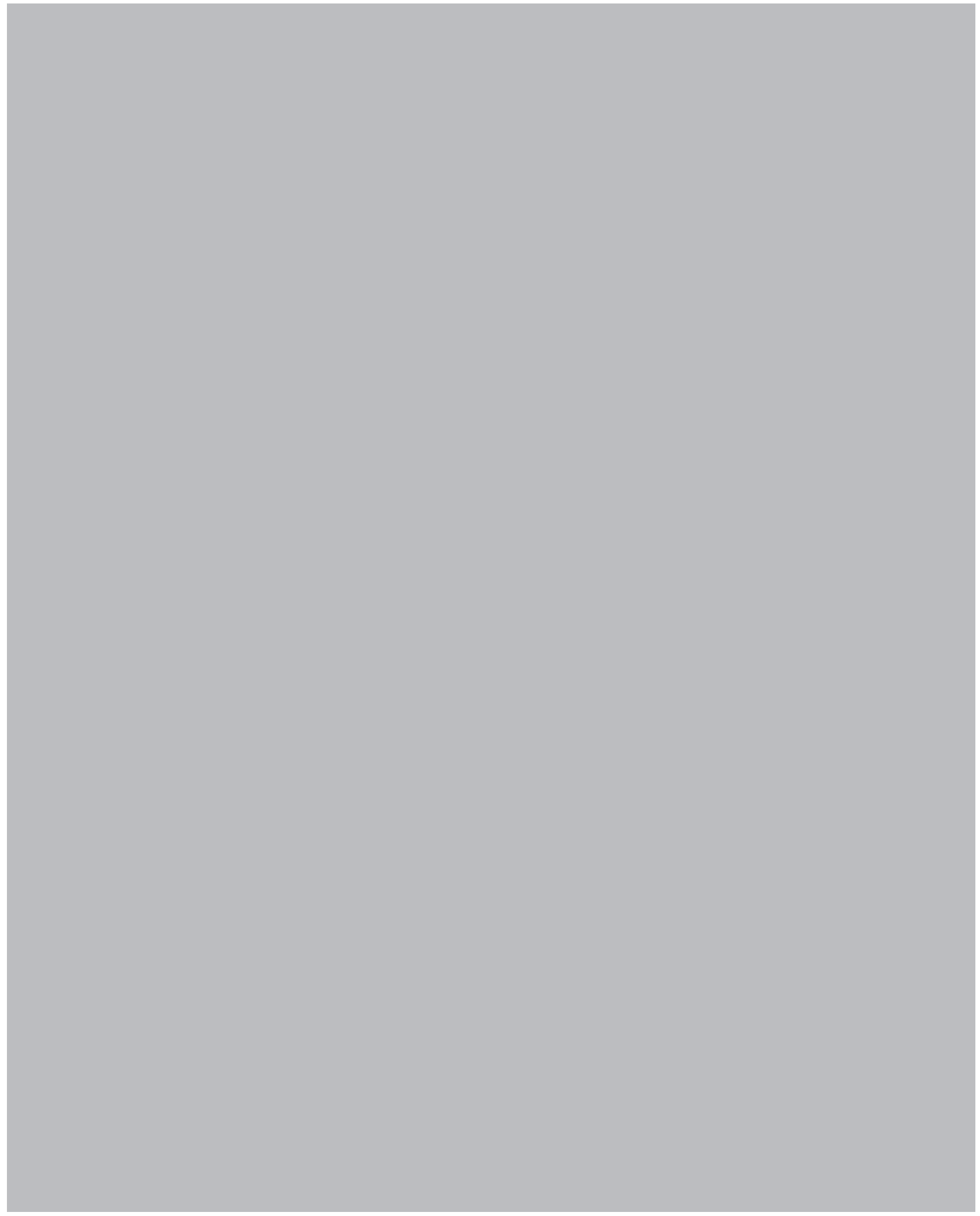




\section{Part II}

Identifying the most appropriate platelet function test for Monitoring $\mathrm{P}_{2} \mathrm{Y}_{12}$-receptor inhibition 


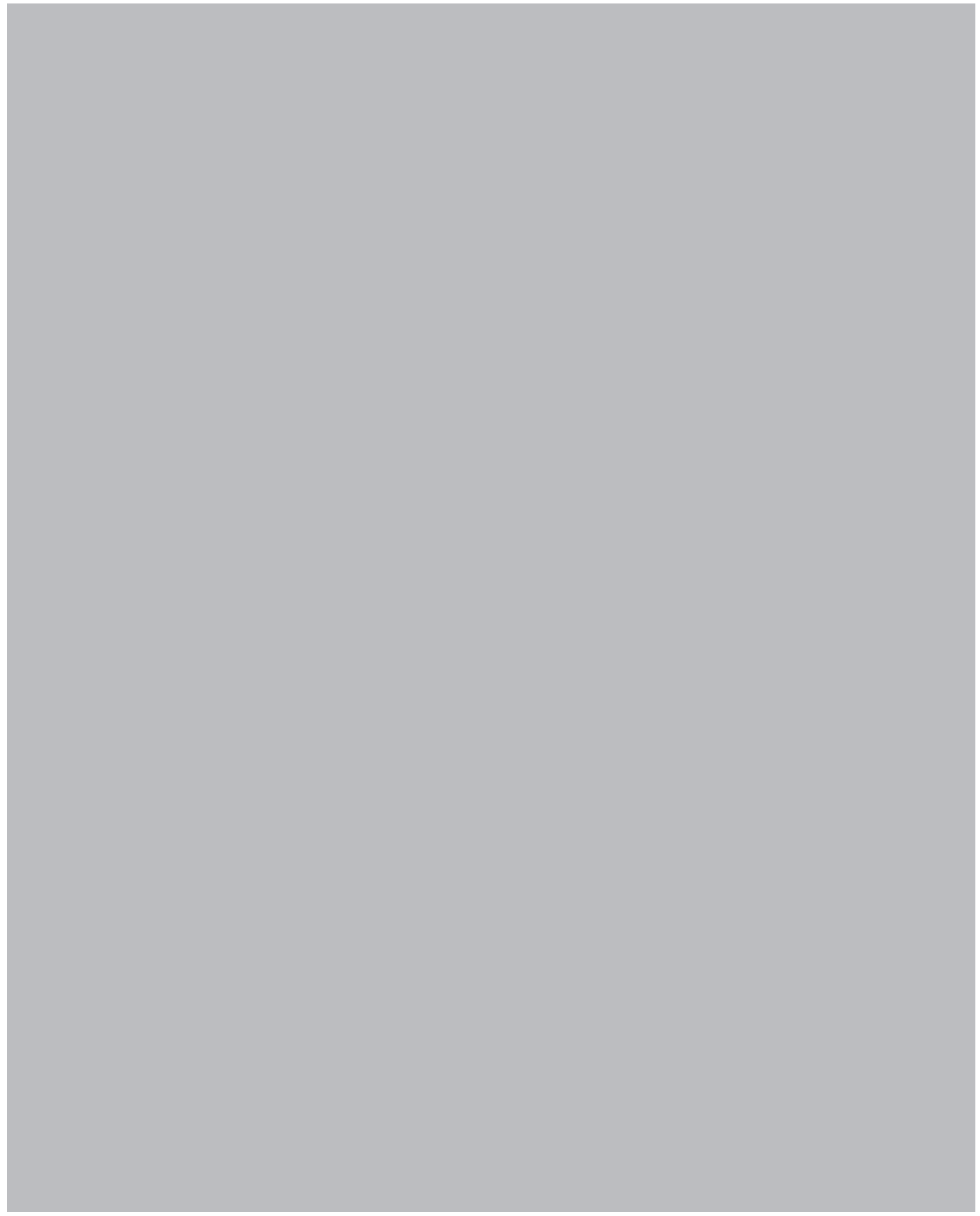




\title{
Chapter 5
}

The Cone-and-Plate(let) analyzer is not suitable to monitor clopidogrel therapy: a comparison with the flowcytometric VASP assay and optical aggregometry

Thromb Res. 2010 Jul;126(1):44-9

\author{
Jochem W van Werkum \\ Heleen J Bouman \\ Nicoline J Breet \\ Jurriën M ten Berg \\ Christian M Hackeng
}

Department of Cardiology, St. Antonius Hospital, Nieuwegein, the Netherlands Department of Clinical Chemistry, St. Antonius Hospital, Nieuwegein, the Netherlands 
ABSTRACT

\section{Introduction}

High on-clopidogrel platelet reactivity has been associated with an increased risk for atherothrombotic events. A new player on the horizon is the IMPACT-R ADP-test using ADP pre-stimulation. We here report the results of a thorough evaluation of this new device.

\section{Materials and methods}

The IMPACT-R ADP-test was evaluated in different categories of subjects. First, normal range values were determined in healthy subjects $(n=46)$. Second, the effect of $600 \mathrm{mg}$ of clopidogrel was evaluated with the IMPACT-R ADP-test and two other well-validated methods (flowcytometric VASP-analysis and optical aggregometry) in 21 patients. Third, a head-to-head comparison between the IMPACT-R ADP-test and optical aggregometry was performed in a large cohort of patients on dual antiplatelet therapy.

\section{Results}

The results of the IMPACT-R ADP-test were highly variable throughout healthy subjects. The administration of a high clopidogrel loading dose resulted in a small but significant increase in surface coverage but $61.9 \%$ of the patients were still identified as clopidogrel nonresponder. In contrast, optical aggregometry and VASP-analysis identified $24 \%$ and $33 \%$ of these patients as a clopidogrel nonresponder, respectively. Head-to-head comparison with optical aggregometry in 451 patients showed only a modest correlation between both methods $(r \sim 0.20, p<0.0001)$

\section{Conclusions}

The IMPACT-RADP-test is relatively insensitive to the effects of clopidogrel and cannot substitute for methods such as flowcytometric VASP-analysis and optical aggregometry. Further studies are required to establish the clinical usefulness of IMPACT-RADP-test to accurately predict the occurrence of major adverse cardiovascular events in patients with high on-clopidogrel platelet reactivity before it can be implemented in clinical practice. 


\section{INTRODUCTION}

Dual antiplatelet therapy with aspirin and clopidogrel has demonstrated its effectiveness in the secondary prevention of atherothrombotic events during and after coronary stent implantation. ${ }^{1}$ Nonetheless, numerous studies have reported a wide inter-individual variability in platelet response to clopidogrel with a subset of patients being identified as low-responders. ${ }^{2}$ Moreover, high onclopidogrel platelet reactivity (HPR) despite the use of clopidogrel and aspirin is associated with recurrence of cardiovascular events in prospective studies..$^{3-7}$

Therefore, it would be very helpful to have a simple point-of-care bedside platelet function assay that overcomes the limitations of the labour-intensive "gold standard" and that is capable of providing the results within several minutes. ${ }^{8}$ The Cone-and-Plate(let) analyzer (IMPACT- $R$ ) measures platelet adhesion and aggregation in whole blood under arterial shear conditions. ${ }^{9}$ This assay has recently been modified into a method that claims to be capable to monitor the effectiveness of clopidogrel therapy. ${ }^{9}$

In the present paper we sought to study normal values of the IMPACT-R ADP-test in healthy subjects not using antiplatelet therapy. Second, we studied the effect of a loading dose of clopidogrel on the IMPACT-R ADP-test and compared the results with "gold standard" and flowcytometric vasodilatorstimulated phosphoprotein (VASP)-analysis in patients with stable angina on chronic aspirin therapy. Third, in a large cohort of patients on dual antiplatelet therapy, we studied clinical and haematological variables that may predispose to HPR, as measured with the IMPACT-RADP-test. Lastly, we investigated the correlation between in response to ADP and the IMPACT-R ADP-test in this same patient population.

\section{METHODS}

\section{Study design and patient population}

The present study consisted of three sub-studies: 1) the proposed cut-off value to segregate patients with normal platelet reactivity (NPR) from HPR ( $\geq 2.8 \%$ surface coverage (SC) after pre-incubation with ADP) was evaluated in 46 healthy volunteers. 2 ) the absolute change in platelet reactivity (as measured with the IMPACT-R ADP-test, OA and the flowcytometric VASP-assay) before and after a $600 \mathrm{mg}$ loading of clopidogrel was evaluated in 21 patients with stable angina pectoris who were on aspirin (80-100 mg/day). 3) The magnitude of "on-clopidogrel platelet reactivity" was evaluated by parallel assessment of and the IMPACT-R ADP-test in a large cohort of 451 consecutive patients on aspirin and clopidogrel therapy. Written informed consent was obtained from all patients.

\section{Blood sampling}

Blood samples were drawn from the healthy volunteers and stable angina patients via the antecubital vein through a 18-gauge needle. Blood samples from the patients undergoing $\mathrm{PCl}$ were drawn in the catheterization laboratory from a six-French arterial sheath before the $\mathrm{PCl}$ and at least $24 \mathrm{~h}$ after the loading dose of clopidogrel. All patients were also on aspirin therapy $(80-100 \mathrm{mg})$ for at least 7 days. The first $5 \mathrm{ml}$ of blood was discarded and the blood was immediately collected in Sarstedt tubes containing 3.2\% sodium citrate for platelet function measurements and $K_{3}$-EDTA to determine hematologic parameters such as haemoglobin, haematocrit, platelet count and MPV. 
Part II | chapter 5

\section{The IMPACT-R ADP-test}

The IMPACT- $R$ device (DiaMed, Cressier, Switzerland) is based on the cone and plate(let) analyzer (CPA) technology described previously. ${ }^{10}$ First, the obtained whole-blood samples were prestimulated with ADP at a sub-optimal concentration $(1.38 \mu \mathrm{M})$ for 1 minute under gentle mixing (10 RPM). The rationale behind this step is that pre-stimulation with ADP leads to the formation of microaggregates in patients not using clopidogrel or in whom clopidogrel does not effectively inhibit platelet function. These microaggregated platelet temporarly lose their adhesive properties. ${ }^{9}$

In the second step, the ADP-pre-incubated whole blood sample ( $130 \mu \mathrm{L})$ is placed in a polystyrene well and subjected to shear ( $1800 \mathrm{~s}^{-1}$ for $2 \mathrm{~min}$ ) using a rotating cone. Under these testing conditions, vWF and fibrinogen are instantly immobilized on the polystyrene surface, serving as a substrate for platelet adhesion and subsequent aggregation. The wells are washed and stained with May-Grunwald stain and analyzed with an inverted light microscope which is connected to an image analysis system. Platelet adhesion and aggregation on the surface are evaluated by examining the percentage of total area covered with platelet designated as surface coverage (SC). Patients with a high on treatment platelet reactivity are characterized with low surface coverage percentages. The optimal surface coverage cut-off value $(S C \leq 2.8 \%)$ to segregate patients with HPR from patients with normal ontreatment platelet reactivity (NPR) was derived from the medical literature..$^{9 i 1}$

\section{The flowcytometric VASP-assay}

Flowcytometric analysis of VASP phosphorylation was performed using a CE marked diagnostic kit from Biocytex (Marseille, France) as described previously. ${ }^{12}$ In brief, citrated whole-blood was incubated with $P G E_{1}$ or $P G E_{1}+A D P$ and fixed with paraformaldehyde after which the platelets were permeabilized and immunolabeled for 5 minutes using a CD61 phycoerythrin-labeled platelet specific antibody and a FITC-labeled VASP-P specific mouse monoclonal antibody or a negative isotopic control antibody. Diluted samples were analyzed on a 500 MPL flowcytometer (Beckman Coulter).

Platelet populations were identified by its forward and side scatter distribution and 5.000 platelets were gated at high rate. A platelet reactivity index (PRI) was calculated from the mean fluorescence intensity (MFI) of samples incubated with $\mathrm{PGE}_{1}$ and $P G E_{1}+A D P$ with the following formula:

$\left.\operatorname{PRI}(\%)=\left[\mathrm{MFI}\left(\mathrm{PGE}_{1}\right)-\mathrm{MFI}\left(\mathrm{PGE}_{1}+\mathrm{ADP}\right)\right)\right] /\left[\mathrm{MFI}\left(\mathrm{PGE}_{1}\right)\right] \times 100$

\section{Optical aggregometry (OA)}

Citrated whole-blood samples were centrifuged at $120 \mathrm{~g}$ for 10 minutes to obtain platelet-rich plasma and further centrifuged at $850 \mathrm{~g}$ for 15 minutes to obtain platelet-poor plasma (PPP). Platelet aggregation was measured in non-adjusted platelet-rich-plasma after stimulation with ADP (final concentration: $5 \mathrm{\mu mol} / \mathrm{L}$ ). ${ }^{13}$ "Peak" and "late" aggregation were measured on a APACT 4004 aggregometer (LABiTec, Arensburg, Germany) with PPP as the reference for $100 \%$ aggregation. ${ }^{14}$

\section{Statistical analysis}

The chi-square test was used to detect differences in categorical variables, and a two-sided Fisher exact test was used when any expected cell count was $<5$ for a 2 by 2 table. Comparison of continuous variables was performed using the Student t test. A $p$-value $<0.05$ was considered significant. The results of the IMPACT-RADP-test were log-transformed to account for its skewed distribution. Pearson correlation was used to determine the correlation between the results of the IMPACT-RADP-test and 
ADP-induced OA. Multivariate logistic regression analysis was performed to identify characteristics independently associated with HPR as defined by the IMPACT-R ADP-test.

\section{RESULTS}

\section{Normal subjects study}

A total of 46 healthy volunteers with a mean age \pm SD of $38.2 \pm 8.9$ years were enrolled. The interindividual variation in SC was widely distributed with mean \pm SD and range of $10.7 \pm 4.3 \%$ [3.224.6\%] without ADP pre-stimulation and $3.0 \pm 2.1 \%$ [0.5-11.5\%] with ADP pre-stimulation (Figure 1). Surprisingly, 18 healthy volunteers (39\%) met the criteria for "clopidogrel-responsiveness" (SC>2.8\%) or "NPR" while they were not on any antiplatelet drug. Of note, $20 \mu \mathrm{mol} / \mathrm{L}$ ADP-induced "peak" aggregation was not statistically different in these subjects as compared to those who were considered HPR $(\mathrm{SC} \leq 2.8 \%)(86.3 \pm 3.4 \%$ versus $85.1 \pm 3.3 \%, P=0.26)$

\section{The effects of a $600 \mathrm{mg}$ loading dose of clopidogrel on the IMPACT-R ADP-test}

A total of 21 stable angina patients on aspirin monotherapy were enrolled. The interindividual variability in baseline ("off-drug") platelet reactivity was wide. As expected, the administration of a $600 \mathrm{mg}$ loading dose of clopidogrel significantly decreased the PRI as measured with VASP-analysis from 75.56 $\pm 12.9 \%$ to $41.6 \pm 22.8 \%(P<0.0001 ; F i g u r e ~ 2 A)$ and the magnitude of $20 \mu \mathrm{mol} / \mathrm{L}$ ADP-induced "peak" aggregation from $77.8 \pm 3.6 \%$ to $54.3 \pm 15.1 \%(P<0.0001$; Figure $2 B$ ). The administration of a $600 \mathrm{mg}$ loading dose of clopidogrel significantly increased the SC after ADP pre-stimulation from $1.16 \pm 1.03 \%$ to $3.64 \pm 4.12 \%(p=0.006)$ (Figure $2 \mathrm{C})$. Nonetheless, $61.9 \%$ of the patients were still considered with the IMPACT-R ADP-test (SC $\leq 2.8 \%$ ) as being HPR despite the high clopidogrel loading dose. In contrast, and VASP-analysis identified $24 \%$ and $33 \%$ of these patients as clopidogrel nonresponder, respectively. The SC without ADP pre-stimulation did not change significantly (SC pre-clopidogrel loading: $6.75 \pm$ $5.14 \%$ versus SC post-clopidogrel loading: $5.85 \pm 5.97, P=0.37$; Figure 2D).

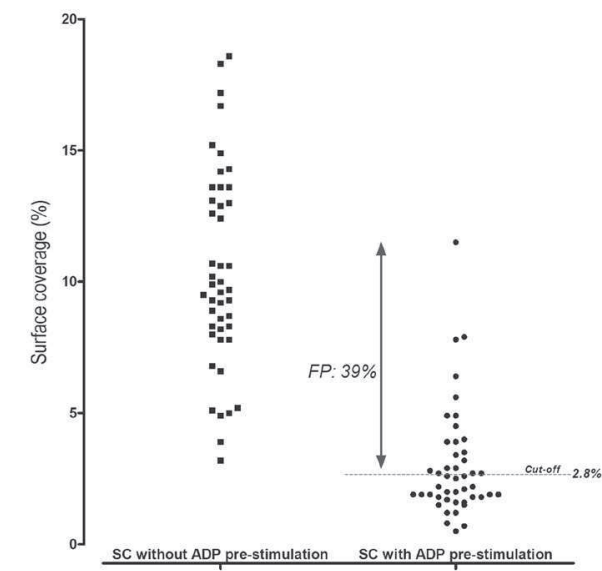

(a)

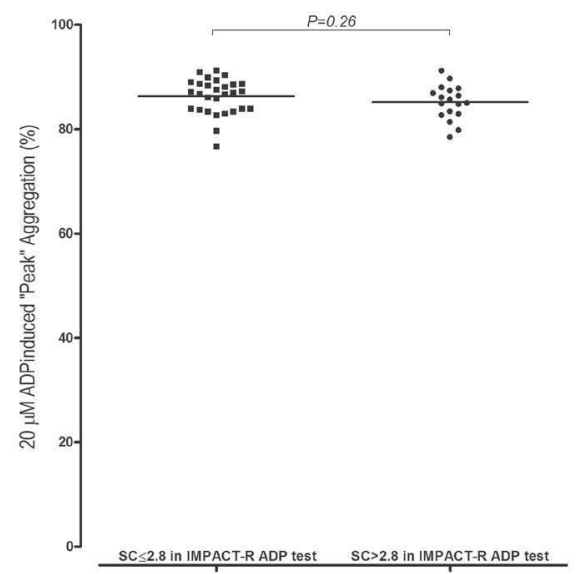

(b)

Figure 1 | Distribution of percentages surface coverage in healthy volunteers. 
The Flowcytometric VASP-assay

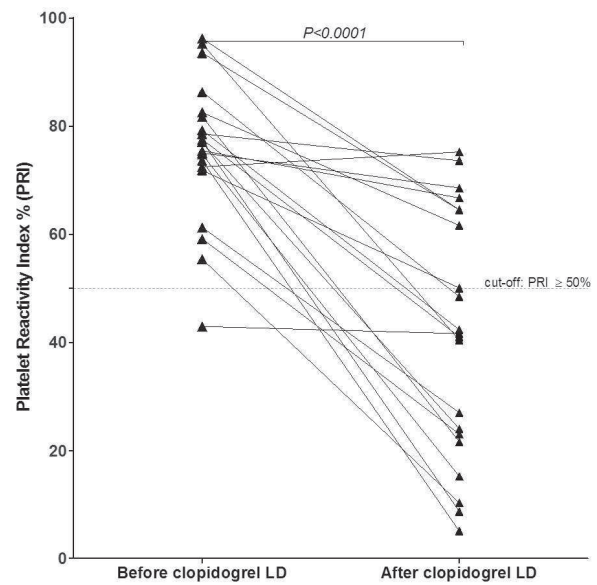

IMPACT-R without pre-stimulation

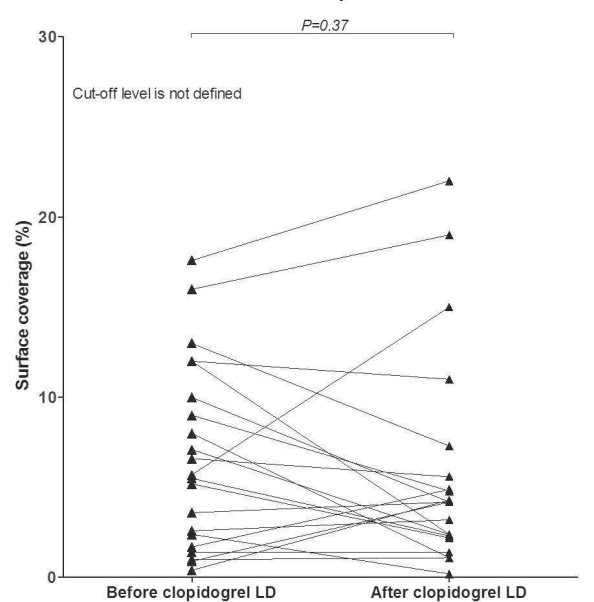

$20 \mu \mathrm{M}$ ADP-induced "peak" aggregation

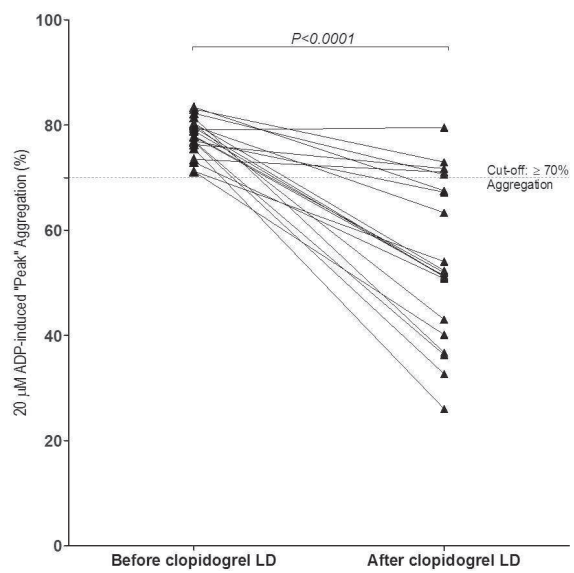

IMPACT- $R$ with ADP pre-stimulation

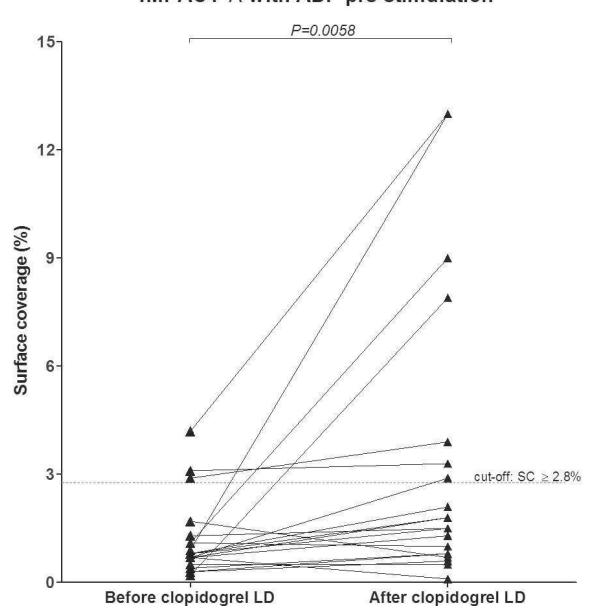

Figure 2 | Individual data as measured with the flowcytometric VASP-assay (left) and the IMPACT-R ADP-test (right) before and $6 \mathrm{~h}$ after the administration of a $600 \mathrm{mg}$ loading dose of clopidogrel.

\section{Patient cohort study}

Four-hundred-fifty-one consecutive patients admitted to our catheterisation laboratory for elective $\mathrm{PCl}$ were enrolled. All were on daily aspirin therapy (80-10omg) for at least 7 days, 303 were on clopidogrel maintenance therapy for at least 7 days and 148 had received a $300 \mathrm{mg}$ loading dose of clopidogrel in the 1-4 days prior to the PCI followed by a maintenance dosing of $75 \mathrm{mg}$ per day. IMPACT- $R$ platelet function testing with ADP pre-stimulation identified 250 patients (55.4\%) who had a SC $<2.8 \%$ ("HPR") while 201 patients (44.6\%) had a SC $\geq 2.8 \%$ ("NPR"). Table 1 shows the baseline characteristics of the two groups. 
Table 1 | Demographics of the Study population

\begin{tabular}{|c|c|c|c|}
\hline & $\begin{array}{c}\mathrm{HPR}(\mathrm{SC}<2.8 \%) \\
n=250\end{array}$ & $\begin{array}{c}\text { NPR }(\geq 2.8 \%) \\
n=201\end{array}$ & $P$-value \\
\hline \multicolumn{4}{|l|}{ Clinical characteristics } \\
\hline Age (yrs) & $65.2 \pm 11.6$ & $62.9 \pm 10.6$ & 0.028 \\
\hline Male gender & $172(68.8 \%)$ & $157(78.1 \%)$ & 0.033 \\
\hline \multicolumn{4}{|l|}{ CV-risk factors } \\
\hline Diabetes Mellitus & $49(19.6 \%)$ & $31(15 \cdot 4 \%)$ & 0.27 \\
\hline Smoking & $43(17.2 \%)$ & $24(11.9 \%)$ & 0.14 \\
\hline Dyslipidemia & $204(81.6 \%)$ & $161(80.1 \%)$ & 0.72 \\
\hline Hypertension & $187(74.8 \%)$ & $148(73.6 \%)$ & 0.83 \\
\hline Family $\mathrm{Hx}$ of CAD & $139(57.2 \%)$ & $121(61.7 \%)$ & 0.38 \\
\hline $\mathrm{BMI}\left(\mathrm{kg} / \mathrm{m}^{2}\right)$ & $27.2 \pm 4.2$ & $27.0 \pm 3.9$ & 0.60 \\
\hline Renal Failure & $13(5 \cdot 5 \%)$ & $6(3.2 \%)$ & 0.35 \\
\hline \multicolumn{4}{|l|}{ Medication } \\
\hline Aspirin & $250(100 \%)$ & $201(100 \%)$ & 1.00 \\
\hline Clopidogrel loading & $92(36.8 \%)$ & $56(27.9 \%)$ & 0.06 \\
\hline Statins & $203(81.2 \%)$ & $163(81.1 \%)$ & 1.00 \\
\hline B-blockers & $195(78.0 \%)$ & $161(80.1 \%)$ & 0.56 \\
\hline \multicolumn{4}{|l|}{ Laboratory Parameters } \\
\hline $\begin{array}{l}5 \mu \mathrm{M} \text { ADP-induced } \\
\text { aggregation (\%) }\end{array}$ & $39 \cdot 3 \pm 13.8$ & $32.8 \pm 12.1$ & $<0.0001$ \\
\hline Platelet Count x109/L & $267 \cdot 3 \pm 75 \cdot 4$ & $269.6 \pm 77.4$ & 0.75 \\
\hline Mean platelet volume & $7.60 \pm 1.05$ & $7.36 \pm 0.86$ & 0.01 \\
\hline Fibrinogen (g/L) & $4.07 \pm 1.06$ & $3.88 \pm 0.85$ & 0.05 \\
\hline Haemoglobin (g/dL) & $13.48 \pm 1.48$ & $14.07 \pm 1.40$ & $<0.0001$ \\
\hline Haematocrit (fraction) & $0.40 \pm 0.04$ & $0.42 \pm 0.04$ & $<0.0001$ \\
\hline vWF:Ag (\%) & $134 \cdot 30 \pm 51.6$ & $136.50 \pm 47.7$ & 0.65 \\
\hline vWF:RCo (\%) & $114.36 \pm 45.1$ & $115.48 \pm 45.8$ & 0.80 \\
\hline
\end{tabular}

Data are expressed as means $\pm S D$ or $n$ with percentages between brackets. CAD: coronary artery disease; $H \mathrm{x}$ : history

Figure 3 shows the scattergram comparing the individual IMPACT- $R$ results (SC with ADP prestimulation) with ADP-induced "peak" and "late" aggregation as measured with OA. The overall agreement between the IMPACT- $R$ results and either "peak" or "late" aggregation was poor $(r=0.21$, $P<0.001$ and $r=0.22, P<0.001$, respectively).

\section{The influence of clinical and laboratory variables on the IMPACT-R ADP-test results}

In univariate analysis, patients with HPR (SC <2.8\%) were significantly older (65.2 \pm 11.6 yrs versus $62.9 \pm 10.6 \mathrm{yrs}, P=0.028$ ) and were more often female ( $31.2 \%$ versus $21.9 \%, P=0.033$ ) as compared to 
Part II | chapter 5

patients with NPR. Mean platelet volume was increased ( $7.60 \pm 1.05 \mathrm{fL}$ versus $7.36 \pm 0.86 \mathrm{fL}, P=0.05$ ) and fibrinogen levels in the plasma were significantly higher in patients with HPR $(4.07 \pm 1.06 \mathrm{~g} / \mathrm{L}$ versus $3.88 \pm 0.85 \mathrm{~g} / \mathrm{L}, P=0.05)$. Importantly, haemoglobin and haematocrit levels were lower in patients with HPR as compared to those with NPR $(13.48 \pm 1.48 \mathrm{~g} / \mathrm{dL}$ versus $14.07 \pm 1.40 \mathrm{~g} / \mathrm{dL}, P<0.0001$ for haemoglobin and $0.40 \pm 0.04$ versus $0.42 \pm 0.04, P<0.0001$ for haematocrit). Patients who were on clopidogrel maintenance therapy of $75 \mathrm{mg} /$ day for 5 days or longer were more likely to have NPR as compared to patients who recently had received a $300 \mathrm{mg}$ loading dose. Of note, patients with HPR displayed a higher magnitude of ADP-induced aggregation as compared to patients with NPR $(39 \cdot 3 \pm$ 13.8 versus $32.8 \pm 12.1, p<0.0001)$.

Multivariate analysis revealed that a higher MPV, an increased magnitude of ADP-induced aggregation and dosing of clopidogrel were independent predictors of HPR as measured with the IMPACT-R ADP test (Table 2).

Table $\mathbf{2}$ | Independent predictors of HPR as measured with the IMPACT-R ADP-test

\begin{tabular}{lccc}
\hline & Odds-ratio & $95 \%-\mathrm{Cl}$ & Significance \\
\hline MPV & 1.350 & $1.08-1.69$ & 0.09 \\
5 HM ADP-induced aggregation (\%) & 1.039 & $1.021-1.057$ & $<0.0001$ \\
Clopidogrel maintenance therapy & 0.59 & $0.37-0.94$ & 0.02 \\
\hline
\end{tabular}
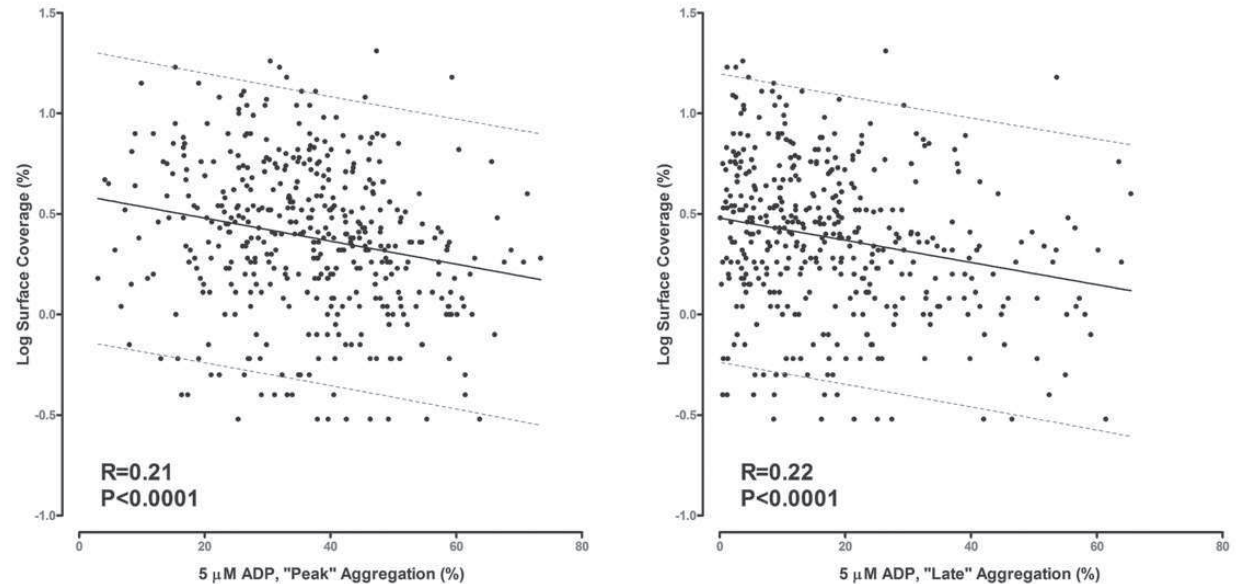

Figure 3 | Frequency histogram of the IMPACT-R test results with and without ADP pre-stimulation in 451 subjects on clopidogrel and aspirin therapy. 


\section{DISCUSSION}

Although it is well-known that the pathophysiology of recurrent atherothrombotic events after coronary stent implantation is multifactorial, recent studies in the setting of coronary stenting have clearly demonstrated the clinical relevance of high on-treatment platelet reactivity as one of the key contributors. ${ }^{3-5}$ Accordingly, risk stratification for atherothrombotic events during-and after $\mathrm{PCl}$ with the use of platelet function tests has become a major field of interest. ${ }^{15}$ In fact, this strategy is also supported by the ACC/AHA PCI guidelines that have recognized this need and incorporated the following recommendation ${ }^{16}$ : "in patients in whom subacute thrombosis may be catastrophic or lethal (unprotected left main, bifurcating left main, or last patent coronary vessel), platelet aggregation studies may be considered and the dose of clopidogrel increased to $150 \mathrm{mg}$ per day if less than $50 \%$ inhibition of platelet aggregation is demonstrated."(level of evidence: $C$ )

Consequently, numerous efforts have been made to develop clinical laboratory tests that provide detailed measurements of the effects of aspirin and clopidogrel therapy on platelet function. ${ }^{8} \mathrm{At}$ present, the gold standard tests to evaluate the effect of clopidogrel therapy are light transmittance aggregometry in response to ADP, and the flowcytometric VASP-assay. However, these tests are only available in specialized centres, labour intensive, and lack standardization and reproducibility. Therefore several automated bedside tests have been developed to measure the effects of clopidogrel. ${ }^{15} \mathrm{~A}$ new player on the horizon is the modified Cone-and-Plate(let) analyzer using ADP pre-stimulation. A potential advantage of this assay is the determination of platelet function under arterial shear conditions. However, limited data exists on the performance of this device. Moreover, the currently available data is provided by its designers and not by an independent resource..$^{911}$

In the present study, we thoroughly evaluated the IMPACT-R ADP test against well-validated platelet evaluation methods such a optical aggregometry and flowcytometric VASP-analysis.

Surprisingly, almost $40 \%$ of the healthy volunteers who did not use any antiplatelet drugs were classified as clopidogrel-responders using the cut-off levels provided by its designers. Furthermore, although there was a small but statistical significant increase in percentage of surface coverage after a $600 \mathrm{mg}$ loading dose of clopidogrel, only 8 of the 21 patients (38\%) were classified as "clopidogrel responders (or NPR)" using the proposed $2.8 \%$ cut-off level. The remaining $62 \%$ was classified with the IMPACT-R ADP as a clopidogrel poor-responder and this prevalence-rate is much higher than reported in the medical literature (range: $4.2 \%$ to $54 \%$ ). ${ }^{17}$ In contrast, the flowcytometric VASP-assay ${ }^{18}$ with a well-validated threshold level $(\sim 50 \%)$ to segregate responders from non-responders identified only 7 out of 21 (33\%) as being a clopidogrel poor-responder in the same population and optical aggregometry identified only 5 out of $21(24 \%)$ as a clopidogrel non-responder using the widely accepted cut-off value of $\geq 70 \%$ aggregation ${ }^{4}{ }^{19}$ Head-to-head comparison with two important parameters of ADP-induced aggregation ("peak" and "late" aggregation) revealed only a modest correlation $\left({ }^{r \sim 0.20}\right)$.

Taking the results of these three substudies into account, it is obvious that the IMPACT-R ADP assay is relatively insensitive to the inhibitory effects of clopidogrel therapy and this is in contrast to the results reported by Shenkman and coworkers. ${ }^{11}$

The most likely explanation for this relative insensitivity to the effects of clopidogrel therapy is related to the aspect of platelet function that is evaluated by the IMPACT-R ADP device. Thus far, the majority of studies investigating the issue of clopidogrel-responsiveness have been performed with solely aggregation based assays (such a optical aggregometry) or biochemical assays such as the 
Part II | chapter 5

flowcytometric VASP analysis. These tests ignore other aspects of platelet function (i.e. platelet adhesion). In contrast, the main principle of the Cone-and-Plate(let) technology is primary based upon platelet adhesion under high shear. ${ }^{10}$ Given the pharmacological target of clopidogrel and the intracellular cascade that is initiated upon $\mathrm{P}_{2} \mathrm{Y}_{12}$-receptor stimulation (glycoprotein Ilb/llla-receptor activation), ${ }^{20}$ it is likely that aggregation is a more important aspect of platelet function for the monitoring of clopidogrel therapy.

Another speculative explanation for the relative insensitivity of the IMPACT-R ADP-test could be the fact that it remains highly questionable whether the platelets of patients who respond adequately to clopidogrel are totally unaffected by ADP-pre-stimulation since the contribution of the $\mathrm{P}_{2} \mathrm{Y}_{1}$-pathway mediated platelet activation should also be taken into account..$^{21}$

Some issues merit careful consideration. First, platelet function testing before and after the administration of a loading dose was only performed in a small number of patients. Second, given the relatively small sample size of our studied population, we did not correlate platelet function test results with clinical outcome. Third, patient compliance to clopidogrel was verified by pharmacy refill data and personal interview but not by measuring the metabolites of clopidogrel.

In conclusion, the IMPACT-R ADP-test is relatively insensitive to the effects of clopidogrel therapy and cannot substitute for "gold standard" methods such as flowcytometric VASP-analysis and optical aggregometry in the monitoring of clopidogrel therapy. Further studies are required to establish the clinical usefulness of IMPACT-R ADP-test to accurately predict the occurrence of major adverse cardiovascular events in patients with high on-clopidogrel platelet reactivity before it can be implemented in clinical practice.

\section{Acknowledgements}

The authors are indebted to Toine Seesing and Rianda van der Stelt for excellent technical support.

What is known on this topic?

- Numerous authors have reported a wide interindividual variability in the response to aspirin and clopidogrel

- Heightened platelet reactivity despite aspirin and clopidogrel therapy has been associated with an increased risk for atherothrombotic events

- Whether the IMPACT-R to is capable to measure the effects of clopidogrel on platelet function remains to be established

- Numerous authors have reported a wide interindividual variability in the response to aspirin and clopidogrel

- Heightened platelet reactivity despite aspirin and clopidogrel therapy has been associated with an increased risk for atherothrombotic events

- Whether the IMPACT-R to is capable to measure the effects of clopidogrel on platelet function remains to be established
What does this paper add?

- The IMPACT-R ADP-test was evaluated in different categories of subjects.

- The IMPACT-R ADP-test is relatively insensitive to the effects of clopidogrel and cannot substitute for methods such as flowcytometric VASP-analysis and optical aggregometry.

- Further research is required to establish the clinical usefulness of IMPACT-R ADP-in predicting the occurrence of major adverse cardiovascular events. 


\section{REFERENCES}

1 Mehta SR, Yusuf S, Peters RJ et al. Clopidogrel in Unstable angina to prevent Recurrent Events trial (CURE) Investigators. Effects of pretreatment with clopidogrel and aspirin followed by long-term therapy in patients undergoing percutaneous coronary intervention: the PCI-CURE study. Lancet 2001;358:527-33.

2 Serebruany VL, Steinhubl SR, Berger PB et al. Variability in platelet responsiveness to clopidogrel among 544 individuals. J Am Coll Cardiol 2005;45:246-51.

3 Geisler T, Langer $\mathrm{H}$, Wydymus $\mathrm{M}$ et al. Low response to clopidogrel is associated with cardiovascular outcome after coronary stent implantation. Eur Heart J 2006;27:2420-5.

4 Buonamici P, Marcucci R, Migliorini A et al. Impact of platelet reactivity after clopidogrel administration on drugeluting stent thrombosis. J Am Coll Cardiol 2007;49:2312-7.

5 Cuisset T, Frere C, Quilici J et al. High post-treatment platelet reactivity identified low-responders to dual antiplatelet therapy at increased risk of recurrent cardiovascular events after stenting for acute coronary syndrome. J Thromb Haemost 2006;4:542-9.

6 Price MJ, Endemann S, Gollapudi RR et al. Prognostic significance of post-clopidogrel platelet reactivity assessed by a point-of-care assay on thrombotic events after drug-eluting stent implantation. Eur Heart J 2008.

7 Sibbing D, Braun S, Morath T et al. Platelet reactivity after clopidogrel treatment assessed with point-of-care analysis and early drug-eluting stent thrombosis. J Am Coll Cardiol 2009;53:849-56.

8 van Werkum JW, Hackeng CM, Smit JJ et al. Monitoring antiplatelet therapy with point-of-care platelet function assays: a review of the evidence. Future Cardiology 2008;8:33-55.

9 Savion N, Varon D. Impact--the cone and plate(let) analyzer: testing platelet function and anti-platelet drug response. Pathophysiol Haemost Thromb 2006;35:83-8.

10 Varon D, Savion N. Impact Cone and Plate(let) Analyzer. In: Platelets; 2nd edition. 2nd ed. ISBN-10: 0-12-369367-5: Elsevier; 2006. p. 535-44.

11 Shenkman B, Matetzky S, Fefer $\mathrm{P}$ et al. Variable responsiveness to clopidogrel and aspirin among patients with acute coronary syndrome as assessed by platelet function tests. Thromb Res 2008;122:336-45.

12 van Werkum JW, van der Stelt CA, Seesing TH et al. The flow cytometric VASP assay can be used to determine the effectiveness of clopidogrel in patients treated with abciximab. J Thromb Haemost 2007;5:881-3.

13 van Werkum JW, Kleibeuker M, Mieremet N et al. Evaluation of the platelet response to clopidogrel with light transmittance aggregometry: peak aggregation or late aggregation? J Thromb Haemost 2007;5:884-6.

14 van Werkum JW, Kleibeuker M, Mieremet $\mathrm{N}$ et al. Evaluation of the platelet response to clopidogrel with light transmittance aggregometry: peak aggregation or late aggregation? J Thromb Haemost. 2007;5(4):884-6.

15 van Werkum JW, Heestermans AACM, Deneer VHM et al. Clopidogrel resistance: Fact and Fiction. Future Cardiology $2006 ; 2: 215-28$.

16 Smith SC Jr, Feldman TE, Hirshfeld JW Jr et al; American College of Cardiology/American Heart Association Task Force on Practice Guidelines; ACC/AHA/SCAI Writing Committee to Update 2001 Guidelines for Percutaneous Coronary Intervention. ACC/AHA/SCAl 2005 guideline update for percutaneous coronary intervention: a report of the American College of Cardiology/American Heart Association Task Force on Practice Guidelines (ACC/AHA/SCAI Writing Committee to Update 2001 Guidelines for Percutaneous Coronary Intervention). Circulation 2006;113:e166-e286.

17 Snoep JD, Hovens MM, Eikenboom JC et al. Clopidogrel nonresponsiveness in patients undergoing percutaneous coronary intervention with stenting: a systematic review and meta-analysis. Am Heart J 2007;154:221-31.

18 Morel O, Faure A, Ohlmann P et al. Impaired platelet responsiveness to clopidogrel identified by flow cytometric vasodilator-stimulated phosphoprotein (VASP) phosphorylation in patients with subacute stent thrombosis. Thromb Haemost 2007;98:896-9.

19 Gurbel PA, Bliden KP, Guyer K et al. Platelet reactivity in patients and recurrent events post-stenting: results of the PREPARE POST-STENTING Study. J Am Coll Cardiol 2005;46:1820-6.

20 Gachet C. Regulation of platelet functions by P2 receptors. Annu Rev Pharmacol Toxicol 2006;46:277-300.

21 Gachet C, Hechler B, Leon C et al. Activation of ADP receptors and platelet function. Thromb Haemost 1997;78:271-5. 


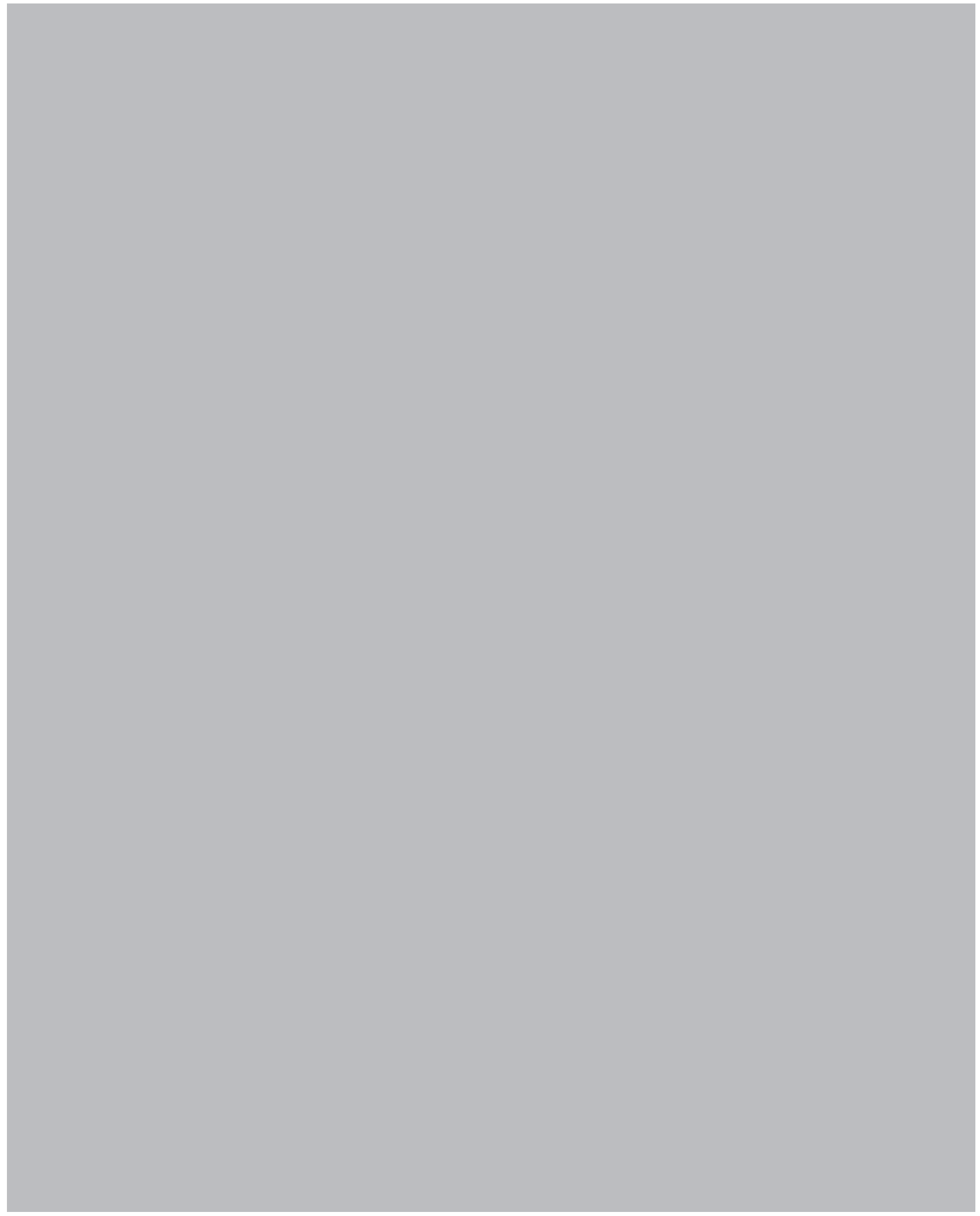




\section{Chapter 6}

\section{Which platelet function test is suitable to monitor clopidogrel responsiveness? A pharmacokinetic analysis on the active metabolite of clopidogrel}

JThromb Haemost. 2010;8(3):482-8

Heleen J Bouman Emel Parlak Jochem W van Werkum

Nicoline J Breet

Hugo Ten Cate

Christian M Hackeng Jurriën $\mathrm{M}$ ten Berg

Dirk Taubert

Department of Cardiology, St Antonius Hospital, Nieuwegein, the Netherlands St Antonius center for Platelet Function Research, St Antonius Hospital, Nieuwegein, the Netherlands Department of Internal Medicine, Cardiovascular Research Institute Maastricht, Maastricht University, Maastricht, the Netherlands Department of Clinical Chemistry, St Antonius Hospital, Nieuwegein, the Netherlands Department of Pharmacology, University Hospital, University of Cologne, Cologne, Germany 


\section{ABSTRACT}

\section{Background}

Multiple platelet function tests claim to be $\mathrm{P}_{2} \mathrm{Y}_{12}$-pathway specific and capable of capturing the biological activity of clopidogrel.

\section{Objectives}

The aim of the present study was to determine which platelet function test provides the best reflection of the in vivo plasma levels of the active metabolite of clopidogrel (AMC)

\section{Patients/Methods}

Clopidogrel-naive patients scheduled for elective $\mathrm{PCI}$ received a $600 \mathrm{mg}$ loading dose of clopidogrel and $100 \mathrm{mg}$ of aspirin. For pharmacokinetic analysis, blood was drawn at 0, 20, 40,60, 90, 120, 180, 240 and 360 minutes after clopidogrel loading and peak plasma concentrations ( $C_{\max }$ ) of the AMC were quantified with liquid chromatography-tandem mass spectrometry. Platelet function testing was performed at baseline and 360 minutes after clopidogrel loading.

\section{Results}

The VASP-assay, the VerifyNow $P_{2} Y_{12}$-assay and $20 \mu \mathrm{mol} / L$ ADP-induced light transmittance aggregometry (LTA) showed strong correlations with cmax of the AMC (VASP: $r=0.75, p<0.001_{i}$ VerifyNow PRU: $r=0.67, p=0.001$; VerifyNow \%inhibition: $r=0.76, p<0.001 ; 20 \mu \mathrm{mol} / \mathrm{L}$ ADP-induced LTA: $r=0.68, p=0.001$ ). Agreement with $C_{\max }$ of the AMC was less evident for $5 \mu \mathrm{mol} / \mathrm{L}$ ADP-induced LTA or WBA, while the IMPACT-R ADP test did not show any correlation with plasmalevels of the AMC.

\section{Conclusion}

The flowcytometric VASP-assay, the VerifyNow $\mathrm{P}_{2} \mathrm{Y}_{12}$ assay and, though to a lesser extent, $20 \mu \mathrm{mol} / \mathrm{L}$ ADP induced LTA correlate best with the maximal plasma level of the AMC, suggesting these may be the preferred platelet function tests for monitoring the responsiveness to clopidogrel. 


\section{INTRODUCTION}

Clopidogrel is administered as an inactive prodrug requiring metabolization by the hepatic cytochrome $\mathrm{P} 450$ system for its antiplatelet activity ${ }^{1}$. The formed active thiol metabolite of clopidogrel (AMC) irreversibly inhibits adenosine diphosphate (ADP) mediated platelet activation and aggregation by antagonizing the $\mathrm{P}_{2} \mathrm{Y}_{12}$-receptor ${ }^{2}$. Although clopidogrel has proven its efficacy in reducing atherothrombotic events after $\mathrm{PCl}$, a considerable interindividual variability in response has been reported ${ }^{3}$. Clinical, genetic and pharmacokinetic factors contribute to this wide variability in response and it has been demonstrated that the absolute magnitude of ADP-induced platelet reactivity at the time of $\mathrm{PCl}$ is associated with an increased risk of atherothrombotic events, including stent thrombosis ${ }^{4-11}$. It is therefore of utmost importance to have a confident parameter of the in vivo activity of clopidogrel. Multiple platelet function tests claim to be $\mathrm{P}_{2} \mathrm{Y}_{12}$-pathway specific and to be capable of capturing the specific biological activity of clopidogre ${ }^{12}$. Since the AMC is prone to rapid inactivation of its reactive thiol group ${ }^{13}$, quantitative methods for the detection of the AMC require a sophisticated stabilization protocol. Data on the performance of different platelet function tests in relation to plasma levels of the AMC are therefore scarce.

In the present study we sought to investigate which of the currently available platelet function tests - if any - provides the best representation of the in vivo plasma levels of the active metabolite of clopidogrel.

\section{METHODS}

\section{Patient population}

Consecutive patients with stable angina pectoris scheduled for $\mathrm{PCl}$ were eligible. All patients were on 80-100 mg aspirin therapy daily. Exclusion criteria were a history of bleeding diathesis, presence of an acute coronary syndrome (ACS), platelet count $<150 \times 10^{9} / \mathrm{L}$, the use of a glycoprotein Ilb/IIla inhibitor or a coumarin within the last 14 days or any contraindication to clopidogrel or aspirin. The study protocol complied with the declaration of Helsinki and was approved by the ethical committee of our institution, and all patients gave written informed consent for participation.

\section{Study protocol and blood sampling}

All eligible patients visited the outpatient clinic for platelet function evaluation, physical examination and a standardized interview. All patients received a witnessed $600 \mathrm{mg}$ loading dose of clopidogrel and $100 \mathrm{mg}$ of aspirin. Blood samples for platelet function evaluation were drawn from the antecubital vein with a loose tourniquet and collected in citrated (3.2\%) non-vacuum tubes (Sarstedt, Nümbrecht, Germany) before and 6 hours after the clopidogrel loading dose. All blood samples were processed within $2 \mathrm{~h}$ after collection. Blood samples for determining the AMC plasma concentration were collected from the antecubital vein in tubes containing $K_{3}$-EDTA at o, 20, 40, 60, 90 120, 180, 240 and 360 minutes after the clopidogrel loading dose. Samples were immediately centrifugated at $1500 \mathrm{~g}$ for 10 minutes and plasma was pipetted into tubes containing a stabilizing agent (Pat. No. DE 102004 $046159.7)^{14}$ in order to prevent degradation of the AMC. After vortexing for 60 seconds, samples were stored at $-80^{\circ} \mathrm{C}$ until analysis of the AMC plasma concentration with liquid chromatography tandem mass spectrometry (LC-MS/MS). 
Part II | chapter 6

\section{Platelet Function testing}

Platelet function was evaluated using five different ADP-induced platelet function tests. All tests were performed according to the manufacturer's recommendations or according to generally accepted standard procedures.

1. Light transmittance aggregometry (LTA)

LTA was quantified in non-adjusted platelet-rich plasma on a four-channel APACT 4004 aggregometer (LABiTec, Arensburg, Germany). Platelet-poor-plasma was set as 100\% aggregation and after stimulation of platelet aggregation with ADP in final concentrations of 5 and $20 \mu \mathrm{mol} / \mathrm{L}$, both peak (maximal) and late (at 360 seconds) aggregation (\%) were measured ${ }^{15}$.

2. Whole-blood Aggregometry (WBA)

Whole-Blood aggregometry (WBA) was performed in citrated whole blood as described previously ${ }^{16}$. In brief, citrated whole blood was diluted $1: 1$ with pre-warmed $\left(37^{\circ} \mathrm{C}\right)$ saline. Platelet aggregation was induced by the addition of $10 \mu \mathrm{mol} / \mathrm{L}$ ADP and the increase in impedance caused by aggregated platelets between the two electrodes was recorded on a ChronoLog 700 model Aggregometer (ChronoLog, Havertown, PA, USA). The results are reported as the maximal amplitude of impedance $(\Omega)$ after 10 minutes.

3. IMPACT-R test

The IMPACT- $R$ device (DiaMed, Cresier, Switzerland) is based on the cone and plate(let) analyzer technology ${ }^{17}$. Citrated whole-blood samples were incubated for 1 minute with $1.38 \mu \mathrm{mol} / \mathrm{L}$ ADP, causing the formation of micro platelet aggregates in nonresponsive samples. A volume of $130 \mu \mathrm{L}$ of this ADP-pre-incubated whole blood sample was pipetted on a polystyrene well and subjected to shear $\left(1800 \mathrm{~s}^{-1}\right)$ for 2 minutes, using a rotating cone. The wells were washed and stained followed by measurement of the percentage of surface coverage (SC) from shear-induced platelet adhesion and aggregation with an image analysis system. The percentage $\mathrm{SC}$ is inversely correlated with the magnitude of ADP-induced platelet activation.

4. The VerifyNow ${ }^{\circledR} P_{2} Y_{12}$ assay

The VerifyNow ${ }^{\circledR} \mathrm{P}_{2} \mathrm{Y}_{12}$ assay (Accumetrics, San Diego, CA, USA) is based on optical detection of platelet aggregation in whole blood ${ }^{18}$. The assay contains $20 \mu \mathrm{mol} / \mathrm{L}$ ADP to induce platelet aggregation and $22 \mathrm{nmol} / \mathrm{L}$ prostaglandin $E_{1}$ to suppress the undesirable contribution from ADPagonism of $\mathrm{P}_{2} \mathrm{Y}_{1}$-receptors to platelet aggregation. The magnitude of ADP-induced platelet activation is expressed as $\mathrm{P}_{2} \mathrm{Y}_{12}$ reaction units (PRU). In addition, the device calculates the percentage of $\mathrm{P}_{2} \mathrm{Y}_{12}$-inhibition, based on TRAP-induced platelet aggregation ('Base value') and PRU.

5. Flowcytometric Vasodilator-Stimulated Phosphoprotein (VASP)-analysis

Flowcytometric analysis of VASP phosphorylation was performed using a commercially available kit from Biocytex (Marseille, France)[10]. In brief, citrated blood was incubated with either $\mathrm{PGE}_{1}$ or $P G E_{1}+A D P$ and fixed with paraformaldehyde, after which platelets were permeabilized followed by immunolabeling with a CD61 phycoerythrin-labeled platelet specific antibody and a FITC-labeled VASP-P specific mouse monoclonal antibody or a negative isotopic control antibody. Samples were analyzed on a $500 \mathrm{MPL}$ flowcytometer (Beckman Coulter). The magnitude of platelet activation was expressed as the platelet reactivity index (PRI), which can be calculated from the mean fluorescence intensity (MFI) of samples incubated with PGE1 or PGE1+ADP using the following formula: $\mathrm{PRI}(\%)=\left[\mathrm{MFIC}_{(\mathrm{PGE} 1)}-\mathrm{MFIC}_{(\mathrm{PGE} 1+\mathrm{ADP})}\right] /\left[\mathrm{MFIC}_{(\mathrm{PGE})}\right] \times 100$. 


\section{Liquid chromatography-tandem mass spectrometry (LC-MS/MS)}

Analysis and detection of the active thiol metabolite were performed as previously described on a triplequadruple tandem mass spectrometer (TSQ Quantum, Thermo Electron, Dreieich, Germany) ${ }^{19}$. Measurements were performed in triplicate using a Surveyor HPLC system. Plasma concentration versus time data of each patient were fitted by a one-compartment first order model (Bateman function $r>0.94$ ) using WinNolin ${ }^{\text {TM }}$ Software (Pharsight, Palo Alto, CA, USA). The maximal plasma concentration $\left(C_{\max }, \mathrm{ng} / \mathrm{mL}\right)$ was calculated from the individual regression fits.

\section{Sample size calculation and statistics}

The t-test for point biserial correlation based on the noncentrality parameter >delta < was used for a priori sample size calculation assuming a two-sided significance level of $a=0.05$ and a power $1-b=0.95$. From previous assessments (and from the clinical perspective that a diagnostic test should explain at least $50 \%$ of the variance of a variable) a determination coefficient of $r^{2}=0.5$ was deemed relevant ${ }^{19}$. The total required sample size was calculated to be 16 . Platelet function testing results were related to the $c_{\max }$ of the $A M C$, since this appeared to be the pharmacokinetic parameter correlating best with inhibition of platelet aggregation (IPA) in a previous study ${ }^{19}$. Continuous variables are expressed as mean \pm SD and categorical variables as frequencies (\%). The individual clopidogrel responsiveness, defined as the absolute decrease in platelet reactivity from baseline to 6 hours after clopidogrel loading, was tested using a paired t-test. The Pearson correlation coefficient was calculated to test the correlation between the $\mathrm{c}_{\max }$ of the AMC and the absolute inhibition of platelet aggregation (IPA) at 6 $\mathrm{h}$ after clopidogrel loading. Additionally, a normalized ANOVA was performed on the ratio "\% platelet inhibition ([baseline-T6]/baseline) / $c_{\max }$ of the AMC", to determine the statistical significance of the observed differences between platelet function tests with regard to their correlation with plasma levels of the AMC. All Statistical analyses were performed with SPSS (version 15.0, SPSS Inc., Chicago, IL, USA ) and $p$-values $<0.05$ were considered statistically significant.

\section{RESULTS}

A total of 20 consecutive patients were enrolled. Clinical characteristics of the studied population are summarized in Table 1. All patients were on aspirin therapy ( $80-100 \mathrm{mg} / \mathrm{day})$ at the time of inclusion.

\section{Responsiveness to a $600 \mathrm{mg}$ loading dose of clopidogrel}

All platelet function tests were able to detect a significant reduction in platelet function $6 \mathrm{~h}$ after clopidogrel loading dose administration ( $p<0.001$ for all), except the IMPACT-R ADP-test $(p=0.13)$. Despite the observed inhibitory shift in test results after clopidogrel administration, some overlap between baseline and post-clopidogrel values was notable for all platelet function tests.

\section{Correlation between platelet function tests}

Results of the VASP, VerifyNow $\mathrm{P}_{2} \mathrm{Y}_{12}$ assay and $20 \mu \mathrm{mol} / \mathrm{L}$ ADP induced LTA showed moderate to good correlation with one and another, but lacked significant correlation with WBA and the IMPACT- $R$ ADP-test (Table 2). Agreement between LTA induced by $5 \mu \mathrm{mol} / \mathrm{L}$ ADP and the other tests was less explicit, showing a moderate correlation with $20 \mu \mathrm{mol} / L$ ADP induced LTA and the VerifyNow $P_{2} Y_{12}$ assay, but no correlation at all with the VASP-assay, nor with the WBA and the IMPACT-R ADP-test. 
Part II | chapter 6

Table 1 | Baseline characteristics

\begin{tabular}{|c|c|}
\hline \multicolumn{2}{|l|}{ Baseline characteristics $(n=20)$} \\
\hline Age (yrs) & $60.2 \pm 10.3$ \\
\hline Men & $19(95 \%)$ \\
\hline \multicolumn{2}{|l|}{ Risk Factors } \\
\hline Hypertension & $13(65 \%)$ \\
\hline $\operatorname{BMI}\left(\mathrm{kg} / \mathrm{m}^{2}\right)$ & $27.90 \pm 3.31$ \\
\hline Diabetes Mellitus & $2(10 \%)$ \\
\hline Dyslipidemia & $13(65 \%)$ \\
\hline Current smoker & $12(60 \%)$ \\
\hline Familial history of CAD & $12(60 \%)$ \\
\hline Previous MI & $9(45 \%)$ \\
\hline Previous $\mathrm{PCl}$ & $9(45 \%)$ \\
\hline \multicolumn{2}{|l|}{ Concomitant medication } \\
\hline Aspirin & $20(100 \%)$ \\
\hline ACE inhibitor & $8(40 \%)$ \\
\hline Beta-blocker & $14(70 \%)$ \\
\hline Statin & $18(90 \%)$ \\
\hline \multicolumn{2}{|l|}{ Laboratory parameters } \\
\hline Platelet count in whole blood (x 109/L) & $242 \pm 53$ \\
\hline Platelet count in PRP ( × 109/L) & $356 \pm 96$ \\
\hline Hemoglobin (mmol/L) & $8.9 \pm 0.5$ \\
\hline
\end{tabular}

Continuous variables are presented as mean $\pm S D$, and categorical variables as counts (\%). BMI=body mass index, $C A D=$ coronary artery disease, $M I=$ myocardial inf arction, $P C l=$ percutaneous coronary intervention, $P R P=$ platelet-rich plasma
Flowcytometric VASP-analysis

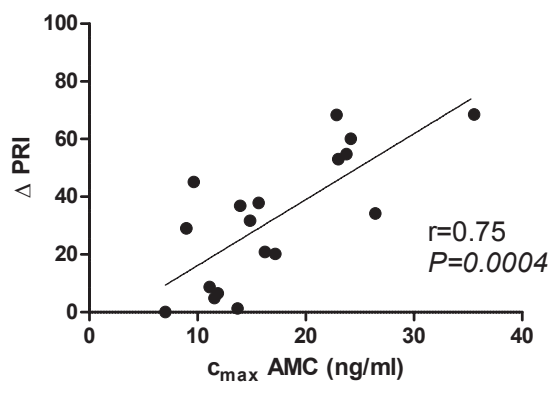

VerifyNow P2Y12 assay

$\triangle \mathrm{PRU}$

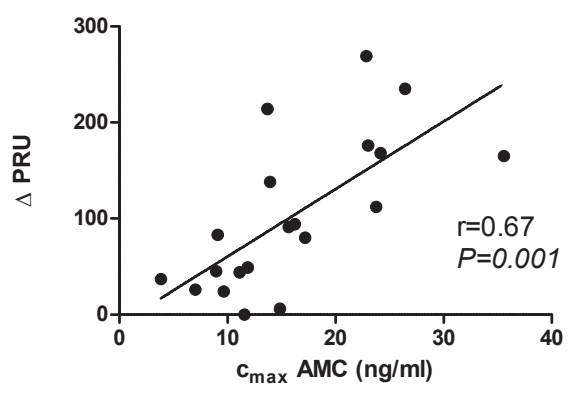

VerifyNow P2Y12 assay

$\Delta \%$ inhibition

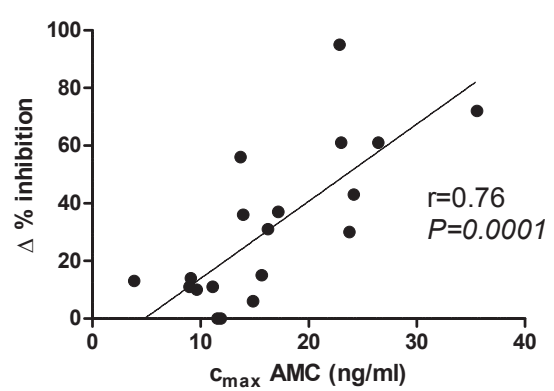

Figure 1 | Correlation between the $c_{\max }$ of the AMC $(\mathrm{ng} / \mathrm{mL})$ and IPA assessed using the flowcytometric VASP-assay (upper graph) and the VerifyNow $P_{2} Y_{12}$ assay, both PRU (middle graph) and \% inhibition (lower graph). IPA was calculated as $\Delta$ [baseline-T6] of the results for each platelet function test. The correlation coefficient ( $r$ ) and the corresponding $p$-values are represented in the separate graphs. 


\section{Correlation between IPA and plasmalevels of the AMC}

Linear regression analysis revealed major differences between the various platelet function tests regarding correlations between IPA and the $c_{\max }$ of the AMC. The highest correlation coefficients were observed for the flowcytometric VASP-assay ( $r=0.75, p<0.001$; Figure 1) and the VerifyNow $\mathrm{P}_{2} \mathrm{Y}_{12}$ assay $(r=0.67, p=0.001$ for $P R U$ and $r=0.76, p<0.001$ for $\%$ inhibition). The absolute change in platelet reactivity when measured with $20 \mu \mathrm{mol} / \mathrm{L}$ ADP induced LTA also showed strong correlations with the $c_{\max }$ value of the AMC ( $r=0.68, p=0.001$ for both peak and late IPA; Figure 2$)$. In contrast, no significant association was observed between the $c_{\max }$ value of the AMC and IPA when measured with LTA using a lower concentration of $5 \mu \mathrm{mol} / \mathrm{L}$ ADP (peak: $r=0.43, p=0.06$; late: $r=0.14, p=0.56)$ or WBA $(r=0.27, p=0.28$; Figure 2,3 ). The IMPACT-R ADP-test did not show any correlation with $c_{\max }$ of the AMC (Figure 3 ). The normalized ANOVA revealed that the IMPACT- $R$ ADP-test was significantly inferior as compared to all other platelet function tests ( $p$ values for comparisons with all other tests were $<0.05$ ), while no statistical differences were observed between all other platelet function tests $(p>0.05)$.

Table 2 | Correlation between different platelet function tests

\begin{tabular}{|c|c|c|c|c|c|c|c|c|c|}
\hline Correlation coefficient $(r)$ & 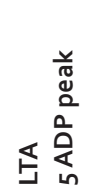 & 尊 & 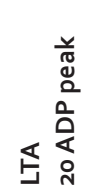 & 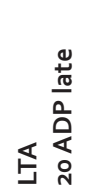 & 吕 & 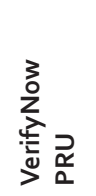 & 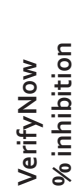 & 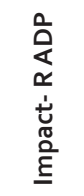 & $\stackrel{\hat{n}}{\frac{\hat{u}}{\alpha}}$ \\
\hline LTA 5 ADP peak & 1 & $0.84^{\neq}$ & $0.81^{\ddagger}$ & $0.78^{\ddagger}$ & 0.13 & $0.56^{*}$ & $0.56^{+}$ & -0.19 & 0.16 \\
\hline LTA 5 ADP late & & 1 & $0.59^{+}$ & $0.56^{*}$ & -0.01 & 0.36 & 0.34 & -0.03 & 0.02 \\
\hline LTA 20 ADP peak & & & 1 & $0.96^{\ddagger}$ & 0.21 & $0.82^{\ddagger}$ & $0.80^{*}$ & -0.36 & $0.50^{*}$ \\
\hline LTA 20 ADP late & & & & 1 & 0.32 & $0.83^{\neq}$ & $0.79^{\neq}$ & -0.25 & $0.49^{*}$ \\
\hline WBA & & & & & 1 & 0.20 & 0.23 & 0.16 & 0.08 \\
\hline VerifyNow PRU & & & & & & 1 & $0.94^{\ddagger}$ & -0.3 & $0.55^{*}$ \\
\hline VerifyNow \% inhibition & & & & & & & 1 & -0.38 & $0.64^{+}$ \\
\hline Impact-R ADP & & & & & & & & 1 & $-0.48^{*}$ \\
\hline VASP PRI & & & & & & & & & 1 \\
\hline
\end{tabular}

Correlation coefficients ( $r$ ) are presented for each mutual comparison, ${ }^{*} p<0.05,{ }^{+} p<0.01,{ }^{\ddagger} p<0.001$. ADP $=$ adenosine diphosphate, $L T A=$ light transmittance aggregometry, $P R I=$ platelet reactivity index, $P R U=P 2 Y_{12}$ reaction units, VASP= vasodilator-stimulated phosphoprotein, WBA=whole blood impedance aggregometry. 

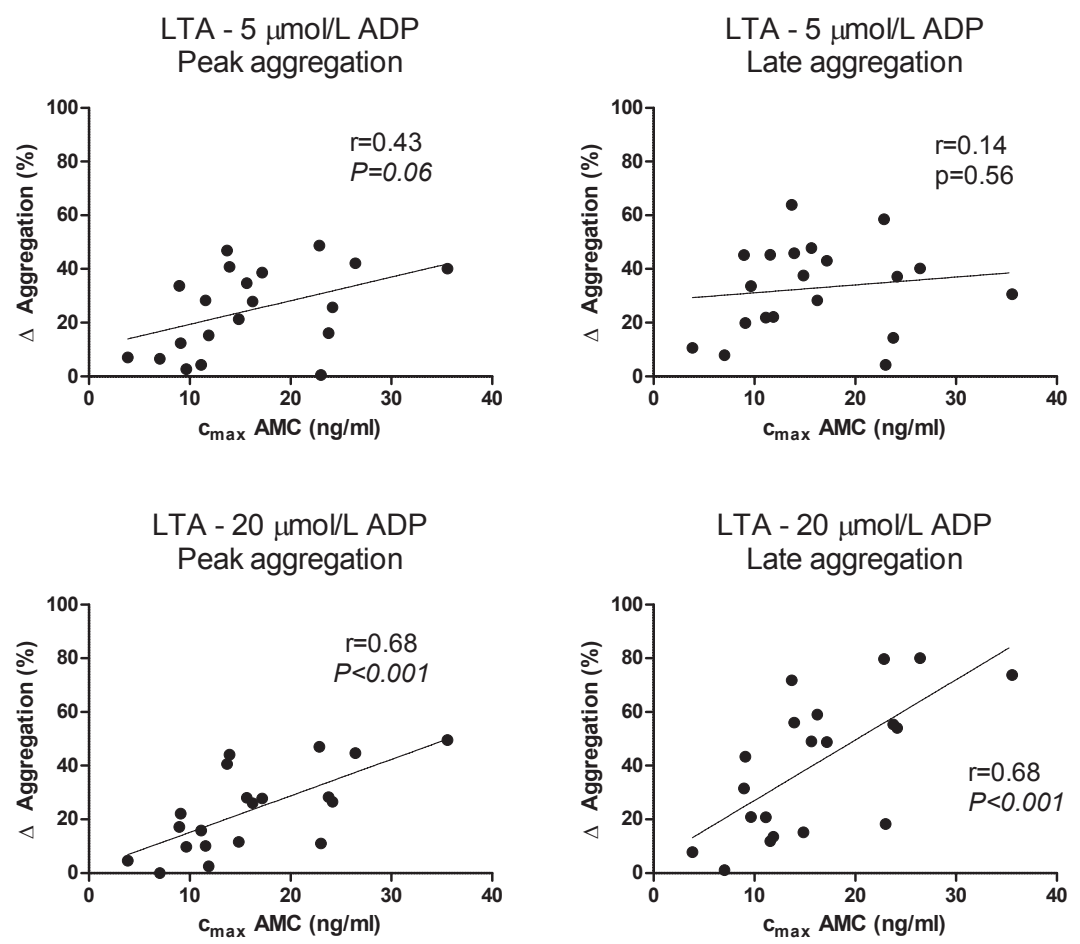

Figure 2 | Correlation between the $c_{\max }$ of the $A M C(n g / m L)$ and IPA assessed using the ADPinduced LTA using $5 \mu \mathrm{mol} / \mathrm{L}$ and $20 \mu \mathrm{mol} / \mathrm{L}$ (upper and lower panels, respectively) ADP-induced peak and late (at 360 sec.) aggregation (left and right panels, respectively). IPA was calculated as $\Delta$ [baseline-T6] of the results for each platelet function test. For each test, the correlation coefficient ( $r$ ) and the corresponding $p$-values are represented in the separate graphs.

\section{DISCUSSION}

The magnitude of platelet inhibition varies widely according to the platelet function assay used in monitoring responsiveness to clopidogrel. The current recommendations issued by the American College of Cardiology (ACC), the American Heart Association (AHA), and the Society for Cardiovascular Angiography and Interventions (SCAI) state the following: "In patients in whom stent thrombosis may be catastrophic or lethal (unprotected left main, bifurcating left main, or last patent coronary vessel), platelet aggregation studies may be considered and the dose of clopidogrel increased to $150 \mathrm{mg}$ per day if $<50 \%$ inhibition of platelet aggregation is demonstrated ${ }^{\prime 20}$. However, these guidelines do not further specify any details on which test or test conditions should be used. This puts the clinician in a difficult situation since multiple platelet function tests are now widely available but little is known about their ability to provide a reliable reflection of the in vivo biological activity of clopidogrel. The present study demonstrates that the flowcytometric VASP-assay and the VerifyNow $\mathrm{P}_{2} \mathrm{Y}_{12}$-assay are the most appropriate platelet function tests to monitor peak plasma levels of the AMC, achieved by a 6oomg loading dose of clopidogrel. Therefore, these platelet function tests are likely to be the most accurate in measuring the actual in vivo biological activity of clopidogrel. 


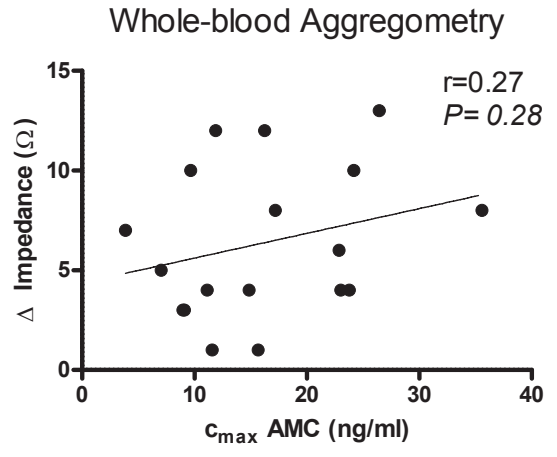

IMPACT- $R$ with ADP pre-stimulation

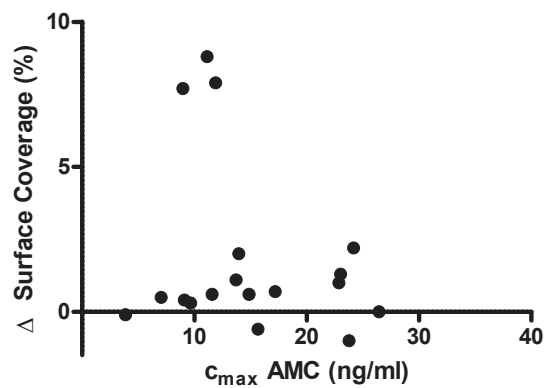

Figure 3 | Correlation between the $c_{\max }$ of the $A M C$ (ng) $m L$ ) and IPA assessed using the ADP-induced whole blood impedance aggregometry (WBA) and the IMPACT-R ADP test. IPA was calculated as $\triangle$ [baseline-T6] of the results for each platelet function test. For each test, the correlation coefficient ( $r$ ) and the corresponding $p$-values are represented in the separate graphs.

LTA is commonly recognized as the "gold standard" platelet function test and showed fine correlations with peak plasma levels of the AMC as well, though only when platelet aggregation was stimulated with a high concentration of ADP $(20 \mu \mathrm{mol} / \mathrm{L})$. LTA induced by $5 \mu \mathrm{mol} / \mathrm{L}$ lacks significant correlation with peak plasmalevels of the $A M C$, and should therefore not be used to determine clopidogrel responsiveness. Both the flowcytometric VASP-assay and the VerifyNow $\mathrm{P}_{2} \mathrm{Y}_{12}$-assay incorporate $\mathrm{PGE}_{1}$ to decrease the contribution of $A D P$-agonism at the $\mathrm{P}_{2} \mathrm{Y}_{1}$-receptor to platelet aggregation, thereby increasing the selectivity of these tests for the $P_{2} Y_{12}$-pathway ${ }^{21,22}$. This might indeed be reflected by the high agreement between IPA and the $\mathrm{C}_{\max }$ of the AMC when measured with these tests. Using a higher concentration of the agonist ADP ( $20 \mu \mathrm{mol} / \mathrm{L})$ appears to improve the assessment of the responsiveness to clopidogrel as well, since $20 \mu \mathrm{mol} / \mathrm{L}$ ADP-induced LTA showed a higher degree of correlation with peak plasma levels of the AMC than $5 \mu \mathrm{mol} / L$ ADP-induced LTA.

Although the VASP-assay has the advantage of providing stable test results until 24 hour after blood drawing, both the VASP-assay and LTA are relatively labour intensive ${ }^{23}$. In contrast, the point-of-care VerifyNow $\mathrm{P}_{2} \mathrm{Y}_{12}$ assay is suitable for use in daily clinical practice, since the semi-automated technique allows rapid assessment of platelet inhibition in whole blood without the need for expert laboratory personnel. The accuracy of the IMPACT-R ADP-test in monitoring clopidogrel-responsiveness might be seriously hampered by the requirement of multiple sample preparation proceedings that are sensitive to introduction of variation in test results by the technician performing the test.

Furthermore, the IMPACT-R ADP-test relies on a mechanism of platelet activation induced by shear stress, which is a different aspect of platelet reactivity, and apparently not a very suitable method for monitoring inhibition of the $\mathrm{P}_{2} \mathrm{Y}_{12}$-pathway. 
Part II | chapter 6

The present study shows that the flowcytometric VASP, the VerifyNow $\mathrm{P}_{2} \mathrm{Y}_{12}$-assay and $20 \mu \mathrm{mol} / \mathrm{L}$ ADP induced LTA are the most appropriate tests for determining the in vivo plasma levels of the AMC. In addition, these tests have previously been shown to predict clinical outcome in patients treated with clopidogrel5-10. Poor responsiveness to clopidogrel is however one out of multiple factors contributing to the development of atherothrombotic events. Furthermore, the magnitude of posttreatment platelet reactivity is a composite of both clopidogrel responsiveness as well as pre-treatment (baseline) platelet reactivity, resulting in a high on-treatment platelet reactivity in some patients

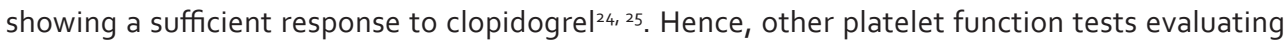
different aspects of platelet function, may as well be capable of predicting clinical outcome in patients on clopidogrel, despite the lack of correlation with plasma levels of the AMC.

The present study describes the level of correlation of different ADP-induced platelet function tests with peak plasma levels of the AMC. This important message might resolve the ongoing debate on which platelet function test is suitable for monitoring clopidogrel responsiveness. Two aspects have to be addressed that need to be explored to further improve the clinical applicability of this message. First, the present study does not cover the complete subset of platelet function tests available for monitoring clopidogrel-responsiveness. Additional tests include the Multiplate and the thromboelastography, which might show correlation with the plasma levels of the AMC as well. Second, although the present study contains a sufficient number of patients for a pharmacokinetic analysis, it does not allow an answer to the question whether patients with low plasma levels of the AMC are the ones to develop atherothrombotic complications after PCI. Nonetheless, combining the results of the present study with the already available evidence on the clinical efficacy of clopidogrel in reducing atherothrombotic events after $\mathrm{PCl}$ suggests a positive answer to that question.

In conclusion, the flowcytometric VASP-assay, the VerifyNow $\mathrm{P}_{2} \mathrm{Y}_{12}$ assay and, though to a lesser extent, $20 \mu \mathrm{mol} / \mathrm{L}$ ADP induced LTA correlate best with the maximal plasma level of the AMC, suggesting these may be the preferred platelet function tests for monitoring the responsiveness to clopidogrel. Further distinction between these tests should be based on their labour intensiveness, costs, and most importantly their sensitivity and specificity in predicting the occurrence of atherothrombotic events after $\mathrm{PCl}$. 


\section{REFERENCES}

1. Savi P, Pereillo JM, Uzabiaga MF et al. Identification and biological activity of the active metabolite of clopidogrel. Thromb Haemost 2000;84:891-6.

2. Hollopeter $G$, Jantzen HM, Vincent $D$ et al. Identification of the platelet ADP receptor targeted by antithrombotic drugs. Nature 2001;409:202-7.

3. Serebruany VL, Steinhubl SR, Berger PB et al. Variability in platelet responsiveness to clopidogrel among 544 individuals. J Am Coll Cardiol 2005;45:246-51.

4. Mega JL, Close SL, Wiviott SD et al. Cytochrome p-450 polymorphisms and response to clopidogrel. N Engl J Med 2009;360:354-62.

5. Price MJ, Endemann S, Gollapudi RR et al. Prognostic significance of post-clopidogrel platelet reactivity assessed by a point-of-care assay on thrombotic events after drug-eluting stent implantation. Eur Heart J 2008;29:992-1000.

6. Marcucci R, Gori AM, Paniccia R et al. Cardiovascular death and nonfatal myocardial infarction in acute coronary syndrome patients receiving coronary stenting are predicted by residual platelet reactivity to ADP detected by a point-of-care assay: a 12-month follow-up. Circulation 2009;119:237-42.

7. Buonamici P, Marcucci R, Migliorini A et al. Impact of platelet reactivity after clopidogrel administration on drug-eluting stent thrombosis. J Am Coll Cardiol 2007;49:2312-7.

8. Sibbing D, Braun S, Morath T et al. Platelet reactivity after clopidogrel treatment assessed with point-of-care analysis and early drug-eluting stent thrombosis. J Am Coll Cardiol 2009;53:849-56.

9. Geisler T, Langer $\mathrm{H}$, Wydymus $\mathrm{M}$ et al. Low response to clopidogrel is associated with cardiovascular outcome after coronary stent implantation. Eur Heart J 2006;27:2420-5.

10. Bonello L, Camoin-Jau L, Arques S et al. Adjusted clopidogrel loading doses according to vasodilator-stimulated phosphoprotein phosphorylation index decrease rate of major adverse cardiovascular events in patients with clopidogrel resistance: a multicenter randomized prospective study. J Am Coll Cardiol 2008;51:1404-11.

11. van Werkum JW, TopcuY, Postma S et al. Effects of diabetes mellitus on platelet reactivity after dual antiplatelet therapy with aspirin and clopidogrel. Thromb Haemost 2008;99:637-9.

12. van Werkum JW, Hackeng CM, Smit JJ et al. Monitoring antiplatelet therapy with point-of-care platelet function assays: a review of the evidence. Future Cardiology 2008;8:33-55.

13. Takahashi M, Pang $\mathrm{H}$, Kawabata K et al. Quantitative determination of clopidogrel active metabolite in human plasma by LC-MS/MS. J Pharm Biomed Anal 2008;48:1219-24

14. Sibbing D, Taubert D, Schomig A et al. Pharmacokinetics of clopidogrel in patients with stent thrombosis. J Thromb Haemost 2008;6:1230-2.

15. van Werkum JW, Kleibeuker M, Mieremet $\mathrm{N}$ et al. Evaluation of the platelet response to clopidogrel with light transmittance aggregometry: peak aggregation or late aggregation? J Thromb Haemost 2007:5:884-6.

16. Ivandic BT, Schlick P, Staritz P et al. Determination of Clopidogrel Resistance by Whole Blood Platelet Aggregometry and Inhibitors of the $\mathrm{P}_{2} \mathrm{Y}_{12}$ Receptor. Clin Chem 2006;52:383-8.

17. Shenkman B, Matetzky S, Fefer $\mathrm{P}$ et al. Variable responsiveness to clopidogrel and aspirin among patients with acute coronary syndrome as assessed by platelet function tests. Thromb Res 2008; 122:336-45

18. van Werkum JW, van der Stelt CA, Seesing TH et al. A head-to-head comparison between the VerifyNowP2Y12 assay and light transmittance aggregometry for monitoring the individual platelet response to clopidogrel in patients undergoing elective PCl. J Thromb Haemost 2006;4:2516-8.

19. Taubert D, Kastrati A, Harlfinger S et al. Pharmacokinetics of clopidogrel after administration of a high loading dose. Thromb Haemost 2004;92:311-6. 
Part II | chapter 6

20. King SB 3rd, Smith SC Jr, Hirshfeld JW Jr et al. 2007 Focused Update of the ACC/AHA/SCAI 2005 Guideline Update for Percutaneous Coronary Intervention: a report of the American College of Cardiology/American Heart Association Task Force on Practice Guidelines: 2007 Writing Group to Review New Evidence and Update the ACC/AHA/SCAI 2005 Guideline Update for Percutaneous Coronary Intervention, Writing on Behalf of the 2005 Writing Committee. Circulation 2008;117:261-95.

21. Malinin A, Pokov A, Swaim L et al. Validation of a VerifyNow- $P_{2} Y_{12}$ cartridge for monitoring platelet inhibition with clopidogrel. Methods Find Exp Clin Pharmacol 2006;28:315-22.

22. van Werkum JW, van der Stelt CA, Seesing TH et al. The flow cytometric VASP assay can be used to determine the effectiveness of clopidogrel in patients treated with abciximab. JThromb Haemost 2007;5:881-3.

23. Aleil B, Meyer N, Cazenave JP et al. High stability of blood samples for flow cytometric analysis of VASP phosphorylation to measure the clopidogrel responsiveness in patients with coronary artery disease. Thromb Haemost 2005;94:886-7.

24. Gurbel PA, Bliden KP, Hiatt BL, O'Connor CM. Clopidogrel for coronary stenting: response variability, drug resistance, and the effect of pretreatment platelet reactivity. Circulation 2003;107:2908-13.

25. Michelson $A D$, Linden $M D$, Furman $M I$ et al. Evidence that pre-existent variability in platelet response to ADP accounts for "clopidogrel resistance". J Thromb Haemost 2007;5:75-81. 


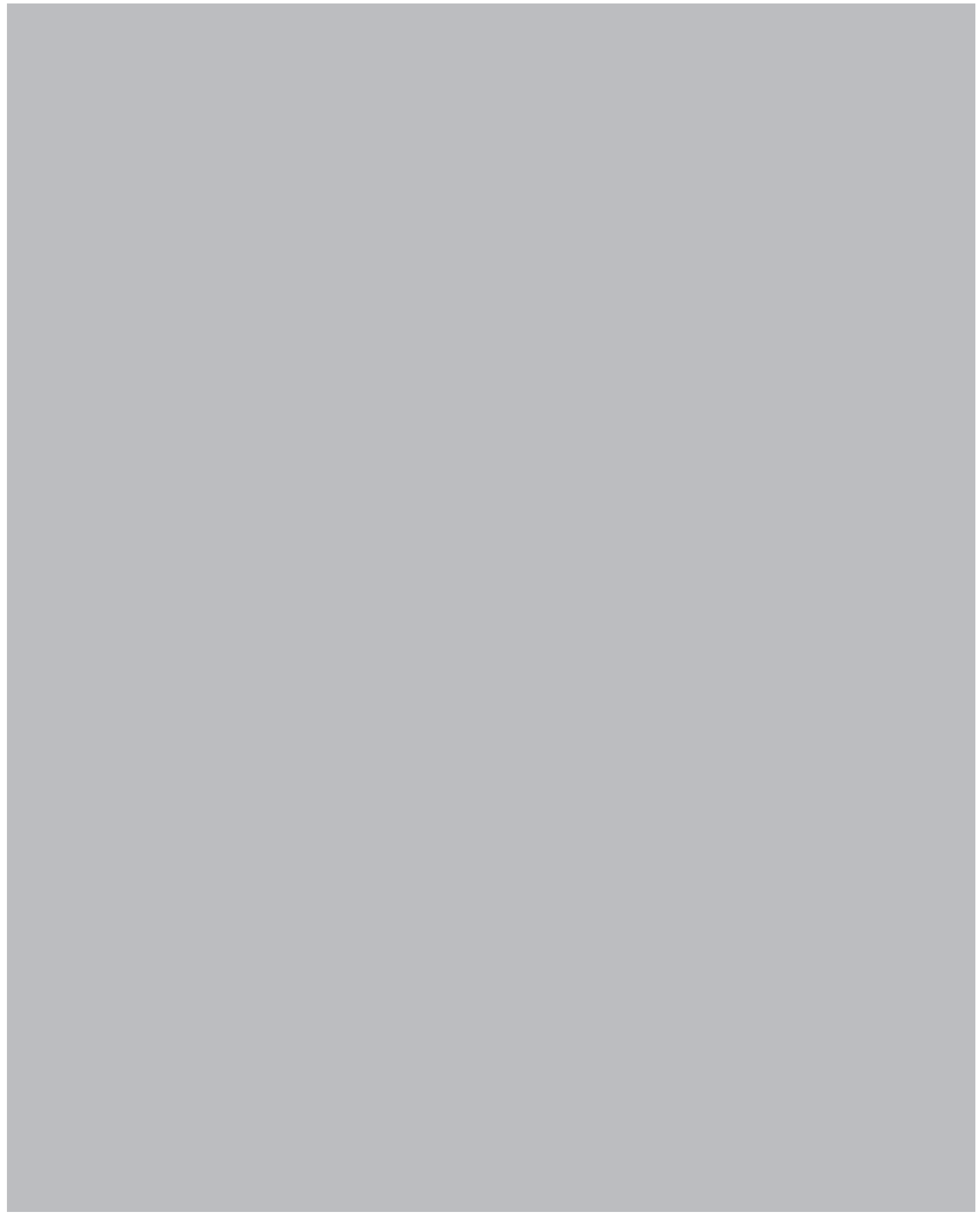




\section{Chapter 7}

\section{Comparison of platelet function tests in predicting clinical outcome in patients undergoing coronary stent implantation}

JAMA 2010; 303(8):754-62

Nicoline J Breet Jochem $W$ van Werkum Heleen J Bouman Johannes C Kelder Henk JT Ruven Egbert T Bal Vera HM Deneer Ankie M Harmsze Jan AS van der Heyden Benno J Rensing Maarten J Suttorp Christian M Hackeng Jurriën $\mathrm{M}$ ten Berg

Department of Cardiology, St. Antonius Ziekenhuis, Nieuwegein, the Netherlands Department of Clinical Chemistry, St. Antonius Ziekenhuis, Nieuwegein, the Netherlands Department of Clinical Pharmacology, St. Antonius Ziekenhuis, Nieuwegein, the Netherlands St. Antonius Center for Platelet Function Research, Nieuwegein, the Netherlands 


\section{ABSTRACT}

\section{Context}

High on-treatment platelet reactivity (HPR) is associated with atherothrombotic events following coronary stent implantation.

\section{Objective}

To evaluate the capability of multiple platelet function tests to predict clinical outcome.

\section{Design, Setting and patients}

Prospective, observational, single-center cohort study of $106 \mathrm{~g}$ consecutive patients on clopidogrel undergoing elective coronary stent implantation between December 2005 and December 2007. Ontreatment platelet reactivity was measured in parallel by light transmittance aggregometry (LTA), the VerifyNow ${ }^{\circledR} \mathrm{P}_{2} \mathrm{Y}_{12}$ assay, the Plateletworks ${ }^{\circledR}$ assay, the IMPACT-R and the PFA-100 ${ }^{\circledR}$ System (with the Dade ${ }^{\circledR}$ PFA Collagen/ADP Cartridge and INNOVANCE ${ }^{\circledR}$ PFA P2Y). Cut-off values for HPR were established by receiver-operator characteristic (ROC) curve analysis.

\section{Main Outcome Measurement}

The primary endpoint was defined as a composite of all-cause death, non-fatal acute myocardial infarction, stent thrombosis and ischemic stroke. The primary safety endpoint included TIMI major and minor bleeding.

\section{Results}

Kaplan-Meijer analysis demonstrated that at one-year follow-up, the primary endpoint occurred more frequently in patients with HPR when assessed by LTA $(52[11.7 \%\{95 \%-\mathrm{Cl}=8.9-15.0 \%\}]$ vs $36[6.0 \%[\{95 \%$ $\mathrm{Cl}=4.2-8.2 \%\}], p=0.0009[\mathrm{n}=1049])$, VerifyNow ${ }^{\circledR}(54[13.3 \%\{95 \%-\mathrm{Cl}=10.2-17.0 \%\}]$ vs $37[5.7 \%\{95 \%$ $\mathrm{Cl}=4.1-7.8 \%\}], \mathrm{p}<0.0001[\mathrm{n}=1052)])$, Plateletworks ${ }^{\circledR}(33[12.6 \%\{95 \%-\mathrm{Cl}=8.8-17.2 \%\}]$ vs $21[6.1 \%\{95 \%-$ $\left.\left.\left.\mathrm{Cl}_{3} .8-9.2 \%\right\}\right], p=0.005[\mathrm{n}=606]\right)$ and INNOVANCE ${ }^{\circ}$ PFA P $2 Y(18[12.2 \%\{95 \%-\mathrm{Cl}=7.4-18.6 \%\}]$ vs $28[6.3 \%\{95 \%-\mathrm{Cl}=4.3-8.9 \%\}, p=0.02[\mathrm{n}=588])$. ROC-curve analysis demonstrated that LTA $(A \cup C=0.63 ; 95 \%-C l: 0.58-0.68)$, VerifyNow ${ }^{\circledR}(A \cup C=0.62 ; 95 \%-C l: 0.57-0.67)$ and Plateletworks ${ }^{\circledR}$ (AUC $=0.61 ; 95 \%-\mathrm{Cl}: 0.53-0.69$ ) were able to discriminate between patients with and without primary endpoint. The IMPACT- $R(n=905)$ and the Siemens ${ }^{\circledR}$ PFA Collagen/ADP $(n=812)$ were unable to discriminate between patients with and without the primary endpoint at one-year follow-up. None of the platelet function tests were able to identify patients at risk for bleeding.

\section{Conclusion}

Of the platelet function tests assessed only LTA, VerifyNow ${ }^{\circledR}$, Plateletworks ${ }^{\circledR}$ and INNOVANCE ${ }^{\circledR}$ PFA $\mathrm{P}_{2} \mathrm{Y}$ were significantly associated with the primary endpoint. However, the predictability of these four tests was only modest. None of the tests provided accurate prognostic information to identify patients at higher risk of bleeding. Thus, the POPular-study does not support the use of platelet function testing to guide clinical practice in a low-risk population of patients undergoing elective $\mathrm{PCI}$. 


\section{INTRODUCTION}

Dual antiplatelet therapy with aspirin and clopidogrel reduces atherothrombotic complications in patients undergoing percutaneous coronary intervention $(\mathrm{PCl})$ with stenting ${ }^{1,2}$ However, the individual response to dual antiplatelet therapy is not uniform and consistent findings across multiple investigations support the association between a lower degree of platelet inhibition, a high ontreatment platelet reactivity (HPR), and the occurrence of atherothrombotic events..$^{3-10}$

The major drawbacks of these previous investigations are the relatively small sample size of the studied populations and the fact that on-treatment platelet reactivity was evaluated by only one platelet function test per study. There is currently no consensus regarding the most appropriate method to quantify the magnitude of on-treatment platelet reactivity. Therefore, the aim of The Do Platelet Function Assays Predict Clinical Outcomes in clopidogrel Pretreated patients undergoing elective $\mathrm{PCl}$ (the POPular-study) was to evaluate the ability of multiple platelet function tests in predicting atherothrombotic events, including stent thrombosis, in clopidogrel pre-treated patients undergoing $\mathrm{PCl}$ with stent implantation.

\section{METHODS}

\section{Study Population}

Consecutive patients with established coronary artery disease scheduled for elective $\mathrm{PCl}$ with stent implantation were included in this study. All patients received optimal clopidogrel treatment (defined as a maintenance of $75 \mathrm{mg}$ daily therapy for $>5$ days or a loading dose of $300 \mathrm{mg}$ at least $24 \mathrm{~h}$ before $\mathrm{PCl}$ or $600 \mathrm{mg}$ at least 4 hours before $\mathrm{PCl}$. All patients received aspirin at a dose of 80 to $100 \mathrm{mg}$ daily $\geq 10 d a y s$, unless they were on long-term anticoagulation with coumadins. According to our institutional practice, all patients (both after drug eluting and bare-metal stenting) are treated with clopidogrel for at least one year since the year 2003. Clopidogrel and aspirin maintenance doses are $75 \mathrm{mg}$ and 80-100 mg daily respectively. Higher maintenance doses are not used. Compliance to antiplatelet medication is routinely assessed by outpatient visits at 6 weeks, 3 months and 1 year. For patients included in the POPular-study additional telephone contact at 30 days and 12 months were performed. Compliance was also verified by pharmacy refill data.

All interventions were performed according to current guidelines ${ }^{11}$ and the choice of stent type and periprocedural use of glycoprotein (GP) Ilb/Illa inhibitors was left to the operator's discretion, but the latter werealways administered after blood collection. Patients using concomitant medication known to affect platelet function other than aspirin (i.e. NSAIDs, dipyramidole, upstream GP IIb/llla inhibitors), patients with a known platelet function disorder or a whole blood platelet count $<150.000 / \mu \mathrm{L}$ were excluded. Written informed consent was obtained before $\mathrm{PCl}$. All data were prospectively collected and entered into a central database. Clinical follow-up was obtained by contacting all patients at 30 days and 12 months and a double-check was performed on the basis of source documents obtained from medical records from the referring hospitals.

The study was conducted according to the principles of the Declaration of Helsinki and the laws and regulations applicable in the Netherlands. The local institutional review board (Verenigde Commissies Mensgebonden Onderzoek [VCMO]) approved the study. 
Part II | chapter 7

\section{Follow-up and endpoints}

The primary endpoint of the POPular-study was defined as a composite of all-cause death, non-fatal myocardial infarction (defined as the occurrence of ischemic symptoms and a spontaneous [i.e. not peri- or post-procedural] troponin T value or creatine kinase MB greater than the upper limit of normal), stent thrombosis (definite stent thrombosis according to the Academic Research Consortion criteria ${ }^{12}$ ) and ischemic stroke (focal loss of neurologic function caused by an ischemic event). The primary safety endpoint was defined as major or minor bleeding according to the modified Thrombolysis In Myocardial Infarction (TIMI) Study Group criteria. ${ }^{13}$

Exploratory endpoints included elective target vessel revascularization (TVR; revascularization of the vessel treated at the time of inclusion in the study), elective non-target vessel revascularization (nonTVR; revascularization of a vessel different from that treated at the time of enrolment) and hospitalization for ischemia (hospitalization with ischemic symptoms, evidence for ischemia on electrocardiogram, but without elevated cardiac markers).

An independent committee, blinded for platelet function data, adjudicated all endpoints through review of source documents of medical records.

\section{Blood sampling}

Before heparinization, whole blood was drawn from the femoral or radial artery sheath. Blood samples were collected into $3.2 \%$ citrate tubes for light transmittance aggregometry, (LTA) and the IMPACT- $R$. The VerifyNow ${ }^{\circledR} \mathrm{P}_{2} \mathrm{Y}_{12}$ was performed using Greiner tubes, according to the manufacturer's test protocol. For the PFA-100 ${ }^{\circledR}$ System (Siemens Healthcare Diagnostics Products GmbH, Germany) 3.8\% buffered citrated blood was used, according to the manufacturer's test protocol. Blood samples for whole blood count were drawn into tubes containing $\mathrm{K}_{3}$-EDTA and tubes containing PPACK $(50 \mu \mathrm{mol} / \mathrm{L})$ to perform the Plateletworks ${ }^{\circledR}$.

\section{Platelet Function Measurements}

The magnitude of on-treatment platelet reactivity was quantified using the platelet function tests in parallel: LTA with adenosine diphosphate (ADP) 5 and $20 \mu \mathrm{mol} / \mathrm{L}$ as the agonist, the VerifyNow ${ }^{\circledR} \mathrm{P}_{2} \mathrm{Y}_{12}$ assay, the Plateletworks ${ }^{\circledR}$ assay using ADP tubes, the IMPACT- $R$ assay (both with and without ADP pre-stimulation) and the Dade ${ }^{\circledR}$ PFA Collagen/ADP Test Cartridge (PFA-100 ${ }^{\circledR}$ System). Halfway through the POPular-study, the final prototype of the novel INNOVANCE ${ }^{\circledR}$ PFA P 2 Y (PFA-100 ${ }^{\circledR}$ System) became available for performance evaluation. Except for the INNOVANCE ${ }^{\circledR}$ PFA $P_{2} Y$, which is still under development at time of submission, all platelet function tests were commercially available at the start of the study. All platelet function measurements were performed within 2 hours after blood collection. A detailed description of the platelet function tests is summarized in Supplementary Online Content. ${ }^{14}$ $15,16,17,18$

\section{Statistical Analysis}

Sample size calculation was based on the ISAR-REACT I trial ${ }^{19}$ that included a cohort with similar selection criteria and the same treatment strategy. Therefore, we assumed an incidence of the primary endpoint of $6 \%$. The study was designed on the basis of the superiority principle to have 80 percent power to observe an incidence of the primary end point in patients exhibiting high on-treatment platelet reactivity (HPR) of $10 \%$ and $4 \%$ in patients without HPR. On this basis, 380 patients were needed in each group. To compensate for loss to follow-up, we aimed for a population of 800 as 
measured with each test. Owing to irregularities in platelet assay supply as well as technical failure in a minority of platelet function tests, not all platelet function assays were performed in every patient. Inclusion continued until at least 4 tests had sufficient power.

Continuous variables are presented as mean \pm SD. Categorical data are reported as frequencies (percentages). Categorical variables were compared using the chi-square test. Normally distributed continuous variables were compared with a two-sided unpaired t test. Since the PFA-100 ${ }^{\circledR}$ System confines detection of a closure time to a 300-s window, and, because the majority of patients on adequate antiplatelet therapy exhibit non-closure according to INNOVANCE ${ }^{\circledR}$ PFA P2Y, the results of the PFA-100 ${ }^{\circledR}$ System are depicted as a Kaplan Meier time-to-aperture-closure plot and a log-rank test was used.

To evaluate a platelet function assay's ability to distinguish between patients with and without primary endpoint at one-year follow-up, a receiver-operator characteristic (ROC) curve analysis was calculated for each test. The optimal cut-off level was calculated by determining the smallest distance between the ROC-curve and the upper left corner of the graph. Patients above the optimal cut-off level were considered to exhibit HPR. Survival analysis for patients with and without HPR according to the ROC of the specific test, were performed using the Kaplan-Meier method, and the differences between groups were assessed by the log-rank test. The measure of effect was the Odds Ratio (OR) and estimated from a logistic regression analysis. A second ROC curve analysis was performed based on the one-year primary safety endpoint; combined TIMI major and minor bleedings.

Logistic regression modelling was used to identify independent correlates of the primary endpoint and to adjust for potential confounders (classic cardiovascular risk factors, renal failure, left ventricular ejection fraction $<45 \%$, total stent length, number of lesions treated, amount of stents implanted, bifurcation lesions, co-medication [including use of clopidogrel loading dose, coumadins, proton pump inhibitors, calcium channel blockers, statins or GP IIb/IIla inhibitors], laboratory parameters [hemoglobin, platelet count and mean platelet volume], left anterior descendens coronary artery (LAD) or graft-stenting). All univariate variables with a $p$-value $<0.10$ were included in multivariable analysis. Whether a variable had additional contribution to a logistic regression model without that variable was tested with the likelihood-ratio test. The Hosmer-Le Cessie goodness-of-fit test was performed to assess the adequacy of the model. All statistical analyses were performed with $\mathrm{R}$ (version 2.9, http://www.r-project.org) and a two-tailed $p$-value of $<0.05$ was considered significant. The authors had full access to and take full responsibility for the integrity of the data. All authors have read and agreed to the manuscript as written.

\section{RESULTS}

In total 1328 consecutive patients were invited to participate in the study, 21 (1.6\%) refused to participate. Another 238 patients were initially included in the study, but since no stent was implanted they were also excluded (e.g. patients underwent only balloon angioplasty or a fractional flow reservemeasurement demonstrating non-ischemic coronary disease), resulting in a population of 1069 consecutive patients Owing to irregularities in platelet assay supply, particularly in the supply of the Plateletworks ${ }^{\circledR}$, as well as technical failure in a minority of platelet function tests, not all platelet function assays were performed in every patient. As a consequence, LTA was performed in a total of 1049 patients with $5 \mu \mathrm{mol} / L$ ADP and in 1051 with $20 \mu \mathrm{mol} / \mathrm{L}$ ADP; the VerifyNow ${ }^{\circledR} \mathrm{P}_{2} \mathrm{Y}_{12}$ cartridge in 
1052 patients; the Plateletworks ${ }^{\circledR}$ assay in 606 patients and the IMPACT- $R$ in 910 patients without pre-stimulation and in 905 with ADPpre-stimulation. The PFA COL/ADP was performed in 812 patients and INNOVANCE ${ }^{\circledR}$ PFA $\mathrm{P}_{2} \mathrm{Y}$ in 588 patients.

Baseline characteristics of the cohort are depicted in Table 1. Baseline characteristics of the subpopulations according to the tests performed are summarized in eTable $\mathbf{1}$, demonstrating that the subpopulations tested were well balanced (except for white blood cell counts, $p=0.04$, all $p$-values were $>0.85)$ ). All patients received optimal clopidogrel pre-treatment; $50.6 \%$ received a maintenance dose of $75 \mathrm{mg}$ daily therapy for $>5$ days, $41.6 \%$ received a loading dose of $300 \mathrm{mg}$ at least $24 \mathrm{~h}$ before $\mathrm{PCl}$ and $8.3 \%$ received a loading dose of $600 \mathrm{mg}$ at least 4 hours before $\mathrm{PCl}$. One thousand fifty two patients (98.4\%) were on 80-100 mg aspirin daily for more than 10 days.

Clinical outcome at 12 months was available for 1067 (99.8\%) of the patients. Compliance for clopidogrel was $95.2 \%$ after 6 months and $82.1 \%$ after one year. During one-year follow-up a total of 18 died (1.7\%), 64 (6.0\%) patients had non-fatal acute myocardial infarction, $13(1.2 \%)$ presented with definite stent thrombosis and 14 patients suffered from non-fatal ischemic stroke (1.3\%). Three possible stent thromboses occurred (0.3\%) and no probable stent thromboses were found. A total of 55 (5.1\%) patients presented with bleeding; 33 (3.1\%) TIMI-major and 24 (2.2\%) TIMI-minor bleedings.

\section{Receiver-Operating Characteristic Curve Analysis}

Receiver operator characteristic curve (ROC) analysis demonstrated that LTA (both 5 $\mu \mathrm{mol} / \mathrm{L}$ ADP and $20 \mu \mathrm{mol} / \mathrm{L}$ ), the VerifyNow ${ }^{\circledR}$ $\mathrm{P}_{2} \mathrm{Y}_{12}$-cartridge and the Plateletworks ${ }^{\circledR}$ assay were able to distinguish between patients
Table 1 | Baseline characteristics total population

\begin{tabular}{|c|c|}
\hline & Total population \\
\hline \multicolumn{2}{|l|}{ Clinical parameters } \\
\hline Age & $64 \pm 10.6$ \\
\hline Gender & $802 / 1069$ \\
\hline Hypertension & $823 / 1069(77.0 \%)$ \\
\hline Hypercholesterolemia & $858 / 1069(80.3 \%)$ \\
\hline Diabetes Mellitus & $199 / 1069$ (18.6\%) \\
\hline Family history & $646 / 1069(60.4 \%)$ \\
\hline Current smoking & $119 / 1069$ (11.1\%) \\
\hline LVEF $<45 \%$ & $165 / 1069$ (15.4\%) \\
\hline Renal insufficiency & $86 / 1069$ (8.0\%) \\
\hline Prior myocardial infarction & $583 / 1069(54.5 \%)$ \\
\hline \multicolumn{2}{|l|}{ Medication } \\
\hline Aspirin & $955 / 1068(89.4 \%)$ \\
\hline Loading dose clopidogrel & $548 / 1068(51.3 \%)$ \\
\hline PPI & $297 / 1068(27.8 \%)$ \\
\hline Coumadins & $108 / 1068(10.1 \%)$ \\
\hline \multicolumn{2}{|l|}{ Laboratory Parameters } \\
\hline Platelet count $\left(\times 10^{9}\right)$ & $271.7 \pm 81.6$ \\
\hline WBC $\left(x 10^{9}\right)$ & $7.6 \pm 2.3$ \\
\hline Hemoglobin (mmol/L) & $8.6 \pm 2.1$ \\
\hline \multicolumn{2}{|l|}{ Procedural Parameters } \\
\hline No.of stents implanted & 1669 \\
\hline Minimal stent diameter ( $\mathrm{mm}$ ) & $3.1 \pm 0.8$ \\
\hline Total stent length $(\mathrm{mm})$ & $28.1 \pm 16.8$ \\
\hline Bifurcation lesion & $33 / 1069(3.1 \%)$ \\
\hline Drug eluting stent & $675 / 1063(63.5 \%)$ \\
\hline LAD & $515(48.2 \%)$ \\
\hline
\end{tabular}

$\angle V E F=$ left ventricular ejection fraction; $P P I=$ proton pump inhibitors. $C C B=$ calcium channel blockers; $W B C=$ white bloodcell count, $L A D=$ Left Anterior Descending Artery Definitions: Hypertension: Systolic blood pressure $>140 \mathrm{~mm}$ $\mathrm{Hg}$ or diastolic blood pressure $>90 \mathrm{~mm} \mathrm{Hg}$; Hypercholesterolemia: A fasting LDL-cholesterol $\geq 3.4$ $\mathrm{mmol} / \mathrm{L}$ or being on statin therapy at the time of inclusion; Diabetes mellitus: According to the World Health Organization criteria Family history: One or more firstdegree relatives have developed $C A D$ before the age of 55 years (men) or 65 years (women); Renal insufficiency: Creatin $>120 \mu \mathrm{mol} / \mathrm{L}$ 
with and without ischemic events at 1-year follow-up. On the contrary, neither the IMPACT- $R$ with and without ADP-pre-stimulation, nor the PFA COL/ADP or INNOVANCE ${ }^{\circledR}$ PFA P2Y were able to discriminate between patients with and without post-procedural events. Table $\mathbf{2}$ displays the area under the curve (AUC) and optimal cut-off value for every test. eFigure 1 depicts the optimal cut-off values per test and the percentages of patients exhibiting HPR according to the test. Baseline characteristics for every test, for patients with and without HPR, are depicted in eTablez, showing significant differences between the two groups.

Logistic regression modelling was used to identify independent predictors for the primary endpoint. The model included on-treatment platelet reactivity according to the various tests as a categorical variable (HPR vs patients without HPR using the cut-off defined with the ROC-analysis) and multiple potential confounders. Independent predictors of 1-year primary endpoint were age (calculated for an increase of 10 years (OR $=1.22 ; 95 \%-\mathrm{Cl}$ : 0.97-1.51, $p=0.08)$, hypertension ( $\mathrm{OR}=2.50 ; 95 \%-\mathrm{Cl}$ : 1.30-4.82, $p=0.006)$, hypercholesterolemia (OR =0.57; 95\%-Cl: 0.33-0.98, $p=0.04)$, a left ventricular ejection fraction $<45 \%(\mathrm{OR}=1.83 ; 95 \%-\mathrm{Cl}: 1.07-3.11, p=0.06)$ and a prior CABG $(\mathrm{OR}=1.91 ; 95 \%-\mathrm{Cl}$ : $0.96-3.81, p=0.06)$. Procedural factors independently predicting the primary endpoint were total stent length $(\mathrm{OR}=0.97,95 \%-\mathrm{Cl}: 0.94-1.00, p=0.05)$, number of lesions treated $(\mathrm{OR}=1.92 ; 95 \%-\mathrm{Cl}$ : 1.10-3.39, $p=0.02$ ), number of stents implanted ( $\mathrm{OR}=2.4,95 \%-\mathrm{Cl}: 1.38-4.30, p=0.002)$, LAD-stenting $(\mathrm{OR}=1.79 ; 95 \%-\mathrm{Cl}: 1.11-2.88, p=0.017)$ or graft-stenting $(\mathrm{OR}=2.88 ; 95 \%-\mathrm{Cl}: 1.00-8.32, p=0.049)$, stenting a bifurcation lesion ( $\mathrm{OR}=5.43 ; 95 \%-\mathrm{Cl}: 1.91-15.45, p=0.002)$ and a plavix loading dose $(\mathrm{OR}=1.73,95 \%-\mathrm{Cl}: 2.73-1.09, p=0.02)$. The remaining variables included for multivariate analysis were not found to be independent correlates of the primary endpoint $(p>0.10)$ and were not included in the model.

The addition of HPR to this statistical model revealed that HPR as measured with LTA (both 5 $\mu \mathrm{mol} / \mathrm{L}$ ADP and $20 \mu \mathrm{mol} / \mathrm{L}$ ), the VerifyNow ${ }^{\circledR}-\mathrm{P}_{2} \mathrm{Y}_{12}$-cartridge and the Plateletworks ${ }^{\circledR}$ assay significantly improved the AUC. Likewise, the likelihood-ratio test demonstrated that HPR according to these tests had additional contribution to the model (Table 3 ). The goodness-of-fit test demonstrated that the predicting model was adequate (all $p$-values $>0.10$ ). On the contrary, the AUC did not improve when HPR as measured with IMPACT- $R$ (both with and without ADP prestimulation) or the PFA Test Cartridges (both PFA COL/ADP and INNOVANCE ${ }^{\circledR}$ PFA P 2 Y) was added to the model.

\section{Relationship between high on-treatment platelet reactivity and clinical outcome}

At one-year follow-up, the primary endpoint occurred more frequently in patients with HPR compared to patients without HPR when platelet function was evaluated with LTA (11.7\% vs $6.0 \%, p=0.0009$ using $5 \mu \mathrm{mol} / \mathrm{L}$ ADP and $12.0 \%$ vs $6.2 \%, p=0.001$ using $20 \mu \mathrm{mol} / \mathrm{L}$ ADP respectively), the VerifyNow ${ }^{\circledR}$ $\mathrm{P}_{2} \mathrm{Y}_{12}$ assay $(13.3 \%$ vs $5.7 \%, \mathrm{p}<0.0001)$, the Plateletworks ${ }^{\circledR}$ assay $(12.6 \%$ vs $6.1 \%, p=0.005)$ and the INNOVANCE ${ }^{\circledR}$ PFA $P_{2} Y(12.2 \%$ vs. $6.3 \%, p=0.02)$. One-year follow-up for patients with and without HPR according to each platelet function test is depicted in Table 3.

The survival rate free from the primary endpoint was significantly lower in patients with HPR when measured with LTA $5 \mu \mathrm{mol} / \mathrm{L}$ ADP, LTA $20 \mu \mathrm{mol} /$ L ADP, VerifyNow $^{\circledR}$, Plateletworks ${ }^{\circledR}$ and INNOVANCE ${ }^{\circledR}$ PFA $P_{2} Y$ as compared to patients without HPR, whereas no significant relation was detected when platelet function was assessed by the IMPACT- $R$ (both with and without pre-stimulation) or by the PFA COL/ADP (Figure 1). 
Part II | chapter 7
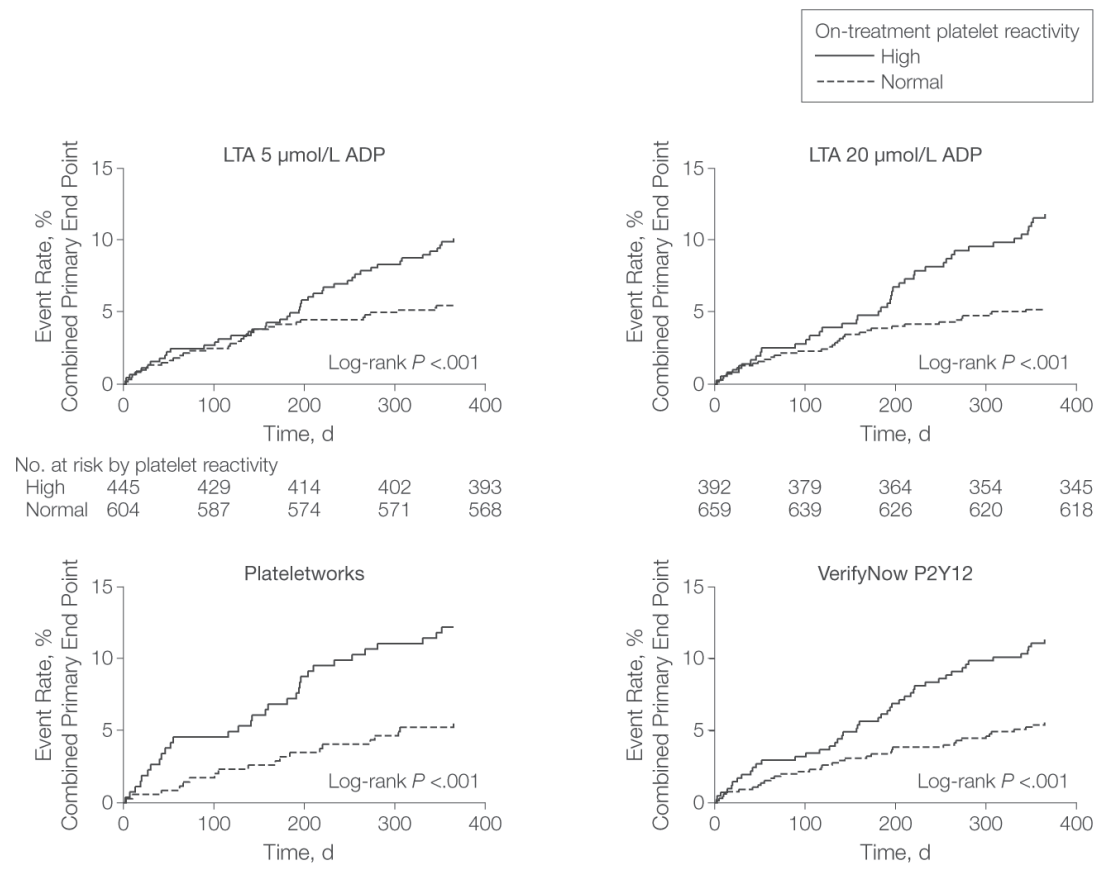

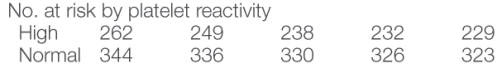
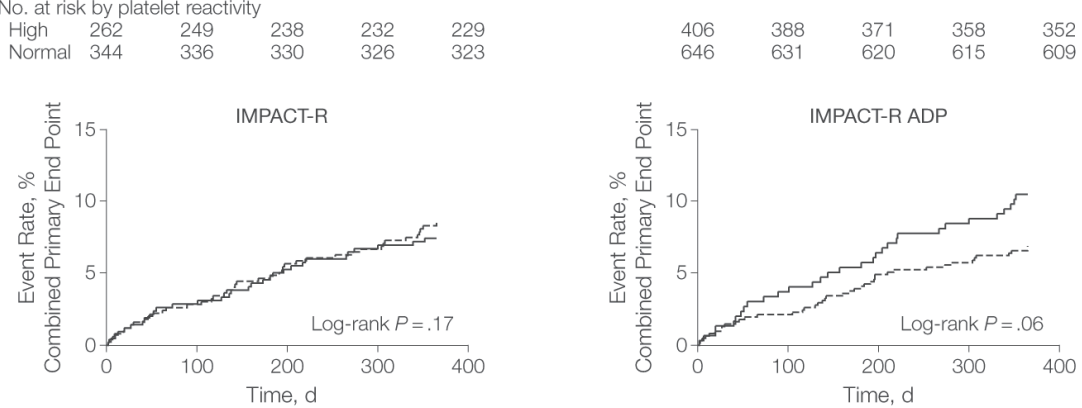

$\begin{array}{llllll}\text { No. at risk by platelet reactivity } & & & \\ \text { High } & 429 & 415 & 402 & 396 & 387 \\ \text { Normal } & 481 & 467 & 455 & 448 & 445\end{array}$
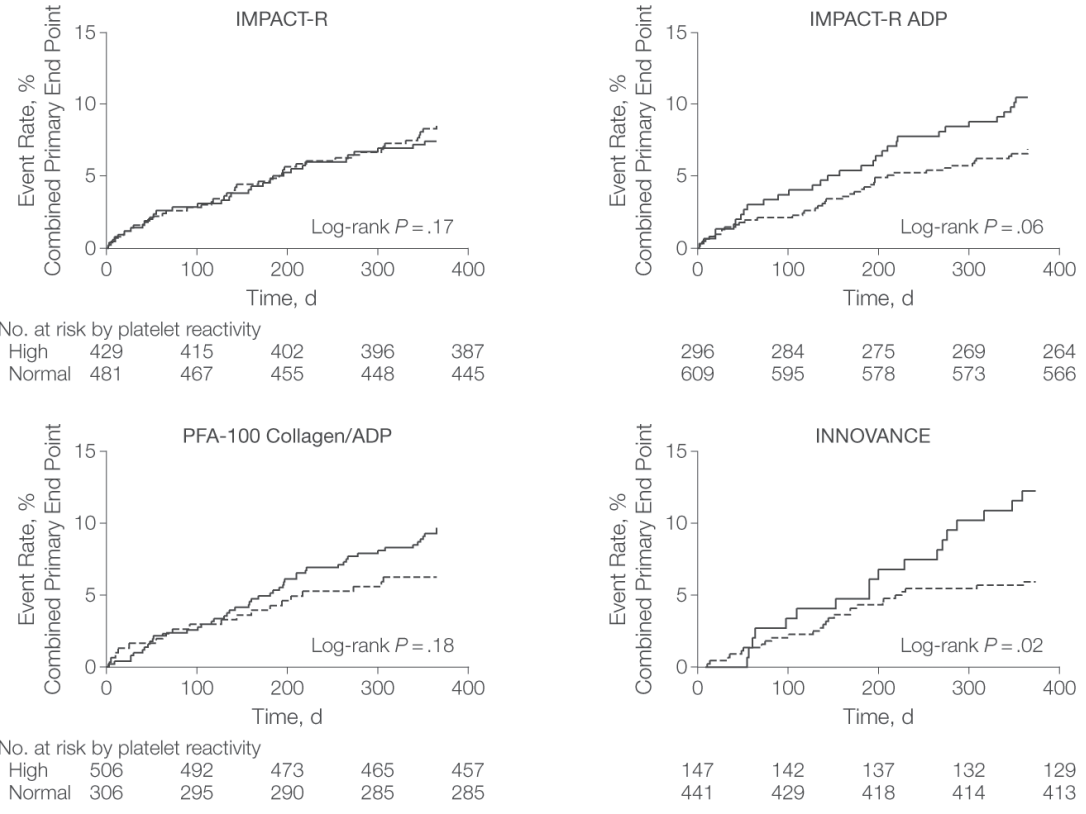

Figure 1 | Kaplan-Meier Analysis

Kaplan Meier analysis for the survival free from the combined primary endpoint in patients with and without HPR as measured by the multiple platelet function assays. HPR = high on-treatment platelet reactivity, NPR = normal on-treatment platelet reactivity 
Platelet function tests and outcomes in patients with coronary stents

Table 2 | Area under the curve

\begin{tabular}{|c|c|c|c|c|c|c|c|c|c|}
\hline & 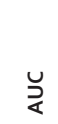 & $\begin{array}{l}\text { चे } \\
\text { े̀े }\end{array}$ & $\begin{array}{l}\text { 先 } \\
\text { பे }\end{array}$ & 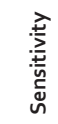 & $\begin{array}{l}\text { তे } \\
\text { ํํ }\end{array}$ & 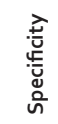 & $\begin{array}{l}\text { ড̄ } \\
\text { ㅇํ }\end{array}$ & 主 & a \\
\hline LTA $5 \mu \mathrm{mol} / \mathrm{L}$ & 0.63 & $0.58-0.68$ & $42.9 \%$ & 60.2 & $49.8-69.8$ & 59.1 & $56.0-62.2$ & $94.0 \%$ & $11.7 \%$ \\
\hline LTA $20 \mu \mathrm{mol} / \mathrm{L}$ & 0.62 & $0.56-0.67$ & $64.5 \%$ & 54.6 & $44.2-64.5$ & 63.9 & $60.8-66.8$ & $93.8 \%$ & $12.0 \%$ \\
\hline VerifyNow $\mathrm{P}_{2} \mathrm{Y}_{12}$ & 0.62 & $0.57-0.67$ & $236 \mathrm{PRU}$ & 60.4 & $50.2-69.9$ & 63.1 & $60.0-66.1$ & $94 \cdot 3 \%$ & $13.3 \%$ \\
\hline Plateletworks & 0.61 & $0.53-0.69$ & $80.5 \%$ & 63.0 & $49 \cdot 6-74.6$ & 58.5 & $54.4-62.6$ & $93.9 \%$ & $12.6 \%$ \\
\hline IMPACT-R spontaneous & 0.56 & $0.50-0.62$ & SC 8.4 & 56.4 & $45 \cdot 4-66.9$ & 52.5 & $49.1-55.9$ & $90.0 \%$ & $7.2 \%$ \\
\hline IMPACT-R ADP stimulated & 0.53 & $0.47-0.59$ & $2.0 \mathrm{SC}$ & 44.0 & $33 \cdot 3-55 \cdot 3$ & 66.9 & $63.6-70.0$ & $93.0 \%$ & $10.7 \%$ \\
\hline PFA-100 COL/ADP & 0.50 & $0.46-0.55$ & 147 seconds & 70.0 & $58 \cdot 5-79 \cdot 5$ & 38.4 & $35 \cdot 0-42.0$ & $93.1 \%$ & $9.7 \%$ \\
\hline INNOVANCE ${ }^{\circledR}$ PFA $P_{2} Y$ & 0.56 & $0.50-0.62$ & 159 seconds & 39.1 & $26.4-53.5$ & 76.2 & $72.4-79.6$ & $93.7 \%$ & $12.2 \%$ \\
\hline
\end{tabular}

AUC of different backward regression models for the prediction of the primary

end point at one-year follow-up

\begin{tabular}{|c|c|c|}
\hline & 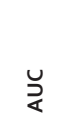 & 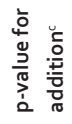 \\
\hline Model 1 : Classic cardiovascular risk factors ${ }^{\mathrm{a}}$ & 0.66 & \\
\hline Model 2: Model 1 + procedural risk factors ${ }^{\mathrm{b}}$ & 0.72 & 0.0001 \\
\hline \multicolumn{3}{|l|}{ Model 3: Model 2 + HPR } \\
\hline - LTA peak $5 \mu \mathrm{mol} / \mathrm{L}$ & 0.73 & 0.004 \\
\hline - LTA peak $20 \mu \mathrm{mol} / \mathrm{L}$ & 0.73 & 0.001 \\
\hline - VerifyNow $\mathrm{P}_{2} \mathrm{Y}_{12}{ }^{\circledR}$ cartridge & 0.74 & 0.0002 \\
\hline - Plateletworks ${ }^{\circledR}$ & 0.77 & 0.001 \\
\hline - IMPACT-R spontaneous & 0.72 & 0.20 \\
\hline - IMPACT-R ADP stimulated & 0.72 & 0.13 \\
\hline - PFA-100 COL/ADP & 0.72 & 0.20 \\
\hline - INNOVANCE® PFA $P_{2} Y$ & 0.73 & 0.07 \\
\hline
\end{tabular}

AUC and optimal cut-off values for each test ; $A U C=$ Area under the curve; $C I=$ confidence interval; $N P V=$ negative predictive valu; $P P V=$ positive predictive value; $L T A=$ light transmittance aggregometry; $P R U=P 2 Y_{12}$ reaction units; $S C=$ surface coverage; HPR = high on-treatment platelet reactivity; AUC of different backward regression models for the prediction of the primary end point at one-year follow-up.

a Age, hypertension, hypercholesterolemia, LVEF (left ventricular ejection fraction) $<45 \%$, prior CABG. ${ }^{b}$ Total stent length, no. of lesions treated, no. of stents implanted, LAD-stenting, graft-stenting, bifurcation lesion, plavix loading dose vs maintenance dose. ' Likelihood Ratio Test for additional value of HPR (increase in AUC) as measured with multiple platelet function tests. 
Part II | chapter 7

Table 3 | Clinical Outcome

\begin{tabular}{|c|c|c|c|c|}
\hline & $\begin{array}{l}5 \mu \mathrm{mol} / \mathrm{L} \text { ADP } \\
\text { NPR }(n=604) \\
<42.9 \% \text { aggregation }\end{array}$ & $\begin{array}{l}\text { HPR }(n=445) \\
>42.9 \% \text { aggregation }\end{array}$ & OR $(95 \mathrm{Cl})$ & $p$-value \\
\hline Death, MI, ST, stroke & $36(6.0 \%)$ & $52(11.7 \%)$ & $2.09(1.34-3.25)$ & 0.0009 \\
\hline Death & $6(1.0 \%)$ & $11(2.5 \%)$ & $2.53(0.93-6.88)$ & 0.06 \\
\hline MI & $24(4.0 \%)$ & $37(8.3 \%)$ & $2.19(1.29-3.72)$ & 0.003 \\
\hline ST & $6(1.0 \%)$ & $7(1.6 \%)$ & $1.59(0.53-4.77)$ & 0.40 \\
\hline Stroke & $7(1.2 \%)$ & $6(1.3 \%)$ & $1.17(0.39-3.49)$ & 0.78 \\
\hline TVR & $18(3.0 \%)$ & $7(1.6 \%)$ & $0.52(0.22-1.26)$ & 0.14 \\
\hline Non-TVR & $21(3.5 \%)$ & $8(1.8 \%)$ & $0.51(0.22-1.16)$ & 0.10 \\
\hline \multirow[t]{2}{*}{ Rehospitalization } & $16(2.6 \%)$ & $11(2.5 \%)$ & $0.93(0.43-2.03)$ & 0.87 \\
\hline & $\begin{array}{l}20 \mu \mathrm{mol} / \mathrm{L} \text { ADP } \\
\text { NPR }(n=659) \\
<64.5 \% \text { aggregation }\end{array}$ & $\begin{array}{l}\text { HPR }(n=392) \\
>64.5 \% \text { aggregation }\end{array}$ & OR $(95 \mathrm{Cl})$ & $p$-value \\
\hline Death, MI, ST, stroke & $41(6.2 \%)$ & $47(12.0 \%)$ & $2.05(1.32-3.19)$ & 0.001 \\
\hline Death & $11(1.7 \%)$ & $6(1.5 \%)$ & $0.92(0.34-2.50)$ & 0.86 \\
\hline MI & $24(3.6 \%)$ & $37(9.4 \%)$ & $2.76(1.62-4.68)$ & 0.0001 \\
\hline ST & $4(0.6 \%)$ & $9(2.3 \%)$ & $3.85(1.18-12.58)$ & 0.017 \\
\hline Stroke & $8(1.2 \%)$ & $5(1.3 \%)$ & $1.05(0.34-3.24)$ & 0.93 \\
\hline TVR & $21(3.2 \%)$ & $4(1.0 \%)$ & $0.31(0.11-0.92)$ & 0.03 \\
\hline Non-TVR & $23(3.5 \%)$ & $6(1.5 \%)$ & $0.43(0.17-1.07)$ & 0.06 \\
\hline \multirow[t]{2}{*}{ Rehospitalization } & $21(3.2 \%)$ & $6(1.5 \%)$ & $0.47(0.19-1.18)$ & 0.10 \\
\hline & $\begin{array}{l}\text { VerifyNow P2Y12 } \\
\text { NPR }(n=646) \\
<236 \text { PRU }\end{array}$ & $\begin{array}{l}\text { HPR }(n=406) \\
>236 \text { PRU }\end{array}$ & OR $(95 \% \mathrm{Cl})$ & $p$-value \\
\hline Death, MI, ST, stroke & $37(5.7 \%)$ & $54(13.3 \%)$ & $2.53(1.63-3.91)$ & $<0.0001$ \\
\hline Death & $9(1.4 \%)$ & $9(2.2 \%)$ & $1.60(0.63-4.08)$ & 0.32 \\
\hline MI & $23(3.6 \%)$ & $40(9.9 \%)$ & $2.96(1.74-5.02)$ & $<0.0001$ \\
\hline ST & $5(0.8 \%)$ & $8(2.0 \%)$ & $2.58(0.84-7.93)$ & 0.09 \\
\hline Stroke & $6(0.9 \%)$ & $7(1.7 \%)$ & $1.87(0.62-5.61)$ & 0.26 \\
\hline TVR & $16(2.5 \%)$ & $9(2.2 \%)$ & $0.89(0.39-2.04)$ & 0.79 \\
\hline Non-TVR & $20(3.1 \%)$ & $9(2.2 \%)$ & $0.71(0.32-1.57)$ & 0.40 \\
\hline \multirow[t]{2}{*}{ Rehospitalization } & $18(2.8 \%)$ & $8(2.0 \%)$ & $0.70(0.30-1.63)$ & 0.41 \\
\hline & $\begin{array}{l}\text { Plateletworks }{ }^{\circledR} \\
\text { NPR }(n=344) \\
<80.5 \% \text { aggregation }\end{array}$ & $\begin{array}{l}\text { HPR }(n=262) \\
>80.5 \% \text { aggregation }\end{array}$ & OR $(95 \% \mathrm{Cl})$ & $p$-value \\
\hline Death, MI, ST, stroke & $21(6.1 \%)$ & $33(12.6 \%)$ & $2.22(1.25-3.93)$ & 0.005 \\
\hline Death & $9(2.6 \%)$ & $4(1.5 \%)$ & $0.58(0.18-1.89)$ & 0.36 \\
\hline MI & $10(2.9 \%)$ & $25(9.5 \%)$ & $3.52(1.66-7.47)$ & 0.0005 \\
\hline ST & $3(0.9 \%)$ & $6(2.3 \%)$ & $2.66(0.66-10.75)$ & 0.15 \\
\hline Stroke & $3(0.9 \%)$ & $4(1.5 \%)$ & $1.76(0.39-7.94)$ & 0.45 \\
\hline TVR & $12(3.5 \%)$ & $5(1.9 \%)$ & $0.54(0.19-1.55)$ & 0.24 \\
\hline Non-TVR & $11(3.2 \%)$ & $7(2.7 \%)$ & $0.83(0.32-2.17)$ & 0.71 \\
\hline Rehospitalization & $10(2.9 \%)$ & $7(2.7 \%)$ & $0.92(0.34-2.44)$ & 0.86 \\
\hline
\end{tabular}




\begin{tabular}{|c|c|c|c|c|}
\hline & IMPACT-R & & & \\
\hline & NPR $(n=481)$ & $\operatorname{HPR}(n=429)$ & & \\
\hline & $\mathrm{SC}<8.4$ & $S C>8.4$ & OR $(95 \% \mathrm{Cl})$ & $p$-value \\
\hline Death, MI, ST, stroke & $36(7.5 \%)$ & $42(9.8 \%)$ & $1.34(0.84-2.14)$ & 0.21 \\
\hline Death & $5(1.0 \%)$ & $11(2.6 \%)$ & $2.51(0.86-7.27)$ & 0.08 \\
\hline MI & $28(5.8 \%)$ & $25(5.8 \%)$ & $1.00(0.57-1.75)$ & 0.99 \\
\hline ST & $5(1.0 \%)$ & $6(1.4 \%)$ & $1.35(0.41-4.46)$ & 0.62 \\
\hline Stroke & $4(0.8 \%)$ & $7(1.6 \%)$ & $1.98(0.58-6.8)$ & 0.27 \\
\hline TVR & $15(3.1 \%)$ & $6(1.4 \%)$ & $0.44(0.17-1.15)$ & 0.08 \\
\hline Non-TVR & $15(3.1 \%)$ & $9(2.1 \%)$ & $0.67(0.29-1.54)$ & 0.33 \\
\hline \multirow[t]{4}{*}{ Rehospitalization } & $12(2.5 \%)$ & $12(2.8 \%)$ & $1.12(0.5-2.53)$ & 0.78 \\
\hline & IMPACT-R ADP & & & \\
\hline & NPR $(n=609)$ & HPR $(n=296)$ & & \\
\hline & $S C>2.0$ & $S C \leq 2.0$ & OR $(95 \% \mathrm{Cl})$ & $p$-value \\
\hline Death, MI, ST, stroke & $43(7.1 \%)$ & $32(10.8 \%)$ & $1.60(0.99-2.58)$ & 0.05 \\
\hline Death & $9(1.5 \%)$ & $6(2.0 \%)$ & $1.38(0.49-3.91)$ & 0.54 \\
\hline MI & $29(4.8 \%)$ & $22(7.4 \%)$ & $1.61(0.91-2.85)$ & 0.10 \\
\hline ST & $7(1.1 \%)$ & $3(1.0 \%)$ & $0.88(0.23-3.43)$ & 0.85 \\
\hline Stroke & $7(1.1 \%)$ & $4(1.4 \%)$ & $1.18(0.34-4.06)$ & 0.79 \\
\hline TVR & $12(2.0 \%)$ & $9(3.0 \%)$ & $1.56(0.65-3.75)$ & 0.32 \\
\hline Non-TVR & $15(2.5 \%)$ & $9(3.0 \%)$ & $1.24(0.54-2.87)$ & 0.61 \\
\hline \multirow[t]{4}{*}{ Rehospitalization } & $17(2.8 \%)$ & $7(2.4 \%)$ & $0.84(0.35-2.06)$ & 0.71 \\
\hline & PFA 100 COL/ADP & & & \\
\hline & NPR $(n=306)$ & $\operatorname{HPR}(n=506)$ & & \\
\hline & $C T>147$ & $C T \leq 147$ & OR $(95 \% \mathrm{Cl})$ & $p$-value \\
\hline Death, MI, ST, stroke & $21 / 306(6.9 \%)$ & $49 / 506(9.7 \%)$ & $1.46(0.85-2.48)$ & 0.17 \\
\hline Death & $5 / 306(1.6 \%)$ & $10 / 506(2.0 \%)$ & $1.21(0.41-3.58)$ & 0.73 \\
\hline MI & $16 / 306(5.2 \%)$ & $4 / 506(6.7 \%)$ & $1.31(0.71-2.41)$ & 0.39 \\
\hline ST & 4/306 (1.3\%) & $5 / 506(1.0 \%)$ & $0.75(0.20-2.83)$ & 0.67 \\
\hline Stroke & $1 / 306(0.3 \%)$ & $7 / 506(1.4 \%)$ & $4.28(0.52-34.90)$ & 0.14 \\
\hline TVR & $11 / 306(3.6 \%)$ & $9 / 506(1.8 \%)$ & $0.49(0.20-1.19)$ & 0.11 \\
\hline Non-TVR & $11 / 306(3.6 \%)$ & $12 / 506(2.4 \%)$ & $0.65(0.28-1.50)$ & 0.31 \\
\hline \multirow[t]{4}{*}{ Rehospitalization } & $9 / 306(2.9 \%)$ & $7 / 506(1.4 \%)$ & $0.46(0.17-1.26)$ & 0.12 \\
\hline & INNOVANCE ${ }^{\circledR}$ PFA $\mathrm{P}_{2} \mathrm{Y}$ & & & \\
\hline & NPR $(n=441)$ & HPR $(n=147)$ & & \\
\hline & $C T>159$ & $C T \leq 159$ & OR $(95 \% \mathrm{Cl})$ & $p$-value \\
\hline Death, MI, ST, stroke & $28 / 441(6.3 \%)$ & $18 / 147(12.2 \%)$ & $2.06(1.10-3.84)$ & 0.02 \\
\hline Death & $4 / 441(0.9 \%)$ & $6 / 147(4.1 \%)$ & $4.65(1.29-16.70)$ & 0.01 \\
\hline $\mathrm{MI}$ & $20 / 441(4.5 \%)$ & $11 / 147(7.5 \%)$ & $1.70(0.80-3.64)$ & 0.17 \\
\hline ST & 4/441 (0.9\%) & $1 / 147(0.7 \%)$ & $0.75(0.08-6.75)$ & 0.80 \\
\hline Stroke & $5 / 441(1.1 \%)$ & $1 / 147(0.7 \%)$ & $0.60(0.07-5.15)$ & 0.65 \\
\hline TVR & $16 / 441(3.6 \%)$ & $1 / 147(0.7 \%)$ & $0.18(0.02-1.38)$ & 0.06 \\
\hline Non-TVR & $14 / 441(3.2 \%)$ & $1 / 147(0.7 \%)$ & $0.21(0.03-1.60)$ & 0.10 \\
\hline Rehospitalization & $12 / 441(2.7 \%)$ & $1 / 147(0.7 \%)$ & $0.24(0.03-1.90)$ & 0.15 \\
\hline
\end{tabular}


Part II | chapter 7
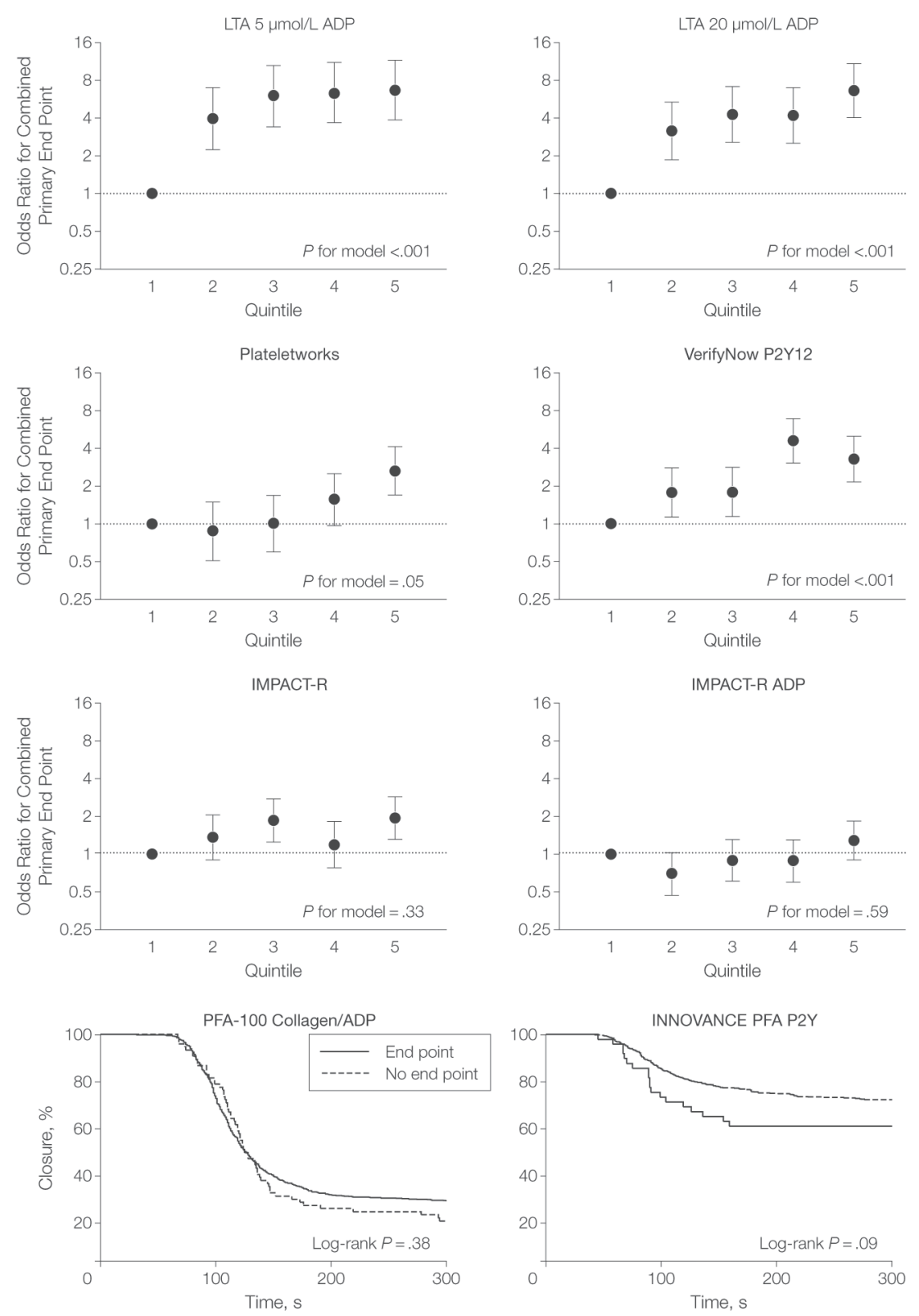

Figure $\mathbf{2} \mid$ Odds Ratios for the primary endpoint

Odds Ratios for the combined primary endpoint by quintiles of on-treatment platelet reactivity according to the multiple platelet function assays. Incidences (\%) of the combined primary endpoint are depicted in the bars. Cumulative Kaplan Meier time-to-aperture-closure plot in patients with and without the combined primary endpoint according to the $P F A-100^{\circledR}$ System. $Q=$ quintile HPR = high on-treatment platelet reactivity, $N P R=$ normal on-treatment platelet reactivity 
The occurrence of the primary end point was also compared when groups were divided in quintiles according to on-treatment platelet reactivity (Figure 2). Patients in the higher quintiles according to the LTA $5 \mu \mathrm{mol} / \mathrm{L} A D P$ and $20 \mu \mathrm{mol} / L$ ADP and the VerifyNow ${ }^{\circledR} \mathrm{P}_{2} \mathrm{Y}_{12}$ assay were at significantly higher risk for the primary end point. In contrast, no significant difference in the occurrence of the primary endpoint was observed between quintiles as measured with the IMPACT- $R$ tests and Plateletworks ${ }^{\circledR}$. Since the PFA-100 ${ }^{\circledR}$ System confines detection of a closure time to a $300-5$ window, the results of both PFA-cartridges are depicted as time to aperture closure Kaplan-Meier curves. Closure times as measured by the PFA COL/ADP were not significantly different between patients with and without a primary endpoint.

\section{Relationship between platelet reactivity and bleeding}

A second ROC-analysis demonstrated that none of the performed tests was able to discriminate between patients with and without bleeding (all AUC's included 0.50 in the confidence interval $[\mathrm{Cl}])$ ). Stratification by quintiles based on on-treatment platelet reactivity demonstrated no significant difference in the occurrence of bleeding between the quintiles (eFigure 2). In addition, no significant increase in bleeding was observed in the lowest quintile of patients compared to quintiles 2 to 5 . A third ROC-analysis further demonstrated that the platelet function tests were not able to predict post-discharge (>48 hrs) minor or major bleedings (all AUC's included 0.50 in the confidence interval $[\mathrm{Cl}]$ ).

\section{DISCUSSION}

The POPular-study is a prospective study evaluating the capability of multiple platelet function to predict clinical outcome in clopidogrel-treated patients undergoing elective $\mathrm{PCl}$ with stent implantation.

High on-treatment platelet reactivity when assessed by LTA (both $5 \mu \mathrm{mol} / \mathrm{L}$ and $20 \mu \mathrm{mol} / \mathrm{L}$ ADP) and the VerifyNow ${ }^{\circledR} \mathrm{P}_{2} \mathrm{Y}_{12}$ assay, the Plateletworks ${ }^{\circledR}$ and INNOVANCE ${ }^{\circledR} \mathrm{PFA} \mathrm{P}_{2} \mathrm{Y}$ is significantly associated with atherothrombotic events. In contrast, the shear stress based tests IMPACT- $R$ (both with and without ADP pre-stimulation) and the Dade ${ }^{\circledR}$ PFA-100 COL/ADP-cartridge did not show an association with outcome.

The 'gold standard' LTA has been the most widely used technique and has clearly demonstrated the relationship between high-on treatment platelet reactivity and subsequent atherothrombotic events..$^{4 \cdot 6}$ The POPular-study found an optimal diagnostic cut-off level discriminating patients with atherothrombotic events from those who were uneventful similar to that found by Gurbel et al. However, LTA is not suitable for routine use in clinical practice due to the poor reproducibility, the long sample processing time and the need for specialized technicians. Therefore, several new more easy to use platelet function tests have been introduced. The POPular-study reveals that the VerifyNow ${ }^{\circledR}$ $\mathrm{P}_{2} \mathrm{Y}_{12}$ cartridge is capable of identifying patients who are at risk for atherothrombotic events post- $\mathrm{PCl}$. Our optimal diagnostic cut-off value of $236 \mathrm{PRU}$ is perfectly consistent with that reported in previous reports. ${ }^{7,8,20}$ The POPular-study is the largest study to demonstrate a relation between the Plateletworks ${ }^{\circledR}$ ADP assay and clinical outcome and the first to establish an optimal cut-off value. The results seem promising with the largest increase in predictive value of all tests performed in the POPular-study. However, rapid performance (within 10 minutes after blood withdrawal) of this assay 
Part II | chapter 7

is required, since the ADP-induced platelet aggregates disaggregate after this time-point, resulting in a unreliable test result as descibed in the Online Supplement.16 Therefore, the use of the Plateletworks ${ }^{\circledR}$ in routine clinical practice might be limited.

The POPular-study also reports performance data of the prototype INNOVANCE ${ }^{\circledR}$ PFA $P_{2} Y$, which in its final design became available halfway through the inclusion-period. A lower incidence of the primary endpoint in patients without high on-treatment platelet reactivity was demonstrated. However, high on-treatment platelet reactivity as measured with INNOVANCE ${ }^{\circledR}$ PFA $P_{2} Y$ did not improve the predictability of the risk-model.

In the light of the POPular data, should high on-treatment platelet reactivity be used as a prognostic marker in clinical practice? Despite growing evidence that high on-treatment platelet reactivity is associated with adverse clinical outcome, platelet function testing is not widely implemented in clinical practice due to a lack of consensus on the optimal method and on the optimal cut-off values of the different tests to identify patients at higher risk. The POPular-study provides additional evidence including optimal cut-off values - that three tests might be used (LTA, VerifyNow ${ }^{\circledR}$ and Plateletworks $\left.{ }^{\circledR}\right)$. Although the sample size has insufficient statistical power, the novel INNOVANCE ${ }^{\circledR}$ PFA $P_{2} Y$ seems promising for this purpose as well. However, also other risk factors such as diabetes mellitus and poor left ventricular function have been demonstrated to predict atherothrombotic events post-stent implantation. ${ }^{21,22,23,24}$ Furthermore, these same risk factors have been shown to be associated with high on-treatment platelet reactivity ${ }^{25,26}$ and thus, high on-treatment platelet reactivity is probably a composite of several of these risk factors as well as the response to antiplatelet therapy.

In the POPular-study high on-treatment platelet reactivity indeed added to the overall risk-model. The modest contribution of high on-treatment platelet reactivity in the POPular-study might be attributed to its relatively low risk population, excluding higher-risk patients (in particular ST-elevation myocardial infarction). The greater importance of high on-treatment platelet reactivity in patients at higher risk, has been demonstrated by Sibbing and colleagues and Marcucci and colleagues.7,9

Despite numerous data on the association between high on-treatment platelet reactivity and adverse outcome there is only preliminary data concerning the benefit of tailoring therapy based on the results of platelet function testing. ${ }^{27}$ Therefore, the correct treatment-if any-of high on-treatment platelet reactivity remains unknown and we have to await currently ongoing clinical trials; the GRAVITAS (NCToo645918), the DANTE (NCTo0774475), the ARCTIC (NCTo0827411) - randomizing patients to higher clopidogrel doses versus routine doses based on platelet function testing as well as the TRIGGER$\mathrm{PCl}$ (NCTo0910299) randomizing to prasugrel versus clopidogrel - which will reveal whether individualized antiplatelet treatment based on platelet function testing improves outcome. Until than clinical practice should not be guided by (point-of-care) platelet function testing.

Some issues merit careful consideration. First, the sample size of INNOVANCE ${ }^{\circledR}$ PFA $P_{2} Y$ was too small to have sufficient statistical power to detect the relationship between high on-treatment platelet reactivity and clinical outcome. Second, not all currently available platelet function tests were included. Additional tests include the Multiplate, the thromboelastograph and the Flowcytometric VasodilatorStimulated Phosphoprotein (VASP)-analysis. However, at the start of our inclusion the Multiplate and the platelet assay for the thromboelastograph were not available. Furthermore, the published results with the VASP-assay were mainly preliminary and did not provide a solid base for choosing VASP as one of the platelet function tests. Third, patients received three different, but adequate, clopidogrel dosing strategies. Previous studies have demonstrated differences in the effect on platelet reactivity of these three dosing regimes. However, these three regimens are current clinical practice, and the 
POPular-study therefore reflects the clinical relevance of monitoring platelet function in daily practice.

In conclusion, of the platelet function tests assessed, only LTA, VerifyNow ${ }^{\circledR}$, Plateletworks $^{\circledR}$ and INNOVANCE ${ }^{\circledR}$ PFA $P_{2} Y$ were significantly associated with the primary endpoint. However, the predictability of these four tests was only modest. None of the tests provided accurate prognostic information to identify patient at higher risk of bleeding. Thus, the POPular-study does not support the use of platelet function testing to guide clinical practice in a low-risk population of patients undergoing elective $\mathrm{PCl}$.

\section{Acknowledgments}

We thank the independent committee that adjudicated all events: B.M. Swinkels, W.Dewilde and F.W.A. Verheugt.

\section{Role of the sponsor}

Siemens Healthcare Diagnostics was not involved in the design and conduct of the study; collection, management, analysis, and interpretation of the data; or in the preparation, review, or approval of the manuscript.

\section{SUPPLEMENTARY ONLINE CONTENT}

\section{Platelet Function Tests}

\section{Light Transmittance Aggregometry}

LTA was quantified in non-adjusted platelet-rich plasma on a four-channel APACT 4004 aggregometer (LABiTec, Arensburg, Germany). Platelet-poor-plasma was set as $100 \%$ aggregation and maximal (peak) platelet aggregation (\%) induced by ADP in final concentrations of 5 and $20 \mu \mathrm{mol} / \mathrm{L}$ was measured.

The VerifyNow ${ }^{\circledR} P_{2} Y_{12}$ assay

The VerifyNow ${ }^{\circledR}$ system (Accumetrics, San Diego, USA) is a whole blood cartridge-based method to determine the magnitude of ADP-induced platelet agglutination (using $20 \mu \mathrm{mol} / \mathrm{L}$ ADP to induce platelet activation and $22 \mathrm{nmol} / \mathrm{L}$ prostaglandin $\mathrm{E}_{1}$ to decrease the contribution of $\mathrm{P}_{2} \mathrm{Y}_{1}$ receptor stimulation by ADP to platelet aggregation. ${ }^{14,15}$

Given the fact that the majority of the studies linking the magnitude of platelet reactivity to the occurrence of atherothrombotic events have used absolute post-clopidogrel platelet reactivity, we preferred using the $\mathrm{P}_{2} \mathrm{Y}_{12}$ Reaction Units (PRUs) over the BASE values or \% inhibition values, which are also reported by the instrument.

\section{The Plateletworks ${ }^{\circledR}$ assay}

The Plateletsworks ${ }^{\circledR}$ assay (Helena Laboratories, Beaumont, Texas) is based on single platelet disappearance. Whole blood samples were collected in tubes containing $\mathrm{K}_{3}$-EDTA and tubes containing PPACK with $20 \mu \mathrm{mol} / \mathrm{L}$ ADP. A routine platelet count was performed on each sample. The platelet count in the $\mathrm{K}_{3}$-EDTA tube was used as reference. As the aggregated platelets exceed the threshold limitations for platelet size ( $<30 \mathrm{fL}$ ) after stimulation with ADP, they are no longer counted as individual 
Part II | chapter 7

platelets. The ratio between the aggregated platelets in the agonist sample and the platelet count in the reference tube $\times 100 \%$ is used as the degree of platelet aggregation. We recently demonstrated that the Plateletworks ${ }^{\circledR}$ assay is highly time-dependent. ${ }^{16}$ Therefore, a cell counter was placed in the catheterization laboratory for rapid measurements between 5 and 10 minutes after blood collection.

\section{The IMPACT- $R$ device}

The IMPACT- $R$ device (DiaMed, Cresier, Switzerland) is based on the cone and plate(let) analyzer technology. ${ }^{17}$ Citrated whole blood samples $(130 \mu \mathrm{L})$ were placed in a polystyrene well and subjected to a shear rate of $18005^{-1}$ for 2 minutes using a Teflon Cone. When shear stress is applied, von Willebrand Factor and fibrinogen are instantly immobilized on the polystyrene surface, serving as a substrate for platelet adhesion and subsequent aggregation. The wells were washed and stained with May-Grunwald stain and analyzed with an inverted light microscope connected to an image analysis system. Platelet adhesion and aggregation on the surface were evaluated by examining the percentage of total area covered with platelets designated as surface coverage (SC).

In addition, the IMPACT- $R$ ADP was used. ${ }^{17}$ With this modified protocol, whole blood samples were pre-stimulated with a sub maximal concentration ADP $(1.38 \mu \mathrm{M})$, gently mixed (10 RPM) for 1 minute and then subjected to the IMPACT- $R$ well under defined shear conditions. Exposure to ADP leads to the formation of microaggregates in patients in whom clopidogrel does not effectively inhibit platelet function. These microaggregated platelets temporarily lose their adhesive properties. The percentage $\mathrm{SC}$ in the ADP pre-stimulated aliquots is therefore inversely correlated with the magnitude of ADPinduced platelet activation.

PFA-100 ${ }^{\circledR}$ System

The PFA-100 ${ }^{\circledR}$ System (Siemens Healthcare Diagnostics Products $\mathrm{GmbH}$, Germany), measures platelet function, in particular adhesion and aggregation, in whole blood under high shear conditions $\left(500 \mathrm{~s}^{-1}\right)$. The time needed to form a platelet plug occluding the aperture cut into a collagen/ADP (COL/ADP)coated membrane was determined and reported as closure time (CT) in seconds. Furthermore, halfway through the POPular-study a novel PFA-100 ${ }^{\circledR}$ test cartridge became available, the final prototype of INNOVANCE ${ }^{\circledR}$ PFA $P_{2} Y$ (For investigational use only. The performance characteristics of this product have not been established.). The novel test cartridge intents to measure the effect of clopidogrel on platelet function irrespective of the concentration of buffered sodium citrate used for anticoagulation or concurrent therapy with aspirin. Its membrane is coated with $20 \mu \mathrm{g} \mathrm{ADP}, 5 \mathrm{ng}$ prostaglandin $\mathrm{E} 1$ and $125 \mathrm{\mu g}$ calcium (as calcium chloride) and the closure time inversely reflects the magnitude of platelet reactivity. ${ }^{18}$ 
Platelet function tests and outcomes in patients with coronary stents

eTable 1 | Baseline characteristics of the subpopulations according to the available platelet function measurements

\begin{tabular}{|c|c|c|c|c|}
\hline & $\begin{array}{l}\text { LTA } 5 \mu \mathrm{mol} / \mathrm{L} \text { ADP } \\
\mathrm{n}=1049\end{array}$ & $\begin{array}{l}\text { LTA } 20 \mu \mathrm{mol} / \mathrm{L} \text { ADP } \\
\mathrm{n}=1051\end{array}$ & $\begin{array}{l}\text { VerifyNow } P_{2} Y_{12} \\
n=1052\end{array}$ & $\begin{array}{l}\text { Plateletworks } \\
n=606\end{array}$ \\
\hline \multicolumn{5}{|l|}{ Clinical parameters } \\
\hline Age (yrs) & $64 \pm 10.6$ & $64 \pm 10.6$ & $64 \pm 10.6$ & $64 \pm 10.6$ \\
\hline $\mathrm{BMI}\left(\mathrm{kg} / \mathrm{m}^{2}\right)$ & $27.2 \pm 4.0$ & $27.2 \pm 4.0$ & $27.2 \pm 4.0$ & $27.2 \pm 3.8$ \\
\hline Gender (m/f) & $784 / 265$ & $786 / 265$ & $790 / 262$ & $458 / 148$ \\
\hline Hypertension & $810 / 1049(77.2 \%)$ & $812 / 1051(77.3 \%)$ & $812 / 1052(77.2 \%)$ & $461 / 606(76.1 \%)$ \\
\hline Hypercholesterolemia & $841 / 1049(80.2 \%)$ & $843 / 1051(80.2 \%)$ & $843 / 1052(80.1 \%)$ & $479 / 606(79.0 \%)$ \\
\hline Diabetes Mellitus & $194 / 1049(18.5 \%)$ & $195 / 1051(18.6 \%)$ & $194 / 1052(18.4 \%)$ & $109 / 606(18.0 \%)$ \\
\hline Family History & $637 / 1049(60.7 \%)$ & $638 / 1051(60.7 \%)$ & $634 / 1052(60.3 \%)$ & $365 / 606(60.2 \%)$ \\
\hline Current smoking & $115 / 1049(11.0 \%)$ & $116 / 1051(11.0 \%)$ & $116 / 1052(11.0 \%)$ & $60 / 606(9.9 \%)$ \\
\hline LVEF $<45 \%$ & $161 / 1049(15 \cdot 3 \%)$ & $160 / 1051(15.2 \%)$ & $163 / 1052(15.5 \%)$ & $96 / 606(15.8 \%)$ \\
\hline Renal insufficiency & $85 / 1049(8.1 \%)$ & $85 / 1051(8.1 \%)$ & $82 / 1052(7.8 \%)$ & $46 / 606(7.6 \%)$ \\
\hline Prior myocardial infarction & $576 / 1049(54.9 \%)$ & $577 / 1051(54.9 \%)$ & $573 / 1052(54.5 \%)$ & $320 / 606(52.8 \%)$ \\
\hline Prior $\mathrm{PCl}$ & $341 / 1049(32.5 \%)$ & $340 / 1051(32.4 \%)$ & $340 / 1052(32.3 \%)$ & $204 / 606(33.7 \%)$ \\
\hline Prior CABG & $110 / 1049(10.5 \%)$ & $111 / 1051(10.6 \%)$ & $107 / 1052(10.2 \%)$ & $67 / 606(11.1 \%)$ \\
\hline \multicolumn{5}{|l|}{ Medication } \\
\hline Aspirin & $936 / 1048(89.2 \%)$ & $938 / 1050(89.2 \%)$ & $940 / 1051(89.4 \%)$ & $544 / 605(89.8 \%)$ \\
\hline Loading dose clopidogrel & $533 / 1048(50.9 \%)$ & $534 / 1050(50.9 \%)$ & $536 / 1051(51.0 \%)$ & $305 / 605(50.4 \%)$ \\
\hline Statin & $833 / 1048(79.5 \%)$ & $834 / 1050(79.4 \%)$ & $834 / 1051(79.4 \%)$ & $467 / 605(77.2 \%)$ \\
\hline Beta-blocker & $799 / 1048(76.2 \%)$ & $800 / 1050(76.2 \%)$ & $802 / 1051(76.3 \%)$ & $463 / 605(76.5 \%)$ \\
\hline ACE-inhibitor & $392 / 1048(37.4 \%)$ & $392 / 1050(37.3 \%)$ & $391 / 1051(37.2 \%)$ & $220 / 605(36.4 \%)$ \\
\hline PPI & $296 / 1048(28.2 \%)$ & $296 / 1050(28.2 \%)$ & $295 / 1051(28.1 \%)$ & $159 / 605(26.3 \%)$ \\
\hline $\mathrm{CCB}$ & $394 / 1048(37.6 \%)$ & $394 / 1050(37.5 \%)$ & $397 / 1051(37.8 \%)$ & $245 / 605(40.5 \%)$ \\
\hline Oral antidiabetics & $70 / 1048(6.6 \%)$ & $71 / 1050(6.8 \%)$ & $69 / 1051(6.6 \%)$ & 40/605 (6.6\%) \\
\hline Coumadins & $108 / 1048(10.3 \%)$ & $108 / 1050(10.3 \%)$ & $106 / 1051(10.1 \%)$ & $48 / 605(7.9 \%)$ \\
\hline \multicolumn{5}{|l|}{ Laboratory Parameters } \\
\hline Platelet count $\left(\mathrm{x}_{10} 0^{9}\right)$ & $271.1 \pm 79.3$ & $271.1 \pm 79.3$ & $271.8 \pm 81.7$ & $274.5 \pm 82.7$ \\
\hline WBC $\left.\left(x_{10}\right)^{9}\right)$ & $7.9 \pm 8.5$ & $7.9 \pm 8.5$ & $7.9 \pm 8.5$ & $8.1 \pm 10.6$ \\
\hline Hemoglobin (mmol/L) & $8.6 \pm 2.1$ & $8.6 \pm 2.1$ & $8.6 \pm 2.1$ & $8.7 \pm 2.6$ \\
\hline \multicolumn{5}{|l|}{ Procedural Parameters } \\
\hline No.of stents implanted & 1635 & 1656 & 1646 & 936 \\
\hline No.of lesions treated & 1448 & 1452 & 1454 & 833 \\
\hline Minimal Stent diameter ( $\mathrm{mm})$ & $3.1 \pm 0.8$ & $3.1 \pm 0.8$ & $3.1 \pm 0.8$ & $3.1 \pm 0.5$ \\
\hline Total Stent length (mm) & $28.1 \pm 16.9$ & $28.2 \pm 16.9$ & $28.1 \pm 16.8$ & $28.2 \pm 16.5$ \\
\hline Bifurcation lesion & $31 / 1049(3.0 \%)$ & $32 / 1050(3.0 \%)$ & $33 / / 1052(3.1 \%)$ & $15 / 606(2.5 \%)$ \\
\hline Drug eluting stent & $594 / 1043(57.0 \%)$ & $596 / 1045(57.0 \%)$ & $598 / 1047(57.1 \%)$ & $358 / 602(59.5 \%)$ \\
\hline LAD & $506 / 1049(48.2 \%)$ & $505 / 1050(48.0 \%)$ & $514 / 1052(48.9 \%)$ & $300 / 606(49.5 \%)$ \\
\hline Graft & $33 / 1049(3.1 \%)$ & $33 / 1050(3.1 \%)$ & $31 / 1052(2.9 \%)$ & $16 / 606(2.6 \%)$ \\
\hline \multicolumn{5}{|l|}{ Events } \\
\hline Death, MI, ST, stroke & $88 / 1049(8.4 \%)$ & $88 / 1051(8.4 \%)$ & $91 / 1052(8.7 \%)$ & $54 / 606(8.9 \%)$ \\
\hline Death & $17 / 1049(1.6 \%)$ & $17 / 1051(1.6 \%)$ & $18 / 1052(1.7 \%)$ & $13 / 606(2.1 \%)$ \\
\hline MI & $61 / 1049(5.8 \%)$ & $61 / 1051(5.8 \%)$ & $63 / 1052(6.0 \%)$ & $35 / 606(5.7 \%)$ \\
\hline ST & $13 / 1049(1.2 \%)$ & $13 / 1051(1.2 \%)$ & $13 / 1052(1.2 \%)$ & $9 / 606(1.2 \%)$ \\
\hline Stroke & $13 / 1049(1.2 \%)$ & $13 / 1051(1.2 \%)$ & $13 / 1052(1.2 \%)$ & $7 / 606(1.2 \%)$ \\
\hline TVR & $25 / 1049(2.4 \%)$ & $25 / 1051(2.4 \%)$ & $25 / 1052(2.4 \%)$ & $17 / 606(2.8 \%)$ \\
\hline Non-TVR & $29 / 1049(2.8 \%)$ & $29 / 1051(2.8 \%)$ & $29 / 1052(2.8 \%)$ & $18 / 606(3.0 \%)$ \\
\hline Rehospitalization & $27 / 1049(2.6 \%)$ & $27 / 1051(2.6 \%)$ & $26 / 1052(2.5 \%)$ & $17 / 606(2.8 \%)$ \\
\hline
\end{tabular}


Part II | chapter 7

\begin{tabular}{|c|c|c|c|c|}
\hline & $\begin{array}{l}\text { IMPACT- } R \\
\mathrm{n}=910\end{array}$ & $\begin{array}{l}\text { IMPACT- } R \text { ADP } \\
\mathrm{n}=905\end{array}$ & $\begin{array}{l}\text { PFA-100 COL/ADP } \\
n=812\end{array}$ & $\begin{array}{l}\text { INNOVANCE }{ }^{\circledR} \text { PFA P2Y } \\
n=588\end{array}$ \\
\hline \multicolumn{5}{|l|}{ Clinical parameters } \\
\hline Age (yrs) & $64 \pm 10.7$ & $64 \pm 10.7$ & $64 \pm 10.5$ & $65 \pm 10.7$ \\
\hline BMI $\left(\mathrm{kg} / \mathrm{m}^{2}\right)$ & $27.3 \pm 4.1$ & $27.3 \pm 4.1$ & $27.2 \pm 4.1$ & $27.2 \pm 4.3$ \\
\hline Gender (m/f) & $683 / 227$ & $680 / 225$ & $597 / 215$ & $424 / 164$ \\
\hline Hypertension & $708 / 910(77.8 \%)$ & $704 / 905(77.8 \%)$ & $620 / 812(76.4 \%)$ & $436 / 588(74.1 \%)$ \\
\hline Hypercholesterolemia & $732 / 910(80.4 \%)$ & $724 / 905(80.4 \%)$ & $652 / 812(80.3 \%)$ & $464 / 588(78.9 \%)$ \\
\hline Diabetes Mellitus & $166 / 910(18.2 \%)$ & $165 / 905(18.2 \%)$ & $150 / 812(18.5 \%)$ & $113 / 588(19.2 \%)$ \\
\hline Family History & $544 / 910(59.8 \%)$ & $539 / 905(59.6 \%)$ & $488 / 812(60.1 \%)$ & $344 / 588(58.5 \%)$ \\
\hline Current smoking & $98 / 910(10.8 \%)$ & $95 / 905(10.5 \%)$ & $84 / 812(10.3 \%)$ & $61 / 588(10.4 \%)$ \\
\hline LVEF $<45 \%$ & $132 / 910(14.5 \%)$ & $133 / 905(14.7 \%)$ & $117 / 812(14 \cdot 4 \%)$ & $91 / 588(15.5 \%)$ \\
\hline Renal insufficiency & $72 / 910(7.9 \%)$ & $72 / 905(8.0 \%)$ & $58 / 812(7.1 \%)$ & $48 / 588(8.2 \%)$ \\
\hline Prior Ml & $500 / 910(54.9 \%)$ & 497/905 (54.9\%) & $462 / 812(56.9 \%)$ & $339 / 588(57.7 \%)$ \\
\hline Prior $\mathrm{PCl}$ & $292 / 910(32.1 \%)$ & $290 / 905(32.0 \%)$ & $246 / 812(30.3 \%)$ & $171 / 588(29.1 \%)$ \\
\hline Prior CABG & $100 / 910(11.0 \%)$ & $100 / 905(11.0 \%)$ & $91 / 812(11.2 \%)$ & $67 / 588(11.4 \%)$ \\
\hline \multicolumn{5}{|l|}{ Medication } \\
\hline Aspirin & $807 / 909$ (88.7\%) & $801 / 904(88.5 \%)$ & $716 / 811(88.3 \%)$ & $513 / 588(87.2 \%)$ \\
\hline Loading dose clopidogrel & 464/909 (51.0\%) & $463 / 904(51.2 \%)$ & $395 / 811(48.7 \%)$ & $288 / 588(49.0 \%)$ \\
\hline Statin & $732 / 909(80.5 \%)$ & $729 / 904(80.6 \%)$ & $643 / 811(79.3 \%)$ & $457 / 588(77.7 \%)$ \\
\hline Beta-blocker & $701 / 909(77.1 \%)$ & $695 / 904(76.9 \%)$ & $622 / 811(76.7 \%)$ & $453 / 588(77.0 \%)$ \\
\hline ACE-inhibitor & $334 / 909(36.7 \%)$ & $332 / 904(36.7 \%)$ & $310 / 811(38.2 \%)$ & $224 / 588(38.1 \%)$ \\
\hline PPI & $241 / 909(26.5 \%)$ & $240 / 904(26.5 \%)$ & $229 / 811(28.2 \%)$ & $181 / 588(30.8 \%)$ \\
\hline CCB & $344 / 909(37.8 \%)$ & $344 / 904(38.1 \%)$ & $303 / 811(37.4 \%)$ & $212 / 588(36.1 \%)$ \\
\hline Oral antidiabetics & $56 / 909(6.2 \%)$ & $55 / 904(6.1 \%)$ & $53 / 811(6.5 \%)$ & $36 / 588(6.1 \%)$ \\
\hline Coumadins & $90 / 909(9.9 \%)$ & $91 / 904(10.1 \%)$ & $87 / 811(10.7 \%)$ & $73 / 588(12.4 \%)$ \\
\hline \multicolumn{5}{|l|}{ Laboratory Parameters } \\
\hline Platelet count $\left(\times 10^{9}\right)$ & $271.9 \pm 81.8$ & $271.9 \pm 81.6$ & $271.3 \pm 82.3$ & $264.5 \pm 76.5$ \\
\hline WBC $\left(x 10^{9}\right)$ & $8.0 \pm 8.9$ & $8.0 \pm 8.9$ & $8.0 \pm 9.4$ & $8.1 \pm 11.0$ \\
\hline Hemoglobin (mmol/L) & $8.6 \pm 2.2$ & $8.5 \pm 2.2$ & $8.6 \pm 2.3$ & $8.6 \pm 2.7$ \\
\hline \multicolumn{5}{|l|}{ Procedural Parameters } \\
\hline No.of stents implanted & 1421 & 1406 & 1255 & 893 \\
\hline No.of lesions treated & 1253 & 1243 & 1098 & 775 \\
\hline Minimal Stent diameter ( $\mathrm{mm})$ & $3.1 \pm 0.86$ & $3.1 \pm 0.86$ & $3.1 \pm 0.8$ & $3.1 \pm 1.0$ \\
\hline Total Stent length (mm) & $28.1 \pm 16.6$ & $27.9 \pm 16.4$ & $27.6 \pm 16.3$ & $26.7 \pm 15.4$ \\
\hline Bifurcation lesion & $25 / 910(2.7 \%)$ & $25 / 605(2.8 \%)$ & $20 / 812(2.5 \%)$ & $12 / 588(2.0 \%)$ \\
\hline Drug eluting stent & $515 / 905(56.9 \%)$ & $513 / 900(57 \%)$ & $445 / 810(54.9 \%)$ & $328 / 588(55.8 \%)$ \\
\hline LAD & 437/910 (48.0\%) & 435/905 (48.1\%) & $399 / 812(49.1 \%)$ & $291 / 588(49.5 \%)$ \\
\hline \multicolumn{5}{|l|}{ Events } \\
\hline Death, MI, ST, stroke & $78 / 910(8.6 \%)$ & $65 / 905(7.2 \%)$ & $70 / 812(8.6 \%)$ & $46 / 588(7.8 \%)$ \\
\hline Death & $16 / 910(1.8 \%)$ & $15 / 905(1.7 \%)$ & $15 / 812(1.8 \%)$ & $10 / 588(1.7 \%)$ \\
\hline MI & $53 / 910(5.8 \%)$ & $51 / 905(5.6 \%)$ & $50 / 812(6.2 \%)$ & $31 / 588(5.3 \%)$ \\
\hline ST & $11 / 910(1.2 \%)$ & 10/905 (1.1\%) & $9 / 812(1.1 \%)$ & $5 / 588(0.9 \%)$ \\
\hline Stroke & $11 / 910(1.2 \%)$ & $11 / 905(1.2 \%)$ & $8 / 812(1.0 \%)$ & $6 / 588(1.0 \%)$ \\
\hline TVR & $21 / 910(2.3 \%)$ & $21 / 905(2.3 \%)$ & $21 / 812(2.6 \%)$ & $17 / 588(2.9 \%)$ \\
\hline Non-TVR & $24 / 910(2.6 \%)$ & $24 / 905(2.7 \%)$ & $23 / 812(2.8 \%)$ & $15 / 588(2.6 \%)$ \\
\hline Rehospitalization & $24 / 910(2.6 \%)$ & $24 / 905(2.7 \%)$ & $16 / 812(2.0 \%)$ & $13 / 588(2.2 \%)$ \\
\hline Bleeding & $47 / 910(5.2 \%)$ & $48 / 905(5.3 \%)$ & $47 / 812(5.8 \%)$ & $36 / 588(6.1 \%)$ \\
\hline CAB-related bleeding & $6 / 910(0.7 \%)$ & $6 / 905(0.7 \%)$ & $8 / 812(1.0 \%)$ & $6 / 588(1.0 \%)$ \\
\hline
\end{tabular}

$B M I=$ Body Mass Index $; \mathrm{LVEF}=$ left ventricular ejection fraction; $P C I=$ percutaneous coronary intervention; $C A B G=$ coronary artery bypass grafting; $P P I=$ proton pump inhibitors; $C C B=$ calcium channel blockers; $W B C=$ white bloodcell count, $L A D=$ Left Anterior Descending Artery $;$ $M I=$ myocardial infarction; $S T=$ stent thrombosis; $T V R=$ target vessel Revascularization; non-TVR=non-target vessel revascularization

Definitions as in Table 1 Hypertension: Systolic blood pressure $>140 \mathrm{~mm} \mathrm{Hg}$ or diastolic blood pressure $>90 \mathrm{~mm} \mathrm{Hg}$; Hypercholesterolemia: A fasting LDL-cholesterol $\geq 3.4 \mathrm{mmol} / \mathrm{L}$ or being on statin therapy at the time of inclusion; Diabetes mellitus: According to the World Health Organization criteria; Family history: One or more first-degree relatives have developed CAD before the age of 55 years (men) or 65 years (women); Renal insufficiency: Creatin $>120 \mu \mathrm{mol} / \mathrm{L}$ 
Platelet function tests and outcomes in patients with coronary stents

eTable 2 | Baseline characteristics of the study population according to the magnitude of platelet reactivity Baseline characteristics of the subpopulations according to the available platelet function measurements, divided in two group, according to HPR and NPR. HPR = high on-treatment platelet reactivity, NPR = normal on-treatment platelet reactivity. Further abbreviations as in eTable 1.

\begin{tabular}{|c|c|c|c|c|c|c|}
\hline & \multicolumn{3}{|c|}{ LTA $5 \mu \mathrm{mol} / \mathrm{L}$ ADP } & \multicolumn{3}{|c|}{ LTA $20 \mu \mathrm{mol} / \mathrm{L}$ ADP } \\
\hline & $\operatorname{NPR}(n=604)$ & $\operatorname{HPR}(n=445)$ & $p$-value & $\operatorname{NPR}(n=659)$ & $\operatorname{HPR}(n=392)$ & $p$-value \\
\hline \multicolumn{7}{|l|}{ Clinical parameters } \\
\hline Age (yrs) & $63 \pm 10.7$ & $66 \pm 10.2$ & $<0.0001$ & $63 \pm 10.5$ & $65 \pm 10.7$ & 0.002 \\
\hline BMI $\left(\mathrm{kg} / \mathrm{m}^{2}\right)$ & $26.9 \pm 4.0$ & $27.6 \pm 4.0$ & 0.006 & $26.8 \pm 3.9$ & $27.9 \pm 4.1$ & $<0.0001$ \\
\hline Gender (m/f) & $463 / 141$ & $321 / 124$ & 0.10 & $506 / 153$ & $280 / 112$ & 0.53 \\
\hline Hypertension & $458 / 604(75.8 \%)$ & $352 / 445(79.1 \%)$ & 0.21 & $503 / 659(76.3 \%)$ & $309 / 392(78.8 \%)$ & 0.05 \\
\hline Hypercholesterolemia & $490 / 604(81.1 \%)$ & $351 / 445(78.9 \%)$ & 0.37 & $534 / 659(81.0 \%)$ & $309 / 392(78.8 \%)$ & 0.39 \\
\hline Diabetes Mellitus & $88 / 604(14.6 \%)$ & $106 / 445(23.8 \%)$ & 0.0001 & $102 / 659(15 \cdot 5 \%)$ & $93 / 392(23.7 \%)$ & 0.0009 \\
\hline Family History & $357 / 604(59.1 \%)$ & $280 / 445(62.9 \%)$ & 0.21 & $388 / 659(58.9 \%)$ & $250 / 392(63.8 \%)$ & 0.12 \\
\hline Current smoking & $74 / 604(12.3 \%)$ & $41 / 445(9.2 \%)$ & 0.12 & $78 / 659(11.8 \%)$ & $38 / 392(9.7 \%)$ & 0.28 \\
\hline LVEF $<45 \%$ & $84 / 604(13.9 \%)$ & $77 / 445(17.3 \%)$ & 0.13 & $89 / 659(13.5 \%)$ & $71 / 392(18.1 \%)$ & 0.04 \\
\hline Renal insufficiency & $38 / 604(6.3 \%)$ & $47 / 445(10.6 \%)$ & 0.01 & $54 / 659(8.2 \%)$ & $31 / 392(7.9 \%)$ & 0.87 \\
\hline Prior Ml & $338 / 604(56.0 \%)$ & $238 / 445(53.5 \%)$ & 0.43 & $354 / 659(53.7 \%)$ & $223 / 392(56.9 \%)$ & 0.32 \\
\hline Prior $\mathrm{PCl}$ & $196 / 604(32.5 \%)$ & $145 / 445(32.6 \%)$ & 0.96 & $209 / 659(31.7 \%)$ & $131 / 392(33.4 \%)$ & 0.57 \\
\hline Prior CABG & $60 / 604(9.9 \%)$ & $50 / 445(11.2 \%)$ & 0.50 & $70 / 659(10.6 \%)$ & 41/392 (10.5\%) & 0.93 \\
\hline \multicolumn{7}{|l|}{ Medication } \\
\hline Aspirin & $545 / 604(90.2 \%)$ & $391 / 444(88.1 \%)$ & 0.26 & $597 / 659(90.6 \%)$ & $341 / 391(87.2 \%)$ & 0.09 \\
\hline Loading dose clopidogrel & $291 / 604(48.2 \%)$ & $242 / 444(54.5 \%)$ & 0.04 & $312 / 659(47.3 \%)$ & $222 / 391(56.8 \%)$ & 0.003 \\
\hline Statin & $484 / 604(80.1 \%)$ & $349 / 444(78.6 \%)$ & 0.54 & $529 / 659(80.3 \%)$ & $305 / 391(78.0 \%)$ & 0.38 \\
\hline Beta-blocker & $463 / 604(76.7 \%)$ & $336 / 444(75.7 \%)$ & 0.71 & $499 / 659(75.7 \%)$ & $301 / 391(77.0 \%)$ & 0.64 \\
\hline ACE-inhibitor & $218 / 604(36.1 \%)$ & $174 / 444(39.2 \%)$ & 0.31 & $245 / 659(37.2 \%)$ & $147 / 391(37.6 \%)$ & 0.89 \\
\hline PPI & $179 / 604(29.6 \%)$ & $117 / 444(26.4 \%)$ & 0.24 & $189 / 659(28.7 \%)$ & $107 / 391(27.4 \%)$ & 0.65 \\
\hline CCB & $219 / 604(36.3 \%)$ & $175 / 444(39.4 \%)$ & 0.30 & $236 / 659(35.8 \%)$ & $158 / 391(40.4 \%)$ & 0.14 \\
\hline Oral antidiabetics & $35 / 604(5.8 \%)$ & $35 / 444(7.9 \%)$ & 0.18 & $40 / 659(6.1 \%)$ & $31 / 391(7.9 \%)$ & 0.25 \\
\hline Coumadins & $61 / 604(10.1 \%)$ & $47 / 444(10.6 \%)$ & 0.80 & $65 / 659(9.9 \%)$ & 43/391 (11.0\%) & 0.56 \\
\hline \multicolumn{7}{|l|}{ Laboratory Parameters } \\
\hline Platelet count $\left(\times 10^{9}\right)$ & $267.8 \pm 76.1$ & $275 \cdot 7 \pm 83 \cdot 4$ & 0.13 & $271 \pm 82.2$ & $270.4 \pm 74.4$ & 0.85 \\
\hline WBC $\left(\times 10^{9}\right)$ & $8.1 \pm 11.0$ & $7.7 \pm 2.3$ & 0.48 & $8.0 \pm 10.6$ & $7.8 \pm 2.4$ & 0.57 \\
\hline Haemoglobin (mmol/L) & $8.7 \pm 2.6$ & $8.3 \pm 1.0$ & 0.002 & $8.6 \pm 2.6$ & $8.4 \pm 1.0$ & 0.06 \\
\hline \multicolumn{7}{|l|}{ Procedural Parameters } \\
\hline No.of stents implanted & 938 & 703 & 0.93 & 1135 & 610 & 0.94 \\
\hline No.of lesions treated & 809 & 639 & 0.08 & 896 & 556 & 0.17 \\
\hline Minimal Stent diameter ( $\mathrm{mm}$ ) & $3.1 \pm 0.9$ & $3.1 \pm 0.6$ & 0.99 & $3.1 \pm 0.9$ & $3.1 \pm 0.7$ & 0.78 \\
\hline Total Stent length (mm) & $28.3 \pm 17.0$ & $28.0 \pm 16.7$ & 0.70 & $28.0 \pm 16.7$ & $28.6 \pm 17 \cdot 3$ & 0.56 \\
\hline Bifurcation lesion & $17 / 604(2.8 \%)$ & $14 / 445(3.1 \%)$ & 0.75 & $16 / 659(2.4 \%)$ & $16 / 392(4.1 \%)$ & 0.13 \\
\hline Drug eluting stent & $355 / 603(58.9 \%)$ & $239 / 444(54 \cdot 3 \%)$ & 0.37 & $377 / 658(57.3 \%)$ & $219 / 387(56.6 \%)$ & 0.83 \\
\hline LAD & $277 / 604(45.9 \%)$ & $229 / 445(51.5 \%)$ & 0.07 & $308 / 659(46.7 \%)$ & $197 / 392(50.3 \%)$ & 0.27 \\
\hline \multirow[t]{3}{*}{ Graft } & $17 / 604(2.8 \%)$ & $16 / 445(3.6 \%)$ & 0.47 & $22 / 659(3.3 \%)$ & $11 / 392(2.8 \%)$ & 0.63 \\
\hline & \multicolumn{3}{|l|}{ VerifyNow $\mathrm{P}_{2} \mathrm{Y}_{12}$} & \multicolumn{3}{|l|}{ Plateletworks } \\
\hline & $\operatorname{NPR}(n=646)$ & $\operatorname{HPR}(n=406)$ & $p$-value & $\operatorname{NPR}(n=344)$ & $\operatorname{HPR}(n=262)$ & $p$-value \\
\hline \multicolumn{7}{|l|}{ Clinical parameters } \\
\hline Age (yrs) & $63 \pm 10.4$ & $66 \pm 10.6$ & $<0.0001$ & $63 \pm 11.0$ & $64 \pm 10.1$ & 0.35 \\
\hline BMI $\left(\mathrm{kg} / \mathrm{m}^{2}\right)$ & $26.9 \pm 3.7$ & $27.7 \pm 4.5$ & 0.001 & $26.8 \pm 3.7$ & $27.6 \pm 4.0$ & 0.03 \\
\hline Gender (m/f) & $527 / 119$ & $263 / 143$ & $<0.0001$ & $265 / 79$ & $193 / 69$ & 0.34 \\
\hline Hypertension & $494 / 646(76.5 \%)$ & $318 / 406(78.3 \%)$ & 0.49 & $260 / 344(75.6 \%)$ & $201 / 262(76.7 \%)$ & 0.75 \\
\hline Hypercholesterolemia & $521 / 646(80.7 \%)$ & $322 / 406(79.3 \%)$ & 0.60 & $273 / 344(79.4 \%)$ & $206 / 262(78.6 \%)$ & 0.83 \\
\hline Diabetes Mellitus & $91 / 646(14.1 \%)$ & $103 / 406(25.4 \%)$ & $<0.0001$ & $52 / 344(15.1 \%)$ & $57 / 262(21.8 \%)$ & 0.04 \\
\hline Family History & $379 / 646(58.5 \%)$ & $256 / 406(63.1 \%)$ & 0.14 & $216 / 344(62.8 \%)$ & $149 / 262(56.9 \%)$ & 0.14 \\
\hline Current smoking & $77 / 646(11.9 \%)$ & $39 / 406(9.6 \%)$ & 0.24 & $38 / 344(11.0 \%)$ & $22 / 262(8.4 \%)$ & 0.28 \\
\hline LVEF $<45 \%$ & $88 / 646(13.6 \%)$ & $75 / 406(18.5 \%)$ & 0.03 & $55 / 344(16.0 \%)$ & $41 / 262(15.6 \%)$ & 0.91 \\
\hline Renal insufficiency & $46 / 646(7.1 \%)$ & $36 / 406(8.9 \%)$ & 0.30 & $29 / 344(8.4 \%)$ & $17 / 262(6.5 \%)$ & 0.37 \\
\hline Prior Ml & $347 / 646(53.7 \%)$ & $226 / 406(55.7 \%)$ & 0.54 & $181 / 344(52.6 \%)$ & $139 / 262(53.1 \%)$ & 0.91 \\
\hline Prior $\mathrm{PCl}$ & $212 / 646(32.8 \%)$ & $128 / 406(31.5 \%)$ & 0.66 & $120 / 344(34.9 \%)$ & $84 / 262(32.1 \%)$ & 0.47 \\
\hline Prior CABG & $59 / 646$ (9.1\%) & $48 / 406(11.8 \%)$ & 0.16 & $35 / 344(10.2 \%)$ & $32 / 262(12.2 \%)$ & 0.43 \\
\hline
\end{tabular}


Part II | chapter 7

\begin{tabular}{|c|c|c|c|c|c|c|}
\hline Medication & & & & & & \\
\hline Aspirin & $589 / 646(91.2 \%)$ & $351 / 405(86.7 \%)$ & 0.02 & $317 / 344(92.2 \%)$ & $227 / 261(87.0 \%)$ & 0.04 \\
\hline Loading dose clopidogrel & $320 / 646(49.5 \%)$ & $216 / 405(53.3 \%)$ & 0.23 & $155 / 344(45.1 \%)$ & $150 / 261(57.5 \%)$ & 0.002 \\
\hline Statin & $518 / 646(80.2 \%)$ & $316 / 405(78.0 \%)$ & 0.40 & $266 / 344(77 \cdot 3 \%)$ & $201 / 261(77.0 \%)$ & 0.93 \\
\hline Beta-blocker & $493 / 646(76.3 \%)$ & $309 / 405(76.3 \%)$ & 0.99 & $261 / 344(75 \cdot 9 \%)$ & $202 / 261(77.4 \%)$ & 0.66 \\
\hline ACE-inhibitor & $238 / 646(36.8 \%)$ & $153 / 405(37.8 \%)$ & 0.76 & $121 / 344(35.2 \%)$ & $99 / 261(37.9 \%)$ & 0.49 \\
\hline PPI & $177 / 646(27.4 \%)$ & $118 / 405(29.1 \%)$ & 0.54 & $84 / 344(24 \cdot 4 \%)$ & $75 / 261(28.7 \%)$ & 0.23 \\
\hline $\mathrm{CCB}$ & $242 / 646(37.5 \%)$ & $155 / 405(39.3 \%)$ & 0.79 & $146 / 344(42.4 \%)$ & $99 / 261(37.9 \%)$ & 0.26 \\
\hline Oral antidiabetics & $35 / 646(5.4 \%)$ & $34 / 405(8.4 \%)$ & 0.06 & $19 / 344(5.5 \%)$ & $21 / 261(8.0 \%)$ & 0.22 \\
\hline Coumadins & $62 / 646(9.6 \%)$ & $44 / 405(10.9 \%)$ & 0.51 & $23 / 344(6.7 \%)$ & $25 / 261(9.6 \%)$ & 0.19 \\
\hline \multicolumn{7}{|l|}{ Laboratory Parameters } \\
\hline Platelet count $\left(\times 10^{9}\right)$ & $276.9 \pm 85.6$ & $263.7 \pm 74.4$ & 0.01 & $277.9 \pm 87.2$ & $270.1 \pm 76.5$ & 0.24 \\
\hline WBC $\left(x 10^{9}\right)$ & $7.8 \pm 2.6$ & $8.1 \pm 13.3$ & 0.60 & $7.8 \pm 2.8$ & $8.6 \pm 15.8$ & 0.40 \\
\hline Haemoglobin (mmol/L) & $8.7 \pm 1.0$ & $8.3 \pm 3.2$ & 0.02 & $8.7 \pm 3.3$ & $8.6 \pm 0.9$ & 0.35 \\
\hline \multicolumn{7}{|l|}{ Procedural Parameters } \\
\hline No.of stents implanted & 1018 & 628 & 0.14 & 533 & 403 & 0.61 \\
\hline No.of lesions treated & 882 & 572 & 0.39 & 464 & 369 & 0.60 \\
\hline Minimal Stent diameter $(\mathrm{mm})$ & $3.1 \pm 0.6$ & $3.1 \pm 1.1$ & 0.58 & $3.0 \pm 0.5$ & $3.1 \pm 0.5$ & 0.10 \\
\hline Total Stent length (mm) & $28.4 \pm 17.1$ & $27.8 \pm 16.2$ & 0.55 & $28.0 \pm 16.0$ & $28.4 \pm 17.1$ & 0.76 \\
\hline Bifurcation lesion & $18 / 646(2.8 \%)$ & $15 / 406(3.7 \%)$ & 0.41 & $9 / 344(2.6 \%)$ & $6 / 262(2.3 \%)$ & 0.80 \\
\hline Drug eluting stent & $371 / 642(57.8 \%)$ & $227 / 405(56.0 \%)$ & 0.57 & $191 / 344(55.5 \%)$ & $167 / 258(64.7 \%)$ & 0.10 \\
\hline LAD & $311 / 646(48.1 \%)$ & $203 / 406(50.0 \%)$ & 0.56 & $169 / 344(49.1 \%)$ & $131 / 262(50.0 \%)$ & 0.83 \\
\hline \multirow[t]{3}{*}{ Graft } & $16 / 646(2.5 \%)$ & $15 / 406(3.7 \%)$ & 0.26 & $8 / 344(2.3 \%)$ & $8 / 262(3.1 \%)$ & 0.58 \\
\hline & IMPACT- $R$ & & & IMPACT-R ADP & & \\
\hline & $\operatorname{NPR}(n=481)$ & $\operatorname{HPR}(n=429)$ & $p$-value & NPR $(n=609)$ & $\operatorname{HPR}(n=296)$ & $p$-value \\
\hline \multicolumn{7}{|l|}{ Clinical parameters } \\
\hline Age (yrs) & $64 \pm 11.1$ & $65 \pm 10.2$ & 0.13 & $63 \pm 10.6$ & $66 \pm 10.8$ & 0.002 \\
\hline BMI $\left(\mathrm{kg} / \mathrm{m}^{2}\right)$ & $27 \cdot 4 \pm 4 \cdot 3$ & $27.2 \pm 3.9$ & 0.45 & $27.2 \pm 3.8$ & $27.5 \pm 4.6$ & 0.28 \\
\hline Gender (m/f) & $358 / 123$ & $325 / 104$ & 0.64 & $427 / 137$ & $208 / 88$ & 0.02 \\
\hline Hypertension & $376 / 481(78.2 \%)$ & $332 / 429(77.4 \%)$ & 0.77 & $461 / 609(75.7 \%)$ & $243 / 296(82.1 \%)$ & 0.03 \\
\hline Hypercholesterolemia & $387 / 481(80.5 \%)$ & $345 / 429(80.4 \%)$ & 0.99 & $482 / 609(79.1 \%)$ & $246 / 296(83.1 \%)$ & 0.16 \\
\hline Diabetes Mellitus & $87 / 481(18.1 \%)$ & $79 / 429(18.4 \%)$ & 0.90 & $95 / 609(15.6 \%)$ & $70 / 296(23.6 \%)$ & 0.003 \\
\hline Family History & $266 / 481(55 \cdot 3 \%)$ & $278 / 429(64.8 \%)$ & 0.003 & $379 / 609(62.2 \%)$ & $160 / 296(54.1 \%)$ & 0.02 \\
\hline Current smoking & $55 / 481(11.4 \%)$ & 43/429 (10.0\%) & 0.49 & 71/6og (11.7\%) & $24 / 296(8.1 \%)$ & 0.10 \\
\hline LVEF $<45 \%$ & $64 / 481(13.3 \%)$ & $68 / 429(15.9 \%)$ & 0.27 & $93 / 609(15.3 \%)$ & 40/296 (13.5\%) & 0.48 \\
\hline Renal insufficiency & $39 / 481(8.1 \%)$ & $33 / 429(7.7 \%)$ & 0.82 & 49/609 (8.0\%) & $23 / 296(7.8 \%)$ & 0.89 \\
\hline Prior MI & $271 / 481(56.3 \%)$ & $229 / 429(53.4 \%)$ & 0.37 & $335 / 609(67.4 \%)$ & $162 / 296(32.6 \%)$ & 0.94 \\
\hline Prior $\mathrm{PCl}$ & $144 / 481(29.9 \%)$ & $148 / 429(34.5 \%)$ & 0.14 & $198 / 609(32.5 \%)$ & $92 / 296(31.1 \%)$ & 0.67 \\
\hline Prior CABG & $53 / 481(11.0 \%)$ & $47 / 429(11.0 \%)$ & 0.98 & $59 / 609(9.7 \%)$ & 41/296 (13.9\%) & 0.06 \\
\hline \multicolumn{7}{|l|}{ Medication } \\
\hline Aspirin & $426 / 481(88.6 \%)$ & $381 / 428(89.0 \%)$ & 0.83 & $543 / 609(89.3 \%)$ & $258 / 296(87.2 \%)$ & 0.34 \\
\hline Loading dose clopidogrel & $246 / 481(51.1 \%)$ & $218 / 428(50.9 \%)$ & 0.95 & $299 / 609(49.2 \%)$ & $164 / 296(55.4 \%)$ & 0.08 \\
\hline Statin & $381 / 481(79.2 \%)$ & $351 / 428(82.0 \%)$ & 0.29 & $495 / 609(81.4 \%)$ & $234 / 296(79.1 \%)$ & 0.40 \\
\hline Beta-blocker & $360 / 481(74.8 \%)$ & $341 / 428(79.7 \%)$ & 0.08 & $473 / 609(77.8 \%)$ & $222 / 296(75.0 \%)$ & 0.35 \\
\hline ACE-inhibitor & $170 / 481(35 \cdot 3 \%)$ & $164 / 428(38.3 \%)$ & 0.35 & $230 / 609(37.8 \%)$ & $102 / 296(34.5 \%)$ & 0.32 \\
\hline PPI & $136 / 481(28.3 \%)$ & $105 / 428(24.5 \%)$ & 0.20 & $158 / 609(26.0 \%)$ & $82 / 296(27.7 \%)$ & 0.58 \\
\hline CCB & $178 / 481(37.0 \%)$ & $166 / 428(38.8 \%)$ & 0.58 & $246 / 609(40.5 \%)$ & $98 / 296(33.1 \%)$ & 0.03 \\
\hline Oral antidiabetics & $32 / 481(6.7 \%)$ & $24 / 428(5.6 \%)$ & 0.51 & $34 / 609(5.6 \%)$ & $21 / 296(7.1 \%)$ & 0.38 \\
\hline Coumadins & $51 / 481(10.6 \%)$ & $39 / 428(9.1 \%)$ & 0.45 & $56 / 609(9.2 \%)$ & $35 / 296(11.8 \%)$ & 0.22 \\
\hline \multicolumn{7}{|l|}{ Laboratory Parameters } \\
\hline Platelet count $\left(x_{10} 0^{9}\right)$ & $268.4 \pm 83.6$ & $275.8 \pm 79.5$ & 0.18 & $275.0 \pm 82.9$ & $265.7 \pm 78.7$ & 0.11 \\
\hline WBC $\left(\times 10^{9}\right)$ & $7.7 \pm 2.2$ & $7.7 \pm 2.1$ & 0.73 & $7.7 \pm 2.2$ & $7.7 \pm 2.1$ & 0.77 \\
\hline Haemoglobin (mmol/L) & $8.4 \pm 1.0$ & $8.7 \pm 3.1$ & 0.09 & $13.8 \pm 1.4$ & $13.4 \pm 5.9$ & 0.41 \\
\hline
\end{tabular}


Platelet function tests and outcomes in patients with coronary stents

\begin{tabular}{|c|c|c|c|c|c|c|}
\hline Procedural Parameters & & & & & & \\
\hline No.of stents implanted & 769 & 652 & & 956 & 450 & 0.47 \\
\hline No.of lesions treated & 658 & 595 & & 836 & 505 & 0.73 \\
\hline Minimal Stent diameter $(\mathrm{mm})$ & $3.1 \pm 1.1$ & $3.1 \pm 0.5$ & 0.20 & $3.0 \pm 0.5$ & $3.2 \pm 1.4$ & 0.09 \\
\hline Total Stent length (mm) & $28.7 \pm 17.1$ & $27 \cdot 3 \pm 15 \cdot 9$ & 0.19 & $28.3 \pm 16.5$ & $27.4 \pm 16.2$ & 0.44 \\
\hline Bifurcation lesion & $8 / 481(1.7 \%)$ & $17 / 428(4.0 \%)$ & 0.03 & $17 / 609(2.8 \%)$ & $8 / 296(2.7 \%)$ & 0.94 \\
\hline Drug eluting stent & $281 / 479(58.7 \%)$ & $234 / 426(54.9 \%)$ & 0.45 & $384 / 608(3.2 \%)$ & $188 / 292(64.4 \%)$ & 0.90 \\
\hline LAD & $228 / 481(47.4 \%)$ & $209 / 428(48.7 \%)$ & 0.69 & $293 / 609(48.1 \%)$ & $142 / 296(48.0 \%)$ & 0.97 \\
\hline \multirow[t]{3}{*}{ Graft } & $16 / 481(3.3 \%)$ & $11 / 428(2.6 \%)$ & 0.50 & $13 / 609(2.1 \%)$ & $14 / 296(4.7 \%)$ & 0.03 \\
\hline & \multicolumn{3}{|c|}{ PFA-100 COL/ADP } & \multicolumn{3}{|l|}{ INNOVANCE } \\
\hline & $\operatorname{NPR}(n=306)$ & $\operatorname{HPR}(n=506)$ & $p$-value & $\operatorname{NPR}(n=441)$ & $\operatorname{HPR}(n=147)$ & $p$-value \\
\hline \multicolumn{7}{|l|}{ Clinical parameters } \\
\hline Age (yrs) & $63 \pm 10.2$ & $64.5 \pm 10.7$ & 0.01 & $64 \pm 10.5$ & $66 \pm 11.5$ & 0.12 \\
\hline BMI $\left(\mathrm{kg} / \mathrm{m}^{2}\right)$ & $27.0 \pm 3.9$ & $27.4 \pm 4.2$ & 0.24 & $27.0 \pm 4.4$ & $27.6 \pm 4 \cdot 3$ & 0.18 \\
\hline Gender (m/f) & $234 / 72$ & $363 / 143$ & 0.14 & $331 / 110$ & $93 / 54$ & 0.006 \\
\hline Hypertension & $242 / 306(79.1 \%)$ & $378 / 506(74.7 \%)$ & 0.15 & $331 / 441(75.1 \%)$ & $93 / 147(63.3 \%)$ & 0.66 \\
\hline Hypercholesterolemia & $253 / 306(82.7 \%)$ & $399 / 506$ (78.9\%) & 0.18 & $325 / 441(73.7 \%)$ & $111 / 147(75.5 \%)$ & 0.82 \\
\hline Diabetes Mellitus & $52 / 306(17.0 \%)$ & $98 / 506(19.4 \%)$ & 0.40 & $349 / 441(79.1 \%)$ & $115 / 147(78.2 \%)$ & 0.03 \\
\hline Family History & $187 / 306(61.1 \%)$ & $301 / 506(59.5 \%)$ & 0.65 & $76 / 441(17.2 \%)$ & $37 / 147(25.2 \%)$ & 0.85 \\
\hline Current smoking & $25 / 306(8.2 \%)$ & $59 / 506(11.7 \%)$ & 0.11 & $259 / 441(58.7 \%)$ & $85 / 147(57.8 \%)$ & 0.70 \\
\hline LVEF $<45 \%$ & $36 / 306(11.8 \%)$ & $81 / 506(16.0 \%)$ & 0.10 & $47 / 441(10.7 \%)$ & $14 / 147(9.5 \%)$ & 0.03 \\
\hline Renal insufficiency & $14 / 306(4.6 \%)$ & $44 / 506(8.7 \%)$ & 0.03 & $60 / 441(13.6 \%)$ & $31 / 147(21.1 \%)$ & 0.0005 \\
\hline Prior MI & $174 / 306(56.9 \%)$ & $288 / 506(46.9 \%)$ & 0.99 & $26 / 441(5.9 \%)$ & $22 / 147(15.0 \%)$ & 0.89 \\
\hline Prior PCl & $102 / 306(33.3 \%)$ & $144 / 506(28.5 \%)$ & 0.14 & $255 / 441(57.8 \%)$ & $84 / 147(57.1 \%)$ & 0.37 \\
\hline \multirow[t]{2}{*}{ Prior CABG } & 41/306 (13.4\%) & $50 / 506(9.9 \%)$ & 0.12 & $124 / 441(28.1 \%)$ & $47 / 147(32.0 \%)$ & 0.50 \\
\hline & & & & 48/441 (10.9\%) & $19 / 147(12.9 \%)$ & \\
\hline \multicolumn{7}{|l|}{ Medication } \\
\hline Aspirin & $286 / 306(93.5 \%)$ & $430 / 506(85.1 \%)$ & 0.0004 & $399 / 441(90.5 \%)$ & $114 / 147(77.6 \%)$ & $<0.0001$ \\
\hline Loading dose clopidogrel & $141 / 306(46.1 \%)$ & $254 / 506(50.3 \%)$ & 0.24 & $206 / 441(46.7 \%)$ & $82 / 147(55.8 \%)$ & 0.06 \\
\hline Statin & $249 / 306(81.4 \%)$ & $349 / 506(78.0 \%)$ & 0.25 & $350 / 441(79.4 \%)$ & $107 / 147(72.8 \%)$ & 0.10 \\
\hline Beta-blocker & $223 / 306(72.9 \%)$ & $399 / 506(79.0 \%)$ & 0.05 & $332 / 441(75 \cdot 3 \%)$ & $121 / 147(82.3 \%)$ & 0.08 \\
\hline ACE-inhibitor & $118 / 306(38.6 \%)$ & $192 / 506(38.0 \%)$ & 0.88 & $165 / 441(37.4 \%)$ & $59 / 147(40.1 \%)$ & 0.56 \\
\hline PPI & $88 / 306(28.8 \%)$ & $141 / 506(27.9 \%)$ & 0.80 & $137 / 441(31.1 \%)$ & $44 / 147(29.9 \%)$ & 0.80 \\
\hline $\mathrm{CCB}$ & $114 / 306(37.3 \%)$ & $189 / 506(37.4 \%)$ & 0.96 & $164 / 441(37.2 \%)$ & $48 / 147(32.7 \%)$ & 0.32 \\
\hline Oral antidiabetics & $22 / 306(7.2 \%)$ & $31 / 506(6.1 \%)$ & 0.56 & $26 / 441(5.9 \%)$ & $10 / 147(6.8 \%)$ & 0.69 \\
\hline Coumadins & $19 / 306(6.2 \%)$ & $68 / 506(13.5 \%)$ & 0.001 & 43/441 (9.8\%) & $30 / 147(20.4 \%)$ & 0.0007 \\
\hline \multicolumn{7}{|l|}{ Laboratory Parameters } \\
\hline Platelet count $\left(x_{10} 0^{9}\right)$ & $276.0 \pm 81.8$ & $268.4 \pm 82.5$ & 0.21 & $264.5 \pm 76.8$ & $264.7 \pm 75.8$ & 0.98 \\
\hline WBC $\left(x 10^{9}\right)$ & $7.3 \pm 2.1$ & $7.8 \pm 2.3$ & 0.009 & $7.5 \pm 2.2$ & $7.7 \pm 2.8$ & 0.47 \\
\hline Haemoglobin (mmol/L) & $13.9 \pm 5.8$ & $13.8 \pm 1.4$ & 0.56 & $13.9 \pm 4.8$ & $13.1 \pm 1.8$ & 0.003 \\
\hline \multicolumn{7}{|l|}{ Procedural Parameters } \\
\hline No.of stents implanted & 456 & 799 & 0.11 & 668 & 225 & 0.54 \\
\hline No.of lesions treated & 406 & 683 & 0.31 & 577 & 198 & 0.60 \\
\hline Minimal Stent diameter $(\mathrm{mm})$ & $3.0 \pm 0.4$ & $3.1 \pm 1.0$ & 0.19 & $3.1 \pm 1.06$ & $3.1 \pm 0.5$ & 0.77 \\
\hline Total Stent length (mm) & $27.0 \pm 15.2$ & $27.9 \pm 16.9$ & 0.42 & $26.7 \pm 15.8$ & $26.8 \pm 14 \cdot 3$ & 0.95 \\
\hline Bifurcation lesion & $8 / 306(2.6 \%)$ & $12 / 506(2.4 \%)$ & $0 . .83$ & $8 / 441(1.8 \%)$ & $4 / 147(2.7 \%)$ & 0.50 \\
\hline Drug eluting stent & $196 / 306(64.0 \%)$ & $304 / 506(60.3 \%)$ & 0.53 & $271 / 441(61.5 \%)$ & $94 / 147(63.9 \%)$ & 0.33 \\
\hline LAD & $145 / 306(47.0 \%)$ & $254 / 506(50.2 \%)$ & 0.44 & $213 / 441(48.3 \%)$ & $78 / 147(53.1 \%)$ & 0.32 \\
\hline Graft & $11 / 306(3.6 \%)$ & $13 / 506(2.6 \%)$ & 0.40 & $15 / 441(3.4 \%)$ & $5 / 147(3.4 \%)$ & 1.00 \\
\hline
\end{tabular}

Hypertension: Systolic blood pressure $>140 \mathrm{~mm} \mathrm{Hg}$ or diastolic blood pressure $>90 \mathrm{~mm} \mathrm{Hg}$; Hypercholesterolemia: A fasting $L D L$-cholesterol $\geq 3.4 \mathrm{mmol} / \mathrm{L}$ or being on statin therapy at the time of inclusion; Diabetes mellitus: According to the World Health Organization criteria; Family history: One or more first-degree relatives have developed $C A D$ before the age of 55 years (men) or 65 years (women); Renal insufficiency: Creatin $>120 \mu \mathrm{mol} / \mathrm{L}$ 
Part II | chapter 7
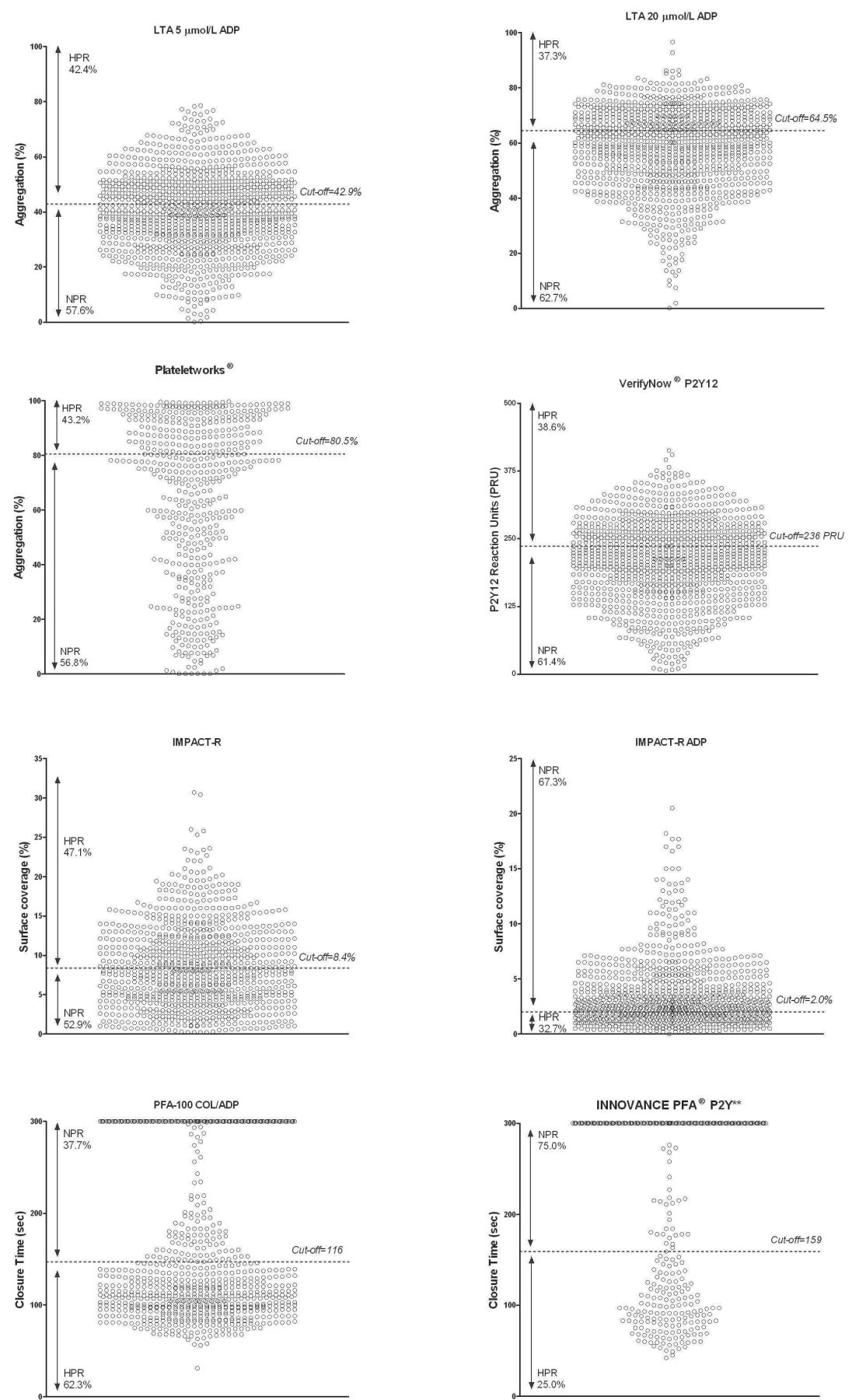

eFigure 1 | Distribution of individual platelet reactivity

Individual platelet reactivity data obtained from the multiple platelet function assays. Horizontal dotted lines indicate the test specific cut-off values for high-on treatment platelet reactivity HPR = high on-treatment platelet reactivity, NPR = normal on-treatment platelet reactivity 
Platelet function tests and outcomes in patients with coronary stents
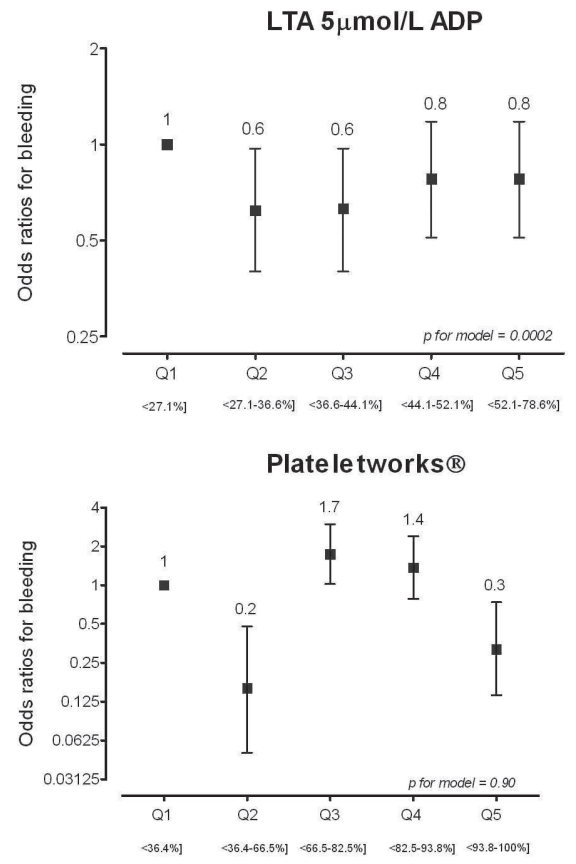

IMPACT-R

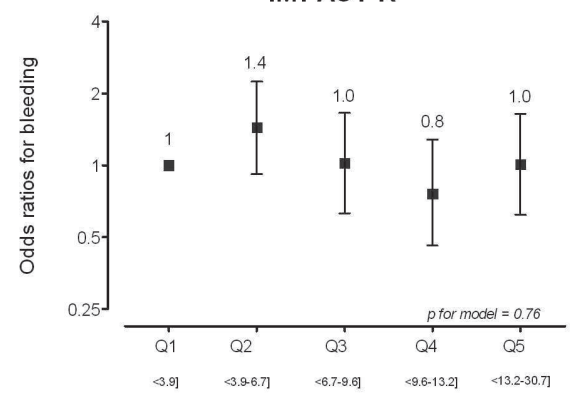

PFA-100 COLADP

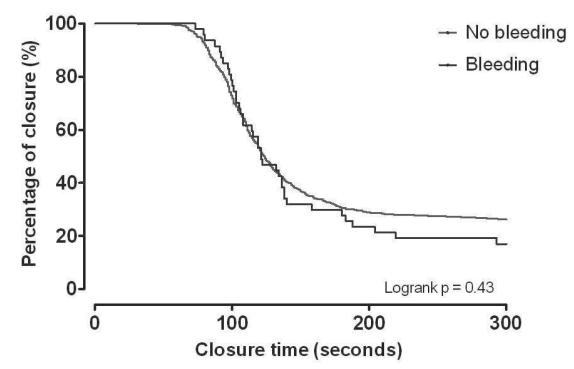

LTA $20 \mu \mathrm{mol} / L$ ADP

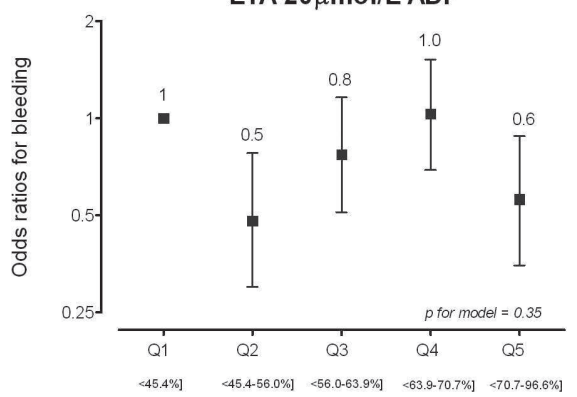

VerifyNow® P2Y12

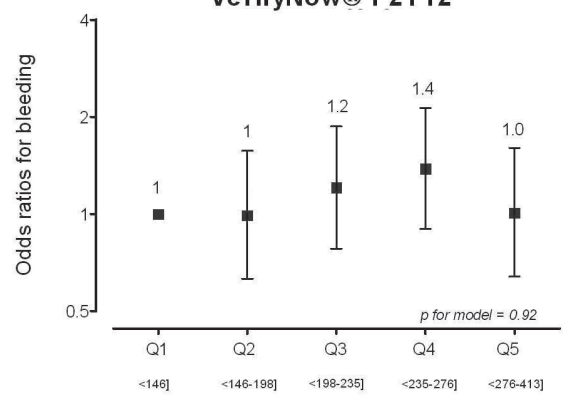

IMACT-R ADP

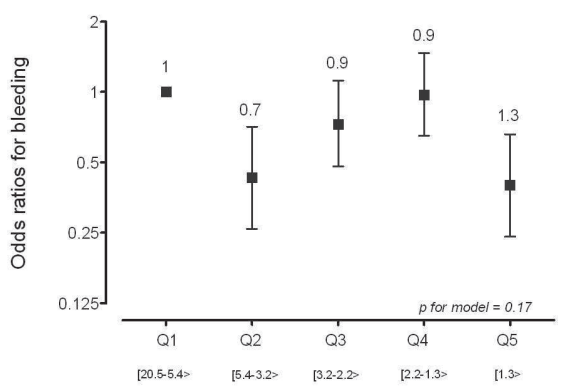

INNOVANCE® PFA P2Y*

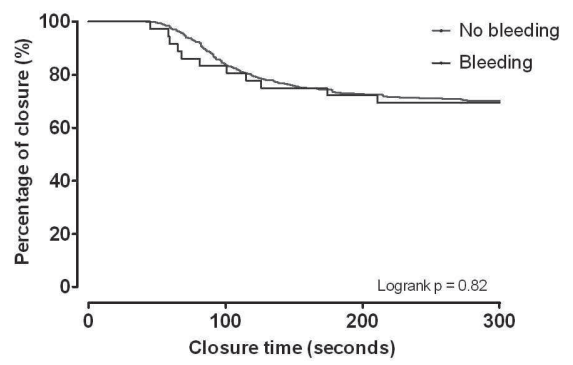

eFigure 2 | Odds Ratios for the primary safety endpoint

Odds Ratios for the occurrence of bleeding by quintiles of on-treatment platelet reactivity according to the multiple platelet function assays. Incidences (\%) of the combined primary endpoint are depicted in the bars. Cumulative Kaplan Meier time-to-aperture-closure plot in patients with and without bleeding according to the PFA-100 ${ }^{\circledR}$ System. $Q=$ quintile HPR = high on-treatment platelet reactivity, NPR = normal on-treatment platelet reactivity 
Part II | chapter 7

\section{REFERENCES}

1. Steinhubl SR, Berger PB, Mann JT, III et al. Early and sustained dual oral antiplatelet therapy following percutaneous coronary intervention: a randomized controlled trial. JAMA. 2002;288:2411-20.

2. Mehta SR, YusufS, Peters RJ et al. Effects of pretreatment with clopidogrel and aspirin followed by long-term therapy in patients undergoing percutaneous coronary intervention: the PCI-CURE study. Lancet. 2001;358:52733.

3. Matetzky S, Shenkman B, Guetta $\vee$ et al. Clopidogrel resistance is associated with increased risk of recurrent atherothrombotic events in patients with acute myocardial infarction. Circulation. 2004;109:3171-5.

4. Gurbel PA, Bliden KP, Guyer K et al. Platelet reactivity in patients and recurrent events post-stenting: results of the PREPARE POST-STENTING Study. J Am Coll Cardiol. 2005;46:1820-6.

5. Geisler T, Langer $\mathrm{H}$, Wydymus $\mathrm{M}$ et al. Low response to clopidogrel is associated with cardiovascular outcome after coronary stent implantation. Eur Heart J. 2006;27:2420-5.

6. HochholzerW, Trenk D, Bestehorn HP et al. Impact of the degree of peri-interventional platelet inhibition after loading with clopidogrel on early clinical outcome of elective coronary stent placement. J Am Coll Cardiol. 2006;48:1742-50.

7. Marcucci R, Gori AM, Paniccia R et al. Cardiovascular death and nonfatal myocardial infarction in acute coronary syndrome patients receiving coronary stenting are predicted by residual platelet reactivity to ADP detected by a point-of-care assay: a 12-month follow-up. Circulation. 2009;119:237-42.

8. Price MJ, Endemann S, Gollapudi RR et al. Prognostic significance of post-clopidogrel platelet reactivity assessed by a point-of-care assay on thrombotic events after drug-eluting stent implantation. Eur Heart J. 2008;29:992-1000.

9. Sibbing D, Braun S, Morath T et al. Platelet reactivity after clopidogrel treatment assessed with point-of-care analysis and early drug-eluting stent thrombosis. J Am Coll Cardiol. 2009;53:849-56.

10. Bonello L, Camoin-Jau L, Arques S et al. Adjusted clopidogrel loading doses according to vasodilator-stimulated phosphoprotein phosphorylation index decrease rate of major adverse cardiovascular events in patients with clopidogrel resistance: a multicenter randomized prospective study. J Am Coll Cardiol. 2008;51:1404-11.

11. Smith SC, Jr., Feldman TE, Hirshfeld JW, Jr. et al. ACC/AHA/SCAI 2005 guideline update for percutaneous coronary intervention: a report of the American College of Cardiology/American Heart Association Task Force on Practice Guidelines (ACC/AHA/SCAI Writing Committee to Update 2001 Guidelines for Percutaneous Coronary Intervention). Circulation 2006;113:e166-e286.

12. Cutlip DE, Windecker S, Mehran R et al. Clinical end points in coronary stent trials: a case for standardized definitions. Circulation. 2007;115:2344-51.

13. TIMI study group: definitions used in TIMI-trials. www.timi.org. 2009. Ref Type: Internet Communication

14. van Werkum JW, Harmsze AM, Elsenberg EH et al. The use of the VerifyNow system to monitor antiplatelet therapy: a review of the current evidence. Platelets. 2008;19:479-88.

15. van Werkum JW, van der Stelt CA, Seesing TH et al. A head-to-head comparison between the VerifyNowP2 $\mathrm{Y}_{12}-$ assay and light transmittance aggregometry for monitoring the individual platelet response to clopidogrel in patients undergoing elective $\mathrm{PCl}$. J Thromb Haemost. 2006;4:2516-8.

16. van Werkum JW, Kleibeuker M, Postma S et al. A comparison between the Plateletworkstrade mark-assay and light transmittance aggregometry for monitoring the inhibitory effects of clopidogrel. Int J Cardiol. 2008. In press.

17. Savion N, Varon D. Impact--the cone and plate(let) analyzer: testing platelet function and anti-platelet drug response. Pathophysiol Haemost Thromb. 2006;35:83-8.

18. Pittens CA, Bouman HJ, van Werkum JW et al. Comparison between hirudin and citrate in monitoring the inhibitory effects of $\mathrm{P}_{2} \mathrm{Y}_{12}$ receptor antagonists with different platelet function tests. J Thromb Haemost. 2009; 2009; 7:1929-1932. 
Platelet function tests and outcomes in patients with coronary stents

19. Kastrati A, Mehilli J, Schuhlen $\mathrm{H}$ et al. A clinical trial of abciximab in elective percutaneous coronary intervention after pretreatment with clopidogrel. N Engl J Med. 2004;350:232-8.

20. Patti G, Nusca A, Mangiacapra F et al. Point-of-care measurement of clopidogrel responsiveness predicts clinical outcome in patients undergoing percutaneous coronary intervention results of the ARMYDA-PRO (Antiplatelet therapy for Reduction of MYocardial Damage during Angioplasty-Platelet Reactivity Predicts Outcome) study. J Am Coll Cardiol. 2008;52:1128-33.

21. Shaw JA, Andrianopoulos N, Duffy S et al. Renal impairment is an independent predictor of adverse events post coronary intervention in patients with and without drug-eluting stents. Cardiovascular Revascularization Medicine 2008; 9: 218-223.

22. Stein B, Weintraub WS, Gebhart SP et al. Influence of diabetes mellitus on early and late outcome after percutaneous transluminal coronary angioplasty. Circulation 1995; 91: 979-989.

23. Steinhubl S, Aronow H, Brennan DM et al. Clinical predictors of major atherothrombotic events 1 year following elective PCI: insights from the CREDO trial. Circulation. 2003;108(Suppl IV):IV-457. Abstract 2099.

24. van Werkum JW, Heestermans AA, Zomer AC et al. Predictors of coronary stent thrombosis: the Dutch Stent Thrombosis Registry. J Am Coll Cardiol. 2009;53(16):1399-409

25. Geisler T, Graß D, Bigalke B et al. The Residual Platelet Aggregation after Deployment of Intracoronary Stent (PREDICT) score. JThromb Haemost 2008; 6: 54-61.

26. Elsenberg EH, van Werkum JW, van de Wal RM et al. The influence of clinical characteristics, laboratory and inflammatory markers on 'high on-treatment platelet reactivity' as measured with different platelet function tests. Thromb Haemost 2009;102:719-27

27. Bonello L, Camoin-Jau L, Armero S et al. Tailored clopidogrel loading dose according to platelet reactivity monitoring to prevent acute and subacute stent thrombosis. Am J Cardiol 2009; 103: 5-10. 


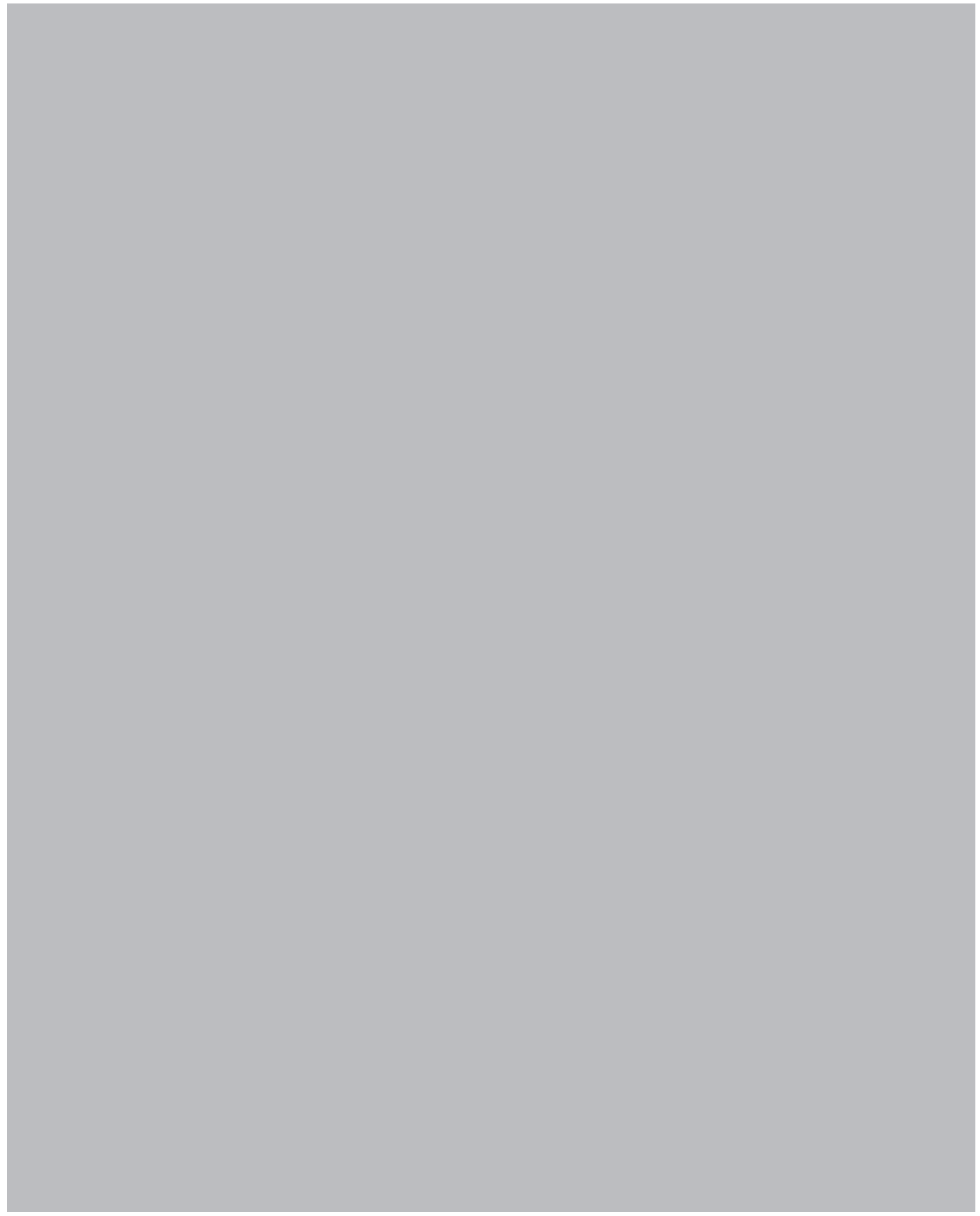




\section{Part III}

Minor contribution of genetic variation in the $\mathrm{P}_{2} \mathrm{Y}_{12}$-receptor to the response to clopidogrel 


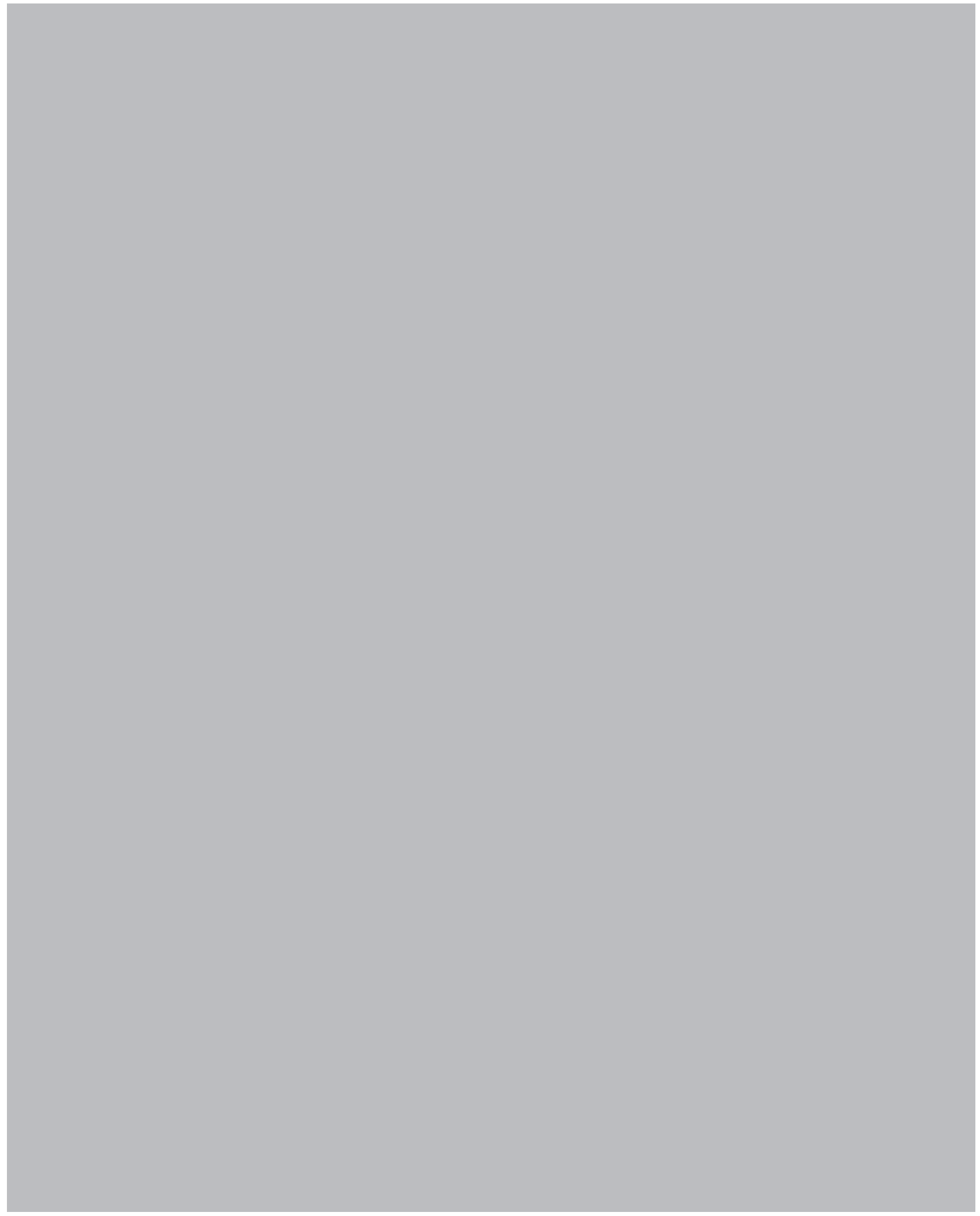




\section{Chapter 8}

The influence of variation in the $\mathrm{P}_{2} \mathrm{Y}_{12}$ receptor gene on in vitro
platelet inhibition with the direct $\mathrm{P}_{2} \mathrm{Y}_{12}$ antagonist cangrelor

Thromb Haemost 2010; 103(2):379-86

Heleen J Bouman Jochem W van Werkum

Goran Rudež

Frank WG Leebeek

Adrian Kruit

Christian M Hackeng

Jurriën M ten Berg

Moniek PM de Maat

Henk JT Ruven

Department of Cardiology, St. Antonius Hospital Nieuwegein, the Netherlands Department of Hematology, Erasmus University Medical Center Rotterdam, the Netherlands Department of Clinical Chemistry, St. Antonius Hospital Nieuwegein, the Netherlands 


\section{ABSTRACT}

\section{Background}

Novel $P_{2} Y_{12}$ inhibitors are in development to overcome the occurrence of atherothrombotic events associated with poor responsiveness to the widely used $\mathrm{P}_{2} \mathrm{Y}_{12}$ inhibitor clopidogrel. Cangrelor is an intravenously administered $\mathrm{P}_{2} \mathrm{Y}_{12}$ inhibitor that does not need metabolic conversion to an active metabolite for its antiplatelet action, and as a consequence exhibits a more potent and consistent antiplatelet profile as compared to clopidogrel.

\section{Objectives}

To determine the contribution of variation in the $\mathrm{P}_{2} \mathrm{Y}_{12}$ receptor gene to platelet aggregation after in vitro partial $\mathrm{P}_{2} \mathrm{Y}_{12}$ receptor blockade with the direct antagonist cangrelor

\section{Methods}

Optical aggregometry was performed at baseline and after in vitro addition of 0.05 and $0.25 \mu \mathrm{mol} / \mathrm{L}$ cangrelor to the platelet-rich plasma of 254 healthy subjects. Five haplotype-tagging (ht)-SNPs covering the entire $\mathrm{P}_{2} \mathrm{Y}_{12}$ receptor gene were genotyped (rs6798347 C>t, rs6787801T>c, rs9859552C>a, rs6801273A>g and rs2046934T>c [T744C]) and haplotypes were inferred.

\section{Results}

The minor c allele of SNP rs6787801 was associated with a $5 \%$ lower $20 \mu \mathrm{mol} / \mathrm{L}$ ADP-induced peak platelet aggregation ( $0.05 \mu \mathrm{mol} / \mathrm{L}$ cangrelor, $\mathrm{p}<0.05)$. Aa homozygotes for SNP rsg859552 showed $20 \%$ and $17 \%$ less inhibition of platelet aggregation with cangrelor when compared to CC homozygotes ( 0.05 and $0.25 \mu \mathrm{mol} / \mathrm{L}$ cangrelor respectively; $\mathrm{P}<0.05$ ). Results of the haplotype analyses were consistent with those of the single SNPs.

\section{Conclusions}

Polymorphisms of the $\mathrm{P}_{2} \mathrm{Y}_{12}$ receptor gene contribute significantly to the interindividual variability in platelet inhibition after partial in vitro blockade with the $\mathrm{P}_{2} \mathrm{Y}_{12}$ antagonist cangrelor. 


\section{INTRODUCTION}

The efficacy of clopidogrel is seriously affected by a wide interindividual variability in response ${ }^{1,2}$. Several mechanisms have been proposed to contribute to this phenomenon including inter-subject differences in gastro intestinal drug absorption, variation in metabolic drug-conversion, and pretreatment platelet reactivity ${ }^{3-9}$. Genetic polymorphisms of the $\mathrm{P}_{2} \mathrm{Y}_{12}$ receptor have also been reported to increase ADP-induced platelet reactivity and to limit the magnitude of platelet inhibition by clopidogrel ${ }^{10-12}$.

Several novel $\mathrm{P}_{2} \mathrm{Y}_{12}$ receptor antagonists have been developed to overcome the problem of nonresponsiveness to clopidogrel ${ }^{13}$. Cangrelor (formerly known as AR-C69931MX, The Medicines Company, Parsippany NJ USA) is a potent $\mathrm{P}_{2} \mathrm{Y}_{12}$ inhibitor that reaches a higher level of platelet inhibition than clopidogrel ${ }^{14}$. It reversibly binds to the $\mathrm{P}_{2} \mathrm{Y}_{12}$ receptor after intravenous administration and does not require conversion to an active metabolite for its antiplatelet action ${ }^{14,15}$. These features allow a direct study of the effects of genetic polymorphisms of the $\mathrm{P}_{2} \mathrm{Y}_{12}$ receptor on platelet aggregation after in vitro $\mathrm{P}_{2} \mathrm{Y}_{12}$ receptor blockade with cangrelor.

The aim of the present study was to determine the contribution of genetic $P_{2} Y_{12}$ receptor polymorphisms to variation in platelet aggregation after partial in vitro blockade of the $\mathrm{P}_{2} \mathrm{Y}_{12}$ receptor with the direct antagonist cangrelor.

\section{METHODS}

\section{Study population}

A total of 254 healthy volunteers without coronary artery disease were included. Due to technical failure of the aggregometer $(n=5)$ and missing samples $(n=7), 12$ subjects were excluded from the analysis. The characteristics of the remaining 242 subjects are shown in Table 1.

Subjects were ineligible if they had used any medication in the past 7 days known to affect platelet function. Other exclusion criteria were known platelet dysfunction or bleeding disorder, use of coumadins, a platelet count $<150 \times 10^{9} / \mathrm{L}$ and age $<18$ years. Data on risk factors and co-morbidities were carefully obtained using a standardized questionnaire. Physical examination of patients was performed by research physicians. Smoking was defined as any cigarette smoking in the last month. Diabetes mellitus was defined according to the World Health Organization criteria. All subjects gave informed consent and the study protocol complied with the declaration of Helsinki and was approved by the local Institutional Review Board.

\begin{tabular}{lc} 
Table $\mathbf{1} \mid$ Characteristics of the study population \\
\hline Population Characteristics $(\mathrm{n}=\mathbf{2 4 2})$ & $162(64.1 \%)$ \\
\hline Male & $49.7 \pm 12.2$ \\
Age (yrs) & $229(94.6 \%)$ \\
Caucasian & $8(5.5 \%)$ \\
Diabetes mellitus & $45(18.5 \%)$ \\
Current smoking & $252 \pm 51$ \\
Platelet Count (109/L) & $271 \pm 21$ \\
Platelet Count in PRP (10\%/L) & $8.3 \pm 0.9$ \\
Mean Platelet Volume (fL) & $8.9 \pm 0.7$ \\
\hline
\end{tabular}

Values are presented as $n(\%)$ or mean $\pm s d$ 
Part III | chapter 8

\section{Sample Collection}

To avoid platelet activation during venapuncture, blood was drawn without a tourniquet from the antecubital vein into non-vacuum K3-EDTA and citrate (3.2\%) tubes (Sarstedt, Nümbrecht, Germany) after discarding the first $10 \mathrm{ml}$ of blood. DNA isolation and measurements of platelet count, mean platelet volume and hemoglobin were performed in $\mathrm{K}_{3}$-EDTA anticoagulated blood. Citrated blood was used for platelet function testing.

\section{Platelet function testing}

Citrated blood samples were centrifuged for 10 minutes at $120 \mathrm{~g}$ to obtain platelet rich plasma (PRP), followed by an additional centrifugation for 15 minutes at $850 \mathrm{~g}$ to recover platelet poor plasma (PPP). "Classical" light transmittance aggregometry (LTA) was performed on an APACT 4004 (LaBiTec, Ahrensburg, Germany), using PPP to set the aggregation to $100 \%$. The PRP was adjusted with autologous PPP to achieve a final platelet count between 250 and $300 \times 10^{9} / \mathrm{L}$. Two-hundred-and-fifty $\mu$ I PRP was then pipetted into each cuvette, followed by incubation of the samples for 5 minutes with either $25 \mu \mathrm{l} 0.9 \% \mathrm{NaCl}$ (for baseline platelet aggregation) or cangrelor in final concentrations of 0.05 $\mu \mathrm{mol} / \mathrm{L}$ and $0.25 \mu \mathrm{mol} / \mathrm{L}$. These concentrations are located in the linear and the end phase of the $\mathrm{S}$-shaped curve plotting the concentration of cangrelor against ADP induced platelet aggregation ${ }^{14}$. The final concentration of $0,25 \mu \mathrm{mol} / \mathrm{L}$ cangrelor corresponds with the infusion rate of $2 \mu \mathrm{g} / \mathrm{kg} / \mathrm{min}$ that has previously been used in a phase II dose-finding study ${ }^{14}$. This concentration corresponds to approximately half of the plasma concentration reached with the dosing regimen currently being evaluated in clinical trials ${ }^{16}$. Since a lower level of $P_{2} Y_{12}$ inhibition is generally associated with an increased variability of platelet aggregation, a more pronounced effect of genetic $\mathrm{P}_{2} \mathrm{Y}_{12}$ receptor polymorphisms was to be expected with the concentrations 0.05 and $0.25 \mu \mathrm{mol} / \mathrm{L}$ cangrelor. After incubation with cangrelor, platelets were stimulated with adenosine diphosphate (ADP) in two final concentrations of 5 and $20 \mu \mathrm{mol} / \mathrm{L}$. Both "peak" (maximal) and "late" (at 360 seconds) absolute \% platelet aggregation were measured ${ }^{17}$. The absolute change in platelet aggregation from baseline (i.e. the cangrelor naïve sample) was measured in order to determine the magnitude of inhibition of platelet aggregation (IPA).

\section{Selection of Single Nucleotide Polymorphisms (SNPs) in the $\mathrm{P}_{2} \mathrm{Y}_{12}$ receptor gene} Haplotype-tagging SNPs (ht-SNPs) were selected according to the approach described previously ${ }^{18}$. Based on the linkage disequilibrium (LD) map of the $\mathrm{P}_{2} \mathrm{Y}_{12}$ locus provided by the International HapMap Project (phase Il, October 2007; http://www.hapmap.org/), blocks of haplotypes with a frequency $>5 \%$ and their ht-SNPs $(n=6)$ were defined using Haploview software (version 3.3, http://www.broad.mit. edu/mpg/haploview/index.php). In the present study population, these haplotypes together cover $92 \%$ of the common DNA sequence variation in the entire $P_{2} Y_{12}$ receptor gene and its $5 \mathrm{~kb}$ flanking regions. None of the ht-SNPs results in an amino acid change, nor are located within consensus transcription factor binding sites in the 3 -kb promoter region, exon-intron junctions, predicted splicing enhancer motifs, the $3-k b$ 3'UTR-region, or domains that are highly conserved among species. SNPs I-III tag the promoter, exon 1 and a part of the intron 1 region, while SNPs IV and V tag the remaining part of intron 1, as well as the entire exon 2, intron 2, exon 3 and the 3 ' UTR region.

Since $97 \%$ linkage appeared to exist between rs9859552 and rs9848789, rs9848789 was excluded from the analysis in the present study. Further details on the 5 remaining ht-SNPs are shown in Table 2. 
$\mathrm{P}_{2} \mathrm{Y}_{12}$ Receptor Gene Polymorphisms and Cangrelor

\begin{tabular}{lllllll} 
Table 2 & Characteristics of the selected ht-SNPs of the $\mathrm{P}_{2} \mathrm{Y}_{12}$ receptor gene \\
\hline SNP & $\begin{array}{l}\text { NCBI dbSNP } \\
\text { accession } \\
\text { number }\end{array}$ & Location* & Allelet & Frequencies (genotype/n) \\
\hline I & rs6798347 & Promoter c.-281-3614 & $\mathrm{C}>\mathrm{t}$ & $\mathrm{CC} / 150$ & $\mathrm{Ct} / 79$ & $\mathrm{tt} / 8$ \\
II & rs6787801 & Intron c.-217+2739 & $\mathrm{T}>\mathrm{C}$ & $\mathrm{TT} / 59$ & $\mathrm{Tc} / 115$ & $\mathrm{cc} / 64$ \\
III & rs9859552 & Intron c.-217+11494 & $\mathrm{C}>\mathrm{a}$ & $\mathrm{CC} / 174$ & $\mathrm{Ca} / 64$ & $\mathrm{aa} / 4$ \\
IV & rs6801273 & Intron c.-216-4445 & $\mathrm{A}>\mathrm{g}$ & $\mathrm{AA} / 92$ & $\mathrm{Ag} / 125$ & $\mathrm{gg} / 25$ \\
- & rs9848789 & Intron c.-216-377 & $\mathrm{G}>\mathrm{a}$ & $\mathrm{GG} / 172$ & $\mathrm{Ga} / 63$ & $\mathrm{aa} / 6$ \\
$\mathrm{~V} ¥$ T744C & rs2046934 & Intron c.-15+742 & $\mathrm{T}>\mathrm{C}$ & $\mathrm{TT} / 152$ & $\mathrm{Tc} / 85$ & $\mathrm{cc} / 5$ \\
\hline
\end{tabular}

*Annotation of the selected ht-SNPs is according to the nomenclature recommendations of the Human Genome Variation Society, with nucleotide +1 being the A of the ATG-translation initiation codon ${ }^{34}$. + The common and minor alleles for each SNP are presented as common > minor, in upper and lower case respectively. The c allele for SNP II appeared to be the minor allele in a large cohort of patients from a previous performed study18. $¥ S N P V[T 744 C]$ was firstly described by Fontana et a ${ }^{10}$.

\section{Genotyping of $\mathrm{P}_{2} \mathrm{Y}_{12}$ receptor polymorphisms}

The 5 selected ht-SNPs were genotyped using Custom TaqMan Genotyping Assays (Applied Biosystems, Foster City, USA) under standard conditions ${ }^{19}$. The nucleotide sequences of the primers and probes used for each assay are available upon request. End-point fluorescence was measured on the $A B I$ $7900 \mathrm{HT}$ instrument (Applied Biosystems, Foster City, USA) and clustered according to genotype using SDS 2.2.2 software (Applied Biosystems, Foster City, USA). A random selection of $10 \%$ of the samples was re-analysed, and the results were confirmed in 99.7\%. All SNPs were in Hardy-Weinberg equilibrium. Haplo.Stats software (http://mayoresearch.mayo.edu/mayo/research/biostat/schaid.cfm) was used to infer haplotypes from the unphased SNP genotype data.

\section{Sample size and Statistical Analysis}

Sample size calculation was based on the pre-defined criterium to include only haplotypes with a frequency of $>5 \%$ in the statistical analysis. In addition, according to the NCBI dbSNP database (http://www.ncbi.nlm.nih.gov/sites/entrez?db=snp), all genotyped haplotype-tagging SNPs occur with an allelic frequency of at least $5 \%$. Assuming a minimum group frequency of $5 \%$, the study requires 250 subjects to detect a statistical significant difference between genotype groups of 1 times the standard deviation in size, with a statistical power of $80 \%$ (alpha $=0.05$, two tailed).

Associations between single SNP genotypes and platelet aggregation as well as IPA, were tested using an ANCOVA, followed by the Fisher's LSD post-hoc test (SPSS for Windows version 14.0; SPSS Inc, (hicago, USA). Based on the obtained platelet aggregation and IPA values, a dominant model was considered appropriate for testing the effects of SNP II genotypes (i.e. TT vs Tc $+\mathrm{cc}$ ) and a recessive model for SNP III (i.e. CC + Ca vs aa). For the other SNPs, no obvious recessive or dominant effect could be observed and these SNPs were therefore tested in an additive model, comparing hetero- and homozygotes for the minor allele to homozygotes for the common allele. To confirm observed trends, an additional analysis was performed comparing the average effects of SNP genotypes across the range of cangrelor concentrations (represented by the combined $p$-value). Analyses of associations between haplotypes and platelet aggregation parameters were performed using the haplo.glm model in Haplo.Stats software. Effects of the haplotypes were calculated as mean difference \pm SEM from the 
Part III | chapter 8

reference haplotype per single allele, using the most frequent haplotype as the reference (Href). In both SNP and haplotype analysis, results were adjusted for the known confounders age, gender, diabetes and smoking status. All platelet aggregation parameters are presented as absolute percentages and $p$ values $<0.05$ were considered statistically significant.

\section{RESULTS}

\section{Platelet Function}

Individual values of 5 and $20 \mu \mathrm{mol} / \mathrm{L}$ ADP-induced peak and late aggregation at baseline and after the addition of 0.05 and $0.25 \mu \mathrm{mol} / \mathrm{L}$ cangrelor are depicted in Figure 1. Baseline mean peak and late platelet aggregation values were between 80 and $85 \%$ for 5 and $20 \mu \mathrm{mol} / \mathrm{L}$ ADP. Cangrelor greatly reduced the absolute magnitude of platelet aggregation, with an absolute IPA of up to $75 \%$ for late 5 $\mu \mathrm{mol} / \mathrm{L}$ ADP induced platelet aggregation. Nonetheless, significant interindividual variability in cangrelor-inhibited platelet aggregation was evident, in particular with $20 \mu \mathrm{mol} / \mathrm{L}$ ADP induced platelet aggregation.

Peak Aggregation (5 mmol/L ADP)

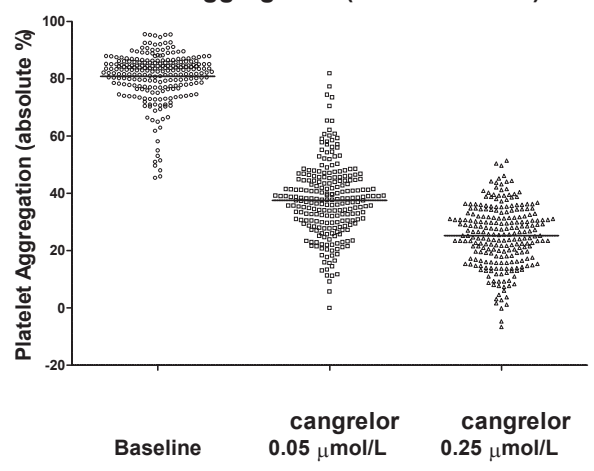

Peak Aggregation (20 $\mu \mathrm{mol} / \mathrm{L}$ ADP)

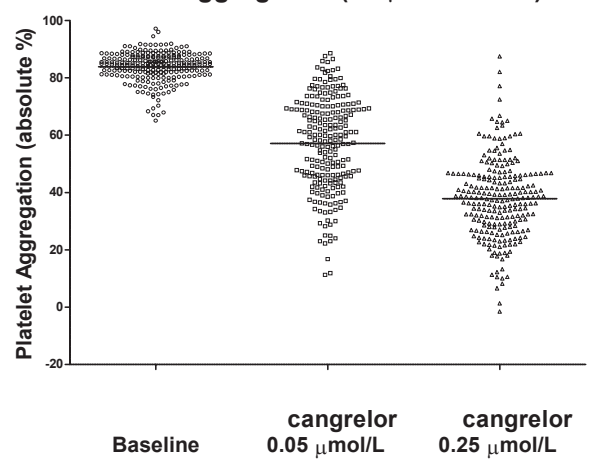

Late Aggregation (5 $\mu \mathrm{mol} / \mathrm{L}$ ADP)

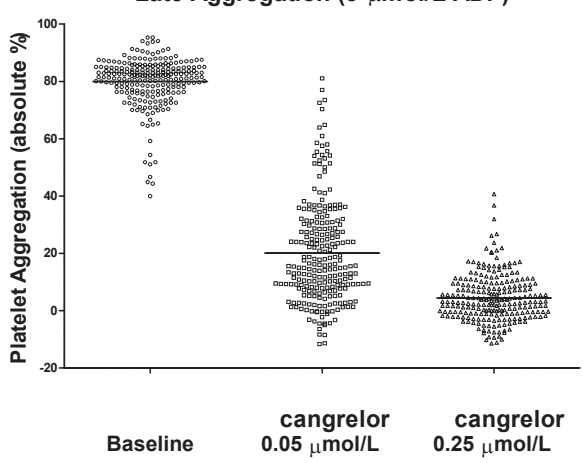

Late Aggregation (20 $\mu \mathrm{mol} / \mathrm{L}$ ADP)

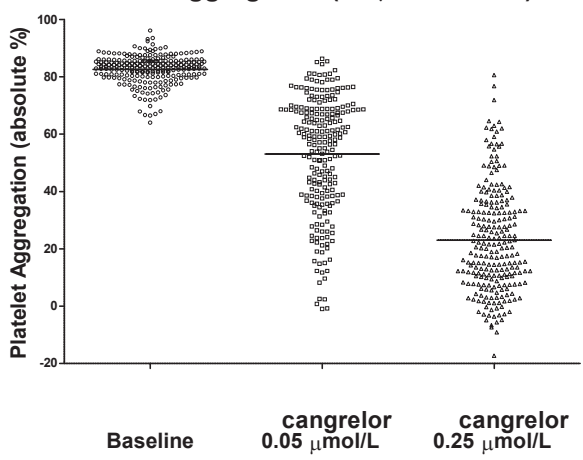

Figure 1 | Individual values of 5 and $20 \mu \mathrm{mol} / \mathrm{L}$ ADP induced peak and late platelet aggregation at baseline and after incubation with $0.05 \mu \mathrm{mol} / \mathrm{L}$ and $0.25 \mu \mathrm{mol} / \mathrm{L}$ cangrelor. Data are presented as the absolute percentage of platelet aggregation, with lines indicating mean platelet aggregation values. 
Table 3 | Associations between SNP genotypes and platelet aggregation and IPA

\begin{tabular}{|c|c|c|c|c|c|c|c|c|}
\hline \multirow{2}{*}{$\begin{array}{l}\text { SNP } \\
\text { Peak Agg }\end{array}$} & \multirow{2}{*}{$\begin{array}{l}\text { Genotype } \\
\text { gregation }\end{array}$} & \multicolumn{3}{|c|}{ Platelet Aggregation (absolute \%) } & \multicolumn{4}{|c|}{ IPA (absolute \%) } \\
\hline & & $\begin{array}{c}\text { Baseline } \\
\text { (mean } \pm \text { SEM) }\end{array}$ & $\begin{array}{c}0.05 \mu \mathrm{mol} / \mathrm{L} \\
\text { cangrelor } \\
\text { (mean } \pm \mathrm{SEM} \text { ) }\end{array}$ & $\begin{array}{c}0.25 \mu \mathrm{mol} / \mathrm{L} \\
\text { cangrelor } \\
\text { (mean } \pm \mathrm{SEM} \text { ) }\end{array}$ & $\begin{array}{c}\text { Combined } \\
p \text {-value* }\end{array}$ & $\begin{array}{c}0.05 \mu \mathrm{mol} / \mathrm{L} \\
\text { cangrelor } \\
\text { (mean } \pm \mathrm{SEM} \text { ) }\end{array}$ & $\begin{array}{c}0.25 \mu \mathrm{mol} / \mathrm{L} \\
\text { cangrelor } \\
\text { (mean } \pm \mathrm{SEM} \text { ) }\end{array}$ & $\begin{array}{c}\text { Combined } \\
p \text {-value* }\end{array}$ \\
\hline \multirow[t]{3}{*}{ I } & $\mathrm{CC}$ & $83 \pm 0.5$ & $59 \pm 1.6$ & $40 \pm 1.4$ & & $24 \pm 1.4$ & $44 \pm 1.3$ & \\
\hline & $\mathrm{Ct}$ & $84 \pm 0.7$ & $57 \pm 2.1$ & $38 \pm 1.7$ & n.s. & $27 \pm 1.8$ & $46 \pm 1.6$ & 0.082 \\
\hline & $\mathrm{tt}$ & $83 \pm 1.9$ & $53 \pm 5.6$ & $34 \pm 4.8$ & 0.095 & $30 \pm 5.1$ & $49 \pm 4.5$ & 0.087 \\
\hline$P$ value & & n.s. & n.s. & n.s. & & n.s. & n.s. & \\
\hline \multirow[t]{2}{*}{ II } & TT & $85 \pm 0.8$ & $63 \pm 2.3$ & $41 \pm 1.9$ & & $22 \pm 2.0$ & $43 \pm 1.8$ & \\
\hline & $\mathrm{Tc}+\mathrm{cc}$ & $83 \pm 0.5$ & $57 \pm 1.5$ & $38 \pm 1.2$ & 0.004 & $26 \pm 1.3$ & $45 \pm 1.2$ & 0.033 \\
\hline$P$ value & & 0.076 & 0.021 & n.s. & & 0.031 & n.s. & \\
\hline \multirow[t]{2}{*}{ III } & $\mathrm{CC}+\mathrm{Ca}$ & $84 \pm 0.5$ & $58 \pm 1.4$ & $39 \pm 1.2$ & & $26 \pm 1.2$ & $45 \pm 1.1$ & \\
\hline & aа & $81 \pm 2.6$ & $72 \pm 7.8$ & $50 \pm 6.6$ & 0.035 & $10 \pm 6.7$ & $32 \pm 6.1$ & 0.002 \\
\hline$P$ value & & n.s. & 0.081 & 0.097 & & 0.025 & 0.037 & \\
\hline \multirow[t]{3}{*}{ IV } & AA & $84 \pm 0.6$ & $61 \pm 1.9$ & $40 \pm 1.6$ & & $24 \pm 1.7$ & $44 \pm 1.5$ & \\
\hline & $\mathrm{Ag}$ & $83 \pm 0.6$ & $57 \pm 1.7$ & $38 \pm 1.4$ & 0.045 & $27 \pm 1.5$ & $45 \pm 1.3$ & n.s. \\
\hline & gg & $83 \pm 1.1$ & $61 \pm 3.5$ & $40 \pm 2.8$ & n.s. & $23 \pm 3.1$ & $43 \pm 2.6$ & n.s. \\
\hline$P$ value & & n.s. & $0.097^{\dagger}$ & n.s. & & n.s. & n.s. & \\
\hline \multirow[t]{3}{*}{ V } & TT & $83 \pm 0.5$ & $57 \pm 1.6$ & $38 \pm 1.4$ & & $26 \pm 1.5$ & $45 \pm 1.3$ & \\
\hline & $\mathrm{Tc}$ & $84 \pm 0.6$ & $60 \pm 2.0$ & $40 \pm 1.6$ & n.s. & $24 \pm 1.7$ & $44 \pm 1.5$ & n.s. \\
\hline & $\mathrm{cc}$ & $85 \pm 2.4$ & $71 \pm 7.1$ & $38 \pm 6.0$ & n.s. & $14 \pm 6.3$ & $47 \pm 5.6$ & n.s. \\
\hline$P$ value & & n.s. & $0.062 \ddagger$ & n.s. & & $0.068 \ddagger$ & n.s. & \\
\hline \multicolumn{2}{|c|}{ Late Aggregation } & $\begin{array}{c}\text { Baseline } \\
\text { (mean } \pm \text { SEM) }\end{array}$ & $\begin{array}{c}0.05 \mu \mathrm{mol} / \mathrm{L} \\
\text { cangrelor } \\
\text { (mean } \pm \mathrm{SEM})\end{array}$ & $\begin{array}{c}0.25 \mu \mathrm{mol} / \mathrm{L} \\
\text { cangrelor } \\
\text { (mean } \pm \mathrm{SEM} \text { ) }\end{array}$ & $\begin{array}{c}\text { Combined } \\
p \text {-value* }\end{array}$ & $\begin{array}{c}0.05 \mu \mathrm{mol} / \mathrm{L} \\
\text { cangrelor } \\
\text { (mean } \pm \mathrm{SEM} \text { ) }\end{array}$ & $\begin{array}{c}0.25 \mu \mathrm{mol} / \mathrm{L} \\
\text { cangrelor } \\
\text { (mean } \pm \mathrm{SEM} \text { ) }\end{array}$ & $\begin{array}{c}\text { Combined } \\
p \text {-value* }\end{array}$ \\
\hline \multirow[t]{3}{*}{ I } & $\mathrm{CC}$ & $82 \pm 0.5$ & $55 \pm 2.0$ & $24 \pm 1.8$ & & $27 \pm 1.9$ & $58 \pm 1.7$ & \\
\hline & $\mathrm{Ct}$ & $83 \pm 0.6$ & $53 \pm 2.6$ & $24 \pm 2.2$ & n.s. & $30 \pm 2.4$ & $59 \pm 2.1$ & n.s. \\
\hline & $\mathrm{tt}$ & $82 \pm 1.8$ & $48 \pm 7.1$ & $16 \pm 6.3$ & 0.095 & $33 \pm 6.6$ & $65 \pm 6.1$ & n.s. \\
\hline$P$ value & & n.s. & n.s. & n.s. & & n.s. & n.s. & \\
\hline \multirow[t]{2}{*}{ II } & TT & $83 \pm 0.7$ & $60 \pm 2.9$ & $27 \pm 2.5$ & & $23 \pm 2.7$ & $56 \pm 2.4$ & \\
\hline & $\mathrm{Tc}+\mathrm{cc}$ & $82 \pm 0.5$ & $53 \pm 1.9$ & $23 \pm 1.6$ & 0.002 & $29 \pm 1.7$ & $59 \pm 1.5$ & 0.009 \\
\hline$P$ value & & 0.064 & 0.019 & 0.091 & & 0.025 & n.s. & \\
\hline \multirow[t]{2}{*}{ III } & $\mathrm{CC}+\mathrm{Ca}$ & $82 \pm 0.5$ & $54 \pm 1.7$ & $24 \pm 1.5$ & & $28 \pm 1.6$ & $59 \pm 1.4$ & \\
\hline & aа & $81 \pm 2.6$ & $73 \pm 9.7$ & $40 \pm 8.6$ & 0.014 & $8.3 \pm 8.9$ & $41 \pm 8.2$ & 0.002 \\
\hline$P$ value & & n.s. & 0.056 & 0.062 & & 0.026 & 0.037 & \\
\hline \multirow[t]{3}{*}{ IV } & AA & $83 \pm 0.6$ & $56 \pm 2.4$ & $25 \pm 2.1$ & & $26 \pm 2.2$ & $57 \pm 2.0$ & \\
\hline & $\mathrm{Ag}$ & $82 \pm 0.5$ & $53 \pm 2.1$ & $23 \pm 1.8$ & 0.068 & $30 \pm 1.9$ & $60 \pm 1.8$ & n.s. \\
\hline & gg & $82 \pm 1.1$ & $57 \pm 4.3$ & $27 \pm 3.7$ & n.s. & $26 \pm 4.0$ & $55 \pm 3.5$ & n.s. \\
\hline Pvalue & & n.s. & n.s. & n.s. & & n.s. & n.s. & \\
\hline \multirow[t]{2}{*}{ V } & TT & $82 \pm 0.5$ & $53 \pm 2.1$ & $22 \pm 1.8$ & & $29 \pm 1.9$ & $60 \pm 1.7$ & \\
\hline & Tc & $83 \pm 0.6$ & $56 \pm 2.4$ & $26 \pm 2.1$ & 0.034 & $27 \pm 2.3$ & $56 \pm 2.1$ & 0.092 \\
\hline \multirow[t]{2}{*}{ Pvalue } & cc & $84 \pm 2.3$ & $67 \pm 8.8$ & $28 \pm 7.8$ & 0.070 & $16 \pm 8.1$ & $55 \pm 7.5$ & n.s. \\
\hline & & n.s. & n.s. & $0.092+$ & & n.s. & n.s. & \\
\hline
\end{tabular}

The mean $( \pm$ SEM) absolute \% platelet aggregation as well as the mean ( \pm SEM) IPA are presented per SNP genotype. *The combined $p$-value represents the result of the additional statistical analysis comparing the average effect of SNP genotypes across the range of cangrelor concentrations. For SNPs tested in the additive model, $p$-values are given for the effect of theterozygotes and $¥$ homozygotes for the minor allele as compared to homozygotes for the common allele. $P$ values $>0.1$ are denoted as n.s. (non significant). 
Part III | chapter 8

\section{Single Nucleotide Polymorphisms and Platelet Function}

Baseline $20 \mu \mathrm{mol} / \mathrm{L}$ ADP induced platelet aggregation was not associated with one of the SNP genotypes (Table 3). Carriers of the minor c allele for SNP II exhibited significantly lower platelet aggregation values and a corresponding larger IPA after incubation with $0.05 \mu \mathrm{mol} / \mathrm{L}$ cangrelor (20 $\mu \mathrm{mol} / \mathrm{L}$ ADP, both peak and late) as compared to TT homozygotes. The magnitude of the effect ranged from 4.5 to 7.0 absolute \% aggregation ( $p<0.05$ for all).

This effect was substantially attenuated after stronger inhibition of platelet aggregation with 0.25 $\mu \mathrm{mol} / \mathrm{L}$ cangrelor. Subjects carrying the aa genotype for SNP III showed a trend towards higher 20 $\mu \mathrm{mol} / \mathrm{L}$ ADP induced platelet aggregation after incubation with 0.05 and $0.25 \mu \mathrm{mol} / \mathrm{L}$ cangrelor as compared to the combined CC + Ca genotype (both peak and late, $p<0.1$ for all). This trend was confirmed in the analysis combining the effects of SNP III on platelet aggregation across the range of cangrelor concentrations (combined $\mathrm{p}<0.05$ for aa vs CC $+\mathrm{Ca}$ ). Correspondingly, the IPA was $16 \%$ and $20 \%$ smaller in aa homozygotes after incubation with $0.05 \mu \mathrm{mol} / \mathrm{L}$ cangrelor (peak and late respectively, $\mathrm{p}<0.05$ ). This observation was consistent after stronger inhibition with $0.25 \mu \mathrm{mol} / \mathrm{L}$ cangrelor, with differences of $13 \%$ and $17 \%$ IPA between aa homozygotes and the combined CC + Ca genotype (peak and late respectively, $\mathrm{p}<0.05$ and combined $p=0.002$ for both). An overall trend towards higher platelet aggregation and a corresponding smaller IPA was observed in homozygote cc carriers for SNP V as compared to TT homozygotes after inhibition of $20 \mu \mathrm{mol} / \mathrm{L}$ ADP induced platelet aggregation with $0.05 \mu \mathrm{mol} / \mathrm{L}$ cangrelor. Absolute differences of $13 \%$ in peak aggregation and $12 \%$ in IPA (peak) were observed (cc vs TT; p 0.06 and p 0.07 respectively). However, this finding was not statistically significant and not evident after inhibition of platelet aggregation with $0.25 \mu \mathrm{mol} / \mathrm{L}$ cangrelor. No clear associations were observed between SNP I and IV genotypes and absolute platelet aggregation values or IPA as measured with $20 \mu \mathrm{mol} / \mathrm{L}$ induced platelet activation after incubation with 0.05 and $0.25 \mu \mathrm{mol} / \mathrm{L}$ cangrelor. Similar trends and results were observed for $5 \mu \mathrm{mol} / \mathrm{L}$ ADP-induced platelet function results (data not shown).

\section{Haplotypes and Platelet Function}

Of the inferred haplotypes, six had a frequency higher than $5 \%$ (Table 4). For $20 \mu \mathrm{mol} / \mathrm{L}$ ADP induced baseline aggregation, no differences were observed between the five haplotypes and the reference haplotype (Figure 2).

Haplotype $\mathrm{C}$ was associated with significantly higher peak and late aggregation after incubation with $0.05 \mu \mathrm{mol} / \mathrm{L}$ cangrelor (mean difference $6.6 \%$ and $7.7 \%$ per allele respectively, $\mathrm{p}<0.05)$. Correspondingly, IPA was smaller for haplotype $C$ as compared to the reference haplotype (5.9\% for peak and $7.0 \%$ for late, $\mathrm{p}<0.05$ for both). Similar results for haplotype $C$ were observed after 0.25 $\mu \mathrm{mol} / \mathrm{L}$ cangrelor, but results were only statistically significant for the parameters late aggregation and IPA (late) (mean absolute difference $6.9 \%$ and $5.9 \%$ per allele respectively, $\mathrm{p}<0.05$ for both).

Table 4 | Characteristics of haplotypes A-F

\begin{tabular}{lcccccc}
\hline Haplotype & \multicolumn{4}{c}{ SNP } & & $\begin{array}{c}\text { Frequency } \\
\text { (\%) }\end{array}$ \\
\hline & I & II & III & IV & V & \\
\hline A & t & T & C & g & T & $10 \%$ \\
B & t & T & C & A & T & $9 \%$ \\
C & C & T & C & A & C & $15 \%$ \\
D & C & T & a & A & T & $14 \%$ \\
E [Href] & C & C & C & g & T & $24 \%$ \\
F & C & C & C & A & T & $20 \%$ \\
\hline
\end{tabular}

Minor alleles are presented in lower case. Href: reference haplotype. 
Peak aggregation
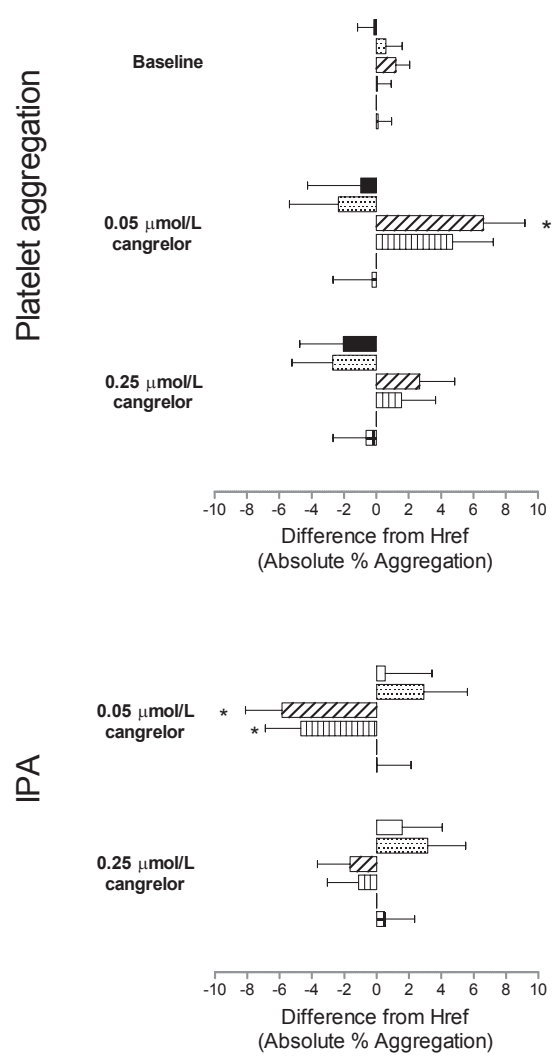

Late aggregation
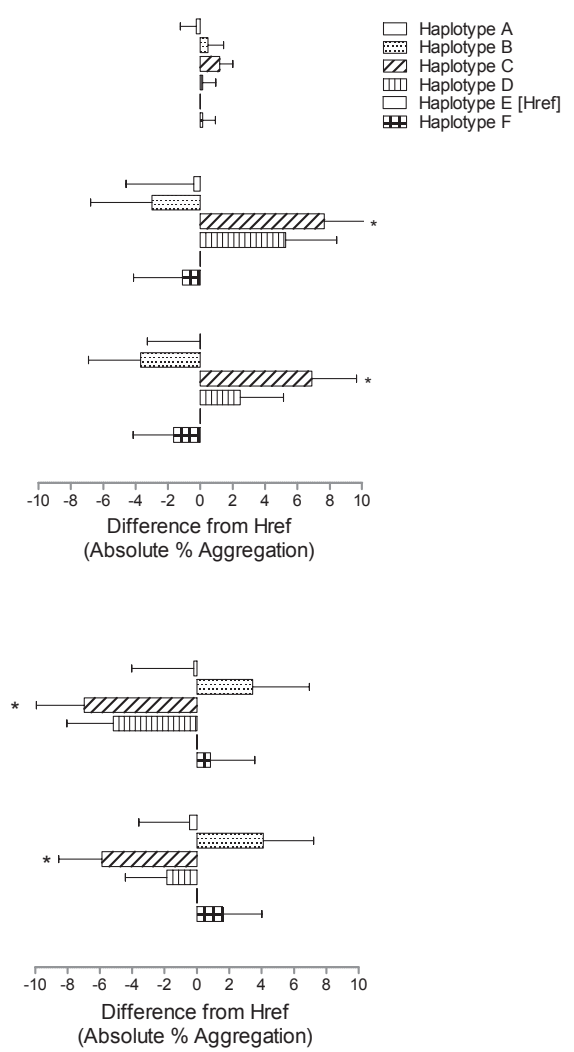

Figure 2 | Absolute \% difference in platelet aggregation and IPA between haplotypes A-F and the reference haplotype (20 $\mathrm{mol} / \mathrm{L}$ ADP induced, both peak and late) at baseline and after the addition of 0.05 and 0.25 $\mu \mathrm{mol} / \mathrm{L}$ cangrelor. Results are presented as the mean difference \pm SEM per single haplotype allele.

Haplotype D also showed an overall trend towards higher platelet aggregation values and smaller IPA as compared to the reference haplotype. After incubation with $0.05 \mu \mathrm{mol} / \mathrm{L}$ cangrelor, peak and late aggregation were $4.7 \%$ and $5.3 \%$ higher as compared to Href ( $p=0.06$ and 0.1 , respectively). A corresponding $4.7 \%$ and $5.2 \%$ smaller IPA as compared to the reference haplotype was observed ( $p<0.05$ and $p=0.07$ for peak and late, respectively). Haplotype $D$ was associated with neither platelet aggregation nor IPA after inhibition of platelet aggregation with $0.25 \mu \mathrm{mol} / \mathrm{L}$ cangrelor.

Haplotypes A, B and F showed no significant differences in platelet function results when compared to the reference haplotype. Similar trends and results were observed for $5 \mu \mathrm{mol} / \mathrm{L}$ ADP induced platelet function results (data not shown). 
Part III | chapter 8

\section{DISCUSSION}

The present study demonstrates that variation in the $\mathrm{P}_{2} \mathrm{Y}_{12}$ receptor gene is significantly associated with interindividual variability in platelet inhibition after partial in vitro blockade with the $\mathrm{P}_{2} \mathrm{Y}_{12}$ receptor antagonist cangrelor. The minor c allele of SNP II increased the response to cangrelor, thereby exhibiting a small but protective effect on platelet function. In contrast, the aa genotype of SNP III was associated with a substantially impaired platelet response to cangrelor. Of note, the effect of SNP III on $\mathrm{P}_{2} \mathrm{Y}_{12}$ inhibition appeared to be recessive, and therefore only displayed by the small subset of the population carrying the aa genotype for SNP III. As part of the $\mathrm{H}_{2}$ haplotype described by Fontana et $\mathrm{al}^{1{ }^{10}}$, the minor $\mathrm{c}$ allele of SNP V has previously been associated with a decreased response to clopidogrel ${ }^{11,24,}$ 25. In the present study, SNPV was likewise associated with a marked reduction of IPA with $0.05 \mu \mathrm{mol} / \mathrm{L}$ cangrelor. Statistical significance could however not be reached. Furthermore, SNP II and SNP V genotypes only affected platelet aggregation after inhibition with $0.05 \mu \mathrm{mol} / \mathrm{L}$ cangrelor, while the aa genotype for SNP III was consistently associated with impaired IPA, also after incubation with the higher concentration of $0.25 \mu \mathrm{mol} / \mathrm{L}$ cangrelor.

Haplotype analysis is useful in testing whether a combination of single SNPs exhibits either an additive, antagonistic or synergistic influence on the effect measure. In the present study, the results of the haplotype analyses were consistent with the results from the single SNP association analyses. Additive effects of the alleles associated with lower levels of IPA are observed for haplotype $C$ (combining the T allele of SNP II with the $c$ allele of SNP V) and haplotype D (combining the T allele of SNP II with the a allele of SNP III), resulting in a heightened magnitude of ADP-induced platelet aggregation as compared to the reference haplotype. However, none of the selected haplotypes with a frequency $>5 \%$ combines the three alleles of SNP II, III and V that are associated with lower levels of IPA. Furthermore, haplotype analysis masks the recessive effect of the minor A allele of SNP III on platelet inhibition. SNP III affects platelet aggregation in a recessive way, while haplotype analysis determines the effect of single haplotype alleles, abolishing the effect of the aa genotype $(n=4)$ by the relatively large number of heterozygote carriers $(n=64)$ of the a allele for SNP III. Therefore, haplotype analysis does not necessarily provide additional information regarding the effects of genetic $P_{2} Y_{12}$ receptor polymorphisms on platelet function in the present study.

Previous studies investigating the possible relationship between genetic variation in the $\mathrm{P}_{2} \mathrm{Y}_{12}$ receptor and inhibition of platelet function with clopidogrel report ambiguous results ${ }^{11,20-27}$. This might in part be attributed to the multifactorial background of the interindividual variability seen in clopidogrel response ${ }^{28,29}$. The two-step metabolisation process preceding the appearance of the active metabolite of clopidogrel in plasma, is thought to be a major contributor to the interindividual variability in plasma levels of the active metabolite of clopidogrel and the consequent variable platelet response to clopidogre $3{ }^{3,4,7}, 9$. Cangrelor is a direct-acting, intravenously administered $\mathrm{P}_{2} \mathrm{Y}_{12}$ inhibitor that does not exhibit the above mentioned pharmacokinetic limitations. Hence, the impact of genetic $P_{2} Y_{12}$ receptor polymorphisms on inhibition of platelet aggregation can directly be studied.

The present study was designed to test the hypothetical association between $\mathrm{P}_{2} \mathrm{Y}_{12}$ receptor gene polymorphism and the platelet response to cangrelor. Answering this question requires relatively high concentrations of 5 and $20 \mu \mathrm{mol} / \mathrm{L} A D P$, to achieve differentiation in the platelet response to the potent inhibitor cangrelor, as measured with LTA. Though outside the scope of this study, it would be interesting to test the possible effects of $\mathrm{P}_{2} \mathrm{Y}_{12}$ receptor gene polymorphisms on baseline platelet function, a question that requires the use of lower concentrations of ADP. 
Several studies have shown that a high on-treatment platelet reactivity in clopidogrel pretreated patients is associated with the occurrence of atherothrombotic events and even death ${ }^{30-33}$. Furthermore, the results of the TRial to Assess Improvement in Therapeutic Outcomes by Optimizing Platelet InhibitioN with Prasugrel (TRITON)-TIMI 38 show that stronger $\mathrm{P}_{2} \mathrm{Y}_{12}$ inhibition with prasugrel compared to clopidogrel reduces early recurrent atherothrombotic events after $\mathrm{PCl}$ 34,35. This emphasizes the importance of sufficient $\mathrm{P}_{2} \mathrm{Y}_{12}$ inhibition during and in the first month following $\mathrm{PCl}$. Patients carrying the aa genotype for SNP III that is associated with a more reactive platelet phenotype, might therefore be at an increased risk for atherothrombotic complications after $\mathrm{PCl}$. Future studies assessing the impact of $\mathrm{P}_{2} \mathrm{Y}_{12}$ receptor gene polymorphisms on clinical outcome in cangrelor-treated patients may elucidate the answer to this hypothesis.

In conclusion, polymorphisms of the $\mathrm{P}_{2} \mathrm{Y}_{12}$ receptor gene significantly contribute to the interindividual variability in platelet inhibition after in vitro partial blockade with the $\mathrm{P}_{2} \mathrm{Y}_{12}$ antagonist cangrelor. The clinical relevance of this finding has yet to be determined.

\section{What is known about this topic?}

- The large variability in response to the $P_{2} Y_{12}$ receptor inhibitor clopidogrel can in part be attributed to polymorphisms of the $P_{2} Y_{12}$-receptor gene.

- Cangrelor is a novel, intravenously administered $P_{2} Y_{12}$-inhibitor, that does not need conversion to an active metabolite for achieving an inhibitory effect on platelet function.

\section{What does this paper add?}

- An investigation on the association between variation in the $P_{2} Y_{12}$-receptor gene and the magnitude of platelet inhibition reached with invariable levels of the direct $P_{2} Y_{12}$-inhibitor cangrelor.

- Polymorphism in the $P_{2} Y_{12}$-receptor gene is associated with the magnitude of the in vitro platelet response to cangrelor as measured with the classical light transmittance aggregometry.

\section{Acknowledgments}

A. Sources of Funding; F.W.G.Leebeek is a recipient of a clinical fellowship of the Dutch Organisation for Health Research and Development (Zon MW), the Hague, The Netherlands. The Medicines Company kindly provided the cangrelor. B. Acknowledgements; The authors wish to thank Sonja Postma and Ellen Elsenberg for their labour and assistance in performing platelet function testing. C. Disclosure; Conflict of Interest: none declared.

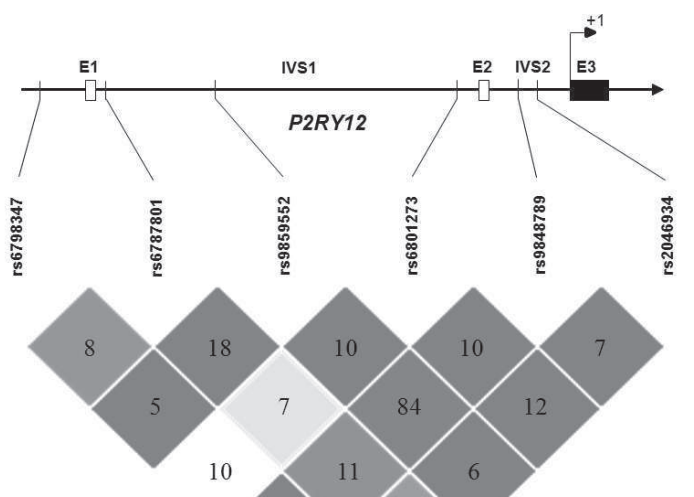

10

Supplementary Figure | Linkage disequilibrium structure of the $P_{2} Y_{12}$ receptor gene, with position of the five selected haplotype-tagging SNPS. 
Part III | chapter 8

\section{REFERENCES}

1. Serebruany VL, Steinhubl SR, Berger PB, et al. Variability in platelet responsiveness to clopidogrel among 544 individuals. J Am Coll Cardiol 2005;45:246-251.

2. Gurbel PA, Bliden $\mathrm{KP}$, Hiatt $\mathrm{BL}$, et al. Clopidogrel for coronary stenting: response variability, drug resistance, and the effect of pretreatment platelet reactivity. Circulation 2003;107:2908-2913.

3. Taubert D, Kastrati A, Harlfinger $S$, et al. Pharmacokinetics of clopidogrel after administration of a high loading dose. Thromb Haemost 2004;92:311-316.

4. Taubert D, von Beckerath N., grimberg G, et al. Impact of P-glycoprotein on clopidogrel absorption. J Pharmacol Exp Ther 2006;80:486-501.

5. Michelson $A D$, Linden $M D$, Furman $M I$, et al. Evidence that pre-existent variability in platelet response to ADP accounts for "clopidogrel resistance". J Thromb Haemost 2007;5:75-81.

6. Trenk D, Hochholzer W, Fromm MF, et al. Cytochrome $\mathrm{P}_{450} 2 \mathrm{C}_{19} 681 \mathrm{G}>\mathrm{A}$ polymorphism and high on-clopidogrel platelet reactivity associated with adverse 1-year clinical outcome of elective percutaneous coronary intervention with drug-eluting or bare-metal stents. J Am Coll Cardiol 2008;51:1925-1934.

7. Mega JL, Close SL, Wiviott SD, et al. Cytochrome p-450 polymorphisms and response to clopidogrel. N Engl J Med 2009;360:354-362.

8. Fontana $\mathrm{P}_{1}$ Hulot JS, De Moerloose $\mathrm{P}_{1}$ et al. Influence of $\mathrm{CYP}_{2} \mathrm{C}_{19}$ and $\mathrm{CYP}_{3} \mathrm{~A}_{4}$ gene polymorphisms on clopidogrel responsiveness in healthy subjects. J Thromb Haemost 2007;5:2153-2155.

9. van Werkum JW, Heestermans AACM, Deneer VHM, et al. Clopidogrel resistance: Fact and Fiction. Future Cardiology 2006;2:215-228.

10. Fontana P, Dupont A, Gandrille S, et al. Adenosine diphosphate-induced platelet aggregation is associated with $P_{2} Y_{12}$ gene sequence variations in healthy subjects. Circulation 2003;108:989-995.

11. Staritz $\mathrm{P}$, Kurz K, Stoll M, et al. Platelet reactivity and clopidogrel resistance are associated with the $\mathrm{H}_{2}$ haplotype of the $\mathrm{P}_{2} \mathrm{Y}(12)-\mathrm{ADP}$ receptor gene. Int J Cardiol 2009; 133:341-345.

12. Evans DJ, Jackman LE, Chamberlain J, et al. Platelet $P_{2} Y(12)$ receptor influences the vessel wall response to arterial injury and thrombosis. Circulation 2009;119:116-122.

13. Michelson AD. P2 12 Antagonism. Promises and Challenges. Arterioscler Thromb Vasc Biol 2008;28:533-8.

14. Storey RF, Wilcox RG, Heptinstall S. Comparison of the pharmacodynamic effects of the platelet ADP receptor antagonists clopidogrel and AR-C69931MX in patients with ischaemic heart disease. Platelets 2002;13:407413.

15. Fugate SE, Cudd LA. Cangrelor for treatment of coronary thrombosis. Ann Pharmacother 2006;40:925-930.

16. A Clinical Trial to Demonstrate the Efficacy of Cangrelor (CHAMPION-PCI). Available at http://www.clinicaltrials.gov/ct2/show/NCT00305162?term=cangrelor\&rank=4. Accessed April 2, 2009.

17. van Werkum JW, Kleibeuker M, Mieremet N, et al. Evaluation of the platelet response to clopidogrel with light transmittance aggregometry: peak aggregation or late aggregation? J Thromb Haemost 2007;5:884-886.

18. Rudez G, Pons D, Leebeek FWG et al. Platelet receptor $P_{2} R Y_{12}$ haplotypes predict restenosis after percutaneous coronary interventions. Hum Mutat 2008;29:375-380.

19. Livak KJ. Allelic discrimination using fluorogenic probes and the $5^{\prime}$ nuclease assay. Genet Anal 1999;14:143149 .

20. Hetherington $S L$, Singh RK, Lodwick $D$, et al. Dimorphism in the $\mathrm{P}_{2} \mathrm{Y}_{1} \mathrm{ADP}$ receptor gene is associated with increased platelet activation response to ADP. Arterioscler Thromb Vasc Biol 2005;25:252-257.

21. Giusti B, Gori AM, Marcucci R, et al. Cytochrome $\mathrm{P}_{450} \mathrm{2}_{19}$ loss-of-function polymorphism, but not CYP3 4 IVS10 +12 G/A and $P_{2} Y_{12} T_{744}$ C polymorphisms, is associated with response variability to dual antiplatelet treatment in high-risk vascular patients. Pharmacogenet Genomics 2007;17:1057-1064. 


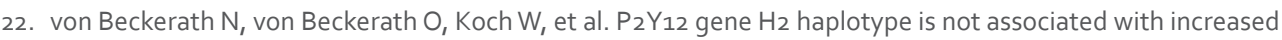
adenosine diphosphate-induced platelet aggregation after initiation of clopidogrel therapy with a high loading dose. Blood Coagul Fibrinolysis 2005;16:199-204.

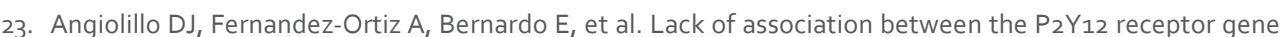
polymorphism and platelet response to clopidogrel in patients with coronary artery disease. Thromb Res 2005;116:491-497.

24. Lev El, Patel RT, Guthikonda S, et al. Genetic polymorphisms of the platelet receptors $P_{2} Y(12), P_{2} Y(1)$ and GP IIlla and response to aspirin and clopidogrel. Thromb Res 2007;119:355-360.

25. Bura A, Bachelot-Loza $C$, Ali FD, et al. Role of the $\mathrm{P}_{2} \mathrm{Y}_{12}$ gene polymorphism in platelet responsiveness to clopidogrel in healthy subjects. J Thromb Haemost 2006;4:2096-2097.

26. Bernardo E, Angiolillo DJ, Ramirez C, et al. Lack of association between gene sequence variations of platelet membrane receptors and aspirin responsiveness detected by the PFA-100 system in patients with coronary artery disease. Platelets 2006;17:586-590.

27. Cuisset T, Frere $C_{\text {, }}$ Quilici J, et al. Role of the $T_{744} \mathrm{C}$ polymorphism of the $\mathrm{P}_{2} \mathrm{Y}_{12}$ gene on platelet response to a 6oo-mg loading dose of clopidogrel in 597 patients with non-ST-segment elevation acute coronary syndrome. Thromb Res 2007;120:893-899.

28. De Miguel A, Ibanez B, Badimon JJ. Clinical implications of clopidogrel resistance. Thromb Haemost 2008 Aug;100(2):196-203.

29. Elsenberg EHAM, van Werkum JW, van de Wal RMA, et al. The influence of clinical characteristics, laboratory and inflammatory markers on 'high on-treatment platelet reactivity' as measured with different platelet function tests. Thromb Haemost 2009; e-pub ahead of print.

30. Geisler $\mathrm{T}$, Langer $\mathrm{H}$, Wydymus $\mathrm{M}$, et al. Low response to clopidogrel is associated with cardiovascular outcome after coronary stent implantation. Eur Heart J 2006;27:2420-2425.

31. Hochholzer W, Trenk D, Bestehorn HP, et al. Impact of the degree of peri-interventional platelet inhibition after loading with clopidogrel on early clinical outcome of elective coronary stent placement. J Am Coll Cardiol 2006;48:1742-1750.

32. Buonamici P, Marcucci R, Migliorini A, et al. Impact of platelet reactivity after clopidogrel administration on drug-eluting stent thrombosis. J Am Coll Cardiol 2007;49:2312-2317.

33. Price MJ, Endemann S, Gollapudi RR, et al. Prognostic significance of post-clopidogrel platelet reactivity assessed by a point-of-care assay on thrombotic events after drug-eluting stent implantation. Eur Heart $J$ 2008.

34. Wiviott $\mathrm{SD}$, Braunwald $\mathrm{E}, \mathrm{McCabe} \mathrm{CH}$, et al. Prasugrel versus clopidogrel in patients with acute coronary syndromes. N Engl J Med 2007;357:2001-2015

35. Wiviott SD, Trenk $D$, Frelinger AL et al. Prasugrel compared with high loading- and maintenance-dose clopidogrel in patients with planned percutaneous coronary intervention: the Prasugrel in Comparison to Clopidogrel for Inhibition of Platelet Activation and Aggregation-Thrombolysis in Myocardial Infarction 44 trial. Circulation 2007;116:2923-2932.

36. den Dunnen JT, Antonarakis SE. Mutation nomenclature extensions and suggestions to describe complex mutations: a discussion. Hum Mutat 2000;15:7-12. 


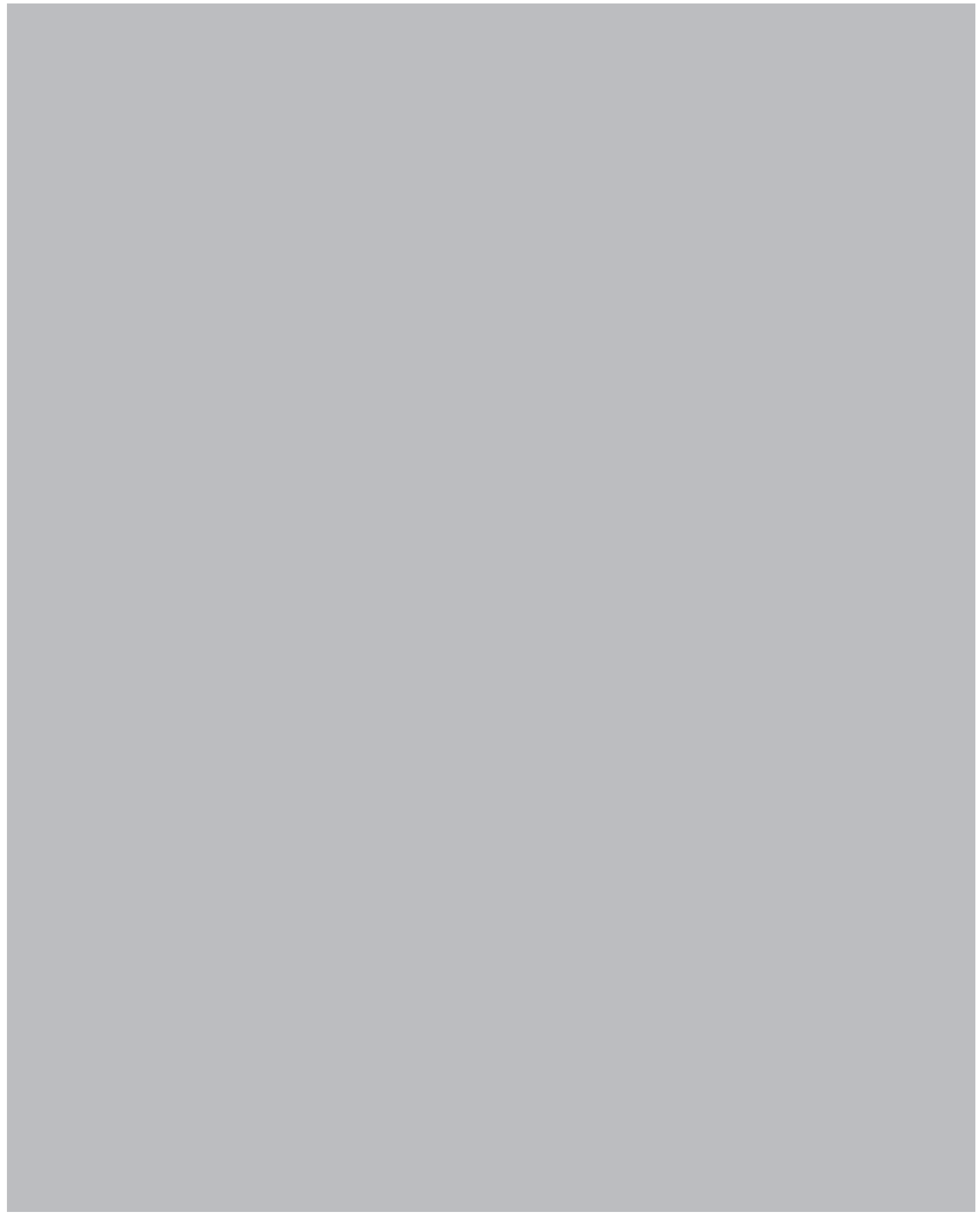




\section{Chapter 9}

\section{Common variation in the platelet receptor $P_{2} R Y_{12}$ gene is associated with residual on-clopidogrel platelet reactivity in patients undergoing elective percutaneous coronary interventions}

Circ Cardiovasc Genet. 2009;2(5):515-21

Goran Rudež* Heleen J Bouman* Jochem $W$ van Werkum Frank WG Leebeek Adrian Kruit

Henk JT Ruven Jurriën M ten Berg Moniek PM de Maat Christian M Hackeng

*Both authors contributed equally

Department of Cardiology, St. Antonius Hospital Nieuwegein, the Netherlands Department of Hematology, Erasmus University Medical Center Rotterdam, the Netherlands Department of Clinical Chemistry, St. Antonius Hospital Nieuwegein, the Netherlands 


\section{ABSTRACT}

\section{Background}

The clinical efficacy of clopidogrel is hampered by a large interindividual variability in platelet inhibition. Polymorphisms in the $P_{2} R Y_{12}$ receptor gene have been suggested to contribute to this variability, but previous studies included a relatively small number of patients and incompletely covered the common variation in the $P_{2} R Y_{12}$ gene. The aim of this study was to comprehensively investigate the possible association between common variation in the entire $P_{2} R Y_{12}$ locus and the magnitude of residual onclopidogrel platelet reactivity measured by two commonly used platelet function assays in a large cohort of patients.

\section{Methods and Results}

A total of 1031 consecutive patients with coronary artery disease (CAD) who were scheduled for elective PCI were enrolled. Platelet function was assessed by means of ADP-induced light-transmittance aggregometry (LTA) and the VerifyNow ${ }^{\circledR} \mathrm{P}_{2} \mathrm{Y}_{12}$ assay. Six haplotype-tagging single nucleotide polymorphisms (ht-SNPs) were carefully selected to comprehensively cover the total common variation in the $P_{2} R Y_{12}$ gene and its flanking regulatory regions. Six common haplotypes were inferred from these ht-SNPs (denoted A-F). Haplotype F was associated with significantly lower residual onclopidogrel platelet reactivity as compared to the reference haplotype A. The size of this effect per haplotype allele was approximately $5 \%$ aggregation in the ADP-induced LTA $(p<0.05)$ and $11 \mathrm{P}_{2} \mathrm{Y}_{12}$ reaction units in the Verify Now ${ }^{\odot} \mathrm{P}_{2} \mathrm{Y}_{12}$ assay $(\mathrm{p}<0.05)$.

\section{Conclusions}

Common variation in the $P_{2} R Y_{12}$ gene is a significant determinant of the interindividual variability in residual on-clopidogrel platelet reactivity in patients with CAD. 


\section{INTRODUCTION}

Dual antiplatelet therapy with clopidogrel and aspirin is currently the treatment of choice for the secondary prevention of atherothrombotic events in patients with coronary artery disease (CAD) and in those undergoing coronary stent implantation. ${ }^{1}$ In approximately $5-30 \%$ of clopidogrel-treated patients the inhibition of platelet aggregation is insufficient. ${ }^{2,3} \mathrm{As}$ a consequence, patients with a high residual on-clopidogrel platelet reactivity may be at a higher risk of atherothrombotic events. ${ }^{4,5}$

Common variation in the $P_{2} R Y_{12}$ gene has been suggested as one of the mechanisms underlying this large variability in clopidogrel response. 5 The $P_{2} R Y_{12}$ gene encodes the adenosine diphosphate (ADP) receptor $\mathrm{P}_{2} \mathrm{Y}_{12}$ the pharmacological target of clopidogrel. Previous investigations on the relationship between $P_{2} R Y_{12}$ single nucleotide polymorphisms (SNPs) and high residual on-clopidogrel platelet reactivity were limited by the fact that only the haplotype-tagging SNP (ht-SNP) rs2046934 ("i-T744C") was studied. Rs2046934 is in complete linkage disequilibrium (LD) with 3 other $P_{2} R Y_{12}$ SNPs and the haplotypes " $\mathrm{H}_{1}$ " and " $\mathrm{H}_{2}$ ", which these SNPs determine, cover only the $3^{\prime}$ part of the $P_{2} R Y_{12}$ gene. ${ }^{6}$ ${ }_{14}$ In addition, most of the cited studies on $P_{2} R Y_{12}$ SNPs included a relatively small number of patients.

A comprehensive study of common variation in the $P_{2} R Y_{12}$ gene should include ht-SNPs that cover all common haplotypes within the entire $P_{2} R Y_{12}$ locus, i.e. the $P_{2} R Y_{12}$ gene and its regulatory regions, such as the promoter and the $3^{\prime}$ untranslated region (UTR). Using this comprehensive approach, we previously demonstrated that common variation in the $P_{2} R Y_{12}$ gene is associated with the risk of restenosis following percutaneous coronary interventions $(\mathrm{PCI}) .{ }^{15}$ Although ADP-induced lighttransmittance aggregometry (LTA) is still considered the gold standard for the assessment of clopidogrel-induced platelet inhibition, methods have been recently introduced that are designed for a more standardized monitoring of the efficacy of clopidogrel, such as the VerifyNow ${ }^{\circledR} \mathrm{P}_{2} \mathrm{Y}_{12}$ assay. ${ }^{16}$ The aim of this study was to investigate a possible association between the common genetic variation of the entire $P_{2} R Y_{12}$ locus and residual on-clopidogrel platelet reactivity using several platelet function assays in a large population of patients who were scheduled to undergo elective $\mathrm{PCl}$.

\section{METHODS}

\section{Study population}

One-thousand-thirty-one consecutive patients with established coronary artery disease (CAD) scheduled for elective $\mathrm{PCl}$ were included in this study. Owing to different protocols of referring hospitals, patients had received a different, but adequate clopidogrel pretreatment: $(A)$ maintenance therapy of $75 \mathrm{mg}$ daily for $>5$ days ( $=659$ ), (B) a clopidogrel loading dose of $300 \mathrm{mg}$ at least $24 \mathrm{~h}$ before $\mathrm{PCl}(n=314)$ or $(C)$ a clopidogrel loading dose of $600 \mathrm{mg}$ at least $6 \mathrm{~h}$ before $\mathrm{PCl}(\mathrm{n}=58)$. Exclusion criteria were the use of GPIIb/IIla antagonists in the last 7 days before the intervention and a platelet count $<150 \times 10^{9}$ platelets/L. Ninety percent of the patients were on aspirin ( $80-100 \mathrm{mg}$ daily) and $10 \%$ were on coumadins. Eighty-one percent of the patients were using statins (Table 1). Over $95 \%$ of the study population was of Caucasian origin. The study protocol was approved by the institutional Medical Ethics Committee. Written informed consent was obtained from each participant. 
Part III | chapter 9

\section{Definitions}

Smoking was defined as any cigarette smoking in the last month. Hypertension was defined as a systolic blood pressure $>140 \mathrm{~mm} \mathrm{Hg}$ or diastolic blood pressure $>90 \mathrm{~mm} \mathrm{Hg}$. Diabetes mellitus was defined according to the World Health Organization criteria. Family history of cardiovascular disease was defined as having a first-degree relative with a history of coronary artery disease $<65$ years for females and $<55$ years for males.

\section{Blood collection}

Blood samples were drawn from the arterial sheath before heparinization into non-vacuum Sarstedt ${ }^{\circledR}$ tubes containing 3.2\% sodium citrate (Sarstedt, Nümbrecht, Germany). Haematocrit (Hct), and platelet count were analysed in $\mathrm{K}_{3}$-EDTA anticoagulated blood. Genomic DNA was extracted from $\mathrm{K}_{3}$-EDTA anticoagulated whole-blood following standard salting-out procedures and stored at $4^{\circ} \mathrm{C}$ for genetic analysis.
Table 1 | Characteristics of the study population

\begin{tabular}{ll}
\hline Demographics & $\mathrm{n}=1031$ \\
\hline Age (yrs) & $64 \pm 11$ \\
Male & $769(75 \%)$ \\
Risk factors & \\
Body mass index $\left(\mathrm{kg} / \mathrm{m}^{2}\right)$ & $27 \pm 4$ \\
Smoking & $210(20 \%)$ \\
Diabetes & $197(19 \%)$ \\
Hypertension & $801(78 \%)$ \\
Family history of cardiovascular disease & $633(61 \%)$ \\
Medication & \\
Clopidogrel - Total group & $1031(100 \%)$ \\
Dosing regimen A & $659(64 \%)$ \\
Dosing regimen B & $314(30 \%)$ \\
Dosing regimen C & $58(6 \%)$ \\
Aspirin & $923(90 \%)$ \\
Coumarins & $105(10 \%)$ \\
Statins & $830(81 \%)$ \\
Haematocrit (\%) & $272 \pm 80$ \\
\hline
\end{tabular}

Values are given as $n(\%)$ for categorical variables and as mean $\pm S D$ for continuous variables.

\section{Light-transmittance aggregometry}

Citrated whole-blood samples were centrifuged at $120 \mathrm{~g}$ for 10 minutes to obtain platelet-rich plasma (PRP) and further centrifuged at $850 \mathrm{~g}$ for 15 minutes to obtain platelet-poor plasma (PPP). Maximal and late aggregation (at 6 minutes) were measured in non-adjusted PRP after stimulation with different concentrations of the agonist ADP (final concentrations: $2,5,10$ and $20 \mu \mathrm{mol} / \mathrm{L}$ ) in an APACT 4004 four-channel aggregometer (LABiTec, Arensburg, Germany). ${ }^{17}$

\section{VerifyNow $\mathrm{P}_{2} \mathrm{Y}_{12}$ Assay}

The VerifyNow ${ }^{\circledR} \mathrm{P}_{2} \mathrm{Y}_{12}$ test cartridge system (Accumetrics, San Diego, CA) was used as described previously. ${ }^{16,18}$ In brief, VerifyNow ${ }^{\circledR} \mathrm{P}_{2} \mathrm{Y}_{12}$ is a rapid cartridge-based platelet-agglutination assay designed to directly measure the inhibitory effects of clopidogrel therapy. The results are reported in $\mathrm{P}_{2} \mathrm{Y}_{12}$ reaction units (PRU), where a higher PRU reflects greater on-clopidogrel ADP-induced platelet reactivity, and in percentage of inhibition, where a higher \% reflects greater change of ADP-induced platelet agglutination from clopidogrel-independent (baseline) platelet agglutination that is induced with thrombin receptor activating peptide (TRAP) and protease-activated receptor 4 activating peptide (PAR4-AP).

\section{Selection of SNPs in the $P_{2} R Y_{12}$ gene}

Ht-SNPs were selected according to the approach described previously. ${ }^{15}$ Based on the latest LD-map of the $P_{2} R Y_{12}$ locus (i.e. $P_{2} R Y_{12}$ gene with $2.5 \mathrm{~kb}$ flanking sequence) provided by the International HapMap Project for a population of Utah residents with Northern and Western European ancestry 
from the CEPH collection (phase II, October 2007; http://www.hapmap.org/) (Figure 1), blocks of haplotypes with frequency $>5 \%$ were defined from these ht-SNPs using Haploview software (version 3.3, http://www.broad.mit.edu/mpg/haploview/index.php). Together, the defined haplotypes cover $88 \%$ of the total common DNA sequence variation in the $P_{2} R Y_{12}$ locus. The 6 selected ht-SNPs that were genotyped are rs6798347 (c.-281-3614C>t), rs6787801 (c.-217+2739T>c) and rs9859552 (c. $217+11494 \mathrm{C}>\mathrm{a}$ ), which tag the promoter, exon 1 and a part of intron 1 region, and rs6801273 (c.-216$4445 \mathrm{~A}>\mathrm{g}$ ), rs9848789 (c.-216-377 G>a) and rs2046934 (c.-15+742 T>c), which tag the remaining part of intron 1, as well as the entire exon 2, intron 2, exon 3, 3' UTR and flanking region (Figure 1).

\section{Genotyping and haplotype analysis}

The 6 selected haplotype-tagging SNPs were genotyped using Custom TaqMan Genotyping Assays (Applied Biosystems, Foster City, USA) under standard conditions. ${ }^{19}$ The nucleotide sequences of the primers and probes used for each assay are available upon request. End-point fluorescence was measured on the $\mathrm{ABI} 7900 \mathrm{HT}$ instrument (Applied Biosystems, Foster City, USA) and clustered according to genotype using SDS 2.2.2 software (Applied Biosystems, Foster City, USA). A random selection of $10 \%$ of the samples was re-analysed, and the results were confirmed in $99.7 \%$.

Laboratory analyses were performed by research technicians who were blinded for the demographic data of the patients. All SNPs were in Hardy-Weinberg equilibrium when genotyped in a healthy population. Haplotypes were inferred using Haplo.Stats software (http://mayoresearch.mayo.edu/ mayo/research/biostat/schaid.cfm) and coded from $A$ to $F$, in the descending order of their effects on $20 \mu \mathrm{mol} / \mathrm{L}$ ADP-induced LTA, where $\mathrm{A}$ is defined as the reference haplotype. ${ }^{20}$

\section{Statistical methods}

Demographic data are presented as means and standard deviations for continuous variables and as counts and percentages for categorical variables. Results of the haplotype analysis are presented as mean effects per haplotype-allele with the corresponding standard errors. Haplotype analysis was performed with Haplo.Stats. ${ }^{20}$ Briefly, this analysis calculates posterior probabilities for each possible haplotype of an individual and assigns an appropriate weight to the corresponding estimated effect on platelet function. Individuals with missing genotype data for more than two SNPs $(n=26)$ were excluded from the analysis. Haplo.Stats assumes an additive effect of haplotype alleles, indicating that the net effect of a person's haplotype is the sum of the effects of its two haplotype alleles.

The associations between the $P_{2} R Y_{12}$ haplotype alleles and on-clopidogrel platelet reactivity were determined by weighted linear or logistic regression analysis, using haplo.glm function and results expressed as mean change from the reference haplotype allele \pm SEM. The genetic analysis of the subgroup of patients who had received clopidogrel according to the dosing regimen $C$ was not performed because of the small sample size $(n=58)$. Other statistical analyses were performed using SPSS for Windows, version 11.5 (SPSS Inc, Chicago, USA). ANCOVA was performed to study the differences between the mean on-clopidogrel platelet reactivity of the total study population and the three clopidogrel loading dose regimens, and to study the association between individual $P_{2} R Y_{12}$ SNPs and platelet function in the total study population. In each analysis, homozygotes for the common allele of these SNPs were used as the reference. Analyses were adjusted for age, sex, BMI, diabetes and smoking. For the total group, additional adjustment for clopidogrel loading-dose was performed. In some analyses, adjustment was also made for the use of aspirin, coumadins and statins. A two-sided value of $\mathrm{P}<0.05$ was considered statistically significant. 
Part III | chapter 9

\section{RESULTS}

A large variability in on-clopidogrel platelet reactivity was found with $20 \mu \mathrm{mol} / L$ ADP-induced LTA and VerifyNow ${ }^{\circledR} \mathrm{P}_{2} \mathrm{Y}_{12}$ assay (Figure $\mathbf{2 A}$ and $\mathbf{B}$ ). For $20 \mu \mathrm{mol} / \mathrm{L}$ ADP-induced LTA, on-clopidogrel platelet aggregation was $58 \% \pm 14 \%$ (total group), $57 \% \pm 14 \%$ (dosing regimen $A$ ), $62 \% \pm 14 \%$ (dosing regimen B) and $56 \% \pm 15 \%$ (dosing regimen C). For the VerifyNow ${ }^{\circledR} P_{2} Y_{12}$ assay, PRU was $211 \pm 76$ (total group), $206 \pm 74$ (dosing regimen A), $228 \pm 78$ (dosing regimen $B$ ) and $187 \pm 83$ (dosing regimen C). Both for LTA and VerifyNow ${ }^{\circledR} \mathrm{P}_{2} \mathrm{Y}_{12}$ assay, mean on-clopidogrel platelet reactivity was significantly higher in de dosing regimen $B$ than the dosing regimens $A$ and $C(p<0.001)$. Similar variability in on-clopidogrel platelet reactivity was seen for the different concentrations of ADP in the LTA (data not shown).

\section{$P_{2} R Y_{12}$ haplotypes}

By combining the $6 P_{2} R Y_{12}$ ht-SNPs, 64 haplotype alleles were inferred of which 6 were common and had an allele frequency higher than 5\%: (A) tTCgGT (10\%), (B) tTCAGT (6\%), (C) CTCAGc (15\%), (D) CTaAaT (15\%), (E) CcCgGT (21\%) and (F) CCCAGT (22\%)(Table 2).

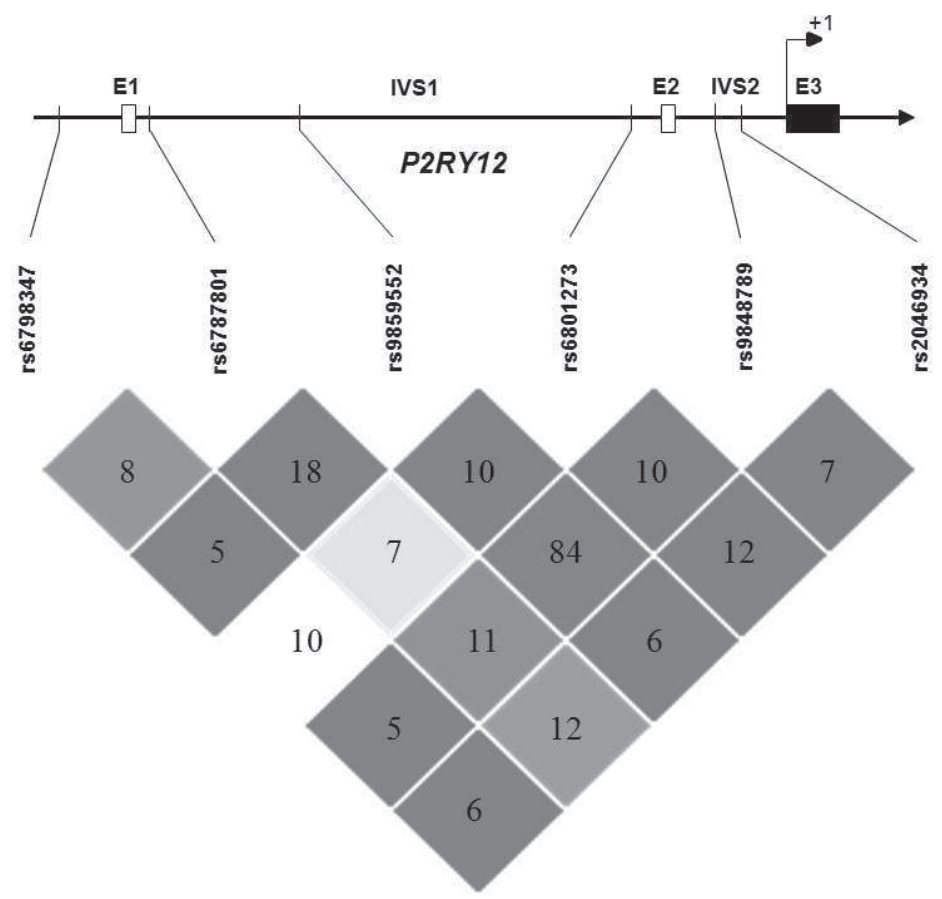

Figure 1 | Schematic representation of the $P_{2} R Y_{12}$ gene and the linkage disequilibrium map of the 6 haplotype-tagging SNPs genotyped.

The $P_{2} R Y_{12}$ gene consists of three exons ( $E_{1}, E_{2}$ and $E_{3}$, of which only $E_{3}$ is coding) and two intervening sequences (IVS1 and IVS2), which span 47kb of genomic DNA on chromosome 3. The six ht-SNPs that are depicted in the Figure with their corresponding rs-numbers tag all common combinations of SNPs (haplotypes with allele frequencies $>5 \%$ ) within the $P_{2} R Y_{12}$ gene and its $2.5 \mathrm{~kb}$ flanking regions (52 kb in total). The triangle-shaped Figure depicts the linkage disequilibrium (LD)-map for these $6 \mathrm{ht}$-SNPs. In shades from white to red are indicated increasing pairwise-LDs between the ht-SNPs with the corresponding $r^{2}$ values given within the blocks. 


\section{Light-transmittance aggregometry}

In the analysis of the total study population of patients, haplotype $\mathrm{F}$ showed a significantly lower 5 $\mu \mathrm{mol} / \mathrm{L}$ ADP-induced maximal and late aggregation (both $-4 \%$ per haplotype allele, $p<0.05$, Figure $3 \mathrm{~A}$ and B) compared to the reference haplotype $A$. Similar results were observed for $20 \mu \mathrm{mol} / \mathrm{L}$ ADPinduced maximal and late aggregation ( $-4 \%$ and $-6 \%$ per haplotype allele; $p<0.001$ and $p<0.05$; Figure ${ }_{3} C$ and $D$, respectively) and for ADP concentrations 2 and $10 \mu \mathrm{mol} / \mathrm{L}$ (supplemental Figure 1 ). Similar differences between haplotype $F$ and the reference haplotype $A$ were seen in the subgroup-analysis of patients from the clopidogrel dosing regimens $A$ and $B$ (Figure 3). In addition, haplotype $E$ was associated with a significantly lower $20 \mu \mathrm{mol} / \mathrm{L}$ ADP-induced maximal and late aggregation in the analysis of the total study population (both $-3 \%$ per haplotype allele, $p<0.05$, Figure ${ }_{3} C$ and $D$ ). Haplotype $\mathrm{E}$ also showed a trend towards lower maximal and late aggregation in the subgroup-analysis of patients from the clopidogrel dosing regimens $A$ and $B$ (Figure ${ }_{3} C$ and $D$ ). Similar trends were seen for 2, 5 and $10 \mu \mathrm{mol} / \mathrm{L}$ ADP (Figure $3 \mathbf{A}$ and $\mathbf{B}$, and supplemental Figure 1 ) and after additional adjustment for the use of aspirin, coumadins and statins (data not shown). Similar results were observed when non-Caucasians were excluded from the analyses (data not shown).

Table $2 \mid P_{2} R Y_{12}$ haplotypes

\begin{tabular}{lll}
\hline Haplotype & $\begin{array}{l}\text { SNP allele } \\
\text { composition }\end{array}$ & $\begin{array}{l}\text { Allele frequency } \\
(\%)\end{array}$ \\
\hline A & tTCgGT & 10 \\
B & tTCAGT & 6 \\
C & CTCAGC & 15 \\
D & CTaAaT & 15 \\
E & CcCgGT & 21 \\
F & CcCAGT & 22 \\
\hline
\end{tabular}

Haplotype alleles were coded $A-F$, in the descending order of their effects on $20 \mu \mathrm{mol} / L A D P$-induced $L T A$, where $A$ is the reference haplotype allele. SNP allele composition (e.g. CTaAaT) represents rs6798347, rs6787801, rs9859552, rs6801273, rs9848789 and rs2046934 respectively, with the minor alleles in lower case.

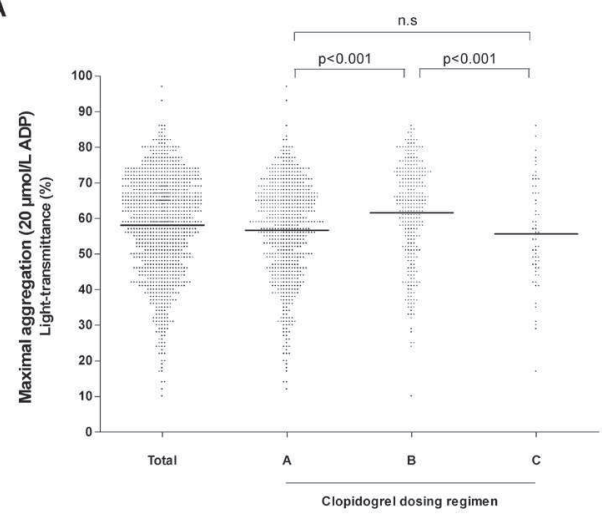

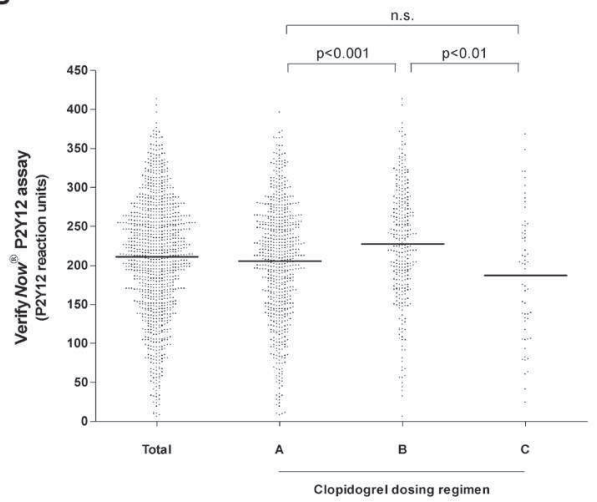

Figure 2 | Maximal $20 \mu \mathrm{mol} / L$ ADP-induced LTA and VerifyNow ${ }^{\circledR} P_{2} Y_{12}$ assay in the total study population and according to the 3 clopidogrel dosing regimens.

The total study population ( $n=1031)$ and the 3 different clopidogrel dosing regimens is presented. Depicted are the maximal $20 \mu \mathrm{mol} / L$ ADP-induced LTA (panel A) and the VerifyNow ${ }^{\circledR} P_{2} Y_{12}$ assay (panel B). Differences between mean platelet reactivity of the three dosing regimens were tested using ANCOVA with adjustment for age, sex, BMI, diabetes and smoking.n.s., not significant. 
Part III | chapter 9

\section{VerifyNow ${ }^{\circledR} \mathrm{P}_{2} \mathrm{Y}_{12}$ Assay}

Consistent with the results for LTA for the total study population, haplotype $F$ was associated with a lower PRU as compared to the reference haplotype A (-11 PRU per haplotype allele, $p<0.05$, Figure 4). These differences were less pronounced and statistically not significant when clopidogrel dosing regimens $A$ and $B$ were analyzed separately (Figure 4 ). A stronger and significant association was

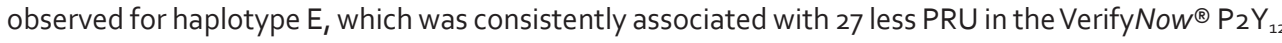
Assay for the total study population and for the clopidogrel dosing regimens $A$ and $B(p<0.05$, Figure 4). Similar results were obtained after additional adjustment for the use of aspirin, coumadins and statins, and when non-Caucasians were excluded from the analyses (data not shown).

Also, similar results were obtained for the associations between haplotypes and percentage of inhibition from baseline platelet agglutination (data not shown).

\section{$P_{2} R Y_{12}$ SNPs}

Comparison of the SNP-alleles within the haplotypes and their effects on platelet function suggested that SNP rs6787801 was responsible for most of the observed haplotype effects. This observation was confirmed in the single SNP analysis where homozygotes of the rare allele of SNP rs6787801 (CC genotype, $n=261$ ) had a significantly lower maximal and late aggregation (ranging from $-2 \%$ to $-7 \%$
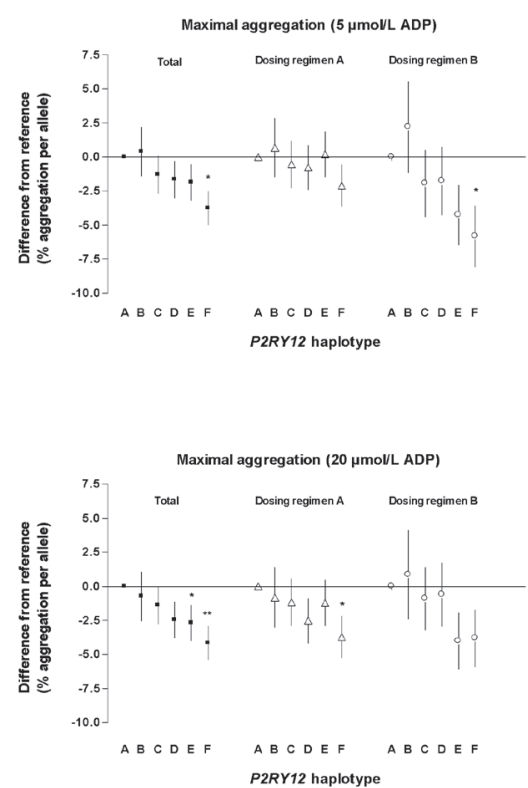

B

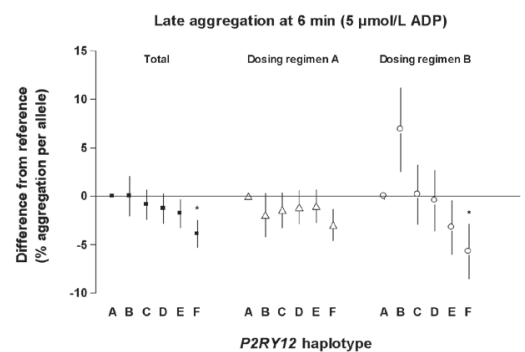

D

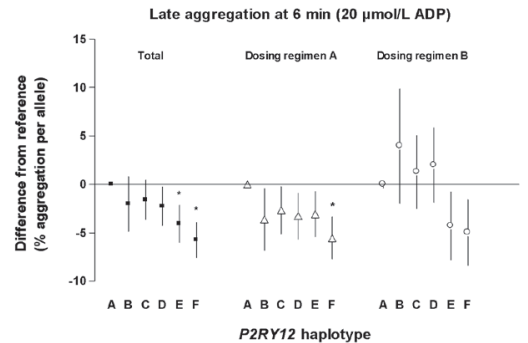

Figure 3 | The effect of $P_{2} R Y_{12}$ haplotypes on platelet reactivity assessed by $L T A$.

Results are shown for 5 mol/L ADP-induced maximal aggregation (panel A) and late aggregation at 6 min (panel B), and $20 \mu \mathrm{mol} / L$ ADP-induced maximal aggregation (panel C) and late aggregation at 6 min (panel D). Values are expressed as mean differences from the reference haplotype in percent of absolute aggregation per haplotype allele. Analyses were performed for the total study population (dosing regimens $A+B+C$ ), and for the subgroup of patients on dosing regimens $A$ and $B$. Dosing regimen $C$ was excluded from the analysis due to small sample size. **p<0.001, $* p<0.05$ 
across various concentrations of $A D P, p<0.05$ for all), as well as a significantly lower number of $P R U$ in the VerifyNow ${ }^{\circledR} \mathrm{P}_{2} \mathrm{Y}_{12}$ assay (-27 PRU, $\mathrm{p}<0.001$, Table 3), as compared to homozygotes of the common allele of SNP rs6787801 (TT genotype, $n=266$ ). None of the other 5 ht-SNPs were associated with any of the platelet function assays, except for homozygotes of the rare allele of SNP rs6798347 (TT genotype, $\mathrm{n}=46$ ), who showed 24 PRU less in the VerifyNow ${ }^{\circledR} \mathrm{P}_{2} \mathrm{Y}_{12}$ assay as compared to homozygotes of the corresponding common allele (CC genotype, $n=638, p<0.05$ ) (data not shown).

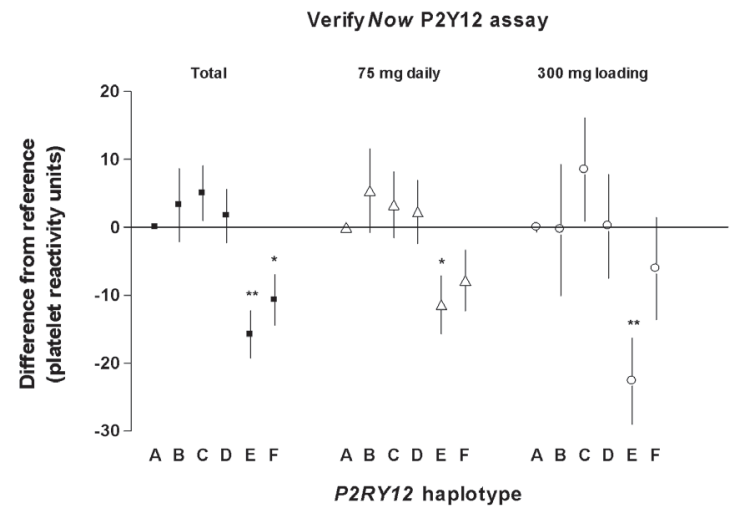

Figure $4 \mid$ The effect of $P_{2} R Y_{12}$ haplotypes on platelet reactivity assessed by VerifyNow ${ }^{\circledR} P_{2} Y_{12}$ assay.

Results are expressed as mean differences from the reference haplotype in $P_{2} Y_{12}$ reaction units $(P R U)$ per single haplotype allele. Analyses were performed for the total study population (dosing regimens $A+B+C$ ), and for the subgroup of patients on dosing regimens $A$ and $B$. Dosing regimen $C$ was excluded from the analysis due to small sample size.

$* * p<0.001, * p<0.05$

Table 3 | The effect of SNP rs6787801 on platelet function in total study population

\begin{tabular}{|c|c|c|c|c|c|}
\hline \multirow[t]{2}{*}{ Platelet function assay } & \multicolumn{3}{|c|}{ Genotype } & \multirow{2}{*}{$\begin{array}{l}p \text {-value } \\
\text { TT vs CC }\end{array}$} & \\
\hline & $\begin{array}{c}\text { TT } \\
(n=266)\end{array}$ & $\begin{array}{c}\text { TC } \\
(n=460)\end{array}$ & $\underset{(n=261)}{C C}$ & & \\
\hline \multicolumn{6}{|l|}{ Maximal aggregation (\%) } \\
\hline $2 \mu \mathrm{mol} / \mathrm{L}$ ADP & $23 \pm 12$ & $23 \pm 12$ & $21 \pm 12$ & 0.046 & \multirow{10}{*}{$\begin{array}{l}\text { Platelet aggregation is } \\
\text { expressed as percent ab- } \\
\text { solute aggregation } \pm S D \text {. } \\
\text { VerifyNow }{ }^{\circledR} P_{2} Y_{12} \text { assay is } \\
\text { expressed as } P_{2} Y_{12} \text { reaction } \\
\text { units }(P R U) \pm S D \text {. P-values } \\
\text { are for } L S D \text { post-hoc test in } \\
\text { ANCOVA with adjustment } \\
\text { forage, sex, BMI, diabetes, } \\
\text { smoking and clopidogrel } \\
\text { loading-dose. }\end{array}$} \\
\hline $5 \mu \mathrm{mol} / \mathrm{L} \mathrm{ADP}$ & $42 \pm 14$ & $40 \pm 15$ & $38 \pm 13$ & 0.012 & \\
\hline $10 \mu \mathrm{mol} / \mathrm{L}$ ADP & $52 \pm 15$ & $50 \pm 15$ & $49 \pm 14$ & 0.020 & \\
\hline $20 \mu \mathrm{mol} / \mathrm{L}$ ADP & $60 \pm 14$ & $59 \pm 15$ & $56 \pm 14$ & 0.005 & \\
\hline Late aggregation at $6 \mathrm{~min}(\%)$ & & & & & \\
\hline $2 \mu \mathrm{mol} / \mathrm{L}$ ADP & $11 \pm 10$ & $11 \pm 9$ & $9 \pm 9$ & 0.023 & \\
\hline $5 \mu \mathrm{mol} / \mathrm{L} \mathrm{ADP}$ & $21 \pm 19$ & $20 \pm 16$ & $17 \pm 15$ & 0.006 & \\
\hline $10 \mu \mathrm{mol} / \mathrm{L}$ ADP & $31 \pm 22$ & $30 \pm 22$ & $27 \pm 21$ & 0.016 & \\
\hline $20 \mu \mathrm{mol} / \mathrm{L}$ ADP & $44 \pm 23$ & $41 \pm 25$ & $38 \pm 24$ & 0.003 & \\
\hline VerifyNow $^{\circledR} \mathrm{P}_{2} \mathrm{Y}_{12}(\mathrm{PRU})$ & $226 \pm 74$ & $209 \pm 78$ & $199 \pm 71$ & $<0.001$ & \\
\hline
\end{tabular}


Part III | chapter 9

\section{DISCUSSION}

In the present study we demonstrate that common variation in the ADP-receptor $P_{2} R Y_{12}$ gene is a significant determinant of the wide interindividual variability in on-clopidogrel platelet reactivity. Haplotype F (allele frequency 22\%) was consistently associated with a higher on-clopidogrel platelet reactivity in the ADP-induced LTA and the VerifyNow ${ }^{\circledR} \mathrm{P}_{2} \mathrm{Y}_{12}$ assay, which may give an adequate protection against atherothrombotic events. Haplotype E (21\%) was also associated with higher onclopidogrel platelet reactivity, especially in the VerifyNow ${ }^{\circledR} \mathrm{P}_{2} \mathrm{Y}_{12}$ assay, but this association was less clear for the LTA. Interestingly, a single $300 \mathrm{mg}$ loading dose of clopidogrel (regimen B) was less effective in inhibiting the platelet ADP response than the daily $75 \mathrm{mg}$ dose (regimen A). However, although the overall mean on-clopidogrel platelet reactivity was significantly higher in clopidogrel dosing regimen $B$ than dosing regimens $A$ and $C$, these differences did not influence the associations between haplotypes across the regimens, nor did the adjustment for various covariates. In line with previous reports, the LTA and the VerifyNow ${ }^{\circledR} \mathrm{P}_{2} \mathrm{Y}_{12}$ assay showed similar results. ${ }^{16}$

The haplotype-based approach enabled a comprehensive investigation of the common variation in the $P_{2} R Y_{12}$ gene. The results suggested that SNP rs6787801, or another SNP that is in high LD with this SNP, is responsible for the observed haplotype effects. SNP rs6787801 is located within the $59 \mathrm{~kb}$ LD-block that contains the promoter region, but not the coding region of the $P_{2} R Y_{12}$ gene. This suggests that altered transcriptional activity of the $P_{2} R Y_{12}$ gene might be the underlying mechanism of the observed haplotype effects, rather than a structural change of the $P_{2} Y_{12}$ receptor. SNP rs6787801

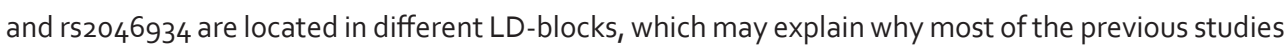
on rs2046934 (the tagging-SNP of haplotype-alleles $\mathrm{H}_{1}$ and $\mathrm{H}_{2}$ ) have not found a similar association between rs2046934 and the response to clopidogrel. ${ }^{6-14}$ Also in this study, we did not find any statistical differences between haplotypes $\mathrm{H}_{1}$ and $\mathrm{H}_{2}$, represented by our individual SNP analysis with $\mathrm{rs}_{2046934}$. Judging from the relative effects of the haplotypes, there is a complex interaction between the SNPs within a haplotype. Therefore, we cannot exclude the possibility that besides rs6787801 other SNPs, including rs2046934, might contribute to the observed haplotype effects. In addition, the effect of haplotype alleles may not be additive, as we assumed in our model.

Results were presented per single haplotype allele, which implies, under the assumption of an additive effect of the haplotype alleles, that the effect of a haplotype in a patient is the sum of the effects of its two single haplotype alleles. A single haplotype allele $\mathrm{F}$ was associated with $7 \%$ lower platelet aggregation as compared to the reference haplotype allele $A$, indicating that the estimated net effect in patients homozygous for haplotype allele $\mathrm{F}$ might be a $14 \%$ lower platelet aggregation as compared to patients homozygous for haplotype allele A. Smoking, polymorphisms of the cytochrome $\mathrm{P}_{450} \mathrm{C}_{1} 9$ $\left(\mathrm{CYP}_{2} \mathrm{C}_{19}\right.$ ) gene, diabetes mellitus, age and proton pump inhibitor treatment are reported to have a similar effect-size on clopidogrel-induced platelet inhibition. ${ }^{21-24}$ It remains, however, to be established whether these differences are associated with clinical outcome and what the underlying biological processes are that explain the observed haplotype effects.

Our study confirmed a wide variability in residual on-clopidogrel platelet reactivity, as measured with ADP-induced LTA and the VerifyNow ${ }^{\circledR} \mathrm{P}_{2} \mathrm{Y}_{12}$ assay. To date, a uniform definition of so-called clopidogrel "resistance" or clopidogrel "non-responsiveness" is lacking. This definition may vary depending on the type of platelet function assay used, or whether adverse clinical events occurred during clopidogrel therapy. ${ }^{5,25}$ In our study, the absolute residual on-clopidogrel platelet reactivity was measured, and not the relative response to clopidogrel from baseline (i.e. the pharmacodynamic response). For this 
reason, we cannot exclude the possibility that the observed differences between haplotypes may already be present at baseline and thus independent of clopidogrel treatment. In addition, we have not genotyped our patients for the $C_{Y P_{2}} C_{1}$ loss-of-function alleles $\left(* 2, *_{3}, *_{4}\right.$ and $*_{5}$ ), nor the $A B C B 1$ gene variants. $C Y P_{2} C_{1}$ variants have recently been shown to affect the hepatic bio-activation of the clopidogrel pro-drug and the concomitant platelet inhibition and risk of adverse ischemic cardiovascular events, whereas the $A B C B_{1}$ variants have been shown to affect clopidogrel absorption. ${ }^{26-28}$ However, since $C Y P_{2} C_{19}$ and $A B C B_{1}$ genes are located on different chromosomes than the $P_{2} R Y_{12}$ gene, we expect that the $C Y P_{2} C_{19}$ and $A B C B_{1}$ alleles are independent of the $P_{2} R Y_{12}$ haplotypes; i.e. the $C Y P_{2} C_{19}$ and $A B C B_{1}$ alleles are randomly distributed over the different $P_{2} R Y_{12}$ haplotype-subgroups of our patients. In addition, $C Y P_{2} C_{1}$ and $A B C_{1}$ genes do not have common biological pathways with the $P_{2} R Y_{12}$ gene, since the $P_{2} R Y_{12}$ gene encodes the target-receptor of clopidogrel, whereas $C Y P_{2} C_{19}$ and $A B C B 1$ genes are involved in clopidogrel bio-availability. Although these notions do not entirely exclude the possibility of interaction between the three genes, the actual effect of $P_{2} R Y_{12}$ gene variants (i.e. adjusted for any confounders) will probably be larger than the one observed in the present study. Although it would have been interesting to include additional pharmacokinetic and pharmacodynamic measurements of clopidogrel in our study, the absolute magnitude of the residual platelet reactivity during clopidogrel treatment is considered to be one of the most important endstage determinants of risk of recurrent atherothrombotic events. Additional studies need to be performed to test whether our results may be generalized to other ethnicities than Caucasians.

In conclusion, common variation in the $P_{2} R Y_{12}$ gene is a significant determinant of the wide interindividual variability in residual on-clopidogrel platelet reactivity in patients with CAD.

\section{Funding sources}

Jochem W. van Werkum received an unrestrictive research grant from Sanofi-Aventis. Frank W.G. Leebeek is a recipient of a clinical fellowship of the Dutch Organization for Health Research and Development (ZonMW), the Hague, the Netherlands. 
Part III | chapter 9

A

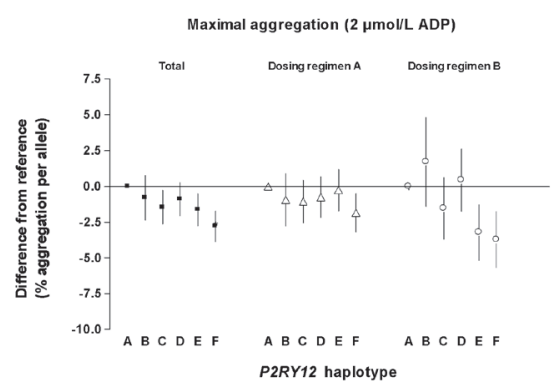

C

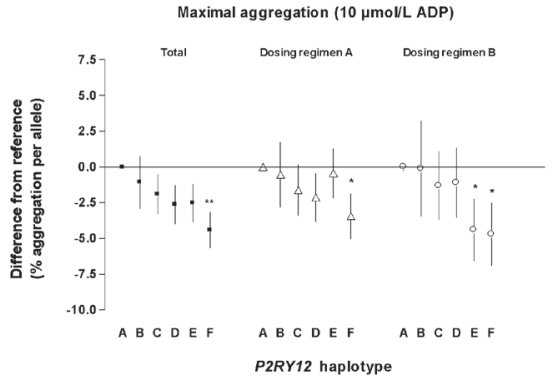

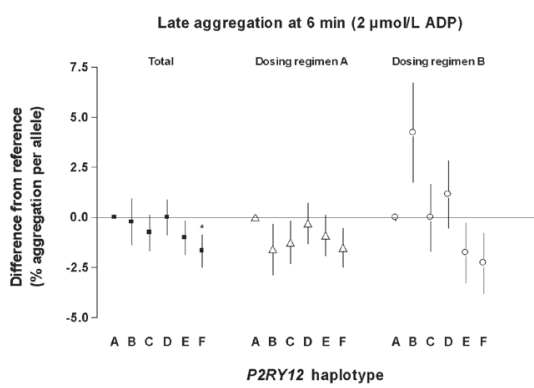

D

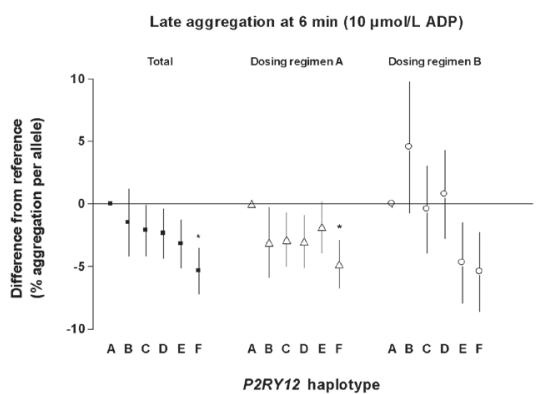

Supplemental Figure 1 |

Results are presented for $2 \mu \mathrm{mol} / \mathrm{L}$ ADP-induced maximal aggregation (panel A) and late aggregation at 6 min (panel $B$ ), and $10 \mu \mathrm{mol} / L$ ADP-induced maximal aggregation (panel $C$ ) and late aggregation at $6 \mathrm{~min}$ (panel D). In each panel, the results are shown for the analysis of the total study population (squares, dosing regimens $A+B+C$ ), the subgroup of patients who were on dosing regimen $A$ (triangles) and dosing regimen $B$ (circles). Dosing regimen $C$ was excluded from the analysis due to small sample size. Values are expressed as mean differences from the reference haplotype in percent of absolute aggregation per haplotype allele, with error bars representing SEM. $* * p<0.001, * p<0.05$ 


\section{REFERENCES}

1. Mehta SR, Yusuf S, Peters RJ et al. Effects of pretreatment with clopidogrel and aspirin followed by long-term therapy in patients undergoing percutaneous coronary intervention: the PCI-CURE study. Lancet. 2001;358:52733.

2. Gurbel PA, Bliden $\mathrm{KP}$, Hiatt BL, $\mathrm{O}^{\prime}$ Connor $\mathrm{CM}$. Clopidogrel for coronary stenting: response variability, drug resistance, and the effect of pretreatment platelet reactivity. Circulation. 2003;107:2908-13.

3. Serebruany VL, Steinhubl SR, Berger PB et al. Variability in platelet responsiveness to clopidogrel among 544 individuals. J Am Coll Cardiol. 2005;45:246-51.

4. Snoep JD, Hovens MM, Eikenboom JC et al. Clopidogrel nonresponsiveness in patients undergoing percutaneous coronary intervention with stenting: a systematic review and meta-analysis. Am Heart J. 2007;154:22131.

5. Angiolillo DJ, Fernandez-Ortiz A, Bernardo E et al. Variability in individual responsiveness to clopidogrel: clinical implications, management, and future perspectives. J Am Coll Cardiol. 2007;49:1505-16.

6. Grossmann R, Sokolova O, Schnurr A et al. Variable extent of clopidogrel responsiveness in patients after coronary stenting. Thromb Haemost. 2004;92:1201-6.

7. Angiolillo DJ, Fernandez-Ortiz A, Bernardo E et al. Lack of association between the $P_{2} Y_{12}$ receptor gene polymorphism and platelet response to clopidogrel in patients with coronary artery disease. Thromb Res. 2005;116:491-7.

8. von Beckerath $\mathrm{N}$, von Beckerath $\mathrm{O}$, Koch W et al. $\mathrm{P}_{2} \mathrm{Y}_{12}$ gene $\mathrm{H}_{2}$ haplotype is not associated with increased adenosine diphosphate-induced platelet aggregation after initiation of clopidogrel therapy with a high loading dose. Blood Coagul Fibrinolysis. 2005;16:199-204

9. Fontana P, Nolli S, Reber G, de Moerloose P. Biological effects of aspirin and clopidogrel in a randomized crossover study in 96 healthy volunteers. J Thromb Haemost. 2006;4:813-9.

10. Smith SM, Judge HM, Peters $G$ et al. Common sequence variations in the $P_{2} Y_{12}$ and $C Y P_{3} A_{5}$ genes do not explain the variability in the inhibitory effects of clopidogrel therapy. Platelets. 2006;17:250-8.

11. Lev El, Patel RT, Guthikonda $S$ et al. Genetic polymorphisms of the platelet receptors $P_{2} Y(12), P_{2} Y(1)$ and GP IIla and response to aspirin and clopidogrel. Thromb Res. 2007;119:355-60.

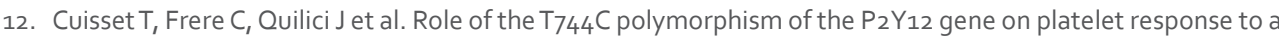
$600-\mathrm{mg}$ loading dose of clopidogrel in 597 patients with non-ST-segment elevation acute coronary syndrome. Thromb Res. 2007;120:893-9.

13. Staritz $\mathrm{P}$, Kurz K, Stoll M et al. Platelet reactivity and clopidogrel resistance are associated with the $\mathrm{H}_{2}$ haplotype of the $\mathrm{P}_{2} \mathrm{Y}(12)$-ADP receptor gene. Int J Cardiol. 2008.

14. Bura A, Bachelot-Loza C, Ali FD et al. Role of the $P_{2} Y_{12}$ gene polymorphism in platelet responsiveness to clopidogrel in healthy subjects. J Thromb Haemost. 2006;4:2096-7.

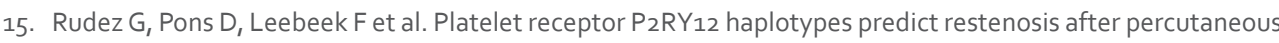
coronary interventions. Hum Mutat. 2008;29:375-80.

16. van Werkum JW, van der Stelt CA, Seesing TH et al. A head-to-head comparison between the VerifyNow $P_{2} Y_{12}$ assay and light transmittance aggregometry for monitoring the individual platelet response to clopidogrel in patients undergoing elective percutaneous coronary intervention. J Thromb Haemost. 2006;4:2516-8.

17. van Werkum JW, Kleibeuker M, Mieremet $\mathrm{N}$ et al. Evaluation of the platelet response to clopidogrel with light transmittance aggregometry: peak aggregation or late aggregation? J Thromb Haemost. 2007;5:884-6.

18. Price MJ, Endemann S, Gollapudi RR et al. Prognostic significance of post-clopidogrel platelet reactivity assessed by a point-of-care assay on thrombotic events after drug-eluting stent implantation. Eur Heart J. 2008;29:992-1000. 
Part III | chapter 9

19. Livak KJ. Allelic discrimination using fluorogenic probes and the 5' nuclease assay. Genet Anal. 1999;14:1439 .

20. Schaid DJ, Rowland CM, Tines DE et al. Score tests for association between traits and haplotypes when linkage phase is ambiguous. Am J Hum Genet. 2002;70:425-34.

21. Bliden KP, Dichiara J, Lawal L et al. The association of cigarette smoking with enhanced platelet inhibition by clopidogrel. J Am Coll Cardiol. 2008;52:531-3.

22. Trenk D, Hochholzer W, Fromm MF et al. Cytochrome P450 2C19 681G>A polymorphism and high on-clopidogrel platelet reactivity associated with adverse 1-year clinical outcome of elective percutaneous coronary intervention with drug-eluting or bare-metal stents. J Am Coll Cardiol. 2008;51:1925-34.

23. Angiolillo DJ, Bernardo E, Sabate M et al. Impact of platelet reactivity on cardiovascular outcomes in patients with type 2 diabetes mellitus and coronary artery disease. J Am Coll Cardiol. 2007;50:1541-7.

24. Gilard M, Arnaud B, Cornily JC et al. Influence of omeprazole on the antiplatelet action of clopidogrel associated with aspirin: the randomized, double-blind OCLA (Omeprazole CLopidogrel Aspirin) study. J Am Coll Cardiol. 2008;51:256-6o.

25. Frelinger AL, 3rd, Michelson AD. Clopidogrel linking evaluation of platelet response variability to mechanism of action. J Am Coll Cardiol. 2005;46:646-7.

26. Collet JP, Hulot JS, Pena A et al. Cytochrome $\mathrm{P}_{450}{ }_{2} \mathrm{C}_{19}$ polymorphism in young patients treated with clopidogrel after myocardial infarction: a cohort study. Lancet. 2009;373:309-17.

27. Mega JL, Close SL, Wiviott SD et al. Cytochrome p-450 polymorphisms and response to clopidogrel. N Engl J Med. 2009;360:354-62.

28. Simon T, Verstuyft C, Mary-Krause M et al. Genetic determinants of response to clopidogrel and cardiovascular events. N Engl J Med. 2009;360:363-75 


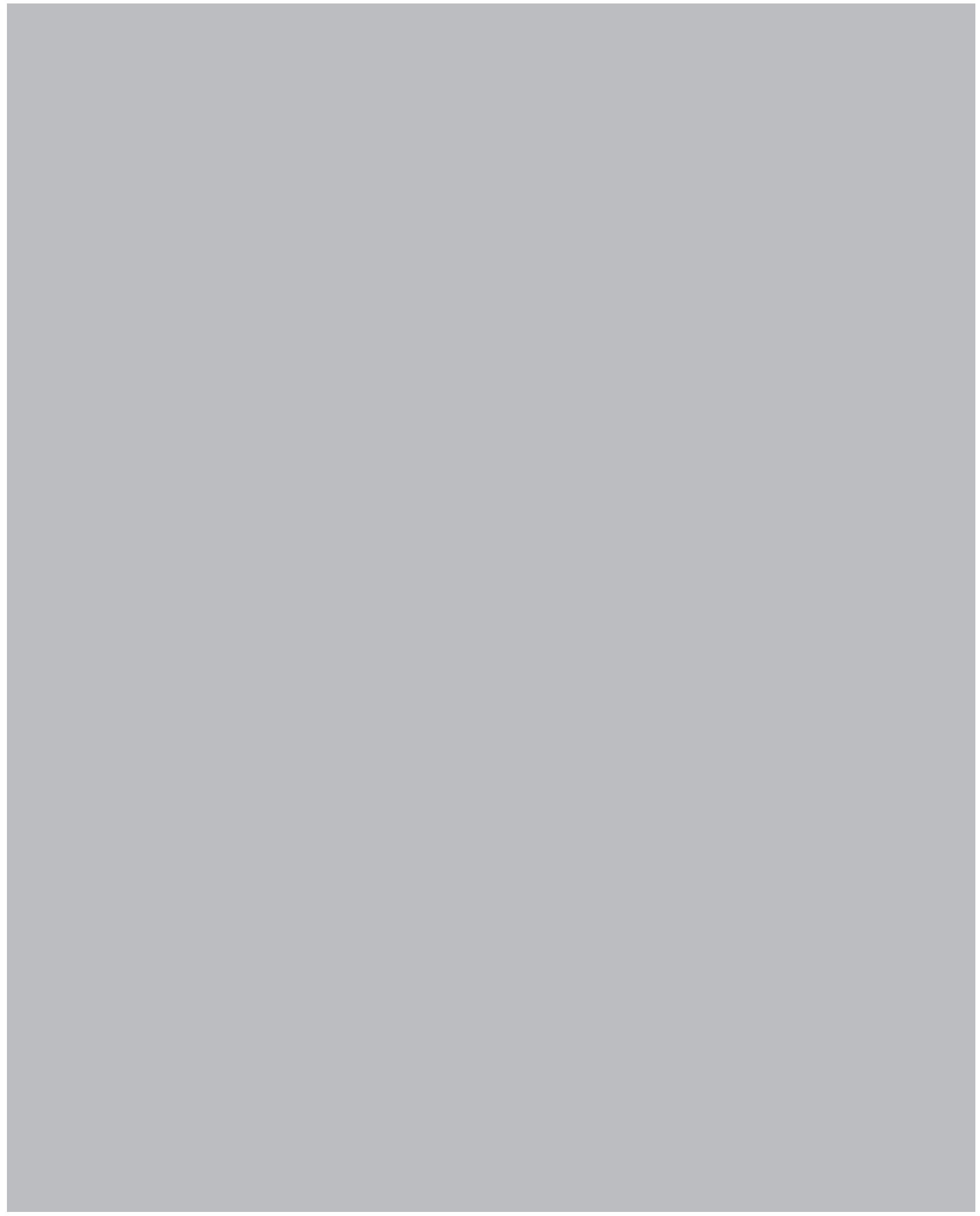




\section{Chapter 10}

\section{The relevance of $\mathrm{P}_{2} \mathrm{Y}_{12}$-receptor gene variation for the outcome of clopidogrel-treated patients undergoing elective coronary stent implantation: a clinical follow-up}

Thromb Haemost. 2012 Jan 3;107(1):189-91

Heleen J Bouman Jochem W van Werkum

Goran Rudež

Christian M Hackeng

Frank WG Leebeek

Hugo ten Cate

Jurriën M ten Berg

Moniek PM de Maat

Department of Cardiology, St. Antonius Hospital Nieuwegein, the Netherlands Department of Hematology, Erasmus University Medical Center Rotterdam, the Netherlands Department of Clinical Chemistry, St. Antonius Hospital Nieuwegein, the Netherlands St. Antonius Center for Platelet Function Research, Nieuwegein, the Netherlands 
Part III | chapter 10

\section{LETTER TO THE EDITOR}

The interindividual variation in the response to the antiplatelet drug clopidogrel is subject of extensive research. Multiple potential determinants of clopidogrel response have been investigated, including genetic variation in the pharmacological target of clopidogrel, the adenosine diphosphate (ADP) receptor $\mathrm{P}_{2} \mathrm{Y}_{12}$. Fontana and colleagues were the first to show that genetic variation in the $\mathrm{P}_{2} \mathrm{Y}_{12}{ }^{-}$ receptor was related to the degree of ADP-induced platelet aggregation ${ }^{1}$. Using a comprehensive approach, we previously demonstrated that $\mathrm{P}_{2} \mathrm{Y}_{12}$-receptor haplotypes were significantly associated with the magnitude of on-treatment platelet reactivity in clopidogrel and aspirin treated patients undergoing elective coronary stent implantation ${ }^{2}$. The aim of the present study was to determine whether this ex vivo association was translated into an effect at the level of clinical outcome.

Clopidogrel and aspirin pre-treated patients undergoing elective percutaneous coronary intervention (PCI) were eligible for inclusion. Blood for laboratory and genetic analysis was drawn into EDTAanticoagulated tubes (Sarstedt, Nümbrecht, Germany) from the femoral artery sheath at the catheterisation laboratory, prior to the administration of heparin. Genomic DNA was isolated from EDTA blood followed by analysis of six haplotype-tagging single nucleotide polymorphisms (ht-SNPs; rs6798347 C>t, rs6787801 T>c, rs9859552 C>a, rs6801273 A>g, rs9848789 G>a, rs2046934 T>c) of the $\mathrm{P}_{2} \mathrm{Y}_{12}$-receptor (selected as described previously ${ }^{2,3}$ ) using TaqMan ${ }^{\circledR}$ SNP Genotyping Assays (Applied Biosystems, Foster City, Calif) on an ABI 790oHT instrument (Applied Biosystems, Foster City, Calif) using SDS 2.2.2 software (Applied Biosystems, Foster City, Calif).

The primary end point was defined as a composite of all-cause death, non-fatal myocardial infarction 5, stent thrombosis ${ }^{6}$, and non-fatal ischemic stroke at one year follow-up. Secondary endpoints were the individual constituents of the primary endpoint. The primary safety endpoint was the combination of minor and major bleeding (according to the modified Thrombolysis In Myocardial Infarction Study Group criteria ${ }^{5}$.

Haplo.Stats software (http://mayoresearch.mayo.edu/mayo/research/biostat/schaid.cfm) was used to calculate odds ratios (OR) with $95 \%$-confidence intervals $(\mathrm{Cl})$ for occurrence of the endpoints relative to reference haplotype $A^{2}$. Associations between single ht-SNPs and clinical outcome were tested using logistic regression with calculation of $\mathrm{OR}(95 \% \mathrm{Cl})$ of heterozygote and homozygote carriers of variant alleles as compared to the wildtype (SPSS version 14.0; SPSS Inc., Chicago, IL, USA). Two-sided $p$-values $<0.05$ were considered significant.

A total of 1069 patients were included, with a mean age of $64 \pm 11$ years, of which $802(75 \%)$ were male, $823(76.9 \%)$ had hypertension, 858 (80.3\%) had hypercholesterolemia, and 199 (18.6\%) suffered from diabetes mellitus. Further baseline characteristics were published previously ${ }^{4}$. During 1-year follow-up $18(1.7 \%)$ patients died, 64 (6.0\%) patients suffered from myocardial infarction, 16 (1.5\%) patients incurred stent thrombosis (13 definite and 3 possible, classified following the Academic Research Consortium criteria ${ }^{6}$ ) and 14 (1.3\%) patients had an ischemic stroke. Bleeding occurred in a total of 55 (5.1\%) patients, of which 33 (3.1\%) major bleeding. None of the selected ht-SNPs in the $\mathrm{P}_{2} \mathrm{Y}_{12}$-receptor gene was associated with the primary endpoint and primary safety endpoint (Table) or secondary thrombotic endpoints (all $p>0.05$, data not shown). Furthermore, the frequency of the primary and secondary endpoints was similar for all haplotypes (all $p>0.05$; Table, data not shown for the secondary thrombotic endpoints). 
The present study is the first using a comprehensive haplotype approach to investigate the association of variation of the $\mathrm{P}_{2} \mathrm{Y}_{12}$-receptor gene to the clinical outcome of clopidogrel-treated patients undergoing elective $\mathrm{PCl}$. The previously demonstrated relationship of $\mathrm{P}_{2} \mathrm{Y}_{12}$-receptor gene variation with on-treatment platelet reactivity could not be translated into an effect on thrombotic or bleeding events in the present clinical follow-up study of the same cohort ${ }^{2}$. Haplotype $E$ and F demonstrated lower on-treatment platelet reactivity as compared to reference haplotype A. Therefore, a lower thrombotic event rate and a higher frequency of bleeding was expected for these haplotypes. In the present follow-up study the odds ratio for the primary endpoint and primary safety endpoint deviated from 1 in the expected directions, but confidence intervals were wide and no relationship between $\mathrm{P}_{2} \mathrm{Y}_{12}$-receptor haplotypes and thrombotic event rate could be established.

Discrepancy between effects on on-treatment platelet reactivity and on clinical events has been shown for other determinants of the laboratory response to clopidogrel, including the use of calcium channel blockers ${ }^{7,8}$, statins or proton pump inhibitors ${ }^{9}$. Possibly, conventionally sized studies are insufficiently powered to clinically detect more subtle effects observed at the level of ex vivo pharmacodynamics. Furthermore, it has become clear that the response to clopidogrel is mainly attributed to plasma levels of the active metabolite reached during treatment, referred to as "No active metabolite, no party" 10, ${ }^{11}$. Genetic variations in the enzymes responsible for formation of the active metabolite of clopidogrel are the main source of the variability in active metabolite plasma levels, resulting in an impaired pharmacodynamic response to clopidogrel and worse clinical outcome in part of clopidogrel-treated patients undergoing coronary stent implantation ${ }^{11-13}$.

Hypothetically, a contribution of variation in the $\mathrm{P}_{2} \mathrm{Y}_{12}$-receptor gene to clopidogrel response or baseline (off-drug) platelet reactivity could become overshadowed by the substantial variability in active metabolite plasma levels caused by pharmacokinetic determinants. Novel $\mathrm{P}_{2} \mathrm{Y}_{12}$-receptor antagonists lacking the noise due to variable formation of active metabolite exhibit more consistent active compound levels ${ }^{14}$, 15, potentially rendering $\mathrm{P}_{2} \mathrm{Y}_{12}$-receptor gene variation more relevant than for clopidogrel.

Table 1 | Association of clinical outcome with single ht-SNPs of the $\mathrm{P}_{2} \mathrm{Y}_{12}$-receptor gene and haplotypes

\begin{tabular}{|c|c|c|c|c|c|c|c|c|c|}
\hline $\begin{array}{l}\text { Single } \\
\text { ht-SNPs* }\end{array}$ & & Primary en & idpoint & & Primary safet & y endpoint & $\begin{array}{l}\text { Haplo- } \\
\text { types* }\end{array}$ & $\begin{array}{l}\text { Primary } \\
\text { endpoint }\end{array}$ & $\begin{array}{l}\text { Primary } \\
\text { safety } \\
\text { endpoint }\end{array}$ \\
\hline & 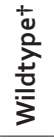 & 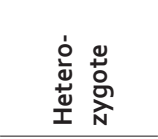 & 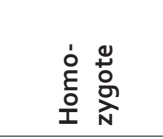 & 竞 & 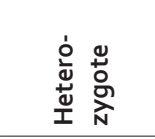 & 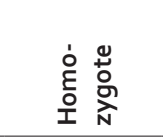 & & & \\
\hline rs6798347C>t & 1 & $1.38[0.86-2.23]$ & $0.26[0.04-1.96]$ & 1 & $0.97[0.50-1.89]$ & $1.94[0.65-5.74]$ & $A \ddagger$ & 1 & 1 \\
\hline rs6787801 T>c & 1 & $1.45[0.82-2.56]$ & $1.22[0.64-2.35]$ & 1 & $0.94[0.48-1.86]$ & $0.88[0.40-1.94]$ & B & $0.57[0.23-1.44]$ & $1.55[0.52-4.62]$ \\
\hline rs9859552 C>a & 1 & $0.81[0.48-1.39]$ & - & 1 & $0.74[0.36-1.51]$ & $1.53[0.45-5.19]$ & C & $0.74[0.40-1.38]$ & $1.30[0.52-3.30]$ \\
\hline rs6801273 A>g & 1 & $1.15[0.71-1.86]$ & $1.33[0.68-2.60]$ & 1 & $1.33[0.71-2.49]$ & $1.29[0.53-3.16]$ & $\mathrm{D}$ & $0.56[0.30-1.07]$ & $1.20[0.48-2.96]$ \\
\hline rs9848789 G>a & 1 & $0.78[0.46-1.32]$ & $0.51[0.12-2.16]$ & 1 & $0.72[0.35-1.47]$ & $1.43[0.42-4.84]$ & E & $0.78\left[0.43^{-1.39}\right]$ & $1.46[0.62-3.44]$ \\
\hline rs2046934 T>C & 1 & $0.84[0.51-1.39]$ & $0.82[0.25-2.73]$ & 1 & $1.18[0.63-2.19]$ & $1.69[0.49-5.78]$ & $\mathrm{F}$ & $0.87[0.50-1.51]$ & $0.75[0.30-1.85]$ \\
\hline
\end{tabular}


Part III | chapter 10

However, these novel antiplatelet agents also exhibit a more potent antiplatelet profile, thereby reducing response variation in general. In conclusion, common variation in the $\mathrm{P}_{2} \mathrm{Y}_{12}$-receptor gene has no impact on the clinical efficacy of clopidogrel in patients undergoing elective $\mathrm{PCl}$. 
$\mathrm{P}_{2} \mathrm{Y}_{12}$-receptor gene variation and clinical outcome

\section{REFERENCES}

1 Fontana P, Dupont A, Gandrille S, et al. Adenosine diphosphate-induced platelet aggregation is associated with $\mathrm{P}_{2} \mathrm{Y}_{12}$ gene sequence variations in healthy subjects. Circulation. 2003; 108: 989-95

2 Rudez G, Bouman HJ, van Werkum JW, et al. Common variation in the platelet receptor P2RY12 gene is associated with residual on-clopidogrel platelet reactivity in patients undergoing elective percutaneous coronary interventions. Circ Cardiovasc Genet. 2009; 2: 515-21.

3 Bouman HJ, van Werkum JW, Rudez G, et al. The influence of variation in the $\mathrm{P}_{2} \mathrm{Y}_{12}$ receptor gene on in vitro platelet inhibition with the direct $\mathrm{P}_{2} \mathrm{Y}_{12}$ antagonist cangrelor. Thromb Haemost. 2010; 103: 379-86.

4 Breet NJ, van Werkum JW, Bouman HJ, et al. Comparison of platelet function tests in predicting clinical outcome in patients undergoing coronary stent implantation. JAMA. 2010; 303: 754-62.

5 TIMI Study Group. Definitions used in TIMI-trials. Accessed at www.timi.org, April 12th 2011.

6 Cutlip DE, Windecker S, Mehran R, et al. Clinical end points in coronary stent trials: a case for standardized definitions. Circulation. 2007; 115: 2344-51.

7 Harmsze AM, Robijns K, van Werkum JW, et al. The use of amlodipine, but not of P-glycoprotein inhibiting calcium channel blockers is associated with clopidogrel poor-response. Thromb Haemost. 2010; 103: 920-5.

8 Sarafoff N, Neumann L, Morath T, et al. Lack of impact of calcium-channel blockers on the pharmacodynamic effect and the clinical efficacy of clopidogrel after drug-eluting stenting. Am Heart J. 2011; 161: 605-10.

9 Bates ER, Lau WC, Angiolillo DJ. Clopidogrel-drug interactions. J Am Coll Cardiol. 2011; 57: 1251-63.

10 Patrono C. The $\mathrm{P}_{2} \mathrm{Y}_{12}$ receptor: no active metabolite, no party. Nat Rev Cardiol. 2009; 6: 271-2.

11 Shuldiner AR, O'Connell JR, Bliden KP, et al. Association of cytochrome $\mathrm{P}_{450}{ }_{2} \mathrm{C}_{1}$ g genotype with the antiplatelet effect and clinical efficacy of clopidogrel therapy. JAMA. 2009; 302: 849-57.

12 Bouman HJ, Schomig E, van Werkum JW, et al. Paraoxonase-1 is a major determinant of clopidogrel efficacy. Nat Med. 2011; 17: 110-6.

13 Mega JL, Close SL, Wiviott SD, et al. Cytochrome p-450 polymorphisms and response to clopidogrel. N Engl J Med. 2009; 360: 354-62

14 Gurbel PA, Kereiakes DJ, Tantry US. Ticagrelor for the treatment of arterial thrombosis. Expert Opin Pharmacother. 2010; 11: 2251-9.

15 Jakubowski JA, Winters KJ, Naganuma H, et al. Prasugrel: a novel thienopyridine antiplatelet agent. A review of preclinical and clinical studies and the mechanistic basis for its distinct antiplatelet profile. Cardiovasc Drug Rev. 2007; 25: 357-74 


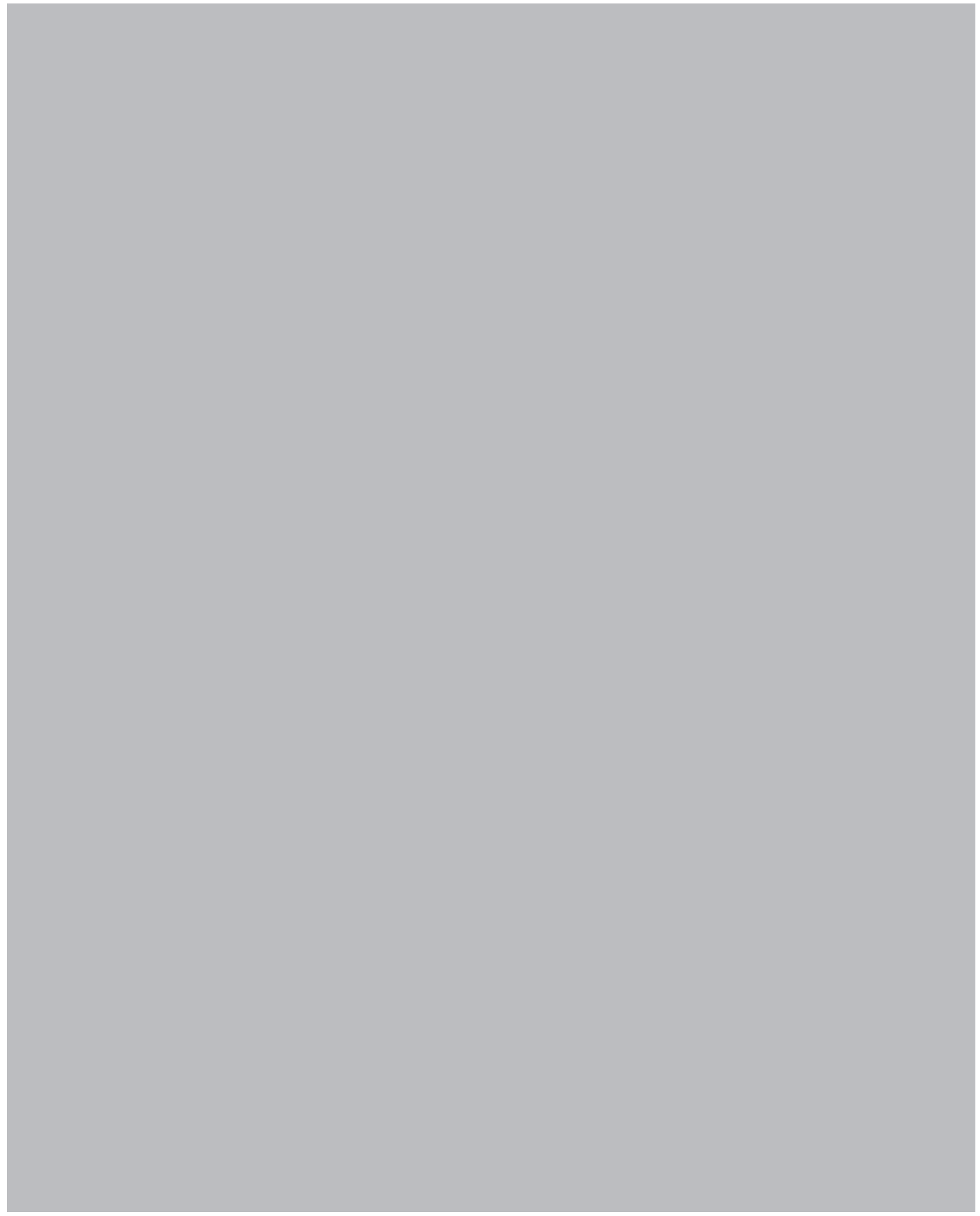




\section{Part IV}

Pharmacokinetic determinants of the response to clopidogrel 


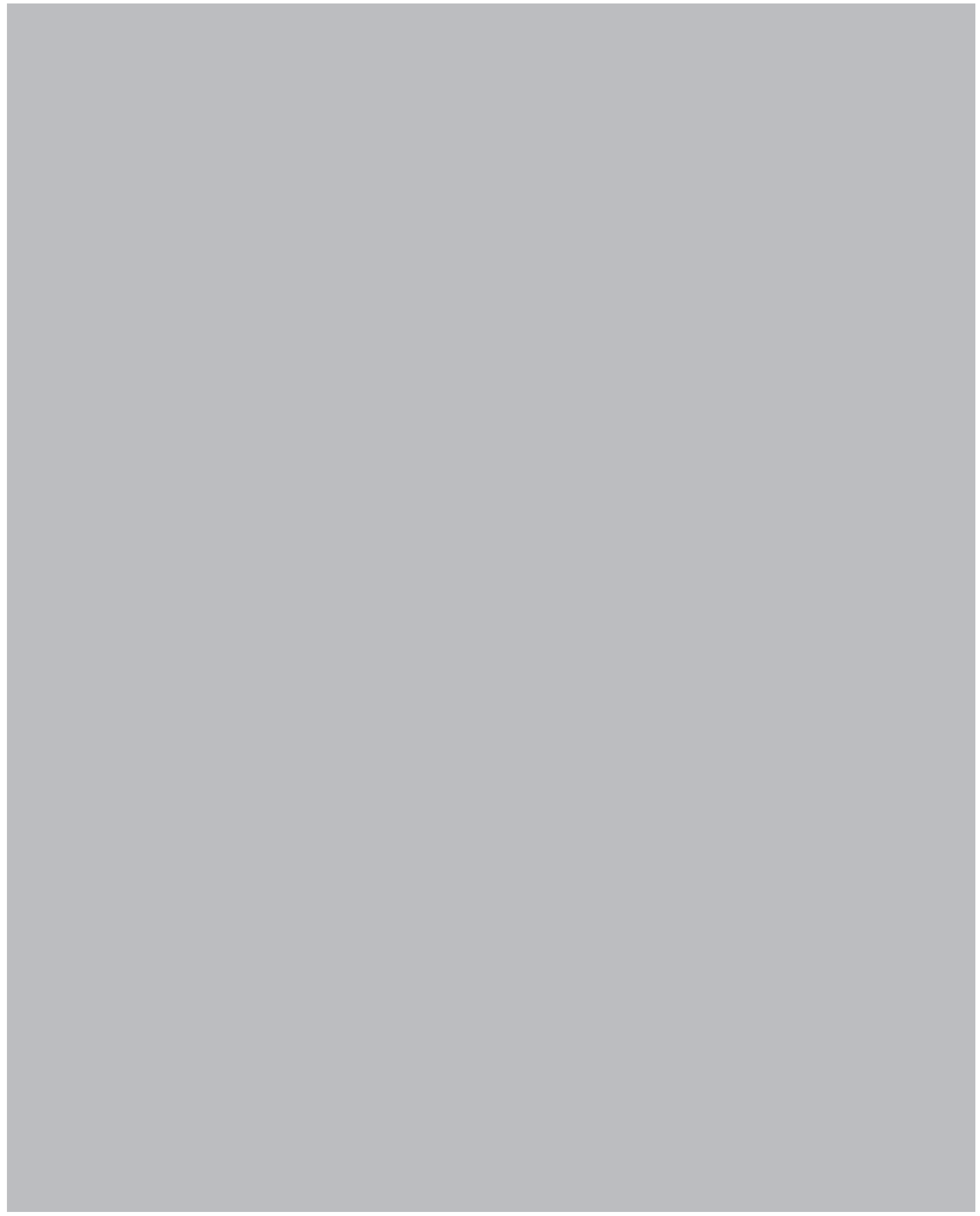




\section{Chapter 11}

\section{Variability in on-clopidogrel platelet reactivity explained by CYP2 $C_{1}{ }^{*} 2$ genotype is modest in patients undergoing coronary stenting}

Heart. 2011 Aug;97(15):1239-44

Heleen J Bouman* Ankie M Harmsze * Jochem $W$ van Werkum

Hugo ten Cate

Nicoline J Breet Christian M Hackeng Vera HM Deneer Jurriën $\mathrm{M}$ ten Berg

*Both authors contributed equally

Department of Cardiology, St. Antonius Hospital, Nieuwegein, The Netherlands St. Antonius Center for Platelet Function Research, St. Antonius Hospital, Nieuwegein, The Netherlands Department of Internal Medicine, Cardiovascular Research Institute Maastricht, Maastricht University Medical Center, Maastricht, the Netherlands

Department of Clinical Pharmacy, St. Antonius Hospital, Nieuwegein, The Netherlands Division of Pharmacoepidemiology and Pharmacotherapy, Utrecht Institute for Pharmaceutical

Sciences (UIPS), Utrecht University, Utrecht, The Netherlands Department of Clinical Chemistry, St Antonius Hospital, Nieuwegein, the Netherlands 


\section{ABSTRACT}

\section{Aims}

An inadequate response to clopidogrel is mainly attributable to the variable formation of its active metabolite. The CYP2 $C_{1}{ }^{*} 2$ loss-of-function polymorphism leads to reduced generation of the active metabolite and is, similarly to high on-treatment platelet reactivity (HPR), associated with recurrent atherothrombotic events following coronary stent implantation. The aim of the present study was to determine the relative contribution of $\mathrm{CYP}_{2} \mathrm{C}_{1}{ }^{*} 2$ genotype to (high) on-treatment platelet reactivity.

\section{Methods and Results}

CYP2 $C_{1} *^{*}$-genotyping and platelet-function-testing using 5 and $20 \mu \mathrm{mol} / \mathrm{L}$ ADP-induced light transmittance aggregometry (LTA), the PlateletWorks-assay, and the VerifyNow P2 Y12-assay, were performed in $106 \mathrm{~g}$ clopidogrel pre-treated patients undergoing elective coronary stenting (POPular

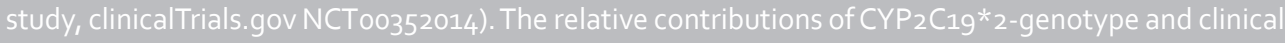
variables to the interindividual variability of on-treatment platelet reactivity and the occurrence of HPR were established using multivariate regression models.

CYP2 $C_{1}{ }^{*} 2$ carrier status was associated with a more frequent occurrence of HPR. CYP $2 C_{1} *_{2}$ genotype alone could explain 5.0\%,6.2\%, 4.4\% and 3.7\% of the variability in 5 and 20 Mmol/L ADP. induced LTA, the PlateletWorks-assay and the VerifyNow P $2 Y_{12}$-assay, respectively, which increased to $13.0 \%, 15.2 \%, 5.6 \%$ and $20.6 \%$ when clinical variables were considered as well. Besides the CYP2 $C_{1} *_{2}$ genotype, multiple clinical variables could be identified as independent predictors of HPR, including age, gender, body mass index, diabetes mellitus, clopidogrel loading dose regimen, use of amlodipine and platelet count.

\section{Conclusion}

The CYP2 $C_{19}{ }_{2}$ loss-of-function polymorphism is associated with a more frequent occurrence of HPR. However, the part of the interindividual variability in on-treatment platelet reactivity explained by CYP $2 C_{1}{ }^{*} 2$ genotype is modest. 


\section{INTRODUCTION}

The large interindividual variability in the response to clopidogrel is mainly attributable to the variable extent to which its active metabolite is formed. Both a $\mathrm{CYP}_{2} \mathrm{C}_{1}{ }^{*} 2$ carrier status as well as the presence of high on-treatment platelet reactivity (HPR) have been associated with recurrent atherothrombotic events following coronary stent implantation ${ }^{[1-5]}$. It is unknown whether genotyping or platelet function testing is superior in tailoring clopidogrel therapy in the individual patient. Genotyping and platelet function testing each have potential advantages for the optimization of clopidogrel therapy. $\mathrm{CYP}_{2} \mathrm{C}_{19}$ genotyping provides reproducible results that are stable over time, regardless of clinical presentation, whereas the individual platelet reactivity status represents the sum of multiple clinical factors and $\mathrm{CYP}_{2} \mathrm{C}_{19}$-genotype.

We have performed $\mathrm{CYP}_{2} \mathrm{C}_{19}$ *2 genotyping in the 'Do Platelet Function Assays Predict Clinical Outcomes in Clopidogrel-Pretreated Patients Undergoing Elective PCl'(POPular) study with the aim to determine the relative contribution of $\mathrm{CYP}_{2} \mathrm{C}_{1}{ }^{*} 2$ carrier status to the interindividual variability in on-treatment platelet reactivity ${ }^{[2]}$.

\section{METHODS}

The study design and methods used for platelet function testing of the POPular-study were described previously ${ }^{[2]}$. In brief, patients with coronary artery disease undergoing elective coronary stent implantation were eligible for inclusion. All patients were adequately pre-treated with clopidogrel (75 $\mathrm{mg}$ daily for $>5$ days, or a loading dose of $300 \mathrm{mg} \geq 24$ hours or $600 \mathrm{mg} \geq 4$ hours before $\mathrm{PCI}$ ) and aspirin (80-100 mg daily $\geq 10$ days prior to $\mathrm{PCl}$ ) unless on long-term anticoagulation with coumarin derivatives. Blood for platelet function testing and genetic analysis was collected from the femoral or radial artery sheath into $3.2 \%$ citrate and $\mathrm{K}_{3}$-EDTA anticoagulated tubes, respectively, prior to heparinization and the administration of glycoprotein IIb/IIla inhibitors. The primary endpoint was the magnitude of ontreatment platelet reactivity as measured with the VerifyNow $\mathrm{P}_{2} \mathrm{Y}_{12}$-assay. Secondary endpoint was on-treatment platelet reactivity as measured with 5 and $20 \mu \mathrm{mol} / \mathrm{L}$ adenosine diphosphate (ADP)induced light transmittance aggregometry (LTA) and the PlateletWorks assay. The study protocol complied with the declaration of Helsinki and was approved by the ethical committee of our institution. All patients gave written informed consent for participation.

\section{Platelet function testing}

The absolute level of platelet reactivity during treatment with clopidogrel (i.e. on-treatment platelet reactivity) was quantified using ADP-activated, aggregation-based platelet function tests that were able to predict clinical outcome in the POPular study, i.e. 5 and $20 \mu \mathrm{mol} / \mathrm{L}$ ADP-induced LTA ( $n=1005$ and $n=1006$, respectively), the PlateletWorks assay (Helena Laboratories, Beaumont, Texas; $n=511$, due to irregularities in supply) and the VerifyNow $\mathrm{P}_{2} \mathrm{Y}_{12}$ assay (Accumetrics, San Diego, California; $\mathrm{n}=1010$ ). High on-treatment platelet reactivity to ADP was defined according to the receiver operator characteristics curve based cut-offs determined for high on-treatment platelet reactivity based on 1-year clinical outcome, i.e. aggregation $>42.9 \%$ for $5 \mu \mathrm{mol} / \mathrm{L}$ ADP-induced LTA, $>64.5 \%$ for $20 \mu \mathrm{mol} / \mathrm{L}$ ADP-induced LTA, $>80.5 \%$ for the PlateletWorks, and $\mathrm{P}_{2} \mathrm{Y}_{12}$ reaction units $(\mathrm{PRU})>236$ for the VerifyNow $\mathrm{P}_{2} \mathrm{Y}_{12}$-assay ${ }^{[2,5]}$. 
Part IV | chapter 11

\section{CYP2C19-genotyping}

Genomic DNA was isolated from EDTA blood followed by identification of the CYP2 $C_{1}$ * 2 (681G $>A$, rs4244285) allele using Real time PCR. DNA sequence analysis was used to validate the genotyping procedure. $\mathrm{CYP}_{2} \mathrm{C}_{19} *_{2}$ genotypes were available for 1024 patients. The $\mathrm{CYP}_{2} \mathrm{C}_{19}$ wildtype $\left(*_{1} / *_{1}\right)$ occurred with a frequency of $72.0 \%$, while $25.4 \%$ were heterozygote for $\mathrm{CYP}_{2} \mathrm{C}_{1}{ }^{*}{ }_{2}\left(*_{1} / *_{2}\right)$, and $2.6 \%$ were $\mathrm{CYP}_{2} \mathrm{C}_{1}{ }^{*} 2$ homozygotes $\left(*_{2} / *_{2}\right)$. These genotype frequencies did not deviate from the HardyWeinberg equilibrium $\left(\chi^{2}=0.50, p=0.48\right)$.

\section{Statistics}

Data are presented as mean \pm standard deviation (SD) for continuous variables and as counts (\%) for categorical variables. The Student's t-test and $\chi^{2}$-test were used to test the association of various clinical variables with on-treatment platelet reactivity $(p<0.10)$, i.e. age (10 years), gender, body mass index $\left(\mathrm{BMl}, \mathrm{kg} / \mathrm{m}^{2}\right)$, current smoking, hypertension (systolic blood pressure $[\mathrm{BP}]>140 \mathrm{~mm} \mathrm{Hg}$ or diastolic BP $>90 \mathrm{~mm} \mathrm{Hg}$ ), diabetes mellitus, left ventricular ejection fraction (LVEF) $<45 \%$, renal failure (creatinine level $>1.36 \mathrm{mg} / \mathrm{dL}$ ), platelet count, mean platelet volume, clopidogrel dosing regimen, proton pump inhibitor (PPI) use, and use of the calcium channel blocker amlodipine ${ }^{[6,7]}$. Differences in the magnitude of on-treatment platelet reactivity between the three $\mathrm{CYP}_{2} \mathrm{C}_{19}$ genotype groups were tested with analysis of variance (ANOVA) followed by the least significant difference (LSD) post-hoc test.

Multivariate linear regression analysis with calculation of the adjusted $\beta$ coefficient and coefficient of determination $\left(R^{2}\right)$ was used to identify the independent contribution of each of the above-mentioned factors to the interindividual variability in on-treatment platelet reactivity. Furthermore, multivariate binary logistic regression analysis was used to compute adjusted odds ratios with corresponding $95 \%$ confidence intervals (ORadj [95\%-CI]) for exhibiting HPR compared to not exhibiting HPR, adjusting for the above mentioned variables. All statistical analyses were performed with SPSS (version 15.0; SPSS Inc., Chicago, IL, USA), and two-sided $p$-values $<0.05$ were considered significant.

\section{RESULTS}

Genetic data was available in 1024 of 1069 patients enrolled in the POPular-study. Patient characteristics stratified by $\mathrm{CYP}_{2} \mathrm{C}_{19}{ }^{*} 2$ genotype are shown in Table 1.

The mean $\pm \mathrm{SD}$ magnitude of on-treatment platelet reactivity was higher in $\mathrm{CYP}_{2} \mathrm{C}_{1}{ }^{*}{ }_{2}$ heterozygotes $(44 \pm 14 \%, 63 \pm 13 \%, 72 \pm 27 \%$, and $230 \pm 71$ PRU) and homozygotes ( $52 \pm 14 \%, 70 \pm 9 \%, 90 \pm 21 \%$, and $257 \pm 60$ $\mathrm{PRU})$ as compared to patients not carrying the $\mathrm{CYP}_{2} \mathrm{C}_{1}{ }^{*} 2$ gene variant $(38 \pm 14 \%, 56 \pm 15 \%, 61 \pm 30 \%$ and $202 \pm 76 \mathrm{PRU}$, for 5 and $20 \mu \mathrm{mol} / \mathrm{L}$ ADP-induced LTA, the PlateletWorks assay, and the VerifyNow $\mathrm{P}_{2} \mathrm{Y}_{12}$ assay, respectively; Figure 1). Furthermore, HPR was more frequent in patients carrying the $\mathrm{CYP}_{2} \mathrm{C}_{19}$ *2 genetic polymorphism (Table 2).

\section{Contribution to on-treatment platelet reactivity}

$\mathrm{CYP}_{2} \mathrm{C}_{1}{ }^{*} 2$ carrier status alone could explain $5.0 \%, 6.2 \%$ and $4.4 \%$ of the interindividual variability in 5 and $20 \mu \mathrm{mol} / \mathrm{L}$ ADP-induced LTA and the PlateletWorks assay, respectively, compared to $13.0 \%$, $15.2 \%$ and $5.6 \%$ when clinical factors were included as well (Table 3 ). The whole blood VerifyNow $\mathrm{P}_{2} \mathrm{Y}_{12}$-assay demonstrated a smaller contribution of $\mathrm{CYP}_{2} \mathrm{C}_{19}$-genotype, $3.7 \%$ of the variability in PRU 
could be attributed to $\mathrm{CYP}_{2} \mathrm{C}_{1}$ * 2 carrier status, which increased more than five-fold to $20.6 \%$ after adding clinical variables. The clinical variables independently associated with the magnitude of ontreatment platelet reactivity were age, BMI, gender, diabetes mellitus, clopidogrel loading dose regimen, use of a PPI, or amlodipine, and platelet count (Table 4 ).

\section{Predictors of HPR}

Multivariate logistic analysis showed that the $\mathrm{CYP}_{2} \mathrm{C}_{1}{ }^{*}{ }_{2}$ heterozygotes ( ${ }^{1} 1 *^{*} 2$ genotype) had an approximately 2 -fold increase in the occurrence of HPR as compared to the patients with the $*_{1} / *_{1}$ genotype, and this association was stronger for patients carrying two copies of the $\mathrm{CYP}_{2} \mathrm{C}_{1}{ }^{*} 2$ gene variant. Besides $\mathrm{CYP}_{2} \mathrm{C}_{1}{ }^{*} 2$ genotype, multiple clinical variables could be identified as independent predictors of HPR, including age, BMI, gender, diabetes mellitus, clopidogrel loading dose regimen, use of amlodipine and platelet count (Figure 2).

Table 1 | Patient characteristics stratified by $\mathrm{CYP}_{2} \mathrm{C}_{1}{ }^{*} 2$ genotype

\begin{tabular}{|c|c|c|c|c|}
\hline Characteristic & $\begin{array}{c}\mathrm{CYP}_{2} \mathrm{C}_{19} *_{1} / *_{1} \\
n=737\end{array}$ & $\begin{array}{c}\mathrm{CYP}_{2} \mathrm{C}_{19} *_{1} / *_{2} \\
n=260\end{array}$ & $\begin{array}{c}\mathrm{CYP}_{2} \mathrm{C}_{19} *_{2} / *_{2} \\
n=27\end{array}$ & $p$-value \\
\hline Age (years) & $64 \pm 11$ & $65 \pm 10$ & $64 \pm 12$ & 0.582 \\
\hline BMI $\left(\mathrm{kg} / \mathrm{m}^{2}\right)$ & $27 \pm 4$ & $27 \pm 4$ & $28 \pm 4$ & 0.249 \\
\hline Male gender & $561(76.1)$ & $189(72.7)$ & $20(74.1)$ & 0.541 \\
\hline Current smoking & $9(1.2)$ & $3(1.2)$ & $o(0)$ & 0.974 \\
\hline Hypertension & $559(75.9)$ & $205(78.8)$ & $23(85.2)$ & 0.368 \\
\hline Diabetes Mellitus & $136(18.5)$ & $49(18.8)$ & $5(18.5)$ & 0.993 \\
\hline LVEF $<45 \%$ & $108(14.7)$ & $43(16.5)$ & $6(22.2)$ & 0.463 \\
\hline Renal failure & $57(7.7)$ & $21(8.1)$ & $2(7.4)$ & 0.981 \\
\hline \multicolumn{5}{|l|}{ Medication } \\
\hline $\begin{array}{l}\text { Clopidogrel LD } \\
\text { (300 mg /600 mg) }\end{array}$ & $299(42.0) / 62(8.7)$ & $105(41.7) / 16(6.3)$ & $17(68.0) / 1(4.0)$ & 0.079 \\
\hline PPI & $195(27.2)$ & $51(19.9)$ & $9(36.0)$ & 0.035 \\
\hline \multirow[t]{2}{*}{ CCB/Amlodipine* } & $241(33.8) /$ & 96 (37.9) / & $10(38.5) /$ & $0.469 /$ \\
\hline & $127(17.8)$ & $55(21.7)$ & $7(26.9)$ & 0.234 \\
\hline Statin & $581(80.7)$ & $211(82.7)$ & $22(81.5)$ & 0.771 \\
\hline B-blocker & $55^{69}(78.6)$ & $201(79.1)$ & $17(63.0)$ & 0.144 \\
\hline \multicolumn{5}{|l|}{ Laboratory parameters } \\
\hline Platelet count (109/L) & $269 \pm 74$ & $280 \pm 97$ & $246 \pm 64$ & 0.049 \\
\hline Mean platelet volume (fL) & $7.4 \pm 0.9$ & $7 \cdot 5 \pm 1.0$ & $7 \cdot 7 \pm 1.1$ & 0.123 \\
\hline \multicolumn{5}{|l|}{ Procedural characteristics } \\
\hline No. of stents implanted & $1.6 \pm 0.8$ & $1.6 \pm 0.8$ & $1.5 \pm 0.8$ & 0.934 \\
\hline LAD & $356(48.3)$ & $120(46.2)$ & $14(51.9)$ & 0.766 \\
\hline Drug-eluting stent & $474(64.7)$ & $154(59.9)$ & $19(70.4)$ & 0.302 \\
\hline
\end{tabular}

Continuous variables are presented as mean $\pm S D$, dichotomous variables as counts (\%). *Amlodipine showed to be the calcium channel blocker associated with HPR in a previously published sub-analysis of POPular [5]. BMI: body mass index, LAD: left anterior descending artery, LD: loading dose, either $300 \mathrm{mg}$ or $600 \mathrm{mg}$ clopidogrel, LVEF: left ventricular ejection fraction, MPV: mean platelet volume, PLT: platelet count, PPI: proton pump inhibitor. 
Part IV | chapter 11

a

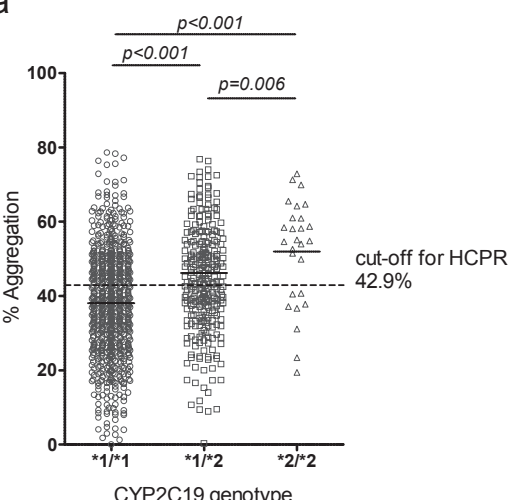

C

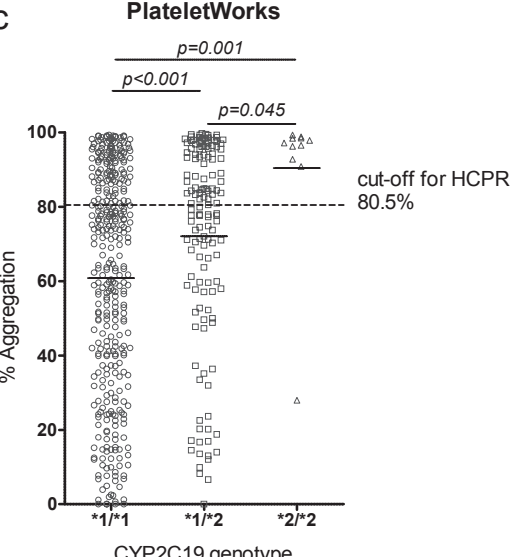

20 umol/L ADP-induced LTA
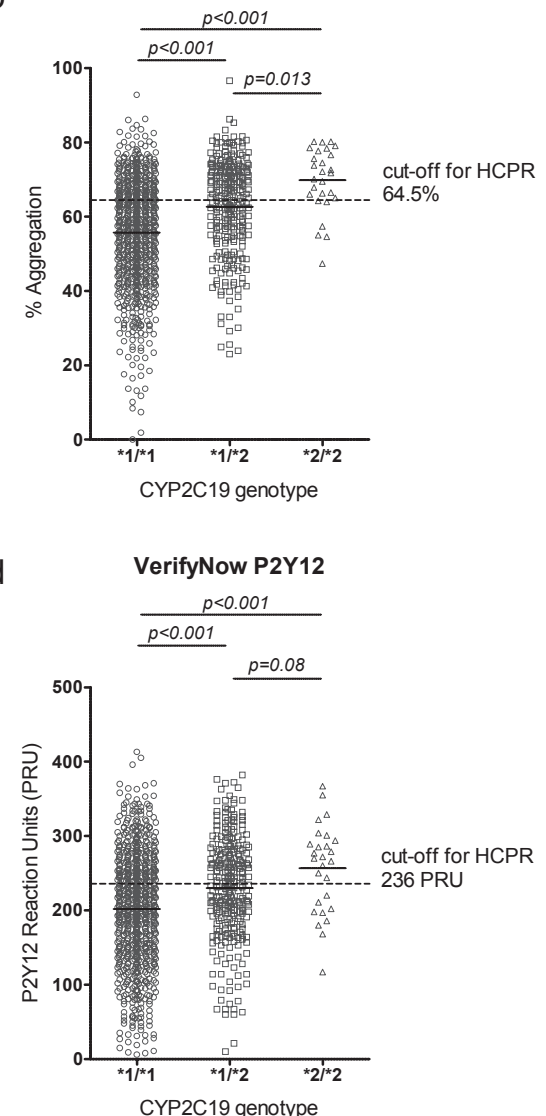

Figure 1 | Individual values of on-treatment platelet reactivity stratified by $\mathrm{CYP}_{2} \mathrm{C}_{1}$-genotype

Individual values $(n=1024)$ of on-treatment platelet reactivity stratified by $\mathrm{CYP}_{2} \mathrm{C}_{19}$-genotype, as measured with 5 umol/L ADP-induced LTA (a), $20 \mu \mathrm{mol} / L$ ADP-induced LTA (b), the PlateletWorks assay (c) and the VerifyNow $P_{2} Y_{12}-$ assay (d). Differences in mean platelet reactivity were tested for significance using analysis of variance (ANOVA) followed by the least significant difference (LSD) post-hoc test. Mean values of platelet reactivity are represented by solid lines and dashed lines indicate cut-off values for HPR based on 1-year clinical outcome ${ }^{2}$. ADP: 5'-adenosine diphosphate, HPR: high on-treatment platelet reactivity, LTA: light transmittance aggregometry, PRU: $P_{2} Y_{12}$ reaction units.

Table 2 | Frequency of HPR stratified by $\mathrm{CYP}_{2} \mathrm{C}_{19}$-genotype

\begin{tabular}{lllll}
\hline CYP $2 C_{19} *_{2}$ genotype & $*_{1} / *_{1}$ & $*_{1} / *_{2}$ & $*_{2} / *_{2}$ & $P$-value \\
\hline $5 \mu \mathrm{mol} / \mathrm{L}$ ADP-induced LTA $>42.9 \%$ & $38 \%$ & $53 \%$ & $70 \%$ & $<0.001$ \\
$20 \mu \mathrm{mol} / \mathrm{L}$ ADP-induced LTA $>64.5 \%$ & $31 \%$ & $52 \%$ & $78 \%$ & $<0.001$ \\
PlateletWorks $>80.5 \%$ & $33 \%$ & $51 \%$ & $91 \%$ & $<0.001$ \\
VerifyNow $>236$ PRU & $34 \%$ & $49 \%$ & $67 \%$ & $<0.001$ \\
\hline
\end{tabular}

$\chi^{2}$ test was used to test the statistical significance of differences in the frequency of HPR in the different CYP 2 C 19-genotypes $*_{1} / *_{1}, *_{1} / *_{2}$ and $*_{2} / *_{2}$. ADP: 5 -adenosine diphosphate, HPR: high on-treatment platelet reactivity, LTA: light transmittance aggregometry, $P R U: P_{2} Y_{12}$ Reaction Units. 
Contribution of $\mathrm{CYP}_{2} \mathrm{C}_{19}{ }_{2}$ to clopidogrel response

Table 3 | Percentage of the variability in on-treatment platelet reactivity explained

\begin{tabular}{|c|c|c|c|c|c|c|c|c|}
\hline & \multicolumn{2}{|c|}{$\begin{array}{l}5 \mu \mathrm{mol} / \mathrm{L} \text { ADP- } \\
\text { induced LTA }\end{array}$} & \multicolumn{2}{|c|}{$\begin{array}{c}20 \mu \mathrm{mol} / \mathrm{L} \text { ADP- } \\
\text { induced LTA }\end{array}$} & \multicolumn{2}{|c|}{ PlateletWorks } & \multicolumn{2}{|c|}{ VerifyNow $\mathrm{P}_{2} \mathrm{Y}_{12}$} \\
\hline & $\mathrm{R}^{2}$ & $p$-value & $\mathrm{R}^{2}$ & $p$-value & $\mathrm{R}^{2}$ & $p$-value & $\mathrm{R}^{2}$ & $p$-value \\
\hline $\mathrm{CYP}_{2} \mathrm{C}_{19}{ }^{*} 2$ & $5.0 \%$ & $<0.001$ & $6.2 \%$ & $<0.001$ & $4 \cdot 4 \%$ & $<0.001$ & $3.7 \%$ & $<0.001$ \\
\hline Clinical variables* & $8.9 \%$ & $<0.001$ & $9.8 \%$ & $<0.001$ & $2.9 \%$ & 0.515 & $17 \cdot 3 \%$ & $<0.001$ \\
\hline $\mathrm{CYP}_{2} \mathrm{C}_{19}{ }^{*} 2+$ Clinical variables & $13.0 \%$ & $<0.001$ & $15.2 \%$ & $<0.001$ & $5.6 \%$ & 0.058 & $20.6 \%$ & $<0.001$ \\
\hline$p$ for change ${ }^{\dagger}$ & & $<0.001$ & & $<0.001$ & & 0.839 & & $<0.001$ \\
\hline
\end{tabular}

The percentage of the variability in on-treatment platelet reactivity explained was defined as the coefficient of determination $\left(R^{2} \cdot 100 \%\right)$. *Clinical variables included were those significantly associated with on-treatment platelet reactivity in univariate analysis. ${ }^{\prime} p$-value for the change in $R^{2}$ when adding clinical variables to $C Y P_{2} C_{1}{ }^{*} 2$ genotype. $A D P: 5^{\prime}$-adenosine diphosphate, LTA: light transmittance aggregometry
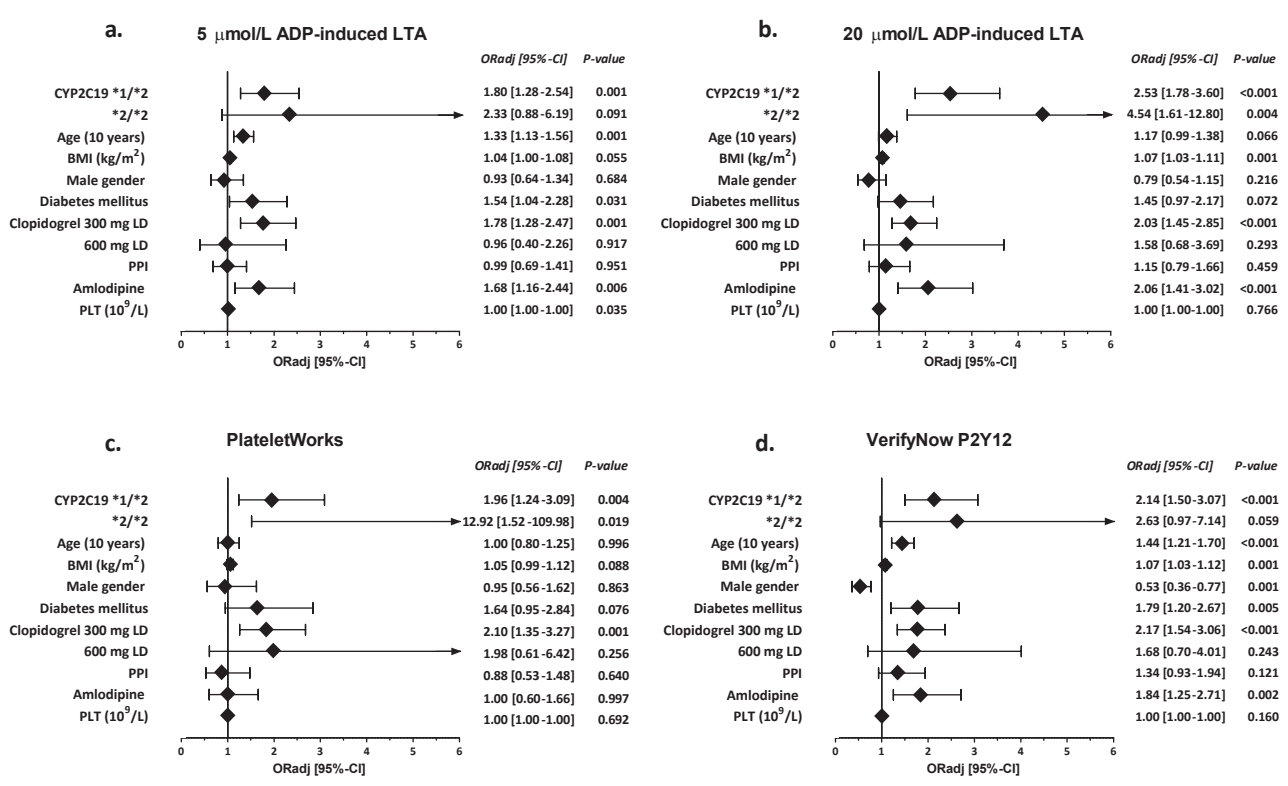

Figure 2 | Predictors of HPR

Adjusted odds ratios with corresponding 95\% confidence intervals (ORadj [95\%-CI]), per unit for multinomial and continuous variables) for exhibiting HPR vs not exhibiting HPR as determined with $5 \mu \mathrm{mol} / L$ ADP-induced LTA (a), 20 $\mu \mathrm{mol} / L$ ADP-induced LTA (b), the PlateletWorks assay (c) and the VerifyNow $P_{2} Y_{12}$-assay (d), using a multivariate binary logistics model containing $C Y P_{2} C_{1} *_{2}$ carrier status $\left(*_{1} / *_{1}, *_{1} / *_{2}\right.$ or $\left.*_{2} / *_{2}\right)$ in addition to clinical variables that were associated with on-treatment platelet reactivity in multivariate linear regression $(p<0.05) . C_{2} P_{2} C_{19} *_{1} / *_{2}$ and $*_{2} / *_{2}$ genotypes were compared with $*_{1} / *_{1}$ genotype; clopidogrel loading dose, either $300 \mathrm{mg}$ or $600 \mathrm{mg}$, was compared with $75 \mathrm{mg}$ daily maintenance dose regimen. ADP: 5'-adenosine diphosphate, BMI: body mass index, LD: loading dose, LTA: light transmittance aggregometry, PLT: platelet count, PPI: proton pump inhibitor, PRU: $P_{2} Y_{12}$ Reaction Units. 
Part IV | chapter 11

Table 4 | Contribution to on-treatment platelet reactivity

\begin{tabular}{|c|c|c|c|c|c|c|c|c|}
\hline & \multicolumn{2}{|c|}{$\begin{array}{l}5 \mu \mathrm{mol} / \mathrm{L} \text { ADP- } \\
\text { induced LTA* }\end{array}$} & \multicolumn{2}{|c|}{$\begin{array}{c}20 \mu \mathrm{mol} / \mathrm{L} \text { ADP- } \\
\text { induced LTA }{ }^{\dagger}\end{array}$} & \multicolumn{2}{|l|}{$\begin{array}{l}\text { Platelet } \\
\text { Works } \neq\end{array}$} & \multicolumn{2}{|l|}{$\begin{array}{l}\text { VerifyNow } \\
\mathrm{P}_{2} \mathrm{Y}_{12} \text {-assay\$ }\end{array}$} \\
\hline & $\begin{array}{l}\text { Badj }[95 \%-\mathrm{Cl}] \\
\% \text { Aggregation }\end{array}$ & $\begin{array}{c}P- \\
\text { value }\end{array}$ & $\begin{array}{l}\text { ßadj }[95 \%-\mathrm{Cl}] \\
\% \text { Aggregation }\end{array}$ & $\begin{array}{c}P \text { - } \\
\text { value }\end{array}$ & $\begin{array}{l}\text { Badj }[95 \%-\mathrm{Cl}] \\
\% \text { Aggregation }\end{array}$ & $\begin{array}{c}P \text { - } \\
\text { value }\end{array}$ & $\begin{array}{c}\text { Badj }[95 \%-\mathrm{Cl}] \\
\text { PRU }\end{array}$ & $\begin{array}{c}P \text { - } \\
\text { value }\end{array}$ \\
\hline $\mathrm{CYP}_{2} \mathrm{C}_{19 * 2}$ & $5.93[4.03-7.83]^{1}$ & $<0.001$ & $6.55[4.66-8.44]^{2}$ & $<0.001$ & $10.48[4.89-16.07]^{3}$ & $<0.001$ & $25.30[15.88-34.73]^{4}$ & $<0.001$ \\
\hline Age (10 years) & $1.91[0.90-2.92]$ & $<0.001$ & $0.82[-0.18-1.83]$ & 0.108 & $1.21[-1.77-4.19]$ & 0.424 & $10.77[5.76-15.78]$ & $<0.001$ \\
\hline BMI (kg/m2) & $0.36[0.10-0.61]$ & 0.006 & $0.61[0.36-0.86]$ & $<0.001$ & $0.64[-0.15-1.44]$ & 0.114 & $2.61[1.36-3.85]$ & $<0.001$ \\
\hline Male gender & $-3.01[-5.39--0.62]$ & 0.014 & $-2.91[-5.28--0.53]$ & 0.016 & $-1.43[-8.62-5.75]$ & 0.695 & $-33.04[-44.82--21.26]$ & $<0.001$ \\
\hline Current smoking & $-0.38[-2.18-1.43]$ & 0.683 & $-0.64[-2.44-1.15]$ & 0.481 & $2.20[-2.67-7.07]$ & 0.374 & $0.48[-8.46-9.42]$ & 0.916 \\
\hline Hypertension & $0.14[-2.25-2.53]$ & 0.908 & $-0.08[-2.46-2.30]$ & 0.949 & $2.49[-4 \cdot 36-9 \cdot 33]$ & 0.476 & $-0.74[-12.53-11.05]$ & 0.902 \\
\hline Diabetes mellitus & $2.12[-0.46-4.70]$ & 0.107 & $2.90[0.34-5.46]$ & 0.027 & $2.79[-4.83-10.41]$ & 0.472 & $17.66[4.98-30.35]$ & 0.006 \\
\hline LVEF $<45 \%$ & $1.12[-1.64-3.88]$ & 0.425 & $2.42[-0.34-5.17]$ & 0.085 & $-2.24[-10.05-5.56]$ & 0.572 & $7.12[-6.44-20.69]$ & 0.303 \\
\hline Renal Failure & $0.62[-3.17-4.40]$ & 0.750 & $-0.25[-4.02-3.52]$ & 0.896 & $-8.20[-18.92-2.52]$ & 0.133 & $-4.98[-23.82-13.86]$ & 0.604 \\
\hline Clopidogrel LD & $3.25[1.48-5.01]$ & $<0.001$ & $3.66[1.91-5.42]$ & $<0.001$ & $2.61[-2.57-7.79]$ & 0.323 & $19.04[10.32-27.75]$ & $<0.001$ \\
\hline PPI & $0.89[-1.43-3.20]$ & 0.452 & $1.31[-0.99-3.61]$ & 0.264 & $-2.48[-9.51-4 \cdot 55]$ & 0.488 & $20.08[8.66-31.50]$ & 0.001 \\
\hline Amlodipine $^{\circ}$ & $3.29[0.85-5.72]$ & 0.008 & $4.21[1.78-6.64]$ & 0.001 & $-0.21[-7.17-6.74]$ & 0.952 & $18.55[6.48-30.62]$ & 0.003 \\
\hline $\operatorname{PLT}\left(10^{9} / \mathrm{L}\right)$ & $0.01[0.00-0.03]$ & 0.035 & $0.01[-0.01-0.02]$ & 0.328 & $0.00[-0.04-0.03]$ & 0.938 & $-0.09[-0.16--0.03]$ & 0.004 \\
\hline $\mathrm{MPV}(\mathrm{fL})$ & $-0.13[-1.30-1.04]$ & 0.822 & $0.40[-0.76-1.57]$ & 0.500 & $0.01[-3.57-3.60]$ & 0.993 & $4.84[-0.90-10.58]$ & 0.098 \\
\hline
\end{tabular}

Adjusted B coefficients with corresponding $95 \%$ confidence intervals (Badj [95\%-Cl]) for on-treatment platelet reactivity, in a multivariate linear regression model containing $\mathrm{CYP}_{2} \mathrm{C}_{1} *_{2}$ carrier status $\left(*_{1} / *_{1}, *_{1} / *_{2}\right.$ or $\left.*_{2} / *_{2}\right)$ in addition to clinical characteristics that were associated with on-treatment platelet reactivity in univariate analysis $(p<0.10)$. Unadjusted $\mathrm{B}$ for CYP $2 C_{1}{ }^{*} 2$ carrier status *6.30 [4-59-8.01], $77.01[5.32-8.71], \neq 12.23[7.28-17.19]$ and ${ }^{5} 28.21$ [19.35-37.07]. 'Amlodipine showed to be the calcium channel blocker associated with HPR in a previously published sub-analysis of POPular5. ADP: 5'-adenosine diphosphate, BMI: body mass index, LD: loading dose, either $300 \mathrm{mg}$ or $600 \mathrm{mg}$ clopidogrel, LTA: light transmittance aggregometry, LVEF: left ventricular ejection fraction, MPV: mean platelet volume, PLT: platelet count, PPI: proton pump inhibitor, PRU: $P_{2} Y_{12}$ Reaction Units.

\section{DISCUSSION}

An inadequate response to clopidogrel is mainly attributable to the variable formation of its active metabolite. The $\mathrm{CYP}_{2} \mathrm{C}_{1}{ }^{*} 2$ loss-of-function polymorphism leads to reduced generation of the active metabolite of clopidogrel and both the loss-of-function $\mathrm{CYP}_{2} \mathrm{C}_{1}{ }^{*}{ }_{2}$ genetic polymorphism as well as high on-treatment platelet reactivity (HPR) have repeatedly shown to be associated with an increased rate of atherothrombotic events following coronary stenting ${ }^{[1-5]}$. Though $\mathrm{CYP}_{2} \mathrm{C}_{19}$ is regarded the most important enzyme in the metabolic activation of clopidogrel, the present study demonstrates that $\mathrm{CYP}_{2} \mathrm{C}_{1}{ }^{*} 2$ carrier status could only explain approximately $5 \%$ of the variability in the pharmacodynamic response to clopidogrel. In addition to $\mathrm{CYP}_{2} \mathrm{C}_{1}{ }^{*} 2$ genotype, multiple clinical variables could be identified as independent predictors of HPR, with adjusted odds ratios closely approximating that for heterozygote carriers of the $\mathrm{CYP}_{2} \mathrm{C}_{1}{ }_{1}{ }_{2}$ allele. Combining these clinical variables with $\mathrm{CYP}_{2} \mathrm{C}_{19}{ }_{2} 2$ carrier status yielded a 2 to 5 -fold increase in the percentage of the variability in on-treatment platelet reactivity that could be explained.

Hochholzer and colleagues recently published a similar approach using $5 \mu \mathrm{mol} / \mathrm{L}$ ADP-induced LTA, a platelet function test has previously shown to correlate only very modest with plasma levels of the active metabolite of clopidogrel, which is an important concern when estimating the relative contribution of $\mathrm{CYP}_{2} \mathrm{C}_{1}{ }^{*}{ }_{2}$ genotype affecting the generation of the active metabolite of clopidogrel ${ }^{[8]}$. Twenty $\mu \mathrm{mol} / \mathrm{L}$ ADP-induced LTA and the VerifyNow $\mathrm{P}_{2} \mathrm{Y}_{12}$-assay have shown to correlate better 
with in vivo plasma levels of the active metabolite of clopidogrel ${ }^{[9]}$. Furthermore, all four platelet function tests included have shown to be capable of predicting clinical outcome in clopidogreltreated patients ${ }^{[2]}$.

The VerifyNow $\mathrm{P}_{2} \mathrm{Y}_{12}$-assay is performed in whole blood, thereby more closely mimicking the in vivo situation than LTA, and is not hampered by pre-analytical variables such as pipetting, centrifugation and agonist sources, as is the case for LTA ${ }^{[10]}$.

Therefore, we hypothesized that a larger part of the interindividual variability of on-treatment platelet reactivity could be attributed to $\mathrm{CYP}_{2} \mathrm{C}_{1} 9 * 2$ carrier status when platelet reactivity was measured using the VerifyNow $\mathrm{P}_{2} \mathrm{Y}_{12}$-assay. The opposite appeared to be true, as the variation in PRU explained by $\mathrm{CYP}_{2} \mathrm{C}_{19}{ }_{2}$ carrier status alone was lower than for LTA (3.7\%), while the combination of $\mathrm{CYP}_{2} \mathrm{C}_{1}$ * $_{2}$ carrier status and clinical risk factors could explain as much as $20.6 \%$ of the interindividual variability in PRU.

The percentage of variability in on-treatment platelet reactivity as measured with the PlateletWorks that could be attributed to $\mathrm{CYP}_{2} \mathrm{C}_{19}{ }^{*} 2$ genotype and clinical variables was low. Although the PlateletWorks has shown to be capable of predicting clinical outcome in the POPular study, the lack of association with different variables known to affect platelet reactivity and to contribute to the interindividual response to clopidogrel, renders interpretation of data difficult.

It has previously been postulated that $73 \%$ of the interindividual variability in the pharmacodynamic response to clopidogrel is genetically determined ${ }^{[11]}$. Assuming the straight-forward relationship between $\mathrm{CYP}_{2} \mathrm{C}_{19}$ and the pharmacodynamic effects of clopidogrel as stated above, it is remarkable that only $5 \%$ of the response to clopidogrel could be attributed to the $\mathrm{CYP}_{2} \mathrm{C}_{19}{ }_{2} 2$ genetic polymorphism. The effects of an impaired enzyme activity associated with the $\mathrm{CYP}_{2} \mathrm{C}_{19}{ }_{2} 2$ genotype was especially evident in $\mathrm{CYP}_{2} \mathrm{C}_{1}{ }^{*} 2$ homozygotes. In March 2010, the Food and Drug Administration (FDA) issued a boxed warning to the label of clopidogrel (Plavix), stating that a higher dose of clopidogrel or alternative antiplatelet drugs should be considered in patients who can be classified as poor metabolisers based on $\mathrm{CYP}_{2} \mathrm{C}_{1}$ g-genotyping, i.e. patients carrying two $\mathrm{CYP}_{2} \mathrm{C}_{1}$ g loss-of-function gene variants ${ }^{[2]}$. For $\mathrm{CYP}_{2} \mathrm{C}_{1}{ }^{*} 2$ heterozygotes, however, the relation with on-treatment platelet reactivity is less profound, and the established on-treatment platelet reactivity in this patient group is characterized by a similar magnitude of intersubject variability as observed in patients without the $\mathrm{CYP}_{2} \mathrm{C}_{1}$ * 2 loss-of-function allele. The present study shows that besides $\mathrm{CYP}_{2} \mathrm{C}_{1}$ * 2 genotype, also clinical variables and the use of concomitant medication known to interfere with generation of the active metabolite of clopidogrel. Furthermore, temporary and ongoing clinical disease states alter an individual's intrinsic platelet reactivity status and this may lead to a higher need of platelet inhibition. For example, diabetes mellitus is characterized by a high intrinsic platelet reactivity status, and several lines of evidence point out that diabetic patients benefit more from stronger antiplatelet therapy as compared to patients without diabetes mellitus ${ }^{[13]}$. The genetics substudy of the PLATelet inhibition and patient Outcomes (PLATO) trial constituted the largest cohort of clopidogrel-treated patients in whom $\mathrm{CYP}_{2} \mathrm{C}_{19}$-genotyping was performed $(n=5148)$ until present ${ }^{[14]}$. Patients carrying at least one $\mathrm{CYP}_{2} \mathrm{C}_{1} 9$ loss-of-function allele had a worse clinical outcome at 30 days follow-up than patients not carrying such a gene variant (primary endpoint reached in $5.7 \%$ vs $3.8 \%$, respectively, $p=0.028$ ), however, no clinical consequences were observed at 1-year follow-up (primary endpoint reached in $11.2 \%$ vs $10.0 \%$, respectively, $p=0.25$ ). The large interindividual variability in the response to clopidogrel can be considered as a matter of systems pharmacology rather than a single-gene determined phenomenon, and prediction of an individual's response to clopidogrel may require integration of 
Part IV | chapter 11

information on genetics and clinical variables, both captured in an individual's on-treatment platelet reactivity status. Moreover, the finding that only a small percentage of variability could be attributed to $\mathrm{CYP}_{2} \mathrm{C}_{19}$-genotype encourages the search for additional genetic factors explaining the highly variable response to clopidogrel, enabling us to accurately and effectively tailor clopidogrel therapy to the individual patient's need.

In conclusion, the $\mathrm{CYP}_{2} \mathrm{C}_{19}{ }^{*} 2$ loss-of-function polymorphism is associated with a higher on-treatment platelet reactivity, though the percentage of the interindividual variability in on-treatment platelet reactivity explained by $\mathrm{CYP}_{2} \mathrm{C}_{19}{ }_{2} 2$ genotype is modest. Prospective studies will have to determine the role of $\mathrm{CYP}_{2} \mathrm{C}_{19}$-genotyping and platelet function testing in tailoring clopidogrel therapy and predicting the clinical outcome of clopidogrel treated patients. 


\section{REFERENCES}

1. Combescure C, Fontana P, Mallouk N, et al. Clinical implications of clopidogrel non-response in cardiovascular patients: a systematic review and meta-analysis. J Thromb Haemost. 2010;8:923-33.

2. Breet NJ, van Werkum JW, Bouman HJ, et al. Comparison of platelet function tests in predicting clinical outcome in patients undergoing coronary stent implantation. JAMA. 2010;303:754-62.

3. El Ghannudi S, Ohlmann P, Meyer $N_{1}$, et al. Impact of $\mathrm{P}_{2} \mathrm{Y}_{12}$ Inhibition by Clopidogrel on Cardiovascular Mortality in Unselected Patients Treated by Percutaneous Coronary Angioplasty. A Prospective Registry. JACC Cardiovasc Interv. 2010;3:648-56.

4. Sofi F, Giusti B, Marcucci R, Gori AM, et al. Cytochrome $\mathrm{P}_{45}{ }_{2} \mathrm{C}_{19}\left(^{*}\right) 2$ polymorphism and cardiovascular recurrences in patients taking clopidogrel: a meta-analysis. Pharmacogenomics J. 2010; Epub ahead of print.

5. Bonello L, Tantry US, Marcucci R, et al. Consensus and future directions on the definition of high on-treatment platelet reactivity to adenosine diphosphate. J Am Coll Cardiol. 2010;56:919-33.

6. Harmsze AM, Robijns K, van Werkum JW, et al. The use of amlodipine, but not of P-glycoprotein inhibiting calcium channel blockers is associated with clopidogrel poor-response. Thromb Haemost. 2010;103:920-5.

7. Gremmel T, Steiner S, Seidinger D, et al. Calcium- channel blockers decrease clopidogrel-mediated platelet inhibition. Heart. 2010;96:186-9.

8. Hochholzer W, Trenk D, Fromm MF, et al. Impact of cytochrome $\mathrm{P}_{450} 2 \mathrm{C}_{1}$ g loss-of-function polymorphism and of major demographic characteristics on residual platelet function after loading and maintenance treatment with clopidogrel in patients undergoing elective coronary stent placement. J Am Coll Cardiol. 2010;55:2427-34.

9. Bouman HJ, Parlak E, van Werkum JW, et al. Which platelet function test is suitable to monitor clopidogrel responsiveness? A pharmacokinetic analysis on the active metabolite of clopidogrel. J Thromb Haemost. 2010;8:482-8.

10. van Werkum JW, Hackeng CM, Smit JJ, et al. Monitoring antiplatelet therapy with point-of-care platelet function assays: a review of the evidence. Future Cardiol. 2008;4:33-55.

11. Shuldiner AR, $\mathrm{O}^{\prime}$ Connell JR, Bliden KP, et al. Association of cytochrome $\mathrm{P}_{45}{ }_{2} \mathrm{C}_{1} 9$ genotype with the antiplatelet effect and clinical efficacy of clopidogrel therapy. JAMA. 2009;302:849-57.

12. Food and Drug Administration. FDA Drug Safety Communication: Reduced effectiveness of Plavix (clopidogrel) in patients who are poor metabolizers of the drug. Release date: 03-12-2010. http://www.fda.gov/Drugs/ DrugSafety/PostmarketDrugSafetylnformationforPatientsandProviders/ucm203888.htm (accessed 10 Dec 2010).

13. Wiviott SD, Braunwald E, Angiolillo DJ, et al. Greater clinical benefit of more intensive oral antiplatelet therapy with prasugrel in patients with diabetes mellitus in the trial to assess improvement in therapeutic outcomes by optimizing platelet inhibition with prasugrel-Thrombolysis in Myocardial Infarction 38. Circulation. 2008;118:1626-36.

14. Wallentin $L$, James $S$, Storey $R F$, et al. Effect of $C_{Y} P_{2} C_{19}$ and $A B C B 1$ single nucleotide polymorphisms on outcomes of treatment with ticagrelor versus clopidogrel for acute coronary syndromes: a genetic substudy of the PLATO trial. Lancet. 2010;376:1320-8. 


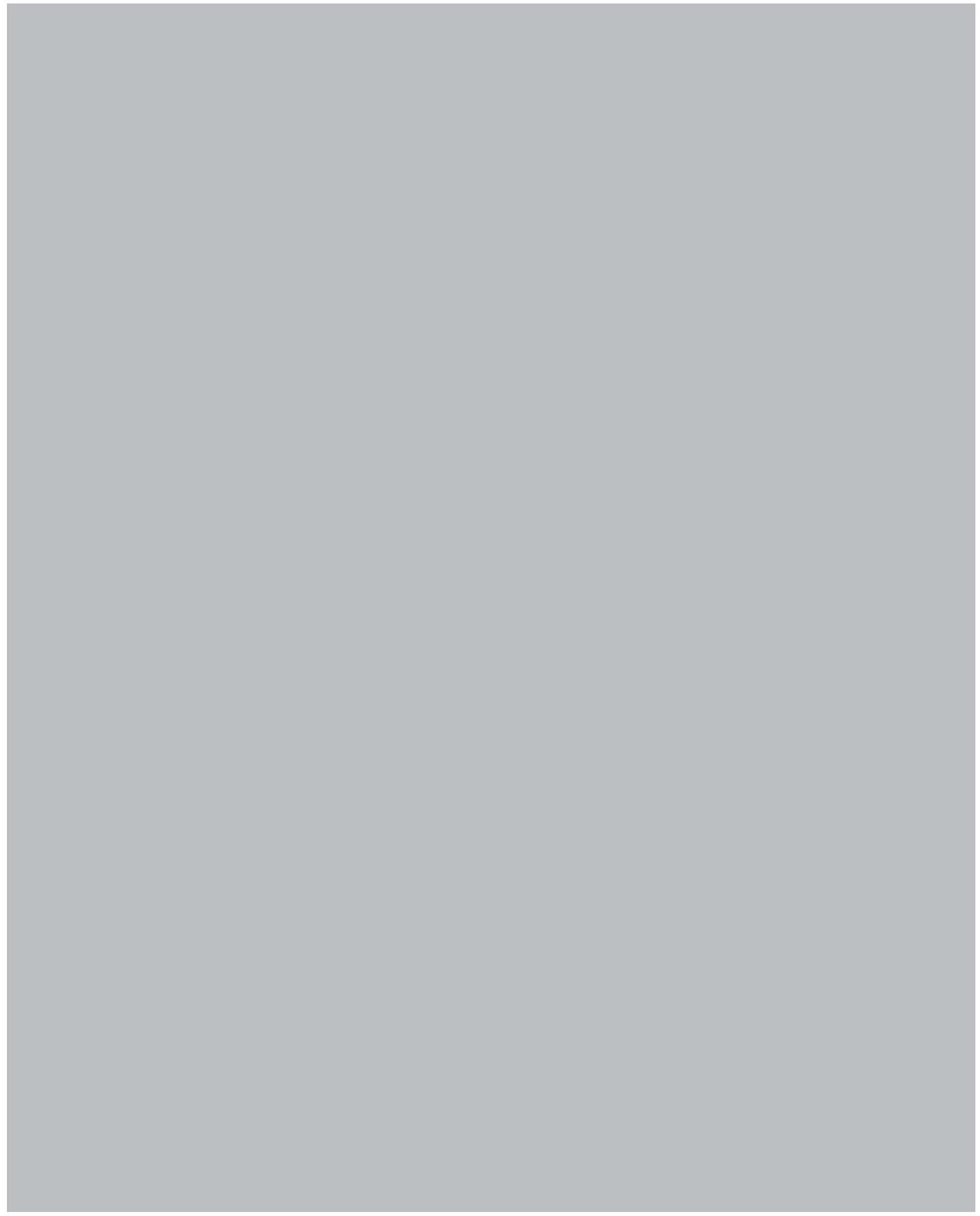




\section{Chapter 12}

\section{Cytochrome P-450 Polymorphisms and Response to Clopidogrel}

N Engl J Med. 2009;360(21):2249-50

Dirk Taubert

Heleen J Bouman

Jochem W van Werkum

Department of Cardiology, St Antonius Hospital, Nieuwegein, the Netherlands St Antonius center for Platelet Function Research, St Antonius Hospital, Nieuwegein, the Netherlands Department of Pharmacology, University Hospital, University of Cologne, Cologne, Germany 
Part IV | chapter 12

\section{TO THE EDITOR}

On the basis of the results of a genetic association study (Jan. 22 issue), 1 Mega et al. conclude that reduced-function variants of the $\mathrm{CYP}_{2} \mathrm{C}_{19}$ allele are responsible for lower plasma levels of the active metabolite of clopidogrel; these lower levels lead to decreased platelet inhibition and thereby increase cardiovascular risk. However, no direct evidence of the causal involvement of the cytochrome P-450 enzyme $\mathrm{CYP}_{2} \mathrm{C}_{19}$ in the biotransformation of clopidogrel to its active metabolite is presented. To test the hypothesis of Mega et al., we incubated clopidogrel, the inactive metabolic intermediate 2-oxoclopidogrel, 2 and the known $\mathrm{CYP}_{2} \mathrm{C}_{1}$ gsubstrate omeprazolez with human microsome preparations expressing $\mathrm{CYP}_{2} \mathrm{C}_{19}$ (Figure 1). Although omeprazole was transformed into 5-hydroxy-omeprazole, no significant biotransformation of clopidogrel into 2-oxo-clopidogrel and active metabolite or of 2-oxo-clopidogrel into active metabolite was observed. Hence, $\mathrm{CYP}_{2} \mathrm{C}_{19}$ does not appear to contribute to the biotransformation of clopidogrel. It is possible that the $\mathrm{CYP}_{2} \mathrm{C}_{19}$ polymorphisms represent only tags for the true causal gene variant involved in clopidogrel activation. Moreover, the $\mathrm{CYP}_{2} \mathrm{C}_{19}$ polymorphisms may directly affect the risk of cardiovascular events. Genomewide association studies may help resolve these discrepancies.

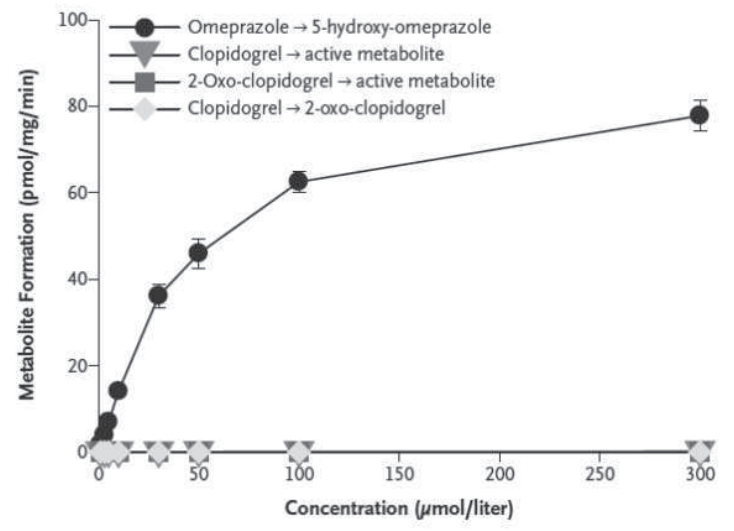

Results of Tests for the CYP $2 C_{19}$-Dependent Biotransformation of Clopidogrel, 2-Oxo-Clopidogrel, and omeprazole into Metabolites. Clopidogrel, 2-oxo-clopidogrel, and omeprazole were incubated for 5 minutes at $37^{\circ} \mathrm{C}$ with microsome preparations from $C_{1} P_{2} C_{1} 9$ (National Center for Biotechnology Information sequence accession number, NM_000769.1) transfected human embryonic kidney 293 cells $\left(200 \mu \mathrm{g}\right.$ of protein containing $7.6 \mathrm{pmol}$ of CYP $2 \mathrm{C}_{1} g$ enzyme and equimolar concentrations of purified recombinant human NADPH-cytochrome $P$-450 reductase and cytochromeb5) in $50 \mathrm{mM}$ sodium phosphate buffer ( $p H 7.4$ ), $10 \mathrm{mM}$ magnesium chloride, and $2 \mathrm{mM} \mathrm{NADPH}$ (final volume, $200 \mu \mathrm{l}$ ). Incubations were performed with eight different concentrations, ranging from 1 to $300 \mu \mathrm{M}$. The formation of metabolites was measured in supernatants extracted by $600 \mu$ lacetonitrile by means of liquid chromatography-tandem mass spectrometry in positive electrospray mode (TSQ Quantum, Thermo Fisher Scientific). Each metabolite was detected by monitoring the mass-to-charge ratio $(\mathrm{m} / \mathrm{z})$ for the transition of the parent ion $[\mathrm{M}+\mathrm{H}]+$ into selected fragment ions. The transition of $\mathrm{m} / \mathrm{z} 338$ to $\mathrm{m} / \mathrm{z} 183$ was used for quantitation of 2-oxo-clopidogrel, $\mathrm{m} / \mathrm{z} 356$ to $\mathrm{m} / \mathrm{z} 183$ for the active thiol metabolite of clopidogrel, and $\mathrm{m} / \mathrm{z} 362$ to $\mathrm{m} / \mathrm{z} 214$ for 5 -hydroxy-omeprazole. Each incubation experiment was performed three times with the use of individual microsome preparations. Arithmetic means and standard deviations are shown. 
Cytochrome P-450 polymorphisms and response to clopidogrel

\section{REFERENCES}

1. Mega JL, Close SL, Wiviott SD, et al. Cytochrome P-450 polymorphisms and response to clopidogrel. N Engl J Med 2009;360:354-62.

2. Pereillo JM, Maftouh M, Andrieu A, et al. Structure and stereochemistry of the active metabolite of clopidogrel. Drug Metab Dispos 2002;30:1288-95.

3. Kanazawa H, Okada A, Higaki M, Yokota H, Mashige F, Nakahara K. Stereospecific analysis of omeprazole in human plasma as a probe for CYP2 2 19 phenotype. J Pharm Biomed Anal 2003; 30:1817-24. 


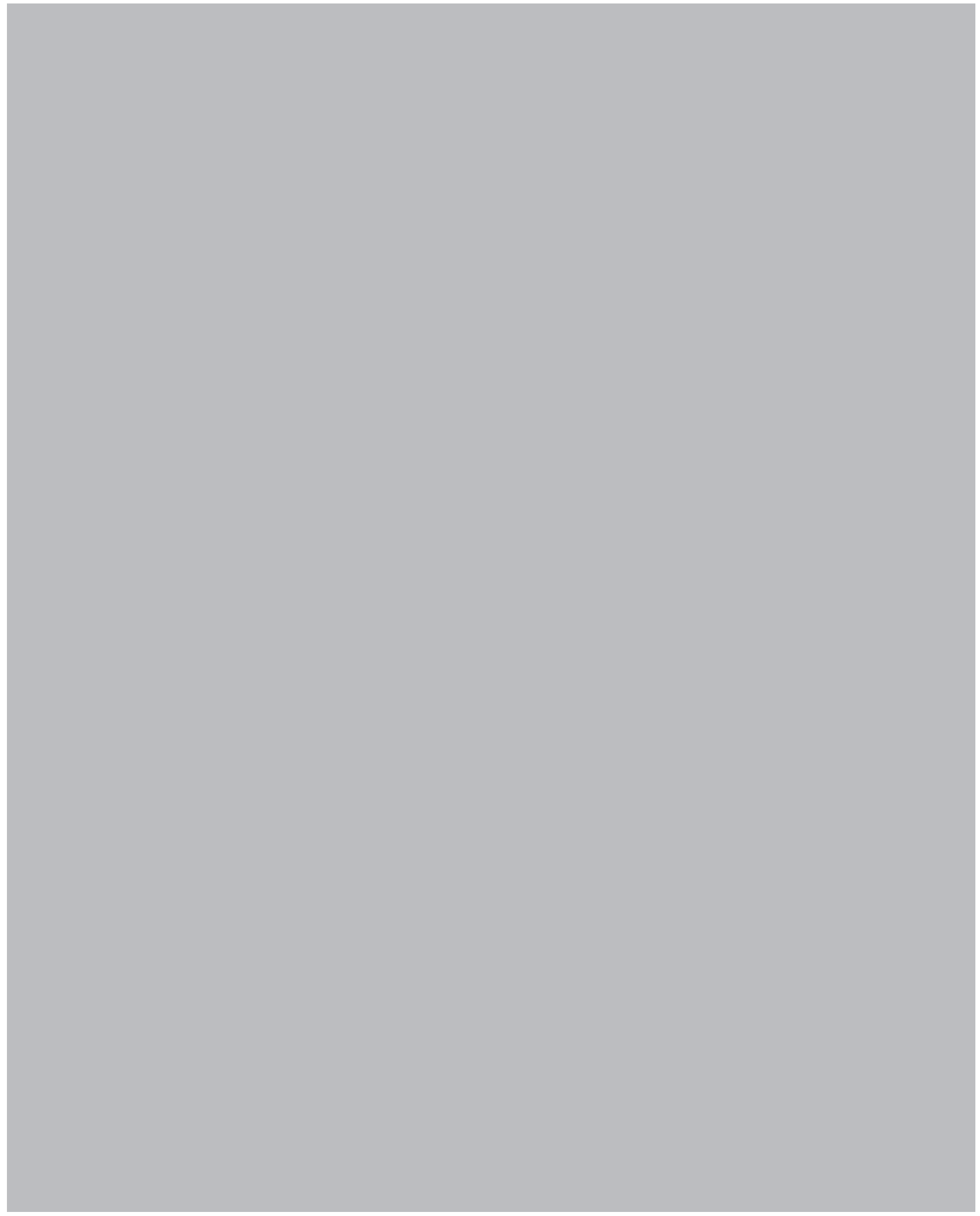




\title{
Chapter 13
}

\section{Paraoxonase-1 is a major determinant of clopidogrel efficacy}

\author{
Nat Med. 2011 Jan;17(1):110-6
}

Bouman HJ

Schomig $\mathrm{E}$ van Werkum JW Velder J Hackeng CM Hirschhäuser C Waldmann C Schmalz HG ten Berg JM

Taubert D

Department of Cardiology, St. Antonius Hospital Nieuwegein, Nieuwegein, The Netherlands St. Antonius Center for Platelet Function Research, St. Antonius Hospital Nieuwegein, Nieuwegein, The Netherlands Department of Biochemistry, Cardiovascular Research Institute Maastricht, University Maastricht, Maastricht, The Netherlands Department of Pharmacology, University Hospital of Cologne, Cologne, Germany Department für Chemie, Universität zu Köln, Cologne, Germany Department of Clinical Chemistry, St. Antonius Hospital Nieuwegein, Nieuwegein, The Netherlands Klinik und Poliklinik für Nuklearmedizin, Universität Münster, Münster, Germany 


\section{ABSTRACT}

Clinical efficacy of the antiplatelet drug clopidogrel is hampered by its variable biotransformation into the active metabolite $e^{1,2}$. The variability in the clinical response to clopidogrel treatment has been attributed to genetic factors, but the specific genes and mechanisms underlying clopidogrel bioactivation remain unclear. Using in vitro metabolomic profiling techniques, we identified paraoxonase-1 (PON1) as the crucial enzyme for clopidogrel bioactivation, with its common $\mathrm{O}_{192} \mathrm{R}$ polymorphism determining the rate of active metabolite formation. We tested the clinical relevance of the PON1 $\mathrm{O}_{1} \mathrm{~g}_{2} \mathrm{R}$ genotype in a population of individuals with coronary artery disease who underwent stent implantation and received clopidogrel therapy. PON1 Q0192 homozygous individuals showed a considerably higher risk than RR192 homozygous individuals of stent thrombosis, lower PON1 plasma activity, lower plasma concentrations of active metabolite and lower

platelet inhibition. Thus, we identified PON1 as a key factor for the bioactivation and clinical activity of clopidogrel. These findings have therapeutic implications and may be exploited to prospectively assess the clinical efficacy of clopidogrel. 


\section{LETTER}

Antiplatelet therapy with the ADP $\mathrm{P}_{2} \mathrm{Y}_{12}$ receptor antagonist clopidogrel is recommended by current clinical practice guidelines to prevent atherothrombotic events in patients with coronary artery disease (CAD) undergoing percutaneous coronary intervention ( $\mathrm{PCl}$ ) with stent implantation. The main drawback of clopidogrel is a high interindividual variability in antiplatelet response ${ }^{3}$. Low platelet responsiveness to clopidogrel has been found to translate into a high incidence of atherothrombotic events, including stent thrombosis as the most serious and often fatal clinical event ${ }^{4}$. However, the biological mechanisms underlying the response variability remain largely

unclear. In a recent genome-wide association analysis, it was estimated that $83 \%$ of individual variance in response to clopidogrel was attributable to genetic effects ${ }^{5}$, but the gene variants investigated thus far explain only a minor proportion of the response variability ${ }^{6,7}$.

Clopidogrel is a thienopyridine prodrug that requires enzymatic conversion into its active thiol metabolite. Pharmacokinetic-pharmacodynamic analyses suggest that the majority of the variability in platelet response is explained by the variability in plasma concentrations of the active metabolite ${ }^{8,9}$.

We postulated that genetic variants of drug-metabolizing enzymes would affect the response to clopidogrel. Using a validated microsomal expression system of metabolizing enzymes, we identified $P O N 1$, an esterase synthesized in the liver and associated with HDL in blood, as the rate-determining enzyme for the formation of the thiol active metabolite from clopidogrel. We found that the common functional PON1 $\mathrm{Q}_{1} \mathrm{P}_{2} \mathrm{R}$ gene polymorphism resulted in a more efficient clopidogrel bioactivation. On the basis of this mechanistic information, we performed a case-cohort study in individuals with CAD who underwent $\mathrm{PCl}$ and received clopidogrel therapy to comprehensively assess

the relationships between the $P O N_{1} Q_{192}$ polymorphism, $P O N_{1}$ enzyme activity, clopidogrel pharmacokinetics, platelet response and the risk of stent thrombosis. Subsequently, we conducted an independent replication study evaluating the reliability and validity of the association between $P O N_{1}$ and clinical end points.

We functionally expressed cytochrome $\mathrm{P} 450$ oxidoreductase isozymes (CYPs) and esterases in a human embryonic kidney cell line and monitored conversion of clopidogrel or potential metabolic clopidogrel intermediates in microsome preparations (Figure 1 and Supplementary Figure 1). We identified bioactivation of clopidogrel as a two-step process. The first step was an oxidation of clopidogrel to 2-oxo-clopidogrel catalyzed by $\mathrm{CYP}_{3} \mathrm{~A}_{4}, \mathrm{CY}_{3} \mathrm{~A}_{5}, \mathrm{CYP}_{2} \mathrm{~B} 6, \mathrm{CYP} 1 \mathrm{~A}_{2}, \mathrm{CYP}_{1} \mathrm{~A}_{1}, \mathrm{CYP}_{2} \mathrm{E}_{1}$ and $\mathrm{CYP}_{2} \mathrm{~A} 6$ at enzymatic efficiencies ( $V \max / \mathrm{Km}$ ) of $16.02,8.67,2.61,1.87,0.88,0.72$ and $0.70 \mu \mathrm{mg}^{-1} \mathrm{~min}^{-1}$, respectively. The second step was a hydrolytic cleavage of the $\gamma$-thiobutyrolactone ring of 2-oxoclopidogrel to the pharmacologically active thiol metabolite catalyzed by the esterases $P O N_{1}$ and $\mathrm{PON}_{3}$ at enzymatic efficiencies of 0.36 and $0.030 \mu \mathrm{mg}^{-1} \mathrm{~min}^{-1}$, respectively. This bioactivation step competed with the hydrolysis of the methyl ester in clopidogrel, 2-oxo-clopidogrel and the thiol metabolite to form inactive carboxylic acid metabolites at considerably higher conversion rates catalyzed by the esterases carboxylesterase-1, carboxylesterase-2 and butyrylcholinesterase (Supplementary Table 1 and Supplementary Figure 2). 


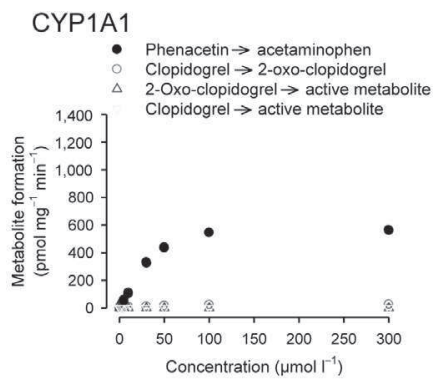

CYP2A6

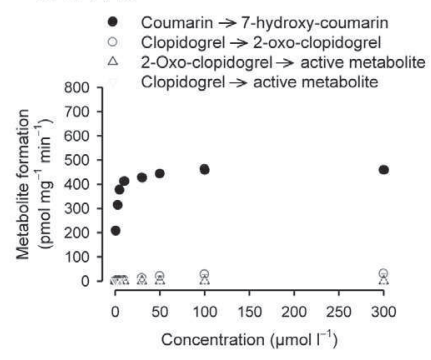

CYP2E1

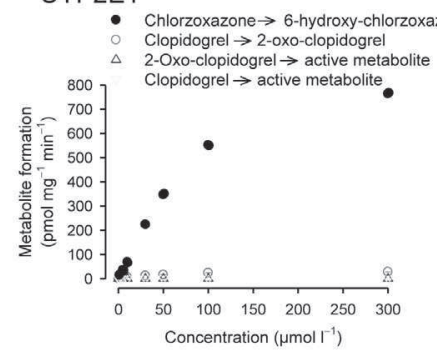

CYP3A5

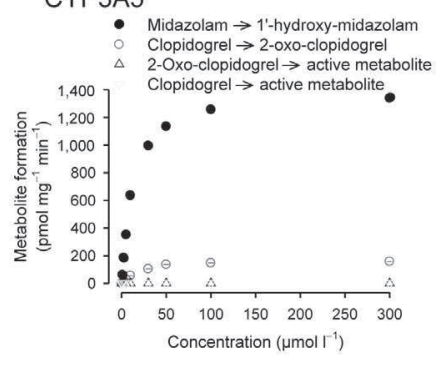

CYP1A2

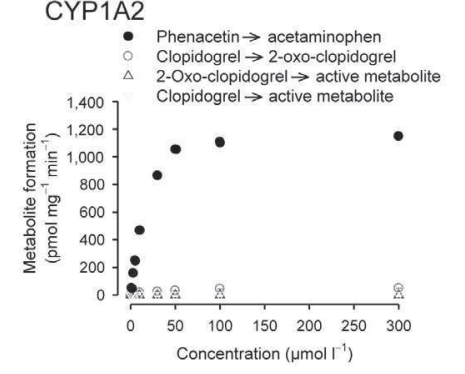

CYP2B6

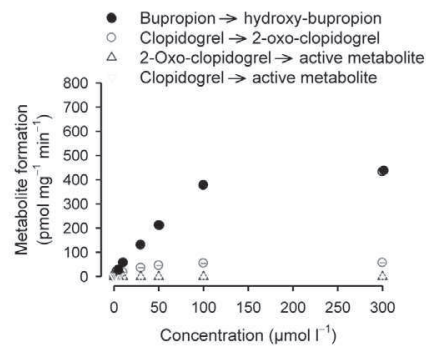

CYP3A4

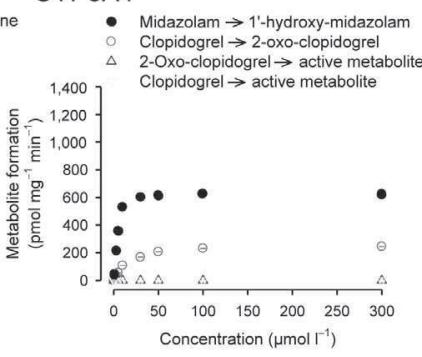

Figure 1 | Kinetics of clopidogrel-metabolizing enzymes. $(a, b)$ Substrate saturation kinetics for microsomal preparations of human cytochrome $\mathrm{P}_{450}$ isozymes (a) (left) and esterases (b) (next page) involved in clopidogrel metabolism. Microsomes were obtained from stably transfected human embryonic kidney cells (HEK 293). Conversion of clopidogrel to 2-oxo-clopidogrel, of 2-oxo-clopidogrel to the active thiol metabolite and of clopidogrel to the thiol metabolite was assayed by incubation with increasing concentrations of substrate for 5 min at $37^{\circ} \mathrm{C}$. For esterases, the conversion of clopidogrel to clopidogrelcarboxylate, of 2-oxo-clopidogrel to 2-oxoclopidogrel-carboxylate, and of the thiol metabolite to thiol metabolite-carboxylate was also assayed. Kinetics of the PON1 allozymes with the $L_{55} M$ and $Q_{192} R$ polymorphisms were determined. For each enzyme a specific probe reaction (positive control) was performed (black circles). Symbols and error bars represent means \pm s.e.m. of three independent incubation experiments each. Supplementary Figure 1 shows similar kinetic measurements for enzymes not involved in clopidogrel metabolism. $B C h E$, butyrylcholinesterase; CES1, carboxylesterase-1; CES2, carboxylesterase-2. DTNB, 5,5'-dithiobis-(2-nitrobenzoic acid). 
PON1(L55, Q192)

- Phenylacetate $\rightarrow$ phenol
a Paraoxon $\rightarrow p$-nitrophenol

Clopidogrel $\rightarrow$ 2-oxo-clopidogrel

2-Oxo-clopidogrel $\rightarrow$ active metabol

Clopidogrel $\rightarrow$ active metabolite

2-Oxo-clopidogrel $\rightarrow$ 2-oxo-clopidogrel-carboxyla

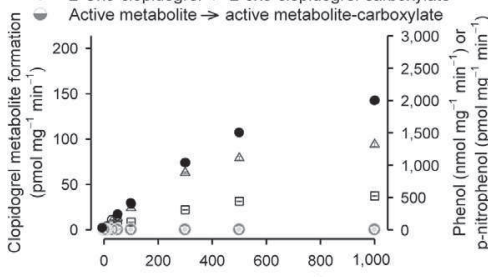

Concentration $\left(\mu \mathrm{mol} \mathrm{I}^{-1}\right.$ )

\section{PON1(M55, Q192)}

- Phenylacetate $\rightarrow$ phenol

Clopidogrel $\rightarrow 2$-oxo-clopidogrel

2-Oxo-clopidogrel $\rightarrow$ active metabo

Clopidogrel $\rightarrow$ active melabollte

2-Oxo-clopidogrel $\rightarrow$ 2-oxo-clopidogrel-carboxyla

- Active metabolite $\rightarrow$ active metabolite-carboxylate

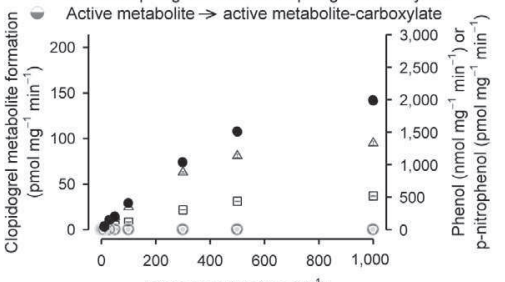

Concentration ( $\left.\mu \mathrm{mol} \mathrm{I}^{\mathrm{H}}\right)$

\section{PON3}

- Phenylacetate $\rightarrow$ phenol

Paraoxon $\rightarrow$ p-nitrophenol

Clopidogrel $\rightarrow$ 2-oxo-clopidogrel

Clopidogrel $\rightarrow$ active metabolite

2-Oxo-clopidogrel $\rightarrow$ 2-oxo-clopidogrel-carboxyl

- Active metabolite $\rightarrow$ active metabolite-carboxylate

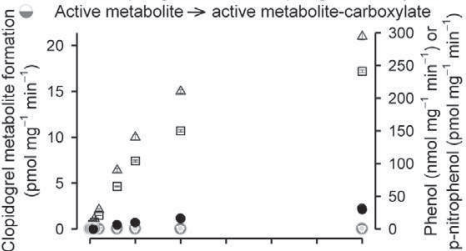

o $5001,0001,5002,0002,5003,000$

Concentration $\left(\mu \mathrm{mol} \mathrm{I}^{-1}\right)$

\section{CES1}

- $p$-Nitrophenyl acetate $\rightarrow p$-nitropheno Clopidogrel $\rightarrow 2$-oxo-clopidogrel

2-Oxo-clopidogrel $\rightarrow$ active metabo

Clopidogre $\rightarrow$ active metabolite

2-Oxo-clopidogrel $\rightarrow 2$ 2-oxo-clopidogrel-carboxylate

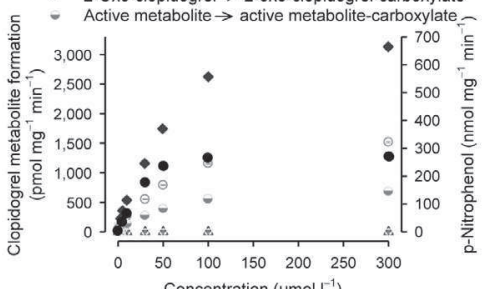

PON1(L55, R192)

- Phenylacetate $\rightarrow$ phenol
Paraoxon $\rightarrow$ p-nitrophenol

Paraoxon $\rightarrow$ p-nitrophenol
Clopidogrel $\rightarrow$ 2-oxo-clopidogrel

2-Oxidogrel $\rightarrow$ 2-oxo-clopidogrel

Clopidogrel $\rightarrow$ active metabolite

Clopidogrel $\rightarrow$ clopidogrel-carboxylate

2-Oxo-clopidogrel $\rightarrow$ 2-oxo-clopidogrel-carboxylate

- Active metabolite $\rightarrow$ active metabolite-carboxylate

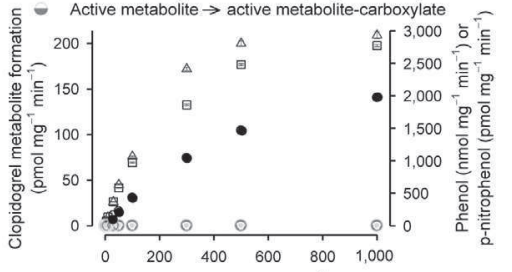

$\begin{array}{llllll}0 & 200 & 400 & 600 & 800 & 1,000\end{array}$

PON1(M55, R192)

- Phenylacetate $\rightarrow$ phenol
a Paraoxon $\rightarrow$ p-nitrophenol

Clopidogrel $\rightarrow 2$-oxo-clopidogrel

2-Oxo-clopidogrel $\rightarrow$ active meta

$\checkmark$ Clopidogre $\rightarrow$ active melabolite

2-Oxo-

Active metabolite $\rightarrow$ active metabolite-carboxylate

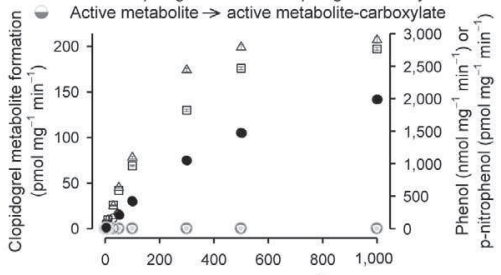

Concentration (umol I)

BChE

- DTNB $\rightarrow$ 5-thio-2-nitrobenzoate

Clopidogrel $\rightarrow$ 2-oxo-clopidogrel

2-Oxo-clopidogrel $\rightarrow$ active metabolit

pidogrel-carboxylate

2-Oxo-clopidogrel $\rightarrow$ 2-oxo-clopidogrel-carboxylate

Active metabolite $\rightarrow$ active metabolite-carboxylate

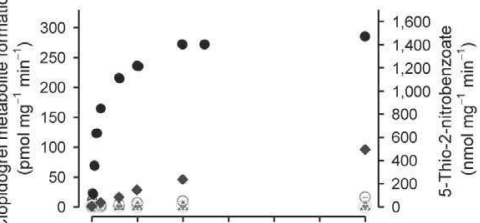

O $5001,0001,5002,0002,5003,000$

Concentration $\left(\mu \mathrm{moll}^{-1}\right)$

\section{CES2}

- $p$-Nitrophenyl acetate $\rightarrow p$-nitrophenol

Clopidogrel $\rightarrow$ 2-oxo-clopidogrel

2-Oxo-clopidogrel $\rightarrow$ active meta

Clopidogrel $\rightarrow$ clopidograt-carboxyla

2-Oxo-clopidogrel $\rightarrow 2-0 \times 0-c l o p i d o g r e l-c a r b o x y l a t e$

ᄃ. Active metabolite $\rightarrow$ active metabolite-carboxylate

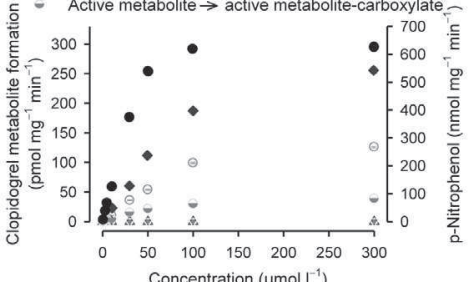


Table 1 | Distribution of variant genotypes among case-cohort patients

\begin{tabular}{|c|c|c|c|}
\hline \multicolumn{4}{|l|}{$\mathrm{CYP}_{2} \mathrm{C}_{9}$} \\
\hline $\mathrm{C}_{430 \mathrm{~T}}\left(\mathrm{CYP}_{2} \mathrm{C}_{9} *_{2}\right)$ & & & $0.84[0.52]$ \\
\hline CC $\left(*_{1} / *_{1}\right)-$ no. $(\%)$ & $30(75.0)$ & $57(80.3)$ & \\
\hline$C T\left(*_{1} / *_{2}\right)-$ no. $(\%)$ & $10(25.0)$ & $14(19.7)$ & \\
\hline $\mathrm{A}_{1075} \mathrm{C}\left(\mathrm{CYP}_{2} \mathrm{C}_{9} * 3\right)$ & & & $0.50[0.69]$ \\
\hline $\mathrm{AA}\left(*_{1} / *_{1}\right)-$ no. $(\%)$ & $32(80.0)$ & $59(83.1)$ & \\
\hline $\mathrm{AC}\left(*_{1} / *_{3}\right)-$ no. $(\%)$ & $8(20.0)$ & $12(16.9)$ & \\
\hline \multicolumn{4}{|l|}{$\mathrm{CYP}_{2} \mathrm{C}_{19}$} \\
\hline G681A (CYP2 $C_{19 * 2)}$ & & & $0.31[0.53]$ \\
\hline $\mathrm{GG}\left(*_{1} / *_{1}\right)-$ no. $(\%)$ & $26(63.4)$ & $49(69.0)$ & \\
\hline $\mathrm{GA}\left(*_{1} / *_{2}\right)-$ no. $(\%)$ & $12(29 \cdot 3)$ & $20(28.2)$ & \\
\hline $\mathrm{AA}\left(*_{2} / *_{2}\right)-$ no. $(\%)$ & $3(7 \cdot 3)$ & $2(2.8)$ & \\
\hline \multicolumn{4}{|l|}{$\mathrm{CYP}_{3} \mathrm{~A}_{4}$} \\
\hline $\mathrm{A}(-392) \mathrm{G}\left(\mathrm{CYP}_{3} \mathrm{~A}_{4} *_{1} \mathrm{~B}\right)$ & & & $0.63[0.85]$ \\
\hline $\mathrm{AA}\left(*_{1} / *_{1}\right)-$ no. $(\%)$ & $38(95.0)$ & $68(95.8)$ & \\
\hline AG $\left(*_{1} / *_{1} B\right)-$ no. $(\%)$ & $2(5.0)$ & $3(4 \cdot 2)$ & \\
\hline $\mathrm{IVS}_{10}+\mathrm{G}_{12} \mathrm{~A}\left(\mathrm{CYP}_{3} \mathrm{~A}_{4} *_{1} \mathrm{G}\right)$ & & & $0.88[0.80]$ \\
\hline GG $\left(*_{1} / *_{1}\right)-$ no. $(\%)$ & $31(77 \cdot 5)$ & $58(81.7)$ & \\
\hline $\mathrm{GA}\left(*_{1} / *_{1} G\right)-$ no. $(\%)$ & $7(17 \cdot 5)$ & $11(15 \cdot 5)$ & \\
\hline$A A\left(*_{1} G / *_{1} G\right)-$ no. $(\%)$ & $2(5.0)$ & $2(2.8)$ & \\
\hline \multicolumn{4}{|l|}{$C Y P_{3} A_{5}$} \\
\hline $\mathrm{A} 6986 \mathrm{G}\left(\mathrm{CYP}_{3} \mathrm{~A}_{5} * 3\right)$ & & & $0.69[0.90]$ \\
\hline $\mathrm{AA}\left(*_{1} / *_{1}\right)-$ no. $(\%)$ & $1(2.5)$ & $1(1.4)$ & \\
\hline AG $\left(*_{1} / *_{3}\right)-$ no. $(\%)$ & $5(12.5)$ & $10(14.1)$ & \\
\hline $\mathrm{GG}\left(*_{3} / *_{3}\right)-$ no. $(\%)$ & $34(85.0)$ & $60(84.5)$ & \\
\hline \multicolumn{4}{|l|}{ PON1 } \\
\hline A576G (Q192R) & & & $<0.001[0.001]$ \\
\hline AA (QQ) - no. (\%) & $27(65.9)$ & $25(35.2)$ & \\
\hline AG (QR) - no. (\%) & $13(31.7)$ & $33(46.5)$ & \\
\hline GG (RR) - no. (\%) & $1(2.4)$ & $13(18.3)$ & \\
\hline \multicolumn{4}{|l|}{$A B C B 1$} \\
\hline $\mathrm{C}_{3435^{\mathrm{T}}}$ & & & $0.71[0.59]$ \\
\hline CC-no. (\%) & $7(17 \cdot 5)$ & $16(22.5)$ & \\
\hline CT - no. $(\%)$ & $20(50)$ & $3^{8}(53 \cdot 5)$ & \\
\hline TT - no. $(\%)$ & $13(32.5)$ & $17(24.0)$ & \\
\hline
\end{tabular}

All variant alleles were designated by their nucleotide substitution (relative to position 1 of the coding DNA reference sequence); for CYP variants the common harmonized star allele designation, and for the $P O N_{1}$ variant the one-letter amino acid substitution (relative to the peptide reference sequence), are given in parentheses. The variant alleles $\mathrm{CYP}_{2} \mathrm{C}_{19} *_{3}, \mathrm{CYP}_{2} \mathrm{C}_{19}{ }_{4}$, $\mathrm{CYP}_{2} \mathrm{C}_{19}{ }^{*}, \quad \mathrm{CYP}_{3} \mathrm{~A}_{4}{ }_{2} 2$ and $\mathrm{CYP}_{3} A_{4}{ }^{*} 3$ were not present in the study population. For one subject in the stent thrombosis group, genotype information was missing for $\mathrm{CYP}_{2} \mathrm{C}_{9} \mathrm{CYP}_{3} \mathrm{~A}_{4}, \mathrm{CYP}_{3} \mathrm{~A}_{5}$ and $A B C B 1$. $P$ values were determined by univariate Cox regression with weighting of subcohort noncases with the inverse of the sampling fraction according to a previously described method33 and additionally by binary logistic regression (values are presented in square brackets). $P$ values were not corrected for multiple testing. Comparison between Cox regression and logistic regression indicates that the significance of the genetic associations did not depend on the timing of the stent thrombosis events. $P<$ 0.05 was considered a statistically significant difference. IVS, intervening sequence; $S N P$, single nucleotide polymorphism. 
To further exclude that oxidative biotransformation was involved in the second step of active metabolite formation, as suggested previously ${ }^{10-12}$, we incubated 2-oxo-clopidogrel with human liver microsomes or with human serum, with equal paraoxonase activity in both preparations. There were no differences in the conversion rates to the thiol metabolite (Supplementary Figure 3). Moreover, pharmacological inhibition of $P O N_{1}$ in liver microsomes suppressed formation of the thiol metabolite from both clopidogrel and 2-oxo-clopidogrel substrates, whereas inhibition of $\mathrm{CYP}_{3} \mathrm{~A}$ activity reduced thiol metabolite formation only from clopidogrel (Supplementary Figure 3).

The low conversion rate of 2-oxo-clopidogrel to the thiol compound indicated that this reaction was the rate-limiting step of bioactivation, with $P O N_{1}$ representing the key enzyme. This was supported by our observation that the rates of thiol metabolite formation were not different after incubation of liver microsomes with clopidogrel or 2-oxo-clopidogrel (Supplementary Figure 3). Two common coding polymorphisms of the $P O N_{1}$ gene are known: $\mathrm{Q}_{192} \mathrm{R}$ and $\mathrm{L}_{55} \mathrm{M}^{13}$. The Arg192 allozyme compared with the Gln192 allozyme showed a higher hydrolysis efficiency for 2-oxo-clopidogrel (Vmax / Km (s.e.m.), 1.36 (0.21) versus $0.36(0.045) \mu \mathrm{mg}^{-1} \mathrm{~min}^{-1}, \mathrm{P}<0.001$ ) and for the probe substrate paraoxon (13.9 (1.1) versus $\left.1.69(0.25) \mu \mathrm{mg}^{-1} \mathrm{~min}^{-1}, \mathrm{P}<0.001\right)$, but not for phenylacetate $(5.19(0.23)$ versus $5.09(0.40) \mathrm{ml}$ $\mathrm{mg}^{-1} \mathrm{~min}^{-1}, \mathrm{P}=0.850$ ), whereas the Met55 allozyme compared with the Leu55 allozyme showed no differences in the hydrolysis rates toward 2-oxo-clopidogrel or the probe substrates (Figure 1 and Supplementary Table 1). Similar effects of the $\mathrm{Q}_{192} \mathrm{R}$ and $\mathrm{L}_{55} \mathrm{M}$ polymorphisms on the hydrolysis efficiency of paraoxon and phenylacetate have been suggested in previous reports ${ }^{14,15}$. Corroborating the enzyme activity data, analysis of the crystal structure of $P O N_{1}$ indicates that position 192 (but not position 55) constitutes part the active histidine dyad16; therefore alteration of the pKa value at position 192 by the Q192R substitution would be expected to affect substrate affinity.

We next conducted a case-cohort study ${ }^{17}$ in individuals with CAD who underwent $\mathrm{PCl}$ and received clopidogrel for 6-12 months in accordance with consensus guidelines ${ }^{18}$. We compared 41 incident cases with nonfatal stent thrombosis and 71 randomly selected subjects without stent thrombosis who accrued in a cohort of 7,719 eligible subjects during 18 months of follow-up. Subsequently, the clopidogrel-free subjects received a single 6oo-mg test dose of clopidogrel to assess pharmacokinetic and pharmacodynamic responses (Supplementary Figure 4). Cases and noncases were well balanced with respect to demographic, clinical and procedural characteristics, minimizing the influence of confounding variables on outcome (Supplementary Tables 2 and 3 and Supplementary Figure 5). Compared with individuals with either the PON1 RR192 or the QR192 genotype, QQ192 homozygous individuals were more frequent in the stent thrombosis group than in the control group (odds ratio, 3.6; $95 \%$ confidence interval, 1.6-7.9; $\mathrm{P}=0.003$; false-positive reporting probability, 3.7\%). In addition, early stent thrombosis (within $30 \mathrm{~d}, \mathrm{n}=30$ ) tended to be more frequent than late or very late stent thrombosis (>30 d, $\mathrm{n}=11$ ) in QQ192 subjects as compared with QR192 heterozygous and RR192 homozygous individuals (odds ratio, 3.3; 95\% confidence interval, o.82-13.3; $\mathrm{P}=0.095$ ). The distributions of variant genotypes of $C Y P_{2} C_{1} 9_{1} C Y P_{2} C_{9}, C Y P_{3} A_{4}, C Y P_{3} A_{5}$ and $A B C B_{1}$, which have been associated with clopidogrel response in previous studies ${ }^{19-22}$, were not significantly different between the stent thrombosis group and the control group (Table 1). The genotype distributions were in agreement with the distributions reported from other populations of European descent ${ }^{19}$, indicating an absence of population stratification.

Considering not only the occurrence of events but also the time of event occurrences after index $\mathrm{PCl}$, the hazard ratio of stent thrombosis for QR192 heterozygous individuals was considerably higher compared with RR192 homozygous individuals and increased in an approximately log-additive fashion 
Part IV | chapter 13

in QQ192 homozygous individuals (Table 2 and Figure 2a,b). The PON1 Q192R genotype was the only significant factor that was independently associated with the occurrence of stent thrombosis in univariate and multivariate stepwise Cox regression analyses $(P<0.001)$. Adjustment for other potentially explanatory covariates did not change the hazard ratios (Table 2). After administration of the 6oo-mg clopidogrel test dose, the individuals who had experienced nonfatal stent thrombosis during follow-up showed a lower plasma concentration of the active clopidogrel metabolite, a higher concentration of the 2-oxo-clopidogrel metabolite, a higher ratio of 2-oxo-clopidogrel to active metabolite and a lower inhibition of platelet aggregation compared with participants without incident stent thrombosis (Figure $\mathbf{2 c}$ and Supplementary Table 4). Concentrations of parent clopidogrel and of the inactive carboxylic acid metabolite and baseline platelet aggregation were not different between the groups (Figure $\mathbf{2 c}$ and Supplementary Table 4).

Table 2 | Hazard ratios of incident non-fatal definite stent thrombosis among case-cohort patients in relation to $\mathrm{PON}_{1} \mathrm{Q}_{192} \mathrm{R}$ genotype, paraoxonase activity, plasma concentration of active clopidogrel metabolite, and platelet inhibition

\begin{tabular}{|c|c|c|c|c|}
\hline Predictor variable & $\begin{array}{l}\text { Unadjusted } \\
\text { hazard ratio } \\
(95 \% \mathrm{Cl})\end{array}$ & P value & $\begin{array}{l}\text { Adjusted } \\
\text { hazard ratio } \\
(95 \% \mathrm{Cl})\end{array}$ & $P$ value \\
\hline \multicolumn{5}{|l|}{ PON1 genotype: } \\
\hline - RR192 & 1 (reference) & & 1 (reference) & \\
\hline - QR192 & $4.41(1.89-10.20)$ & 0.001 & $4.52(1.81-11.24)$ & 0.001 \\
\hline - QQ192 & $12.82(4.74-90.91)$ & $<0.001$ & $12.90(4.54-95.48)$ & $<0.001$ \\
\hline \multicolumn{5}{|c|}{ Paraoxonase plasma activity $\left(\mathrm{nmol} \mathrm{min}^{-1} \mathrm{ml}^{-1}\right)$ : } \\
\hline - Highest tertile ( $\geq 180.4$ ) & 1 (reference) & & 1 (reference) & \\
\hline - Middle tertile (<180.4-104.9) & $6.29(2.79-22.07)$ & $<0.001$ & $7.14(2.93-19.23)$ & $<0.001$ \\
\hline - Lowest tertile $(<104 \cdot 9)$ & $22.03(6.62-73 \cdot 38)$ & $<0.001$ & $22.22(6.67-76.92)$ & $<0.001$ \\
\hline \multicolumn{5}{|c|}{ Active clopidogrel metabolite $\left(c_{\max }, \mathrm{ng} \mathrm{ml}^{-1}\right)$ : } \\
\hline - Highest tertile $(\geq 22.85)$ & 1 (reference) & & 1 (reference) & \\
\hline - Middle tertile $(<22.85-11.57)$ & $6.25(2.34-16.67)$ & $<0.001$ & $6.33(2.57-15.63)$ & $<0.001$ \\
\hline - Lowest tertile $(<11.57)$ & $16.13(5 \cdot 56-45.45)$ & $<0.001$ & $17.24(5.08-58.82)$ & $<0.001$ \\
\hline \multicolumn{5}{|c|}{ Platelet inhibition ( $20 \mu \mathrm{M}$ ADP, $\Delta \%$ ): } \\
\hline - Highest tertile ( $\geq 40.6)$ & 1 (reference) & & 1 (reference) & \\
\hline - Middle tertile (<40.6-19.0) & $3.97(1.64-9.52)$ & 0.002 & $4.13(1.74-9.80)$ & 0.001 \\
\hline - Lowest tertile (<19.0) & $11.23(3.29-38.46)$ & $<0.001$ & $11.24(3.29-38.34)$ & $<0.001$ \\
\hline
\end{tabular}

Hazard ratios were calculated by univariate and multivariate Cox regression with weighting of subcohort noncases with the inverse of the sampling fraction according to a previously described method33. Multivariate adjustments were done for baseline demographic (sex, age, body-mass index and smoking) and clinical characteristics (indication of percutaneous coronary intervention, number of treated vessels, type of stent, clopidogrel loading dose, hypertension, hypercholesterolemia, diabetes mellitus, previous myocardial infarction or coronary artery disease, family history of coronary artery disease and left ventricular ejection fraction $<45 \%$ ), and variant genotypes of CYP $2 \mathrm{C}_{9}{ }_{2}$ and $C Y P_{2} C_{9} *_{3}, C Y P_{2} C_{19} *_{2}, C Y P_{3} A_{4} *_{1} B, C Y P_{3} A_{4} *_{1} G, C Y P_{3} A_{5} *_{3}$ and $A B C B_{1} C_{3435}$ T. Additional adjustment for the use of aspirin and statins did not change the hazard ratios (data not shown). Genotype distribution and tertile limits in the subcohort sample fraction were extrapolated to the total cohort. Maximal plasma concentration of the active metabolite (cmax) and platelet inhibition (maximal predose versus maximal 6- $h$ postdose aggregation induced by 20 $\mu M A D P, \triangle \%)$ were determined after administration of a single 60o-mg clopidogrel dose. $P<0.05$ was considered a statistically significant difference. 
Parameters reflecting clopidogrel activity- paraoxonase plasma activity, maximal plasma concentration of the active metabolite and maximal platelet inhibition - were equally strong predictors as the $P O N_{1}$ Q192R genotype for the risk of stent thrombosis in univariate and multivariate Cox regression analyses (Table 2 and Figure 2a,b). The hazard estimates for the PON1 $\mathrm{Q}_{192 \mathrm{R}}$ genotype lost statistical significance after individual adjustment for variables reflecting clopidogrel activity as listed above, indicating a strong interaction between the $P O N_{1}$ genotype and the clopidogrel activity markers (Supplementary Table 5). Consistently, the $P O N_{1} \mathrm{Q}_{1}{ }_{2} \mathrm{R}$ genotype was the only factor that significantly correlated with paraoxonase plasma activity (unadjusted $\mathrm{R} 2=0.805, \mathrm{P}<0.001$ ), maximal plasma concentration of the active clopidogrel metabolite $(\mathrm{R} 2=0.809, \mathrm{P}<0.001)$ and inhibition of platelet aggregation $\left(R_{2}=0.725, P<0.001\right)$ in univariate and multivariate stepwise linear regression models. There were also close correlations between paraoxonase activity and both active metabolite concentration $\left(R_{2}=0.939, P<0.001\right)$ and platelet inhibition $\left(R_{2}=0.738, P<0.001\right)$. Accordingly, the predictive diagnostic power of the clopidogrel activity markers for stent thrombosis, as determined by receiver operating characteristic curves, did not substantially increase on inclusion of the $P O N_{1}$ genotype, but the combined predictive power of demographic, clinical and other genetic factors was considerably improved by inclusion of the $P O N_{1}$ genotype (Supplementary Figure 6). The distribution of the clopidogrel activity markers was independent of other gene variants and was also independent of treatment with potentially interacting drugs (Supplementary Tables 6 and 7).

For further evaluation of the genotypic and phenotypic association of $P O N_{1}$ with the clinical response to clopidogrel, we conducted a replication study in a prospective cohort of 1,982 individuals with acute coronary syndromes over a 12-month follow-up period. The results confirmed and extended the findings of the case-cohort study. The unadjusted hazard ratio of fatal and nonfatal definite stent thrombosis in PON1 QQ192 versus RR192 homozygous individuals was 10.20 ( $95 \%$ confidence interval, 4.39-71.43; $\mathrm{P}<0.001$ ). Lower but significant risk associations were also found with the etiologically more diverse secondary end points myocardial infarction (hazard ratio, 4.93; 95\% confidence interval, 2.16-11.24; $\mathrm{P}<0.001$ ) and the composite of vascular death, nonfatal myocardial infarction and nonfatal ischemic stroke (hazard ratio, 3.89; 95\% confidence interval, 2.10-7.19; $\mathrm{P}<0.001$ ), suggesting that unmeasured covariates diluted the association with the $P O N_{1}$ genotype. The $P O N_{1}$ genotype was not associated with the risk of ischemic stroke (hazard ratio, 2.38; 95\% confidence interval, 0.54-10.42; $\mathrm{P}=0.250$ ) or nonvascular death (hazard ratio, $0.98 ; 95 \%$ confidence interval, $0.20-4.72 ; \mathrm{P}=0.981$ ) (Supplementary Table 8), consistent with the lack of efficacy of clopidogrel for stroke and nonvascular death in clinical trials23. Q0192 homozygous subjects showed a lower risk of major bleeding (hazard ratio, $0.36 ; 95 \%$ confidence interval, $0.18-0.75 ; \mathrm{P}=0.006$ ) that could be related to a less effective platelet inhibition. Similar risk estimates were obtained for paraoxonase plasma activity (Supplementary Table 9). The subject groups with and without the respective clinical outcome did not differ in demographic and clinical characteristics; the characteristics of subjects with and without stent thrombosis are shown in Supplementary Table 10. Multivariate adjustments failed to alter the risk estimates (Supplementary Tables 8 and 9).

Taken together, these biochemical, clinical and epidemiological studies indicate that the functional $P O N_{1} Q_{192} \mathrm{R}$ gene variant is a major determinant of the pharmacokinetic and pharmacodynamic responsiveness to clopidogrel and thus its clinical efficacy. 
Part IV | chapter 13

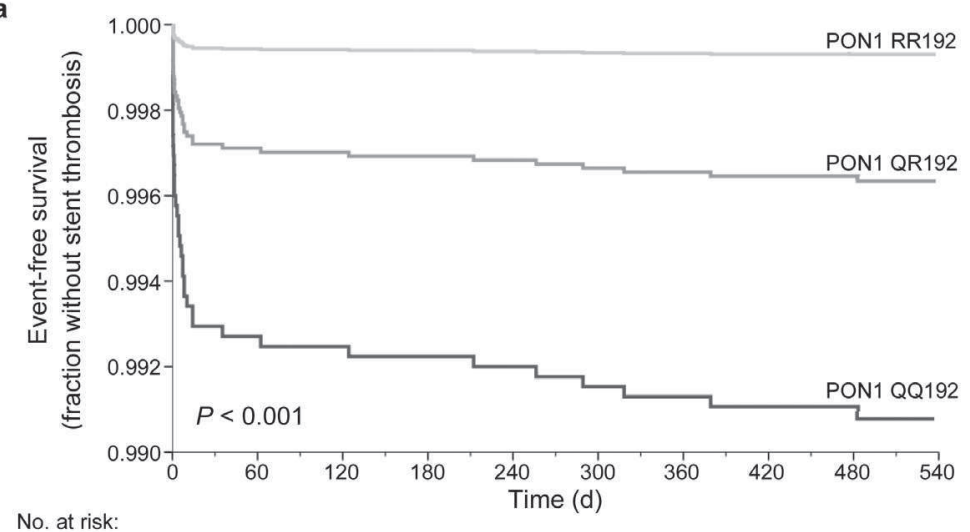

\begin{tabular}{|c|c|c|c|c|}
\hline No. at & & & & \\
\hline Days & $\underline{0} \quad \underline{30} \quad \underline{60}$ & 180 & $\underline{360}$ & 540 \\
\hline RR192 & $1,4071,4061,406$ & 1,406 & 1,406 & 1,406 \\
\hline OR192 & 358235753575 & 3574 & 3.571 & 3569 \\
\hline 00192 & 273027082707 & 2706 & 2705 & $2703+25$ \\
\hline Total & $7,7197,6897,688$ & 7,686 & 7,682 & 7,678 \\
\hline
\end{tabular}

b

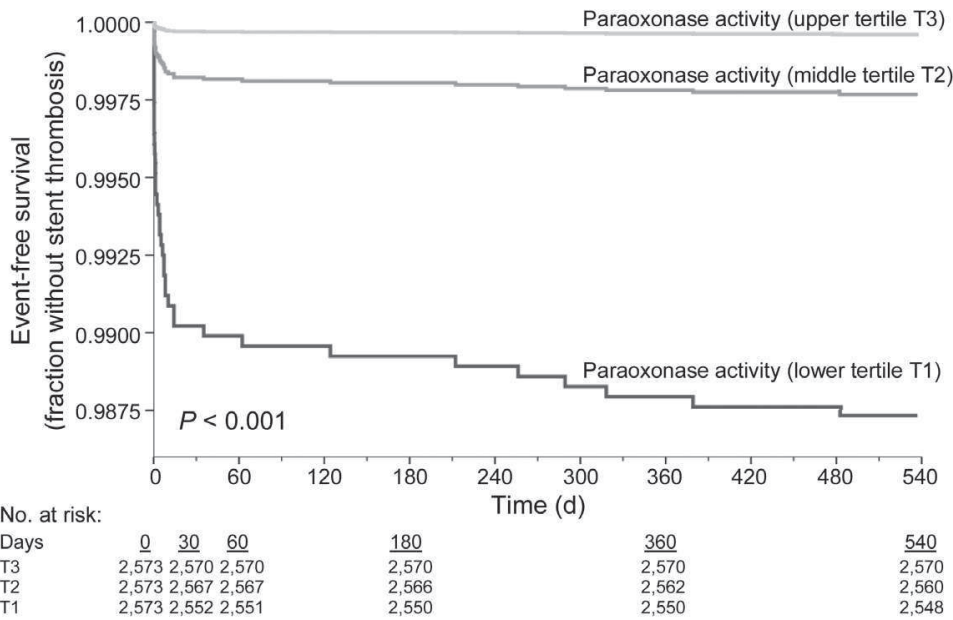

Figure 2a/b | Kaplan-Meier curves for individuals with coronary stent implantation and their pharmacokinetic and pharmacodynamic responses to clopidogrel. $(a, b)$ Kaplan-Meier survival curves showing cumulative probabilities of casecohort subjects without incident nonfatal definite stent thrombosis over 18 months of follow-up according to PON 1 Q192R gene polymorphism (a) and according to tertiles ( $T_{1}, T_{2}$ and $T_{3}$ ) of paraoxonase plasma activity, with $T_{1}<104.9$, $T_{2}<180.4-104.9$ and $T_{3} \geq 180.4 \mathrm{nmol} \mathrm{min}^{-1} \mathrm{ml}^{-1}(b)$. Genotype distribution and tertile limits were extrapolated to the total cohort, and subcohort noncases were weighted with the inverse of the sampling fraction according to a previously described method33. Numbers of individuals at risk at the indicated time points are shown. $P$ values for the total model coefficients were calculated by univariate Cox regression. 
C

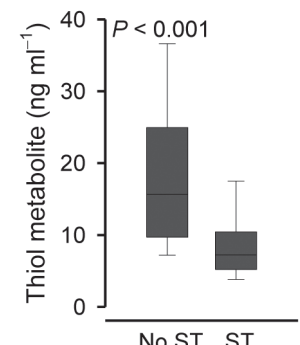

No ST ST

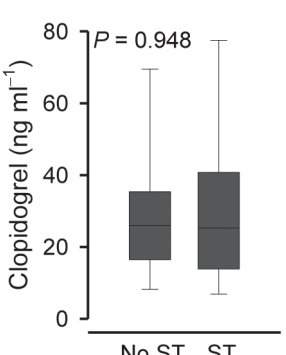

No ST ST

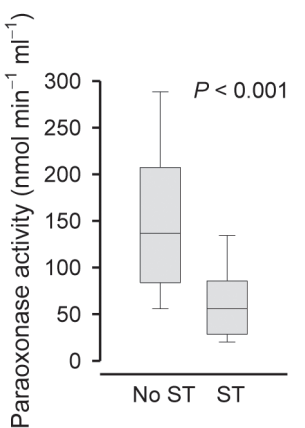

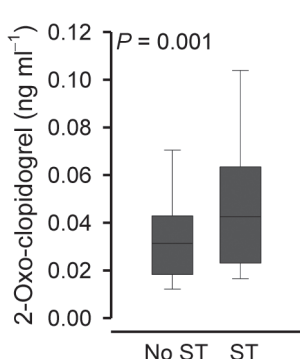

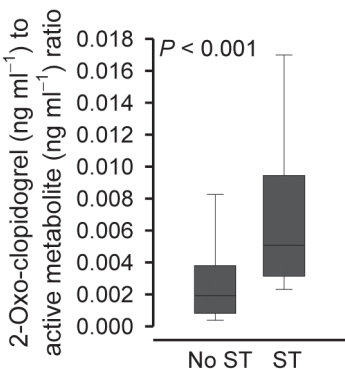

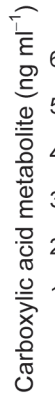

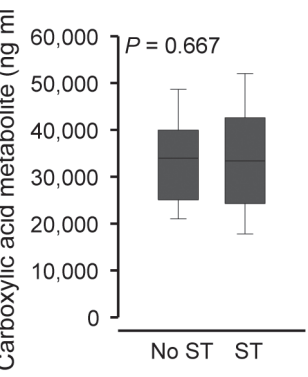

$\widehat{\bar{\varepsilon}}$

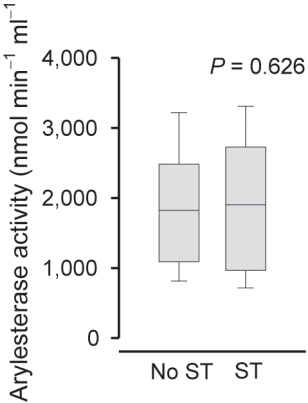

Figure 2c| Kaplan-Meier curves for individuals with coronary stent implantation and their pharmacokinetic and pharmacodynamic responses to clopidogrel.

(c) Box-and-whisker plots showing median response values with twenty-fifth and seventy-fifth percentiles (box) and tenth and ninetieth percentiles (whisker). After the 18-month follow-up, the clopidogrel-free cases with nonfatal stent thrombosis (ST, $n=41$ ) and the subcohort noncases without stent thrombosis (NoST, $n=71$ ) were given a single 6oo$\mathrm{mg}$ clopidogrel dose, and pharmacokinetic and platelet responses were compared by univariate Cox regression. Pharmacokinetic responses are indicated as maximum plasma concentrations (cmax, $\mathrm{ng} \mathrm{m}^{-1}$ ) of active thiol metabolite, 2-oxo-clopidogrel, parent clopidogrel and carboxylic acid metabolite and as ratio of the maximum plasma concentrations of 2-oxo-clopidogrel to thiol metabolite. Platelet response is indicated as percentage of maximal predose versus maximal 6-h postdose aggregation ( $\triangle \%$ induced by $20 \mu M A D P)$, Paraoxonase and arylesterase plasma activities are indicated as the velocity of transformation ( $\mathrm{nmol} \mathrm{min} \mathrm{m}^{-1} \mathrm{ml}^{-1}$ ) of paraoxon to $\mathrm{p}$-nitrophenol and of phenylacetate to phenol, respectively. $P<0.05$ was considered a statistically significant difference. 
Part IV | chapter 13

Previous studies have suggested associations of several variant genes, such as $\mathrm{CYP}_{3} \mathrm{~A}_{4}{ }_{1} \mathrm{G}^{20}$, $\mathrm{CYP}_{3} \mathrm{~A}_{5}{ }^{*} 3^{21}, \mathrm{CYP}_{2} \mathrm{C}_{9} * 2$ or $\mathrm{CYP}_{2} \mathrm{C}_{9}{ }^{*}{ }^{22}$ and the $A B C B_{1}$ drug transporter $\mathrm{C}_{3435}{ }^{\mathrm{T}}$ polymorphism ${ }^{19}$, with pharmacokinetic, antiplatelet or clinical responses to clopidogrel. In particular, the common loss-offunction allele $\mathrm{CYP}_{2} \mathrm{C}_{1} *_{2}$ or concomitant administration of $\mathrm{CYP}_{2} \mathrm{C}_{19}$-inhibiting drugs have repeatedly been associated with lower responsiveness to clopidogrel ${ }^{6,7}$. However, even in a genetically homogenous population, the $\mathrm{CYP}_{2} \mathrm{C}_{19}{ }_{2}$ allele was reported to account for only $12 \%$ of the variability in ADPstimulated platelet response to clopidogrel 5 . The high heritability of clopidogrel response but relatively weak prediction by existing proposed genetic markers argues for the involvement of an as yet undiscovered genetic factor. The $P \mathrm{ON}_{1} \mathrm{Q}_{1} 92 \mathrm{R}$ polymorphism explained $72.5 \%$ (as derived from the R2 statistic of linear regression) of the variability in ADP-stimulated platelet aggregation after clopidogrel administration and thus seems likely to be the primary predictor of clopidogrel response. However, a previous genome-wide association study in a cohort of related healthy subjects of Amish descent provided no evidence for an association of the $P O N_{1}$ gene region with the platelet response to clopidogrel ${ }^{5}$. The basis for this discrepancy with our findings is unclear, but it might be explained by differences in the populations treated with clopidogrel or in the methodology of platelet function testing. Instead of measuring platelet inhibition after a single loading dose, the authors determined platelet inhibition values after multiple doses of clopidogrel 5 , which in our validation studies correlated insufficiently with active metabolite formation (Supplementary Methods). Likewise, a lack of consistency between ex vivo-tested platelet function and clinical response to clopidogrel has been reported in previous studies, and lower magnitudes of the risk estimates to predict clinical events on the basis of platelet function as compared with our studies were found ${ }^{24}$, which could be related to differences in the methodology of platelet function testing or to the heterogeneity of the assessed clinical outcomes. In accordance with our findings, the degree of platelet inhibition after a single 60omg clopidogrel loading dose showed a high predictive ability for definite stent thrombosis in a large prospective study 25 .

The genetic association of clopidogrel response with $P O N_{1}$ genotype was consistent with results from quantitative metabolomic profiling of clopidogrel bioactivation. Two previous studies have quantified the contribution of CYP isozymes to oxidative clopidogrel metabolism but were only in partial agreement with each other ${ }^{12,26}$. Our data are consistent with one of these studies ${ }^{26}$, including the lack of involvement of $\mathrm{CYP}_{2} \mathrm{C}_{19}$ in clopidogrel oxidation. Our finding that 2-oxoclopidogrel, the product of CYP-catalyzed oxidation, was opened to the active thiol by hydrolysis is in agreement with the maintenance of the formal oxidation states at sulfur and carbon atoms upon the conversion of 2-oxo-clopidogrel to the thiol metabolite (Supplementary Figure 2). The basis for the discrepancies between our findings and reports of an oxidative CYP-dependent ring cleavage ${ }^{10-12}$ remains unclear. As we have shown, the ring opening observed in incubation experiments with liver microsomes results from microsomal PON activity but not from CYP activity. The suggested formation of sulfenic acid intermediates ${ }^{11}$ may also result from CYP-dependent oxidation of the free thiol, similarly to the metabolism of spironolactone ${ }^{27}$. In support of our findings, $P O N_{1}$ has been shown to possess thiolactonase activity toward differently substituted $\gamma$-thiobutyrolactone compounds ${ }^{14,28,29}$.

Associations of specific CYP genotypes with a higher atherothrombotic risk might be independent of clopidogrel metabolism. For example, carriers of the $\mathrm{CYP}_{2} \mathrm{C}_{19} *_{2}$ allele showed higher plasma concentrations of inflammatory markers that could have contributed to an increased baseline cardiovascular risk associated with $\mathrm{CYP}_{2} \mathrm{C}_{19} 2^{33^{30}}$. Similarly, the $P \mathrm{ON}_{1} \mathrm{Gln} 192$-encoding allele has been associated with elevated markers of systemic oxidative stress and a higher risk of major cardiovascular 


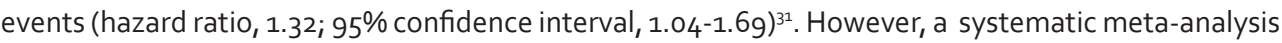
showed an association of the $P O N_{1}$ Arg192-encoding allele with a higher risk of CAD (relative risk, $1.12 ; 95 \%$ confidence interval, $1.02-1.16)^{13}$. It is unlikely that the small magnitude of either potentially harmful or protective effects of $P \mathrm{~N}_{1} \mathrm{Q}_{1} \mathrm{~g}_{2} \mathrm{R}$ on baseline cardiovascular risk could substantially bias the large and consistent effects of the $P O N_{1}$ genotype on cardiovascular risk related to clopidogrel efficacy. Examination of the HapMap-CEU (Caucasian Europeans from Utah) population showed that the $\mathrm{Q}_{192 \mathrm{R}}$ polymorphism is located within a linkage disequilibrium block of $P O N_{1}$ that, with the exception of $\mathrm{Q}_{192} \mathrm{R}$, covers only polymorphisms not affecting paraoxonase activity ( $\mathrm{L}_{55} \mathrm{M}$ and intronic single nucleotide polymorphisms without putative cis-regulatory function) and does not extend to the downstream $P_{3} N_{3}$ and $P O N_{2}$ genes or other genes, inconsistent with the possibility that $Q_{1}{ }_{2} \mathrm{R}$ is a tag for the true causal gene variant. Aside from the $Q_{192} R$ genotype, the activity of $P O N_{1}$ has been suggested to be modified by environmental factors such as age, smoking, plasma lipids, ischemic or inflammatory conditions or medication ${ }^{32}$. However, in accordance with previous studies ${ }^{31,32}$ we found a strong correlation between the $P O N_{1} Q_{1}{ }_{2} R$ genotype and paraoxonase activity $\left(R^{2}>0.80\right)$ that was not altered by adjustment for environmental covariates. In particular, the proportion of the phenotypic variance of paraoxonase plasma activity explained by the $P O N_{1}$ genotype was not different between measurements at nonischemic conditions in the case-cohort study (80.5\%) and measurements conducted during the acute ischemic disease state in the replication study (80.7\%).

Our studies were adequately powered to discover strong risk predictors with an odds ratio of $\geq 3.0$ for the homozygous risk genotype or the highest risk tertile, but weaker predictors conferring smaller risk increases may have remained undiscovered, yielding no significant associations with stent thrombosis or other investigated disease outcomes ( $P>0.05$ ). Consequently, the PON1 Gln 192 encoding risk allele arose as the only significant independent predictor of stent thrombosis, and the magnitudes of the risk estimates were considerably higher compared with those previously reported for any other common single allele. Our findings may have clinical utility in that $P O N_{1}$ genotyping or $P O N_{1}$ activity measurements may provide prognostic information of clopidogrel efficacy beyond common clinical and laboratory risk markers.

\section{METHODS}

Methods and any associated references are available in the online version of the paper at http://www. nature.com/naturemedicine/

\section{Acknowledgments}

We are grateful to all subjects who participated in the study. We thank numerous unnamed staff of our institutions for their efforts in subject recruitment, clinical, laboratory and experimental assessments. 
Part IV | chapter 13

\section{ONLINE METHODS}

Bioanalytics of clopidogrel and its metabolites. For quantification of clopidogrel and its metabolites, we developed a validated liquid chromatography tandem mass spectrometry method. This included synthesis and pharmacological testing of the active metabolite of clopidogrel and conducting a full validation procedure in accordance with regulatory standards for drug approval (Supplementary Methods and Supplementary Figs. 7 and 8).

Metabolomic profiling. We generated human embryonic kidney cell (HEK 293) clones of metabolizing enzymes (including common genetic variants) by stable transfection with their respective cDNAs. We obtained microsomal preparations for each enzyme (cytochrome $\mathrm{P} 450$ isozymes and esterases) from HEK 293 transfectants and determined enzymatic activity by a specific probe reaction. We incubated HEK 293 cell microsomes, human liver microsomes or serum with synthesized primary reference standards of clopidogrel base or clopidogrel metabolites at various concentrations and determined the rates of biotransformation by Michaelis-Menten analysis (Supplementary Methods).

Human studies. From a population of European descent of 7,719 individuals with a clinical presentation of stable angina pectoris or acute coronary syndrome who underwent $\mathrm{PCl}$ and received clopidogrel maintenance therapy for 6-12 months, we compared 41 incident cases involving nonfatal definite stent thrombosis that accrued over an 18-month follow-up and a random sample of 71 noncases in a casecohort design by genotyping, pharmacokinetic and pharmacodynamic testing to evaluate the determinants of clopidogrel response (Supplementary Figure 4). To further assess the association of the $P O N_{1}$ genotype and phenotype with clinical endpoints, we conducted a replication study in prospective cohort design in a population of European descent comprising 1,982 subjects with acute coronary syndrome, who underwent $\mathrm{PCl}$ and were monitored during a 12-month follow-up on clopidogrel maintenance therapy. The Institutional Review Boards of the St. Antonius Hospital Nieuwegein and the University Hospital of Cologne approved the protocols of the studies, and all participants gave written informed consent. We established an optimized assay of platelet function measurement by light transmission aggregometry for assessment of mechanistic pharmacokineticpharmacodynamic relationships in response to clopidogrel (Supplementary Figure 9). Details of study populations, study designs and clinical laboratory testing (including blood processing, pharmacokinetic analysis, aggregometry, determination of $P O N_{1}$ plasma activity and genotyping) are presented in the Supplementary Methods.

\section{Statistical analyses}

Details of the statistical analysis (including prospective sample size calculation, Cox regression models, determination of false-positive reporting probability and assessment of effectiveness of diagnostic variables by receiver operating characteristic curves) are presented in the Supplementary Methods.

\section{Additional methods}

Detailed methodology is described in the Supplementary Methods.

Supplementary files are available on request from the author (heleenbouman@gmail.com) or can be accessed at http://www.nature.com/naturemedicine/. 


\section{REFERENCES}

1. Gurbel, P.A., Antonino, M.J. \& Tantry, U.S. Recent developments in clopidogrel pharmacology and their relation to clinical outcomes. Expert Opin. Drug Metab. Toxicol. 5, 989-1004 (2009).

2. Angiolillo, D.J. \& Ferreiro, J.L. Platelet adenosine diphosphate $\mathrm{P}_{2} \mathrm{Y}_{12}$ receptor antagonism: benefits and limitations of current treatment strategies and future directions. Rev. Esp. Cardiol. 63, 60-76 (2010).

3. Serebruany, V.L. et al. Variability in platelet responsiveness to clopidogrel among 544 individuals. J. Am. Coll. Cardiol. 45, 246-251 (2005).

4. Sofi, F. et al. Clopidogrel non-responsiveness and risk of cardiovascular morbidity. An updated meta-analysis. Thromb. Haemost. 103, 841-848 (2010).

5. Shuldiner, A.R. et al. Association of cytochrome $\mathrm{P}_{45}{ }_{2} \mathrm{C}_{19}$ genotype with the antiplatelet effect and clinical efficacy of clopidogrel therapy. J. Am. Med. Assoc. 302, 849-857 (2009).

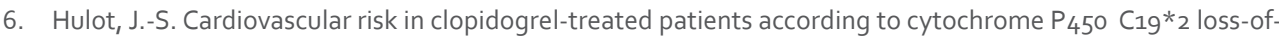
function allele or proton pump inhibitor coadministration: a systematic meta-analysis. J. Am. Coll. Cardiol. 56 $134-143$ (2010).

7. Holmes, D.R. Jr. et al. ACCF/AHA Clopidogrel clinical alert: approaches to the FDA "boxed warning": a report of the American College of Cardiology Foundation Task Force on Clinical Expert Consensus Documents and the American Heart Association. Circulation 122, 537-557 (2010).

8. Taubert, D. et al. Pharmacokinetics of clopidogrel after administration of a high loading dose. Thromb. Haemost. 92, 311-316 (2004).

9. Bouman, H.J. et al. Which platelet function test is suitable to monitor clopidogrel responsiveness? A pharmacokinetic analysis on the active metabolite of clopidogrel. J. Thromb. Haemost. 8, 482-488 (2010).

10. Pereillo, J.M. et al. Structure and stereochemistry of the active metabolite of clopidogrel. Drug Metab. Dispos. 30, 1288-1295 (2002).

11. Dansette, P.M., Libraire, J., Bertho, G. \& Mansuy, D. Metabolic oxidative cleavage of thioesters: evidence for the formation of sulfenic acid intermediates in the bioactivation of the antithrombotic prodrugs ticlopidine and clopidogrel. Chem. Res. Toxicol. 22, 369-373 (2009).

12. Kazui, M. et al. Identification of the human cytochrome $\mathbf{P} 450$ enzymes involved in the two oxidative steps in the bioactivation of clopidogrel to its pharmacologically active metabolite. Drug Metab. Dispos. 38, 92-99 (2010).

13. Wheeler, J.G., Keavney, B.D., Watkins, H., Collins, R. \& Danesh, J. Four paraoxonase gene polymorphisms in 11212 cases of coronary heart disease and 12786 controls: meta-analysis of 43 studies. Lancet 363, 689-695 (2004).

14. Billecke, $\mathrm{S}$. et al. Human serum paraoxonase (PON1) isozymes $\mathrm{Q}$ and $\mathrm{R}$ hydrolyze lactones and cyclic carbonate esters. Drug Metab. Dispos. 28, 1335-1342 (2000).

15. Adkins, S., Gan, K.N., Mody, M. \& La Du, B.N. Molecular basis for the polymorphic forms of human serum paraoxonase/arylesterase: glutamine or arginine at position 191, for the respective A or B allozymes. Am. J. Hum. Genet. 52, 598-608 (1993).

16. Harel, M. et al. Structure and evolution of the serum paraoxonase family of detoxifying and anti-atherosclerotic enzymes. Nat. Struct. Mol. Biol. 11, 412-419 (2004).

17. Prentice, R.L. On the design of synthetic case-control studies. Biometrics 42, 301-310 (1986).

18. King, S.B. III et al. 2007 Focused Update of the ACC/AHA/SCAI 2005 Guideline Update for Percutaneous Coronary Intervention: a report of the American College of Cardiology/American Heart Association Task Force on Practice Guidelines: 2007 Writing Group to Review New Evidence and Update the ACC/AHA/SCAI 2005 Guideline Update for Percutaneous Coronary Intervention, Writing on Behalf of the 2005 Writing Committee. Circulation 117, 261-295(2008). 


\section{Part IV | chapter 13}

19. Simon, T. et al. Genetic determinants of response to clopidogrel and cardiovascular events. N. Engl. J. Med. 360, 363-375 (2009)

20. Angiolillo, D.J. et al. Contribution of gene sequence variations of the hepatic cytochrome $\mathrm{P}_{4} \mathrm{~S}_{3} \mathrm{~A}_{4}$ enzyme to variability in individual responsiveness to clopidogrel. Arterioscler. Thromb. Vasc. Biol. 26, 1895-1900 (2006).

21. Suh, J.W. et al. Increased risk of atherothrombotic events associated with cytochrome $\mathrm{P}_{4} 0_{3} \mathrm{~A}_{5}$ polymorphism in patients taking clopidogrel. CMAJ 174, 1715-1722 (2006).

22. Brandt, J.T. et al. Common polymorphisms of $\mathrm{CYP}_{2} \mathrm{C}_{19}$ and $\mathrm{CYP}_{2} \mathrm{C}_{9}$ affect the pharmacokinetic and pharmacodynamic response to clopidogrel but not prasugrel. J. Thromb. Haemost. 5, 2429-2436 (2007).

23. Yusuf, S. et al. Effects of clopidogrel in addition to aspirin in patients with acute coronary syndromes without ST-segment elevation. N. Engl. J. Med. 345, 494-502 (2001)

24. Gurbel, P.A., Becker, R.C., Mann, K.G., Steinhubl, S.R. \& Michelson, A.D. Platelet function monitoring in patients with coronary artery disease. J. Am. Coll. Cardiol. 50, 1822-1834 (2007).

25. Sibbing, D. et al. Platelet reactivity after clopidogrel treatment assessed with point-of-care analysis and early drug-eluting stent thrombosis. J. Am. Coll. Cardiol. 53, 849-856 (2009).

26. Clarke, T.A. \& Waskell, L.A. The metabolism of clopidogrel is catalyzed by human cytochrome $\mathrm{P}_{450} 3 \mathrm{~A}$ and is inhibited by atorvastatin. Drug Metab. Dispos. 31, 53-59 (2003).

27. Correia, M.A. \& Ortiz de Montellano, P.R. Inhibition of cytochrome P450 enzymes. in Cytochrome P450: Structure, Mechanism, and Biochemistry (ed. Ortiz deMontellano, P.R.) 253 (Kluwer Academic/Plenum Publishers, New York, 2005).

28. Kosaka, T., Yamaguchi, M., Motomura, T. \& Mizuno, K. Investigation of the relationship between atherosclerosis and paraoxonase or homocysteine thiolactonase activity in patients with type 2 diabetes mellitus using a commercially available assay. Clin. Chim. Acta 359, 156-162 (2005).

29. Perla-Kaján, J. \& Jakubowski, H. Paraoxonase 1 protects against protein $\mathrm{N}$-homocysteinylation in humans. FASEB J. 24, 931-936 (2010).

30. Bertrand-Thiébault, C. et al. Genetic polymorphism of $\mathrm{CYP}_{2} \mathrm{C}_{19}$ gene in the Stanislas cohort. A link with inflammation. Ann. Hum. Genet. 72, 178-183 (2008).

31. Bhattacharyya, T. et al. Relationship of paraoxonase $1\left(P O N_{1}\right)$ gene polymorphisms and functional activity with systemic oxidative stress and cardiovascular risk. J. Am. Med. Assoc. 299, 1265-1276 (2008).

32. Rainwater, D.L. et al. Determinants of variation in human serum paraoxonase activity. Heredity 102, 147-154 (2009).

33. Barlow, W.E., Ichikawa, L., Rosner, D. \& Izumi, S. Analysis of case-cohort designs. J. Clin. Epidemiol. 52, 11651172 (1999) 


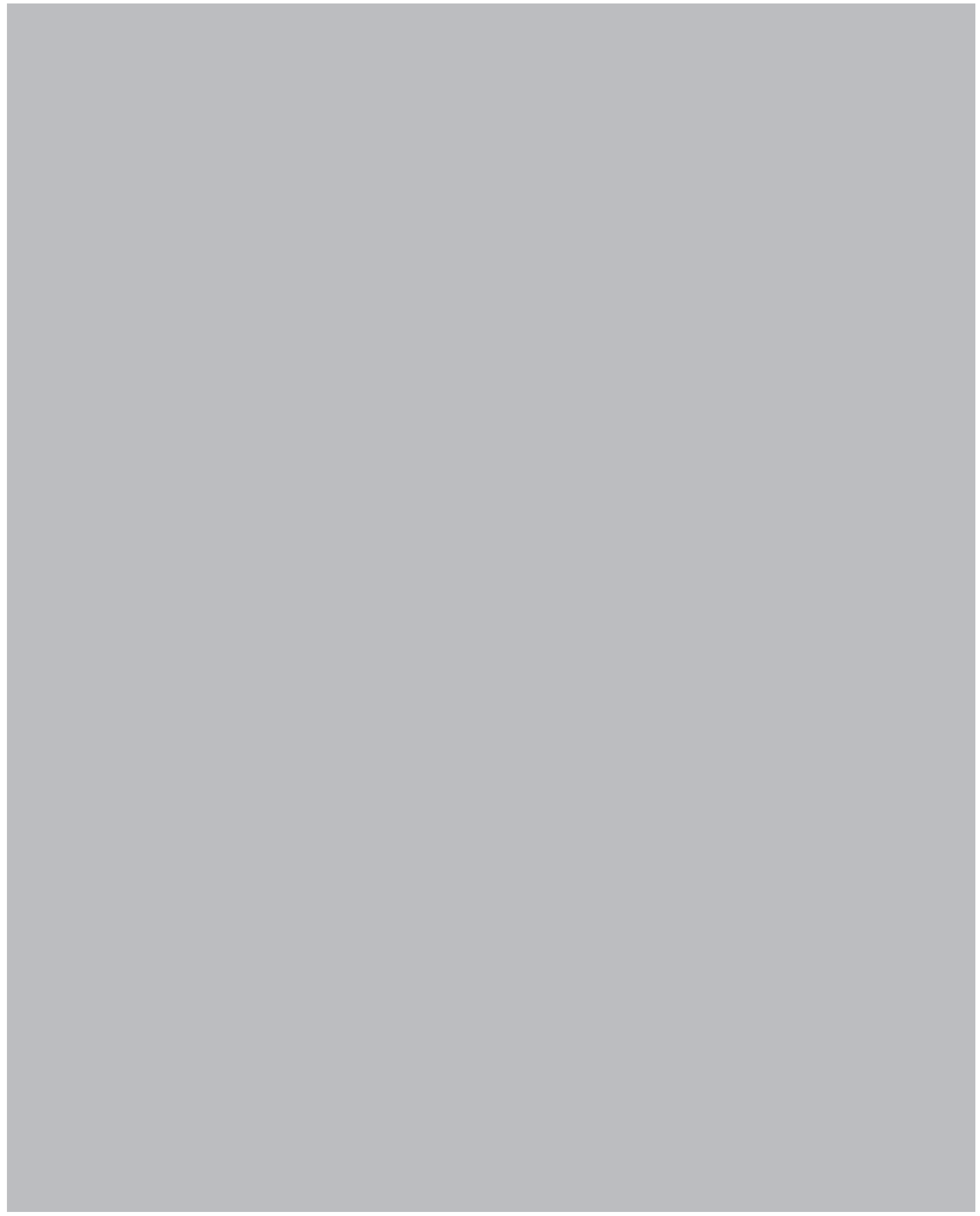


General discussion 
A large heterogeneity exists in the response to clopidogrel among treated patients, resulting in thrombotic complications in poor responding patients exhibiting high on-treatment platelet reactivity to $A D P(H P R)^{1,2}$. The present thesis describes the consequences of HPR, evaluates methods to measure clopidogrel response, and investigates different determinants of HPR that may be used for tailoring antiplatelet therapy to the individual patient.

\section{HIGH ON-TREATMENT PLATELET REACTIVITY AS A NOVEL RISK FACTOR FOR ATHEROTHROMBOTIC EVENTS}

Stent thrombosis remains the most feared complication after coronary stenting and for this key reason patients undergoing coronary stent implantation are treated with dual antiplatelet therapy. Patients with a history of early stent thrombosis exhibit HPR to clopidogrel and aspirin more frequently than patients with previous coronary stent implantation who did not incur stent thrombosis during followup ${ }^{3}$. Interestingly, platelet reactivity was measured months to years after the occurrence of stent thrombosis and most patients did not use clopidogrel at the time of inclusion, implicating that a poor response to clopidogrel and/or HPR status is intrinsic and continuous over time. This observation supports the idea that genetic variations in enzymes involved in the formation of the active metabolite of clopidogrel play an important role in the phenomenon of HPR. Late stent thrombosis appeared not to be associated with high on-clopidogrel platelet reactivity, but high on-aspirin platelet reactivity was frequent in this patient group ${ }^{3,4}$. Little is known about the exact pathophysiological mechanisms that lead to late coronary stent thrombosis and it is generally believed that an accumulation of several distinct, but often overlapping candidate pathological pathways including alterations involved in inflammation, thrombosis (platelet biology, thrombin generation, coagulation), lipoprotein metabolism, calcification, vascular remodeling (smooth muscle cell function), endothelial function and oxidative stress are involved 5 .

The novel, reversible, direct-acting $\mathrm{P}_{2} \mathrm{Y}_{12}$-receptor antagonist cangrelor decreased the magnitude of on-treatment platelet reactivity in clopidogrel-treated patients undergoing elective $\mathrm{PCI}$. Furthermore, the degree of interindividual variation in on-treatment platelet reactivity was clearly attenuated ${ }^{6}$. The clinical evidence supporting the proof of concept that a stronger suppression of platelet function results in an improved clinical outcome was provided by the TRITON and PLATO studies ${ }^{7}$. . Although the decrease in thrombotic events was accompanied by an expected increase in bleeding complications for both prasugrel and ticagrelor, a comprehensive analysis of events in TRITON demonstrated a net clinical benefit in favour of prasugrel ${ }^{8}$.

Platelet function tests are often used to quantify the response to clopidogrel. Pre-analytical variables can affect the test result, including the anticoagulant in which blood is collected after withdrawal . Importantly, cut-offs used for prediction of clinical outcome are only of value when appropriate methods of blood withdrawal are used and sample preparation steps are cautiously taken care of. The direct thrombin-antagonists PPACK and hirudin showed a significant lower on-treatment platelet reactivity compared to the more commonly used citrate ${ }^{10,11}$. Therefore, cut-offs for the prediction of clinical outcome of clopidogrel-treated patients defined in citrate anticoagulated blood, cannot be considered valid when blood is anticoagulated using PPACK or hirudin. 


\section{WHICH PLATELET FUNCTION TEST IS PREFERRED?}

A series of platelet function tests developed to measure the response to clopidogrel has become available in recent years ${ }^{9,12}$. Although associations of individual tests with clinical outcome had been studied previously, no direct comparison between different tests was available. We compared six platelet function tests commonly used and well-described in the literature with respect to the correlation of test results with plasma active metabolite levels after a $600 \mathrm{mg}$ loading dose of clopidogrel. The aggregation-based light transmittance aggregometry (LTA; using $20 \mu \mathrm{mol} / \mathrm{L}$ ADP as the agonist), the VerifyNow ${ }^{\circledR} \mathrm{P}_{2} \mathrm{Y}_{12}$-assay and the flowcytometric VASP-assay correlated best with the peak plasma levels of the active metabolite of clopidogrel, with similar correlation coefficients ${ }^{13}$. Subsequently we evaluated a series of tests regarding their capability to predict one-year clinical outcome in clopidogrel-treated patients undergoing elective PCl in the POPular-study. The aggregationbased tests LTA (using both 5 and $20 \mu \mathrm{mol} / L$ ADP as the agonist), the VerifyNow ${ }^{\circledR} \mathrm{P}_{2} \mathrm{Y}_{12}$-assay and the PlateletWorks ADP-assay significantly predicted clinical outcome ${ }^{2}$. The VASP-assay was not included in this study, since it is needs to be performed at the laboratory, is labour-intensive and therefore not suitable for clinical monitoring of clopidogrel respons $\mathrm{e}^{14}$. Based on their correlation with plasma levels of the active metabolite of clopidogrel and clinical outcome, aggregation-based tests are preferred when measuring an individual's magnitude of on-treatment platelet reactivity. In particular the VerifyNow ${ }^{\circledR} \mathrm{P}_{2} \mathrm{Y}_{12}$-assay appears valuable for use in personalised treatment approaches, since it is a true point-of-care test and clinical studies have repeatedly and consistently demonstrated significant relations with clinical outcome, with ROC-curve analysis revealing very similar optimal cut-off values in several independent study cohorts ${ }^{2,15-18}$. Of the evaluated shear-stress based platelet function tests only the novel PFA-100 assay $P_{2} Y$ Innovance showed promising results for measuring the effects of clopidogrel ${ }^{2,13}$.

\section{GENETIC POLYMORPHISM OF THE P2 $\mathrm{Y}_{12}$-RECEPTOR}

Several years after the identification of the $\mathrm{P}_{2} \mathrm{Y}_{12}$-receptor, Fontana et al. were the first to investigate the clinical relevance of polymorphisms of the gene encoding the $\mathrm{P}_{2} \mathrm{Y}_{12}$-receptor. ADP-induced platelet aggregation was higher in healthy subjects carrying the $\mathrm{P}_{2} \mathrm{Y}_{12}$-receptor $\mathrm{H}_{2}$-haplotype and patients with peripheral arterial disease (PAD) more frequently carried the $\mathrm{H}$ 2-haplotype than matched controls ${ }^{19}, 20$. In the following years several research groups have studied the potential association of $\mathrm{H}_{2}$-haplotype and clopidogrel response, though with ambiguous results ${ }^{21}$. Of note, the $\mathrm{H}_{2}$-haplotype was not a true haplotype but a combination of 4 SNPs of the $\mathrm{P}_{2} \mathrm{Y}_{12}$-receptor gene that were in complete linkage disequilibrium and cover only part of the $\mathrm{P}_{2} \mathrm{Y}_{12}$-receptor gene ${ }^{20}$. In contrast, we used a comprehensive, haplotype-based approach to study common variation in the complete $\mathrm{P}_{2} \mathrm{Y}_{12}$-receptor gene and its flanking regions including the promoter and $3^{\prime}$-untranslated region ${ }^{22}$. Haplotype-tagging (ht) SNP rs6787801 was associated with a better drug-response both to cangrelor added in vitro to platelets of healthy volunteers as well as in clopidogrel-treated patients undergoing elective $\mathrm{PCl}^{22,23}$. Concordantly, on-clopidogrel platelet reactivity was lower in patients carrying haplotypes $\mathrm{E}$ and $\mathrm{F}$, containing the minor allele of htSNP rs678780122. The response to cangrelor was not lower for haplotypes $E$ and $F$, but was attenuated in carriers of haplotypes $C$ and $D$ that respectively include rs2046934 (part of the H2-haplotype identified by Fontana et al.) and rs9859552, which were also 
associated with the effects of cangrelor in single-htSNP analysis ${ }^{23}$. Discrepancies between cangrelor and clopidogrel with respect to the effects of $\mathrm{P}_{2} \mathrm{Y}_{12}$-receptor haplotypes may be attributed to a distinct interaction with the $\mathrm{P}_{2} \mathrm{Y}_{12}$-receptor or other population studied (i.e. healthy volunteers versus patients with established cardiovascular disease $)^{24}$. It is unclear how genetic variation in the $\mathrm{P}_{2} \mathrm{Y}_{12}$-receptor results in an altered response to $\mathrm{P}_{2} \mathrm{Y}_{12}$-inhibitors. The observed associations may be based on structural changes of the $\mathrm{P}_{2} \mathrm{Y}_{12}$-receptor resulting in either altered binding of ADP or interference with interaction of cangrelor and clopidogrel with the $\mathrm{P}_{2} \mathrm{Y}_{12}$-receptor, or modified transcriptional activity.

Since htSNP rs6787801 is located within the promoter region of the $\mathrm{P}_{2} \mathrm{Y}_{12}$-receptor gene, the latter explanation sounds plausible for associations of this polymorphism. The in vitro and ex vivo established relation of $\mathrm{P}_{2} \mathrm{Y}_{12}$-receptor gene variants and the response to $\mathrm{P}_{2} \mathrm{Y}_{12}$-antagonists seemed promising. Results of a study linking genetic variation of the target receptor to clinical outcome were however disappointing. Though odds ratios for atherothrombotic and bleeding events deviated from 1 in the expected directions, no significant clinical consequences could be established during one year followup of clopidogrel-treated patients undergoing elective $\mathrm{PCl}^{25}$. It has become clear that the interindividual variation in on-treatment platelet reactivity in clopidogrel-treated patients is mainly attributable to pharmacokinetic factors, including drug-drug interactions and genetic polymorphisms interfering with the gastrointestinal absorption of clopidogrel and transformation into the active metabolite ${ }^{26,27}$. The resulting variable plasma levels of the active metabolite of clopidogrel may blur the potential association between $\mathrm{P}_{2} \mathrm{Y}_{12}$-receptor genetics and on-treatment platelet reactivity. Nonetheless, at the present time there is no clue to consider genetic variation of the $\mathrm{P}_{2} \mathrm{Y}_{12}$-receptor as a tool for personalizing clopidogrel therapy.

\section{ROLE OF CYP $2 \mathrm{C}_{19}$}

The hepatic enzyme $\mathrm{CYP}_{2} \mathrm{C}_{19}$ has been suggested to be involved in both steps of the metabolic activation of clopidogrel, rendering it of significant importance for the determination of clopidogrel response ${ }^{28}$. Polymorphism of the gene encoding $\mathrm{CYP}_{2} \mathrm{C}_{19}$ comprises both gain-of-function ( $\left.\mathrm{CYP}_{2} \mathrm{C}_{19}{ }^{*} 17\right)$ as well as loss-of-function alleles, with $\mathrm{CYP}_{2} \mathrm{C}_{19}{ }_{2}$ as the most prevalent loss-of-function allele carried by more than $95 \%$ of Caucasian people ${ }^{28,29}$. A series of studies have shown that patients carrying at least one loss-of-function allele exhibit lower levels of the active metabolite of clopidogrel, higher ontreatment platelet reactivity and a higher rate of thrombotic events than patients with the wildtype $\mathrm{CYP}_{2} \mathrm{C}_{19}$ genotype ${ }^{28,30,31}$. Few studies demonstrated that patients who carry the gain-of-function variant $\mathrm{CYP}_{2} \mathrm{C}_{19}{ }_{17}$ are at greater risk of bleeding during clopidogrel treatment ${ }^{32,33}$. A genome-wideassociation study revealed $\mathrm{CYP}_{2} \mathrm{C}_{19}{ }^{*} 2$ as the genetic variant with the strongest contribution to ADPinduced platelet reactivity in clopidogrel-treated patients in a cohort of healthy Amish people ${ }^{34}$. Several large clinical investigations have however questioned the role of $\mathrm{CYP}_{2} \mathrm{C}_{19} *_{2}$ as a causal factor of variation in clopidogrel response since these studies did not find an effect of $\mathrm{CYP}_{2} \mathrm{C}_{1}$ * $_{2}$ on long-term clinical outcome ${ }^{33}, 35$. This suspicion was strengthened by data showing that administration of up to 4 times a $600 \mathrm{mg}$ loading dose of clopidogrel in patients with HPR resulted in a similar percentage of patients maintaining HPR after the $4^{\text {th }}$ loading dose for all $\mathrm{CYP}_{2} \mathrm{C}_{19}{ }^{*} 2$-genotypes ${ }^{36}$. Since the $\mathrm{CYP}_{2} \mathrm{C}_{19}$ *2-allele results in non-functional protein without catalytic activity, apparently other metabolisation routes sufficed to generate enough active metabolite to produce on-treatment platelet reactivity below the level of $\mathrm{HPR}$ in $\mathrm{CYP}_{2} \mathrm{C}_{1} 9^{*} 2$-homozygotes ${ }^{29,30}$. In the POPular-study we showed a 
significant correlation between (high) on-treatment platelet reactivity and $\mathrm{CYP}_{2} \mathrm{C}_{1}$ * $_{2}$ genotype. However, $\mathrm{CYP}_{2} \mathrm{C}_{1}{ }^{*}{ }_{2}$ explained merely $5 \%$ of the total variation in on-treatment platelet reactivity, compared to up to $17 \%$ of variation that could be attributed to the combination of clinical variables and $\mathrm{CYP}_{2} \mathrm{C}_{19}{ }^{2} 2^{37}$. Furthermore, using in vitro human microsome preparations expressing $\mathrm{CYP}_{2} \mathrm{C}_{19}$ we found no evidence of direct involvement of $\mathrm{CYP}_{2} \mathrm{C}_{19}$ in clopidogrel metabolism ${ }^{38,39}$. The reason for the discrepancy between previous studies showing a significant contribution of $\mathrm{CYP}_{2} \mathrm{C}_{1} 9$ and our metabolomics study indicating no direct role for $\mathrm{CYP}_{2} \mathrm{C}_{1} 9$ in clopidogrel metabolism is left to conjecture at this moment. There may be a limited role for a difference in methodology, since we used a $600 \mathrm{mg}$ loading dose of clopidogrel whereas others studied platelet reactivity in patients on maintenance therapy ${ }^{34}$. Bertrand-Thiébault et al. demonstrated that $\mathrm{CYP}_{2} \mathrm{C}_{19}{ }^{*} 2$ is inversely associated with plasma levels of inflammation markers $4^{\circ}$. Given the evidence that on-treatment platelet reactivity is positively correlated with levels of inflammation markers and that coronary artery disease and stent thrombosis are associated with increased levels of inflammation markers, this nourishes the hypothesis that $\mathrm{CYP}_{2} \mathrm{C}_{1}{ }^{*} 2$ exerts its effects on on-treatment platelet reactivity indirectly via inflammatory modulation ${ }^{4-45}$. Whether $\mathrm{CYP}_{2} \mathrm{C}_{19}$ is directly involved in the metabolism of clopidogrel or indirectly affects on-treatment platelet reactivity via an inflammatory pathway does not alter the current body of evidence that $\mathrm{CYP}_{2} \mathrm{C}_{19}{ }^{*}$-genotype is associated with an inferior response to clopidogrel. Therefore, $\mathrm{CYP}_{2} \mathrm{C}_{1}$ \%*2-genotype should be considered as one determinant of on-treatment platelet reactivity, though keeping in mind that the effects are modest.

\section{A NOVEL PLAYER: PARAOXONASE-1}

By comprehensive metabolomic profiling we mapped the complete metabolism of clopidogrel and its active and inactive metabolites. In vitro human microsome preparations expressing over 30 enzymes were used to investigate the participation of these enzymes in clopidogrel metabolism. The most important finding was that the transformation of the inactive intermediate metabolite 2-oxoclopidogrel into the active thiol metabolite of clopidogrel was catalysed by the plasma-esterase paraoxonase-1 (PON-1). Furthermore, this metabolisation step was rate-limiting rendering PON-1 the most relevant enzyme of clopidogrel metabolism. Patients with the lowest PON-1-activity or carrying the reducedfunction Q-allele of the PON-1 Q192R-genotype demonstrated lower levels of the active metabolite, higher on-treatment platelet reactivity and more often incurred stent thrombosis than patients with high PON-1 activity39.

The observed association between $\mathrm{PON}_{1} \mathrm{Q}_{1}$ 22R-genotype with on-treatment platelet reactivity was confirmed by Campo et al., but other groups could not replicate the relation of PON-1 genetic variation with on-treatment platelet reactivity nor clinical outcome in clopidogrel-treated patients ${ }^{46-49}$. The origin of this discrepancy remains unclear. Therefore, implications for the future role of PON-1 in personalized antiplatelet therapy should be formulated carefully.

\section{GENOTYPE VERSUS PHENOTYPE TO TAILOR ANTIPLATELET THERAPY}

Therapeutic drug monitoring of clopidogrel response by direct measurement of plasmalevels of the active metabolite requires complex sample preparation proceedings and analytics and is therefore 
not suitable for incorporation in clinical practice ${ }^{50}$. Traditionally, clopidogrel response was quantified using platelet function tests presenting the quantitative phenotype on-treatment platelet reactivity. However, the identification of genetic variants contributing to HPR and thrombotic events in clopidogrel-treated patients has raised an ongoing discussion on whether genotyping or phenotyping is preferred in the decision making for alternate antiplatelet treatment strategies in the individual patient. Arguments to advocate the use of genotyping include an easy to interpret result - the patient either does or does not carry a genetic polymorphism - and an inherent test result that is stable over time and through different stages of disease ${ }^{51}$. Although the human genome is considered the human's blueprint, at the same time the genetic variant is as far from the final phenotype as possible ${ }^{52}$. The relevance of the latter statement is supported by the often disappointing strength of genotypephenotype relations for multifactorial clinical phenotypes ${ }^{53}$. Besides an altered DNA-makeup, the phenotype can be influenced by varying levels of transcription of DNA into RNA, translation of RNA into protein, post-translational modification of proteins, and regulation at all levels from DNA to final phenotype including epigenetic regulation ${ }^{54}$. In monogenetic diseases genotyping may be of utmost importance and can often be used with a high degree of certainty for diagnosis. However, this may become difficult with polygenetic diseases and even more so when disease is a result of complex systems biology55.

Whereas a genotype is stable over time and through different stages of disease, on-treatment platelet reactivity in clopidogrel-treated patients is not. Besides $\mathrm{CYP}_{2} \mathrm{C}_{1}$ *2-genotype several independent clinical determinants of HPR are increasing age, body mass index (BMI), diabetes mellitus, acute coronary syndrome, and medication interfering with clopidogrel response such as statins, calcium channel blockers and proton pump inhibitors ${ }^{21,37,56-59}$. It is unclear whether these clinical variables affect either platelet reactivity, generation of the active metabolite of clopidogrel or both. Furthermore, due to variable baseline platelet reactivity, a response that is stable over time and equal among individuals can result in a broad range of on-treatment platelet reactivity ${ }^{60,61}$. Therefore, monitoring clopidogrel response using a phenotypic determinant might approach reality more closely than the determination of one single genetic variant. However, no direct comparison between genotyping and phenotyping with regard to clopidogrel efficacy is available currently.

\section{TOWARDS PERSONALISED ANTIPLATELET THERAPY: WHERE DO WE STAND \& FUTURE PERSPECTIVES}

Currently two strategies are available to guide the change of clopidogrel to alternative, more potent antiplatelet therapy in the individual patient treated with clopidogrel: genotyping of enzymes involved in clopidogrel biotransformation and phenotyping by measurement of on-treatment platelet reactivity with platelet function tests. Implementation of personalized antiplatelet therapy in clinical practice requires a diagnostic test that is capable of identifying patients who will benefit from more potent antiplatelet therapy with a sufficient degree of certainty. In prospective clinical studies, HPR demonstrated a high negative predictive value for recurrent thrombotic events of about $95 \%$, but the positive predictive value does not exceed $15 \%$ in most studies; thus patients without HPR are not at increased risk of events but most of the patients who do exhibit HPR will also not incur an event. Of note, similar positive predictive values account for $\mathrm{CYP}_{2} \mathrm{C}_{1}$ g-genotyping with negative predictive values of approximately $90 \%{ }^{2,62}$. The use of a model that incorporates both the response to clopidogrel 
(either genotype or phenotype) complemented by other determinants of clinical outcome of clopidogrel-treated patients to differentiate within the group of patients with HPR, may further select patients at high risk and hence improve the positive predictive value of tailoring strategies.

Practical requirements for both strategies to enable tailoring of clopidogrel therapy are that tests should be easy to use, have a short test-to-result time and be of limited costs. Though for both strategies point-of-care tests are available, platelet function tests (especially the VerifyNow ${ }^{\circledR}$-assay) are less complex and have a test-to-result time of 15 minutes compared to at least 2 hours for genotyping and therefore seem to be advantageous over genotyping. For both strategies, the costaspect is problematic to date, since especially point-of-care tests are expensive and health-care insurances do not cover the use of either method yet.

Personalised therapy is aimed at increasing both efficacy as well as safety of therapy. The safety of clopidogrel therapy is hampered by the occurrence of bleeding, which is still the underdog in the development of personalised treatment approaches. Recently a relation was demonstrated between bleeding and low on-treatment platelet reactivity and $\mathrm{CYP}_{2} \mathrm{C}_{1}$ **17-genotype and also PON-1-genotype was associated with major bleeding $32,33,39,63$. However, the amount of data is limited as compared to the available evidence on determinants of thrombotic events. Potentially, methods used to measure clopidogrel response aimed at prediction of thrombotic events may lack sufficient sensitivity or specificity for prediction of bleeding. Also, the detection of - especially minor - bleeding during followup is challenging. Furthermore, studies may be hampered by a lack of adequate power to detect the association of clopidogrel response with bleeding, since they were powered for the relation of platelet reactivity with the more frequent occurring thrombotic events.

Patients with HPR have an approximately 2 -fold higher risk of recurrent thrombotic events compared to patients without $\mathrm{HPR}^{2}$. For stent thrombosis, especially the occurrence of early events within 30 days post-stenting is associated with higher on-treatment platelet reactivity ${ }^{3 / 4}$. However, when also myocardial infarction and cardiovascular death are taken into account, event-free survival curves separate in a linear fashion continuously during 1-year ${ }^{2}$. Preliminary results of a meta-analysis of individual patient data show that this tendency continues for at least 2 years, despite discontinuation of clopidogrel therapy at 1 year post-stenting according to the guidelines ${ }^{64}$. This observation suggests that the benefit from temporary platelet suppression by clopidogrel results in an ongoing protection against longer term thrombotic events. This further strengthens the importance of tailoring antiplatelet therapy to the individual patient, since the benefits of matching the proper drug to the right patient proceed even long-term after discontinuation of drug-treatment.

Efforts made to improve clinical outcome by tailoring antiplatelet therapy to the individual patient have been disappointing until now. The GRAVITAS-study randomized 2214 patients with HPR based on measurement of platelet reactivity $12-24$ hours post- $\mathrm{PCl}$ with the VerifyNow ${ }^{\circledR} \mathrm{P}_{2} \mathrm{Y}_{12}$-assay to receive either the standard dose of $75 \mathrm{mg}$ clopidogrel daily or a $600 \mathrm{mg}$ loading dose of clopidogrel followed by a double maintenance dose of $150 \mathrm{mg}$ daily. After 6 months of treatment, none of the thrombotic or bleeding endpoints differed significantly between patients treated with single or double maintenance dose of clopidogrel ${ }^{65}$. The lack of benefit of guiding antiplatelet therapy based on platelet reactivity measurements in the GRAVITAS-trial may be related to the lower than anticipated event rates in a relatively low-risk group of patients with stable angina pectoris. The notion that the event rate was only $2.3 \%$ after 6 months follow-up does not leave much room for improvement. Furthermore, the relatively weak augmentation of antiplatelet therapy to double maintenance dose of $150 \mathrm{mg}$ clopidogrel daily has been associated with only a modest reduction of on-treatment platelet reactivity ${ }^{66}$. 


\section{General discussion}

The TRIGGER-PCl-study aimed to alter antiplatelet therapy to prasugrel in patients exhibiting HPR as defined by the VerifyNow ${ }^{\circledR} \mathrm{P}_{2} \mathrm{Y}_{12}$-assay in a total of 2160 patients undergoing elective $\mathrm{PCl}$, but was prematurely halted because of a low event-rate ${ }^{67}$. Potentially, tailoring antiplatelet therapy should be confined to high-risk patients presenting with ACS, diabetes mellitus or other comorbidity known to increase the risk for recurrent thrombotic events. Furthermore, it may be that a clinically significant effect can only be obtained when using an antiplatelet regimen that shows substantially higher suppression of platelet reactivity than $75 \mathrm{mg}$ maintenance dose of clopidogrel. The novel antiplatelet drugs prasugrel and ticagrelor may provide a suitable alternative for patients with a poor response to clopidogrel, since these agents exhibit a faster onset of action, a more potent antiplatelet profile, no influence of $\mathrm{CYP}_{2} \mathrm{C}_{19}$-genotype, and an overall smaller degree of interindividual variation $33,68-70$. Furthermore, novel antiplatelet agents currently under development target other players in platelet activation and aggregation including von Willebrand factor (ARC1779, ALX-0081 and AJW200), the thromboxane receptor (terutroban) and the thrombin-receptor PAR-1 (SCH 530348, SCH 205831, SCH 602539 and $\mathrm{E}_{5555)^{71}}$. Since on-treatment platelet reactivity is associated with clinical outcome and baseline platelet reactivity and clinical variables are important determinants of on-treatment platelet reactivity, it may be that other types of antiplatelet drugs can decrease the burden of thrombotic events after $\mathrm{PCl}$ as well as do $\mathrm{P}_{2} \mathrm{Y}_{12}$-antagonists.

In conclusion, we are on the way towards personalised antiplatelet therapy. Several important steps have been made, including the identification of determinants of HPR and the evaluation of methods to monitor clopidogrel response. Available strategies should be further refined using simple algorithms that aid physicians in their interpretation and use of tailoring strategies, to enable tailoring of antiplatelet therapy to the individual patient in the near future. 


\section{REFERENCES}

1. Serebruany VL, Steinhubl SR, Berger PB et al. Variability in platelet responsiveness to clopidogrel among 544 individuals. J Am Coll Cardiol. 2005;45(2):246-251.

2. Breet NJ, van Werkum JW, Bouman HJ et al. Comparison of platelet function tests in predicting clinical outcome in patients undergoing coronary stent implantation. JAMA.303(8):754-762.

3. Bouman HJ, JW van Werkum, Breet NJ et al. A case-control study on platelet reactivity in patients with coronary stent thrombosis. J Thromb Haemost.9(5):909-916.

4. Sibbing D, Braun S, Morath T et al. Platelet reactivity after clopidogrel treatment assessed with point-of-care analysis and early drug-eluting stent thrombosis. J Am Coll Cardiol. 2009;53(10):849-856.

5. Zwart B, van Werkum JW, Heestermans AA, Ten Berg JM. Coronary stent thrombosis in the current era: challenges and opportunities for treatment. Curr Treat Options Cardiovasc Med.12(1):46-57.

6. Bouman HJ, van Werkum JW, Hackeng CM et al. Cangrelor increases the magnitude of platelet inhibition and reduces interindividual variability in clopidogrel-pretreated subjects. Neth Heart J. 2009;17(5):195-198.

7. Wallentin L, Becker RC, Budaj A et al. Ticagrelor versus clopidogrel in patients with acute coronary syndromes. N Engl J Med. 2009;361(11):1045-1057.

8. Wiviott SD, Braunwald E, McCabe $\mathrm{CH}$ et al. Prasugrel versus clopidogrel in patients with acute coronary syndromes. N Engl J Med. 2007;357(20):2001-2015.

9. van Werkum JW, Hackeng CM, Smit JJ et al. Monitoring antiplatelet therapy with point-of-care platelet function assays: a review of the evidence. Future Cardiol. 2008;4(1):33-55.

10. Bouman HJ, van Werkum JW, Hackeng CM et al. The importance of anticoagulant agents in measuring platelet aggregation in patients treated with clopidogrel and aspirin. J Thromb Haemost. 2008;6(6):1040-1042.

11. Pittens CA, Bouman HJ, van Werkum JW et al. Comparison between hirudin and citrate in monitoring the inhibitory effects of $\mathrm{P}_{2} \mathrm{Y}_{12}$ receptor antagonists with different platelet function tests. J Thromb Haemost. 2009;7(11):1929-1932.

12. Michelson AD. Methods for the measurement of platelet function. Am J Cardiol. 2009;103(3 Suppl):20A-26A.

13. Bouman HJ, Parlak E, van Werkum JW et al. Which platelet function test is suitable to monitor clopidogrel responsiveness? A pharmacokinetic analysis on the active metabolite of clopidogrel. J Thromb Haemost.8(3):482-488.

14. Aleil B, Ravanat C, Cazenave JP et al. Flow cytometric analysis of intraplatelet VASP phosphorylation for the detection of clopidogrel resistance in patients with ischemic cardiovascular diseases. J Thromb Haemost. 2005;3(1):85-92.

15. van Werkum JW, Harmsze AM, Elsenberg EH et al. The use of the VerifyNow system to monitor antiplatelet therapy: a review of the current evidence. Platelets. 2008;19(7):479-488.

16. Marcucci R, Gori AM, Paniccia R et al. Cardiovascular death and nonfatal myocardial infarction in acute coronary syndrome patients receiving coronary stenting are predicted by residual platelet reactivity to ADP detected by a point-of-care assay: a 12-month follow-up. Circulation. 2009;119(2):237-242.

17. Patti G, Nusca A, Mangiacapra F et al. Point-of-care measurement of clopidogrel responsiveness predicts clinical outcome in patients undergoing percutaneous coronary intervention results of the ARMYDA-PRO (Antiplatelet therapy for Reduction of MYocardial Damage during Angioplasty-Platelet Reactivity Predicts Outcome) study. J Am Coll Cardiol. 2008;52(14):1128-1133.

18. Price MJ, Endemann S, Gollapudi RR et al. Prognostic significance of post-clopidogrel platelet reactivity assessed by a point-of-care assay on thrombotic events after drug-eluting stent implantation. Eur Heart J. 2008;29(8):992-1000.

19. Fontana $\mathrm{P}, \mathrm{Gaussem} \mathrm{P}_{1}$ Aiach $\mathrm{M}$ et al. $\mathrm{P}_{2} \mathrm{Y}_{12} \mathrm{H}_{2}$ haplotype is associated with peripheral arterial disease: a casecontrol study. Circulation. 2003;108(24):2971-2973. 


\section{General discussion}

20. Fontana P, Dupont A, Gandrille S et al. Adenosine diphosphate-induced platelet aggregation is associated with $\mathrm{P}_{2} \mathrm{Y}_{12}$ gene sequence variations in healthy subjects. Circulation. 2003;108(8):989-995.

21. Ancrenaz V, DaaliY, Fontana $P$ et al. Impact of genetic polymorphisms and drug-drug interactions on clopidogrel and prasugrel response variability. Curr Drug Metab.11(8):667-677.

22. Rudez G, Bouman HJ, van Werkum JW et al. Common variation in the platelet receptor $P_{2} R_{12}$ gene is associated with residual on-clopidogrel platelet reactivity in patients undergoing elective percutaneous coronary interventions. Circ Cardiovasc Genet. 2009;2(5):515-521.

23. Bouman HJ, van Werkum JW, Rudez G et al. The influence of variation in the $\mathrm{P}_{2} \mathrm{Y}_{12}$ receptor gene on in vitro platelet inhibition with the direct $\mathrm{P}_{2} \mathrm{Y}_{12}$ antagonist cangrelor. Thromb Haemost.103(2):379-386.

24. Husted S, van Giezen JJ. Ticagrelor: the first reversibly binding oral $P_{2} Y_{12}$ receptor antagonist. Cardiovasc Ther. 2009; $27(4): 259-274$

25. Bouman HJ, Van Werkum JW, Rudez G et al. The relevance of $P_{2} Y_{12}$-receptor gene variation for the outcome of clopidogrel-treated patients undergoing elective coronary stent implantation: a clinical follow-up. Submitted. 2011

26. Bates ER, Lau WC, Angiolillo DJ. Clopidogrel-drug interactions. J Am Coll Cardiol.57(11):1251-1263.

27. Campo G, Miccoli M, Tebaldi M et al. Genetic determinants of on-clopidogrel high platelet reactivity. Platelets.22(6):399-407.

28. Mega JL, Close SL, Wiviott SD et al. Cytochrome p-450 polymorphisms and response to clopidogrel. N Engl J Med. 2009;360(4):354-362.

29. Man M, Farmen M, Dumaual C et al. Genetic variation in metabolizing enzyme and transporter genes: comprehensive assessment in 3 major East Asian subpopulations with comparison to Caucasians and Africans. J Clin Pharmacol.50(8):929-940.

30. Hulot JS, Bura A, Villard E et al. Cytochrome $\mathrm{P}_{45}{ }_{2} \mathrm{C}_{19}$ loss-of-function polymorphism is a major determinant of clopidogrel responsiveness in healthy subjects. Blood. 2006;108(7):2244-2247.

31. Trenk D, Hochholzer W, Fromm MF et al. Cytochrome $\mathrm{P}_{450} 2 \mathrm{C}_{19} 68_{1} \mathrm{G}>\mathrm{A}$ polymorphism and high on-clopidogrel platelet reactivity associated with adverse 1-year clinical outcome of elective percutaneous coronary intervention with drug-eluting or bare-metal stents. J Am Coll Cardiol. 2008;51(20):1925-1934.

32. Sibbing D, Koch W, Gebhard D et al. Cytochrome $2 C_{1} *_{1} 17$ allelic variant, platelet aggregation, bleeding events, and stent thrombosis in clopidogrel-treated patients with coronary stent placement. Circulation. 2010;121(4):512-518.

33. Wallentin $L$, James $S$, Storey RF et al. Effect of $C_{Y} P_{2} C_{19}$ and $A B C B 1$ single nucleotide polymorphisms on outcomes of treatment with ticagrelor versus clopidogrel for acute coronary syndromes: a genetic substudy of the PLATO trial. Lancet.376(9749):1320-1328.

34. Shuldiner AR, O'Connell JR, Bliden KP et al. Association of cytochrome $\mathrm{P}_{450}{ }_{2} \mathrm{C}_{1} 9$ genotype with the antiplatelet effect and clinical efficacy of clopidogrel therapy. JAMA. 2009;302(8):849-857.

35. Pare G, Mehta SR, Yusuf S et al. Effects of $\mathrm{CYP}_{2} \mathrm{C}_{19}$ genotype on outcomes of clopidogrel treatment. N Engl J Med.363(18):1704-1714.

36. Bonello L, Armero S, Ait Mokhtar O et al. Clopidogrel loading dose adjustment according to platelet reactivity monitoring in patients carrying the $2 \mathrm{C}_{19} *_{2}$ loss of function polymorphism. J Am Coll Cardiol.56(20):1630-1636.

37. Bouman HJ, Harmsze AM, van Werkum JW et al. Variability in on-treatment platelet reactivity explained by $\mathrm{CYP}_{2} \mathrm{C}_{19}{ }^{*} 2$ genotype is modest in clopidogrel pretreated patients undergoing coronary stenting. Heart.

38. Taubert D, Bouman HJ, van Werkum JW. Cytochrome P-450 polymorphisms and response to clopidogrel. N Engl J Med. 2009;360(21):2249-2250; author reply 2251.

39. Bouman HJ, Schomig E, van Werkum JW et al. Paraoxonase-1 is a major determinant of clopidogrel efficacy. Nat Med.17(1):110-116. 
40. Bertrand-Thiebault C, Berrahmoune H, Thompson A et al. Genetic Polymorphism of CYP $2 C_{19}$ gene in the Stanislas cohort. A link with inflammation. Ann Hum Genet. 2008;72(Pt 2):178-183.

41. SteinhubI SR, Badimon JJ, Bhatt DL et al. Clinical evidence for anti-inflammatory effects of antiplatelet therapy in patients with atherothrombotic disease. Vasc Med. 2007;12(2):113-122.

42. Libby P, Simon DI. Inflammation and thrombosis: the clot thickens. Circulation. 2001;103(13):1718-1720.

43. Niccoli G, Montone RA, Ferrante G, Crea F. The evolving role of inflammatory biomarkers in risk assessment after stent implantation. J Am Coll Cardiol.56(22):1783-1793

44. Muller K, Aichele S, Herkommer M et al. Impact of inflammatory markers on platelet inhibition and cardiovascular outcome including stent thrombosis in patients with symptomatic coronary artery disease. Atherosclerosis. $213(1): 256-262$.

45. Gori AM, Cesari F, Marcucci R et al. The balance between pro- and anti-inflammatory cytokines is associated with platelet aggregability in acute coronary syndrome patients. Atherosclerosis. 2009;202(1):255-262.

46. Fontana P, James R, Barazer I et al. Relationship between paraoxonase-1 activity, its Q192R genetic variant and clopidogrel responsiveness in the ADRIE study. JThromb Haemost.9(8):1664-1666.

47. Rideg O, Komocsi A, Magyarlaki T et al. Impact of genetic variants on post-clopidogrel platelet reactivity in patients after elective percutaneous coronary intervention. Pharmacogenomics.

48. Sibbing D, Koch W, Massberg S et al. No association of paraoxonase-1 Q192R genotypes with platelet response to clopidogrel and risk of stent thrombosis after coronary stenting. Eur Heart J.32(13):1605-1613.

49. Trenk D, Hochholzer W, Fromm MF et al. Paraoxonase-1 Q192R Polymorphism and Antiplatelet Effects of Clopidogrel in Patients Undergoing Elective Coronary Stent Placement. Circ Cardiovasc Genet.4(4):429-436.

50. Taubert D, Kastrati A, Harlfinger S et al. Pharmacokinetics of clopidogrel after administration of a high loading dose. Thromb Haemost. 2004;92(2):311-316.

51. Meyers DA. Genetics of asthma and allergy: what have we learned? J Allergy Clin Immunol.126(3):439-446; quiz 447-438.

52. Noble D. The Music of Life. Biology beyond Genes. 1st ed. New York: Oxford University Press Inc.; 2006.

53. Manolio TA, Collins FS, Cox NJ et al. Finding the missing heritability of complex diseases. Nature. 2009;461(7265):747-753.

54. Kitano H. Systems biology: a brief overview. Science. 2002;295(5560):1662-1664.

55. Noble D. Modeling the heart--from genes to cells to the whole organ. Science. 2002;295(5560):1678-1682.

56. van Werkum JW, TopcuY, Postma S et al. Effects of diabetes mellitus on platelet reactivity after dual antiplatelet therapy with aspirin and clopidogrel. Thromb Haemost. 2008;99(3):637-639.

57. Harmsze AM, Robijns K, van Werkum JW et al. The use of amlodipine, but not of P-glycoprotein inhibiting calcium channel blockers is associated with clopidogrel poor-response. Thromb Haemost.103(5):920-925.

58. Angiolillo DJ, Fernandez-Ortiz A, Bernardo E et al. Platelet aggregation according to body mass index in patients undergoing coronary stenting: should clopidogrel loading-dose be weight adjusted? J Invasive Cardiol. 2004;16(4):169-174.

59. Scalone G, Coviello I, Barone L et al. Evidence of increased platelet reactivity in the first six months after acute ST segment elevation myocardial infarction. Thromb Res.

6o. Samara WM, Bliden KP, Tantry US, Gurbel PA. The difference between clopidogrel responsiveness and posttreatment platelet reactivity. Thromb Res. 2005;115(1-2):89-94

61. Tantry US, Bliden KP, Gurbel PA. What is the best measure of thrombotic risks--pretreatment platelet aggregation, clopidogrel responsiveness, or posttreatment platelet aggregation? Catheter Cardiovasc Interv. 2005;66(4):597-598.

62. Fontana P, Bonvini RF, Roffi M et al. [Evaluating the biological efficacy of clopidogrel: genotype or phenotype?]. Rev Med Suisse.6(235):302-305 


\section{General discussion}

63. Sibbing D, Steinhubl SR, Schulz S et al. Platelet aggregation and its association with stent thrombosis and bleeding in clopidogrel-treated patients: initial evidence of a therapeutic window. J Am Coll Cardiol. 2010;56(4):317-318.

64. Brar S, Ten Berg JM, Marcucci R et al. Impact of platelet reactivity on clinical outcomes after percutaneous coronary intervention: collaborative meta-analysis of individual participant data. J Am Coll Cardiol. 2011:Accepted.

65. Price MJ, Berger PB, Teirstein PS et al. Standard- vs high-dose clopidogrel based on platelet function testing after percutaneous coronary intervention: the GRAVITAS randomized trial. JAMA.305(11):1097-1105.

66. von Beckerath N, Kastrati A, Wieczorek A et al. A double-blind, randomized study on platelet aggregation in patients treated with a daily dose of 150 or $75 \mathrm{mg}$ of clopidogrel for 30 days. Eur Heart J. 2007;28(15):18141819 .

67. Testing Platelet Reactivity In Patients Undergoing Elective Stent Placement on Clopidogrel to Guide Alternative Therapy With Prasugrel (TRIGGER-PCI); NCToog10299. Available at: www.clinicaltrials.gov. Accessed June 1 st 2011.

68. Gaglia MA, Jr., Manoukian SV, Waksman R. Novel antiplatelet therapy. Am Heart J.16o(4):595-604.

69. Tantry US, Bliden KP, Wei C et al. First analysis of the relation between $\mathrm{CYP}_{2} \mathrm{C}_{1} 9$ genotype and pharmacodynamics in patients treated with ticagrelor versus clopidogrel: the ONSET/OFFSET and RESPOND genotype studies. Circ Cardiovasc Genet.3(6):556-566.

70. Mega JL, Close SL, Wiviott SD et al. Genetic variants in $\mathrm{ABCB}_{1}$ and $\mathrm{CYP}_{2} \mathrm{C}_{1} 9$ and cardiovascular outcomes after treatment with clopidogrel and prasugrel in the TRITON-TIMI 38 trial: a pharmacogenetic analysis. Lancet.376(9749):1312-1319.

71. Siller-Matula JM, Krumphuber J, Jilma B. Pharmacokinetic, pharmacodynamic and clinical profile of novel antiplatelet drugs targeting vascular diseases. Br J Pharmacol.159(3):502-517. 


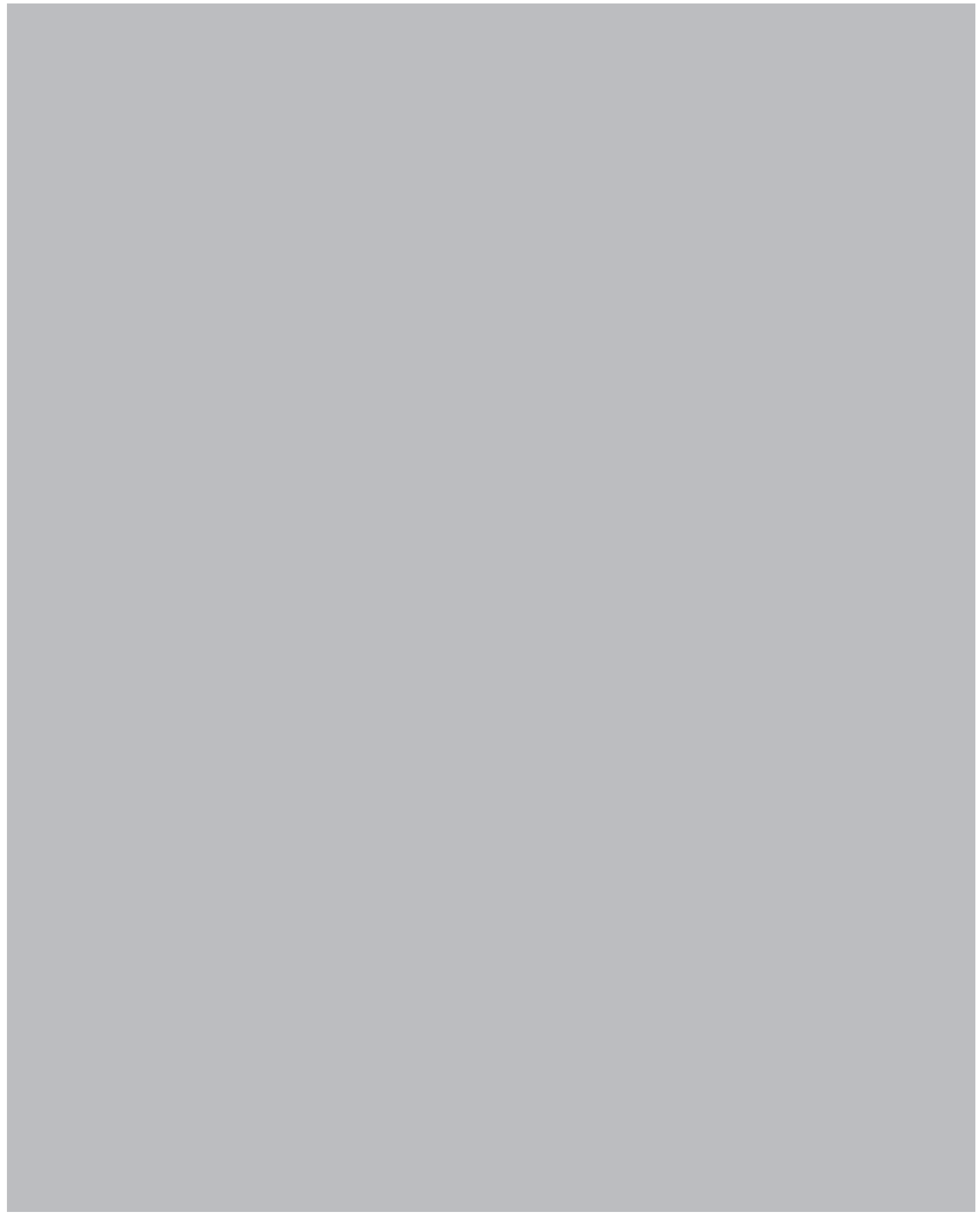


Nederlandse samenvatting 
De toevoeging van de bloedplaatjesaggregatieremmer clopidogrel aan behandeling met aspirine verlaagt het aantal trombotische complicaties in patiënten die een coronaire stentimplantatie ondergaan. Echter, een gemiddelde verbetering op populatieniveau betekent niet dat elke persoon evenveel baat heeft bij het gebruik van clopidogrel. Ongeveer $30 \%$ van de patiënten heeft namelijk een hoge plaatjesreactiviteit ondanks gebruik van clopidogrel (high on-treatment platelet reactivity) en daardoor een hoger risico van trombotische complicaties. Nieuwe bloedplaatjesremmers zoals prasugrel en ticagrelor, onderdrukken de bloedplaatjesreactiviteit sterker dan clopidogrel, wat de kans op trombotische complicaties verder verlaagt. Dit gaat echter ten koste van de veiligheid door een verhoogde kans op bloeding, de belangrijkste bijwerking van bloedplaatjesaggregatieremmers. Het individualiseren van bloedplaatjesremmende therapie beoogt met behulp van determinanten van de respons op clopidogrel de keuze voor een bloedplaatjesremmer te begeleiden, om zo de effectiviteit en veiligheid van bloedplaatjesremmende therapie te optimaliseren.

Deel 1 van dit proefschrift beschrijft high on-treatment platelet reactivity als een belangrijke risicofactor voor trombotische complicaties. In hoofdstuk 1 wordt beschreven dat patiënten met een vroege coronaire stenttrombose ( $\leq 30$ dagen na stentimplantatie) ondanks behandeling met clopidogrel en aspirine een hogere bloedplaatjesreactiviteit vertonen dan patiënten bij wie eerder ook een stent werd geïmplanteerd maar die geen stenttrombose kregen. Daarentegen resulteerde het gebruik van clopidogrel wel in normale plaatjesremming bij patiënten met late stenttrombose, hoewel deze patiëntgroep minder goed op aspirine reageerde en vaker een gecombineerde verminderde gevoeligheid voor aspirine en clopidogrel vertoonde. Cangrelor is een van de nieuw ontwikkelde bloedplaatjesremmers met een sterkere plaatjesremmende werking dan clopidogrel. Zoals beschreven in hoofdstuk 2, verlaagt cangrelor de bloedplaatjesreactiviteit en vermindert het de mate van interindividuele variatie in bloedplaatjesreactiviteit in met clopidogrel voorbehandelde patiënten die electieve stentimplantatie ondergaan. Het bewijs van het concept dat sterkere plaatjesremming het aantal trombotische complicaties verlaagt, werd geleverd door de TRITON en PLATO studies, waarin respectievelijk prasugrel en ticagrelor werden vergeleken met clopidogrel. Het bepalen of een patiënt voldoende reageert op clopidogrel door vast te stellen of er sprake is van high on-treatment platelet reactivity, vereist een uniform analyseprotocol omdat testgerelateerde variabelen de uiteindelijke mate van plaatjesreactiviteit beïnvloeden. Hoofdstuk 3 en 4 demonstreren dat het gebruik van de anticoagulantia hirudine en PPACK resulteert in een lager testresultaat vergeleken met citraat, het meest gebruikte anticoagulans om vroegtijdig stollen van bloed in de afnamebuis tegen te gaan. Daarom kunnen afkapwaarden die patiënten categoriseren naar hoge of normale plaatjesreactiviteit die werden vastgesteld voor bloedmonsters afgenomen in citraat, niet worden toegepast voor bloedmonsters afgenomen in andere anticoagulantia dan citraat.

Een veelvoud aan bloedplaatjesfunctietesten met het specifieke doel de respons op clopidogrel te meten, is tegenwoordig beschikbaar. In deel 2 van dit proefschrift wordt geïdentificeerd welke van de beschikbare testen bij voorkeur gebruikt dient te worden bij het individualiseren van bloedplaatjesremmende therapie. Plaatjesreactiviteit zoals gemeten met de op shear-stress gebaseerde IMPACT-R correleert niet met de op aggregatie gebaseerde, gouden standaard LTA en de flowcytometrische VASP-test in hoofdstuk 5. De op aggregatiegebaseerde LTA (met $20 \mu \mathrm{mol} / \mathrm{L}$ ADP als agonist) en de VerifyNow $\mathrm{P}_{2} \mathrm{Y}_{12}$-assay, evenals de flowcytometrische VASP-assay correleerden het best met maximale plasmaconcentraties van de actieve metaboliet van clopidogrel na inname van 
een oplaaddosis van $600 \mathrm{mg}$ door patiënten met stabiel coronairlijden (hoofdstuk 6). De prospectieve POPular-studie evalueerde een reeks plaatjesfunctietesten met betrekking tot hun vermogen tot het voorspellen van de klinische uitkomst van 1069 met clopidogrel en aspirine behandelde patiënten die een electieve stentimplantatie ondergingen. Hoofdstuk 7 laat zien dat de op aggregatie gebaseerde testen LTA (zowel 5 als $20 \mu \mathrm{mol} / \mathrm{L}$ ADP geïnduceerd), de VerifyNow $\mathrm{P}_{2} \mathrm{Y}_{12}$-assay en de PlateletWorks significant een bij benadering tweemaal zo groot risico op trombotische complicaties voorspelden. Geen van de onderzochte bloedplaatjesfunctietesten kon het optreden van bloedingen voorspellen. Op aggregatie gebaseerde testen hebben dus de voorkeur in het monitoren van clopidogrel behandeling.

In deel 3 werd onderzocht of de interindividuele diversiteit in bloedplaatjesreactiviteit toegeschreven kan worden aan polymorfisme van het gen dat codeert voor de $\mathrm{P}_{2} \mathrm{Y}_{12}$-receptor op bloedplaatjes. We gebruikten een uitgebreide benadering om $\mathrm{P}_{2} \mathrm{Y}_{12}$-haploytypes te relateren aan de respons op $\mathrm{P}_{2} \mathrm{Y}_{12}$ remming. Haplotypes $C$ en D waren geassocieerd met een slechtere in vitro respons op cangrelor in 254 gezonde personen, terwijl haplotypes E en F en hun gemeenschappelijke htSNP rs6787801 resulteerden in lagere plaatjesreactiviteit in 1069 met clopidogrel behandelde patiënten die electieve stentimplantatie ondergingen (hoofdstuk 8 en 9, respectievelijk). Dit laatste cohort werd gedurende 1 jaar vervolgd, maar de waargenomen lagere bloedplaatjesreactiviteit resulteerde niet in een significante afname van trombotische complicaties of toename van bloedingscomplicaties (hoofdstuk 10).

Deel 4 van dit proefschrift onderzoekt de plaats van farmacokinetische determinanten van de respons op clopidogrel. Omdat metabole omzetting naar een actieve metaboliet vereist is voor het bloedplaatjesremmend effect van clopidogrel, worden farmacokinetische variabelen gezien als de primaire bron van de interindividuele variatie in de respons op clopidogrel. Vooral het leverenzym $\mathrm{CYP}_{2} \mathrm{C}_{19}$ staat in de aandacht, omdat het betrokken zou zijn bij beide stappen van de metabole activatie van clopidogrel. Genetische varianten die resulteren in een verminderde functie van het enzym werden in eerdere onderzoeken in verband gebracht met lagere plasmalevels van de actieve metaboliet van clopidogrel, hogere plaatjesreactiviteit en meer trombotische complicaties in met clopidogrel behandelde patiënten. Hoofdstuk 11 laat zien dat het genetische polymorfisme $\mathrm{CYP}_{2} \mathrm{C}_{1} *_{2}$ - dat $95 \%$ van de genetische varianten resulterend in verminderde activiteit van $\mathrm{CYP}_{2} \mathrm{C}_{1}$ g representeert - slechts $5 \%$ verklaart van de interindividuele variatie in plaatjesreactiviteit in met clopidogrel behandelde patiënten die electieve $\mathrm{PCl}$ ondergaan. Met gebruik van in vitro humane microsomen waarin $\mathrm{CYP}_{2} \mathrm{C}_{19}$ tot expressie wordt gebracht, laten we zien dat $\mathrm{CYP}_{2} \mathrm{C}_{19}$ niet direct betrokken is bij de omzetting van clopidogrel naar de inactieve intermediaire metaboliet 2-oxo-clopidogrel, noch bij vorming van de actieve metaboliet van clopidogrel (hoofdstuk 12). Ten slotte beschrijft hoofdstuk 13 een uitgebreide metabolomics studie met het doel de volledige metabole route van clopidogrel in kaart te brengen. Het bleek dat PON-1 de omzetting van 2-oxo-clopidogrel naar de actieve metaboliet van clopidogrel katalyseert. Deze stap was snelheidsbeperkend, wat PON-1 de belangrijkste determinant maakt van de generatie van de actieve metaboliet van clopidogrel. Patiënten met lage PON-1 activiteit of dragers van de $\mathrm{Q}_{192}$-variant welke is geassocieerd met lagere $\mathrm{PON}-1$ activiteit, hebben een groter risico van stenttrombose. 


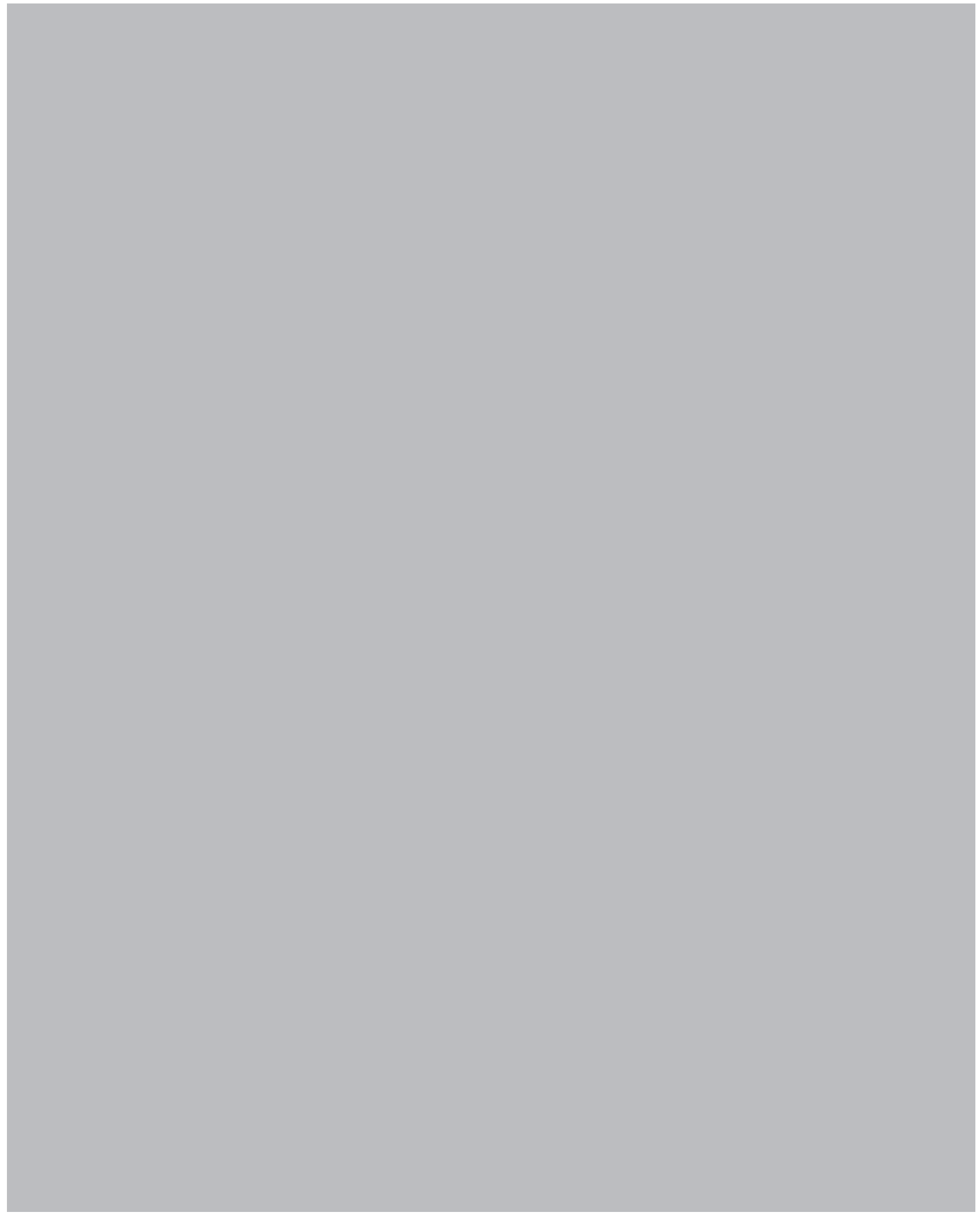


List of publications 
Bouman HJ, van Werkum JW, Hackeng CM, Verheugt FWA, ten Berg JM. The importance of anticoagulant agents in measuring platelet aggregation in patients treated with clopidogrel and aspirin. J Thromb Haemost 2008; 6: 1040-2.

Van Werkum JW, Harmsze AM, Elsenberg EHAM, Bouman HJ, ten Berg JM, Hackeng CM. The use of the VerifyNow system to monitor antiplatelet therapy: A review of the current evidence. Platelets 2008 November; 19(7): 479-488.

Bouman HJ. CYP2 $\mathrm{C}_{19}$-genotype bepalen bij clopidogrel gebruikers? Health Direct Cardiologie, april 2009 .

Bouman HJ, van Werkum JW, Hackeng CM, Clappers N, ten Berg JM. Cangrelor increases the magnitude of platelet inhibition and reduces interindividual variability in clopidogrel pretreated subjects. Neth Heart J 2009 May;17(5):195-8.

Rudež G*, Bouman HJ*, van Werkum JW, Leebeek FWG, Kruit A, Ruven HJT, ten Berg JM, de Maat MPM, Hackeng CM. Common variation in the platelet receptor $P_{2} R Y_{12}$ gene is associated with platelet reactivity in clopidogrel-treated patients undergoing elective PCI. Circ Cardiovasc Genet, Oct 2009;2(5): 515 - 521. *Both authors contributed equally to this study.

Elsenberg EH, van Werkum JW, van de Wal RM, Zomer AC, Bouman HJ, Verheugt FW, Berg JM, Hackeng CM. The influence of clinical characteristics, laboratory and inflammatory markers on 'high on-treatment platelet reactivity' as measured with different platelet function tests. Thromb Haemost. 2009 Oct;102(4):719-27.

Pittens CA, Bouman HJ, van Werkum JW, ten Berg JM, Hackeng CM. Comparison between hirudin and citrate in monitoring the inhibitory effects of $\mathrm{P}_{2} \mathrm{Y}_{12}$ receptor antagonists with different platelet function tests. J Thromb Haemost. 2009 Novi7(11):1929-32.

Taubert D, Bouman HJ, van Werkum JW. Cytochrome P-450 Polymorphisms and Response to Clopidogrel. N Engl J Med 2009 360: 2249-2251.

Harmsze A, van Werkum JW, Bouman HJ, Ruven HJ, Breet NJ, Ten Berg JM, Hackeng CM, Tjoeng MM, Klungel $\mathrm{OH}$, de Boer $\mathrm{A}$, Deneer VH. Besides $\mathrm{CYP}_{2} \mathrm{C}_{19}{ }_{2}$, the variant allele $\mathrm{CYP}_{2} \mathrm{C}_{9}{ }_{3}$ is associated with higher on-clopidogrel platelet reactivity in patients on dual antiplatelet therapy undergoing elective coronary stent implantation. Pharmacogenet Genomics. 2010 Jan;20(1):18-25.

Bouman HJ, van Werkum JW, Rudež G, Leebeek FWG, Kruit A, Hackeng CM, ten Berg JM, de Maat MPM, Ruven HJT. Genetic Polymorphisms of the $P_{2} Y_{12}$ Receptor influence in vitro Inhibition of Platelet Aggregation with the Potent $\mathrm{P}_{2} \mathrm{Y}_{12}$ Receptor antagonist Cangrelor. Thromb Haemost. 2010 Feb;103(2):379-86 
Breet NJ, van Werkum JW, Bouman HJ, Kelder JC, Ruven HJ, Bal ET, Deneer VH, Harmsze AM, van der Heyden JA, Rensing BJ, Suttorp MJ, Hackeng CM, ten Berg JM. Comparison of platelet function tests in predicting clinical outcome in patients undergoing coronary stent implantation. JAMA. 2010 Feb 24;303(8):754-62.

HJ Bouman, E Parlak, JW van Werkum, NJ Breet, H ten Cate, CM Hackeng, JM ten Berg, D Taubert. Which platelet function test is suitable to monitor clopidogrel responsiveness? A pharmacokinetic analysis on the active metabolite of clopidogrel. J Thromb Haemost. 2010 Mar;8(3):482-8.

Van Werkum JW, Kleibeuker M, Postma S, Bouman HJ, Elsenberg EHAM, ten Berg JM, Hackeng CM. A comparison between the Plateletworks trade mark-assay and light transmittance aggregometry for monitoring the inhibitory effects of clopidogrel. Int J Cardiol. 2010 Apr 1;140(1):123-6.

van Werkum JW, Bouman HJ, Breet NJ, ten Berg JM, Hackeng CM. The Cone-and-Plate(let) analyzer is not suitable to monitor clopidogrel therapy: a comparison with the flowcytometric VASP assay and optical aggregometry. Thromb Res. $2010 \mathrm{Jul} ; 126(1): 44-9$

Breet NJ, van Werkum JW, Bouman HJ, Kelder JC, Ten Berg JM, Hackeng CM. Do not adjust the platelet count in light transmittance aggregometry when predicting thrombotic events after percutaneous coronary intervention. J Thromb Haemost. 2010 Oct;8(10):2326-8.

Breet NJ, van Werkum JW, Bouman HJ, Kelder JC, Ten Berg JM, Hackeng CM. High on-aspirin platelet reactivity as measured with aggregation-based, cyclooxygenase-1 inhibition sensitive platelet function tests is associated with the occurrence of atherothrombotic events. J Thromb Haemost. 2010 Oct;8(10):2140-8

Harmsze AM, van Werkum JW, Ten Berg JM, Zwart B, Bouman HJ, Breet NJ, van 't Hof AW, Ruven HJ, Hackeng $\mathrm{CM}_{1}$, Klungel $\mathrm{OH}$, de Boer $\mathrm{A}$, Deneer VH. CYP $\mathrm{C}_{19} *_{2}$ and $\mathrm{CYP}_{2} \mathrm{C}_{9} * 3$ alleles are associated with stent thrombosis: a case-control study. Eur Heart J. 2010 Dec;31(24):3046-53.

Bouman HJ, Schömig E, van Werkum JW, Velder J, Hackeng CM, Hirschhäuser C, Waldmann C, Schmalz HG, Ten Berg JM, Taubert D. Paraoxonase-1 is a major determinant of clopidogrel efficacy. Nature Medicine. $2011 \operatorname{Jan} ; 17(1): 110-6$.

Breet NJ, van Werkum JW, Bouman HJ, Kelder JC, Ten Berg JM, Hackeng CM. Both peak and late aggregation are capable of identifying patients at risk for atherothrombotic events. Thromb Haemost. 2011 Jan;105(1):197-9.

Bouman HJ, van Werkum JW, Breet NJ, ten Cate H, Hackeng CM, ten Berg JM. A case-control study on platelet reactivity in patients with coronary stent thrombosis. J Thromb Haemost. 2011 May;9(5):909-16. 
Breet NJ, van Werkum JW, Bouman HJ, Kelder JC, Harmsze AM, Hackeng CM, ten Berg JM. High ontreatment platelet reactivity to both aspirin and clopidogrel is associated with the highest risk of adverse events following percutaneous coronary intervention. Heart. 2011 Jun;97(12):983-90.

Breet NJ, van Donkersgoed HE, van Werkum JW, Bouman HJ, Kelder JC, Zijlstra F, Hackeng CM, Ten Berg JM. Is platelet inhibition due to thienopyridines increased in elderly patients, in patients with previous stroke and patients with low body weight as a possible explanation of an increased bleeding risk? Neth Heart J. 2011 Jun;19(6):279-84.

Bouman HJ, Harmsze AM, van Werkum JW, Breet NJ, Bergmeijer TO, Ten Cate H, Hackeng CM, Deneer VH, Ten Berg JM. Variability in on-treatment platelet reactivity explained by $\mathrm{CYP}_{2} \mathrm{C}_{19} *_{2}$ genotype is modest in clopidogrel pretreated patients undergoing coronary stenting. Heart. 2011 $\operatorname{Aug} ; 97(15): 1239-44$.

Breet NJ, van Werkum JW, Bouman HJ, Kelder JC, Hackeng CM, ten Berg JM. The relationship between platelet reactivity and infarct-related artery patency in patients presenting with a ST-elevation myocardial infarction. Thromb Haemost. 2011 Aug;106(2):331-6.

Baver T, Bouman HJ, van Werkum JW, Ford NF, ten Berg JM, Taubert D. Impact of CYP $2 C_{19}$ variant genotypes on clinical efficacy of antiplatelet treatment with clopidogrel: systematic review and metaanalysis. BMJ. 2011 Aug 4;343: 44588

Harmsze AM, van Werkum JW, Souverein PC, Breet NJ, Bouman HJ, Hackeng CM, Ruven HJ, ten Berg $J M$, Klungel OH, de Boer A, Deneer VH. Combined influence of proton-pump inhibitors, calcium-channel blockers and $\mathrm{CYP}_{2} \mathrm{C}_{1}{ }^{*}{ }_{2}$ on on-treatment platelet reactivity and on the occurrence of atherothrombotic events after percutaneous coronary intervention. J Thromb Haemost. 2011 Oct;9(10):1892-901.

Breet NJ, Sluman MA, van Berkel MA, van Werkum JW, Bouman HJ, Harmsze AM, Kelder JC, Zijlstra F, Hackeng CM, Ten Berg JM. Effect of gender difference on platelet reactivity. Neth Heart J. 2011 Novi19(11):451-7.

Bouman HJ, van Werkum JW, Rudež G, Hackeng CM, Leebeek FW, Ten Cate H, Ten Berg JM, de Maat MP. The relevance of $\mathrm{P}_{2} \mathrm{Y}_{12}$-receptor gene variation for the outcome of clopidogrel-treated patients undergoing elective coronary stent implantation: A clinical follow-up. Thromb Haemost. 2012 Jan 3;107(1):189-91.

Harmsze AM, van Werkum JW, Hackeng CM, Ruven HJ, Kelder JC, Bouman HJ, Breet NJ, Ten Berg JM, Klungel $\mathrm{OH}$, de Boer $\mathrm{A}$, Deneer $\mathrm{VH}$. The influence of $\mathrm{CYP}_{2} \mathrm{C}_{19}{ }_{2}$ and $*_{17}$ on on-treatment platelet reactivity and bleeding events in patients undergoing elective coronary stenting. Pharmacogenet Genomics. 2012 Jan 5. [Epub ahead of print] 


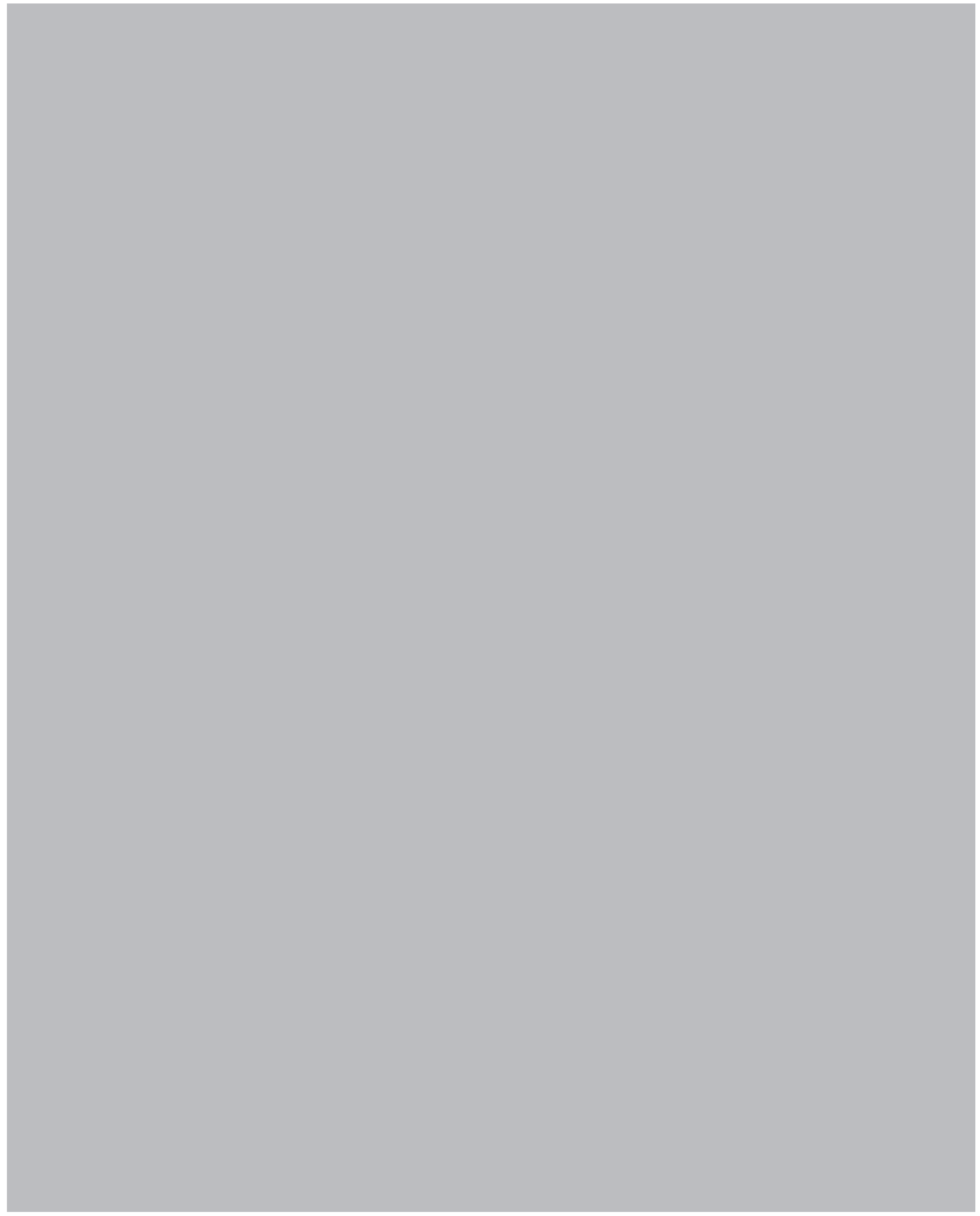


Curriculum vitae 


\section{Curriculum vitae}

De schrijfster van dit proefschrift werd geboren op 3 juli 1985 te Waalwijk. Na tussen het groen en de paarden te zijn opgegroeid in het Brabantse dorpje Meeuwen, behaalde zij in 2003 haar diploma Voortgezet Wetenschappelijk Onderwijs aan het Willem van Oranje College te Waalwijk. Aansluitend volgde de reis naar Utrecht waar zij startte met de studie Farmacie aan de Universiteit Utrecht. Het apothekersdiploma behaalde zij op 26 februari 2010 cum laude. Al eerder, in het $4 \mathrm{e} \mathrm{jaar} \mathrm{van} \mathrm{haar} \mathrm{studie}$ Farmacie maakte Heleen kennis met het klinisch wetenschappelijk onderzoek tijdens een 6 maanden durende wetenschappelijke stage bij de afdelingen cardiologie \& klinische chemie van het St. Antonius Ziekenhuis te Nieuwegein. Naar beider partijen tevredenheid volgde in januari 2008 een aanstelling als promovenda. Geboeid en geprikkeld door de kliniek waarmee zij in het kader van haar onderzoek in aanraking kwam, besloot ze deel te nemen aan de selectieprocedure voor de Selective Utrecht Medical Master, waarmee zij na toelating in september 2010 van start is gegaan. In 2014 hoopt zij af te studeren als arts. 